\author{
UNIVERSIDADE DE SÃO PAULO \\ ESCOLA DE ENGENHARIA DE SÃO CARLOS \\ INSTITUTO DE FÍSICA DE SÃO CARLOS \\ INSTITUTO DE QUÍMICA DE SÃO CARLOS
}

ELTON FRANCO DE MAGALHÃES

\title{
Caracterização e Proposição de Métodos Estimativos das Propriedades Monotônicas e Cíclicas dos Ferros Fundidos Nodulares
}



Elton Franco de Magalhães

\title{
Caracterização e Proposição de Métodos Estimativos das Propriedades Monotônicas e Cíclicas dos Ferros Fundidos Nodulares
}

\author{
Versão Corrigida \\ original na unidade
}

Dissertação apresentada à Área Interunidades em Ciência e Engenharia de Materiais da EESC, IFSC, IQSC, da Universidade de São Paulo, para a obtenção do título de Mestre em Ciência e Engenharia dos Materiais

Área de Concentração:

Desenvolvimento,

Caracterização e Aplicação de Materiais da Universidade de São Paulo.

Orientador:

Prof. Dr. Dirceu Spinelli

São Carlos/SP

2011 


\section{AUTORIZO A REPRODUÇÃO E DIVULGAÇÃO TOTAL OU PARCIAL DESTE TRABALHO, POR QUALQUER MEIO CONVENCIONAL OU ELETRÔNICO, PARA FINS DE ESTUDO E PESQUISA, DESDE QUE CITADA A FONTE.}

Ficha catalográfica preparada pela Seção de Tratamento da Informação do Serviço de Biblioteca - EESC/USP

M188c Magalhães, Elton Franco de

Caracterização e proposição de métodos estimativos das propriedades monotônicas e cíclicas dos ferros fundidos nodulares. / Elton Franco de Magalhães ; orientador Dirceu Spinelli. -- São Carlos, 2011.

Dissertação (Mestrado-Programa de Pós-Graduação de Interunidades em Ciência e Engenharia de Materiais e Área de Concentração em Desenvolvimento, Caracterização e Aplicação de Materiais) -- Escola de Engenharia de São Carlos da Universidade de São Paulo, 2011.

1. Ferro fundido nodular. 2. Propriedades monotônicas e cíclicas. 3. Fadiga de baixo ciclo. 4. Estimativa propriedades mecânicas. 5. Dureza. I. Título. 
Este exemplar foi revisado e alterado em relação ao original seguindo as orientações da comissão julgadora, sob exclusiva responsabilidade do autor.

São Carlos, 3 Maio de 2012

Elton Franco de Magalhães 



\section{Dedicatória}

Dedico este trabalho àquelas pessoas que sempre estiveram ao meu lado nesta minha caminhada, contribuindo de alguma forma para o meu aperfeiçoamento profissional e pessoal, entre estas pessoas cito:

Meu orientador, Prof. Dr. Dirceu Spinelli

A minha mãe, Emirena Franco de Magalhães

O meu pai, José Leocádio de Magalhães

Os meus irmãos Edson e Erika

A minha companheira Suellen

Meus amigos da Engenharia de Produto da Whirlpool, em especial, ao Alexandre Marangoni, Adriano Tebaldi, Alex Prado, Fabio Gennaro, Gustavo Rossetto, Luiz Henrique Baptista, Marcelo Toledo, Bruno Ximenes, Adriano Ioriatti, Alexandre da Luz e Marcos Betioli

Meus amigos da Engenharia de Produto da ZF, entre eles: Vilmar Pereira, Rafael Alonco, Lucas Leal, Bruno Justo, Clayton Rodrigues, Marcelo Tomazela, Fernando Raimundo, Rafael Chaves, Eduardo Henrique, Andersonn Mizobuchi, Tatumi Sobue, Marcos Lopes, Sergio Scabar, Victor Rosales e Thassio Castro

Meus amigos da ESSS, o Msc. Giovanni Moraes, que é uma pessoa que tenho grande admiração pelo grande talento profissional e simplicidade e ao Dr. Cesário.

Meus amigos da Smarttech, em especial, ao Msc. Jeovano Lima, Marcelo Gomes e ao Dr. Gabriel Gueler. 
Meus amigos do Programa de Especialização em Engenharia (PEE) ITAEmbraer, em especial, ao Rafael Gouvêa, Gabriel Pradim, Henrique Forlani, Pedro Zago, Diego Gonçalves, Wenderson Pires, Roberta Ximenes, Alexandre Massoca, Adilson Silvestre, Vinicius Pinky, Renato Caldas, Natasha Sanches, Breno Galizoni, Sidnei Terçoni, Cecil Skaleski, Fernando Pavão e Felipe Iurif

Aos meus velhos amigos Bruno Goulart, Bruno Cantarutti e João Roberto, em comemoração a uma década da nossa amizade. 


\section{Agradecimentos}

Agradeço

a Deus pelas oportunidades, força, saúde e paz

ao meu orientador Prof. Dr. Dirceu Spinelli (em especial) ao qual tenho grande admiração pela postura profissional e brilhante carreira na qual me espelho. Sou grato não só pela orientação na realização deste trabalho como também por todo o incentivo, motivação e ajuda. Obrigado!

ao Altino Farias, Gerente de Desenvolvimento de Produto e Marketing da Schulz, pelo suporte técnico, ajuda na revisão bibliográfica, discussões técnicas e fornecimento dos corpos de prova para a realização dos experimentos

ao Victor Rosales, Gerente de Desenvolvimento de Produto da ZF, por todo o suporte e incentivo

ao Sergio Scabar, Especialista de Produto da ZF, pela grande contribuição na revisão bibliográfica

ao meu estimado amigo Rafael Alonco, por me lembrar diariamente das minhas obrigações e por me mostrar a importância de finalizar o presente estudo,

ao aluno Paulo Guilherme Rodrigues Salgado, pelo acompanhamento dos ensaios experimentais e ajuda no processamento dos dados 

“...Loucura, sonho? Tudo é loucura ou sonho no começo, nada do que o homem fez no mundo teve início de forma diferente, mas tantos sonhos se realizaram que não temos o direito de duvidar de nenhum..."

Monteiro Lobato 



\section{Sumário}

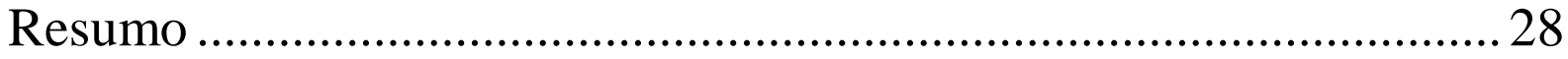

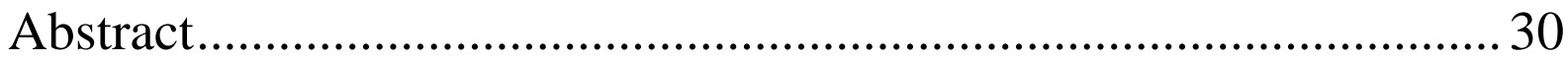

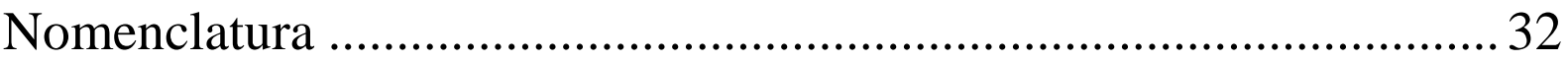

Lista de Figuras ................................................................................ 34

Lista de Tabelas .................................................................................. 40

Introdução ..................................................................................... 42

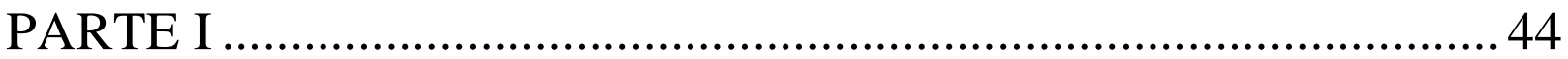

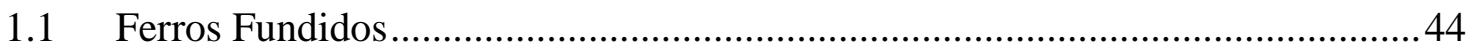

1.1.1 Componentes Microestruturais dos Ferros Fundidos ................................45

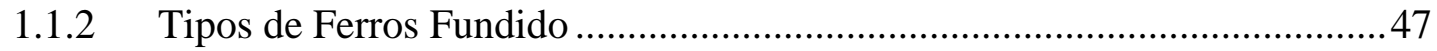

1.1.3 Classificação dos Ferros Fundido Nodulares..............................................50

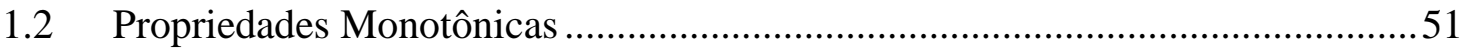

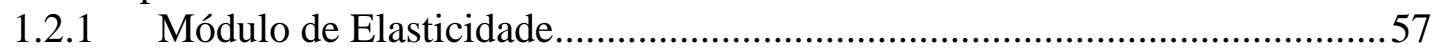

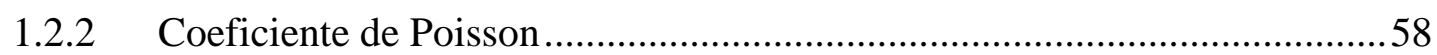

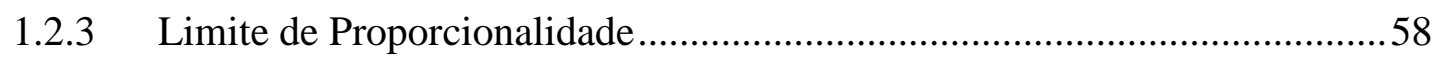

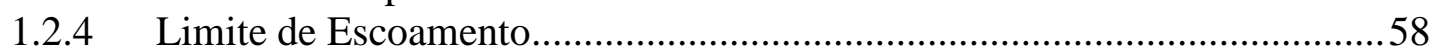

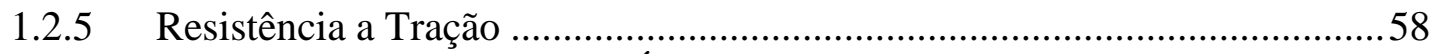

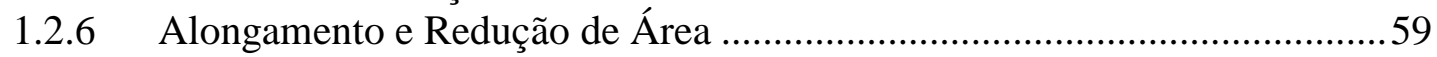

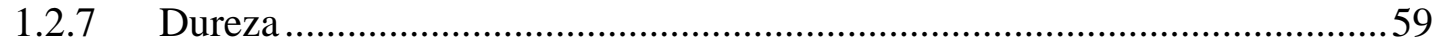

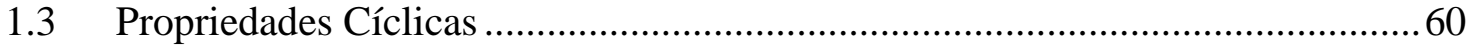

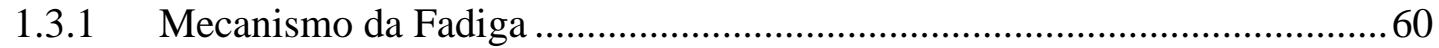

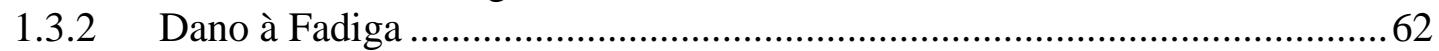

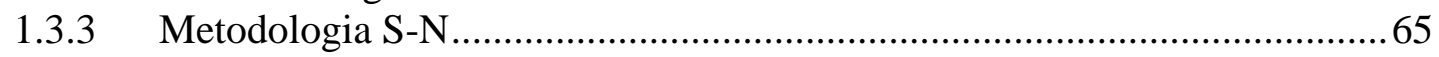

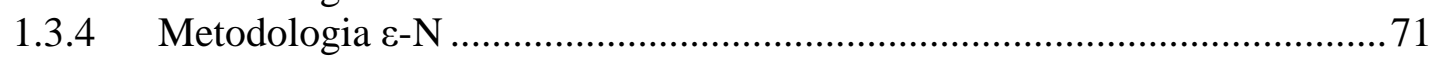

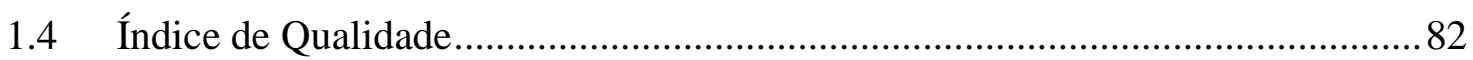

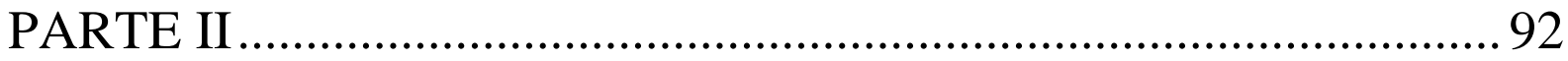

2.1 Propriedades Mecânicas dos Ferros Fundidos - Dados da Literatura .................92

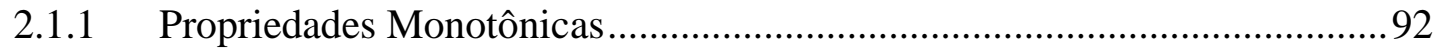

2.1.2 Propriedades Cíclicas ..............................................................................96

2.1.3 Correlação das Propriedades Mecânicas com a Dureza - Dados da

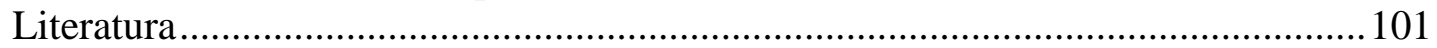




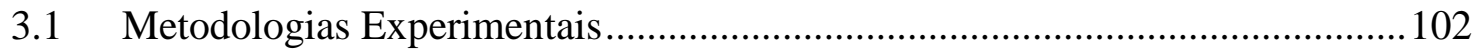

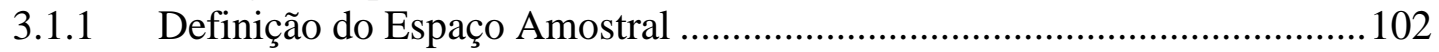

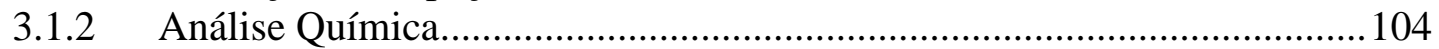

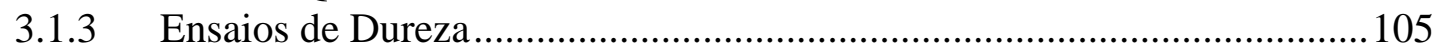

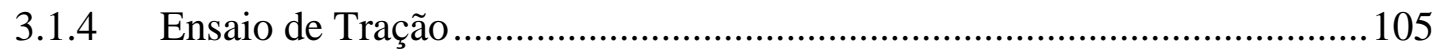

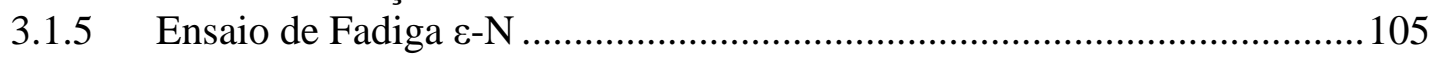

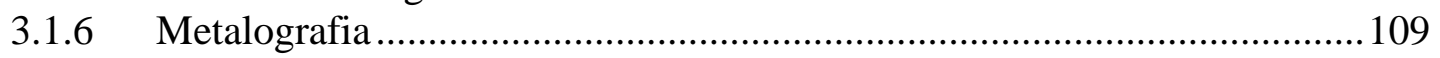

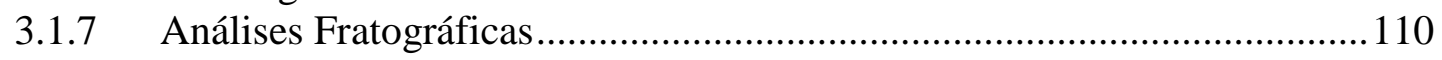

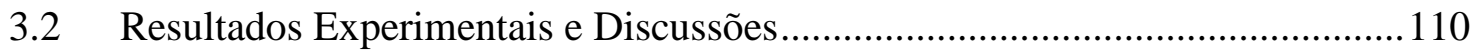

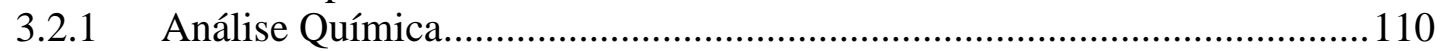

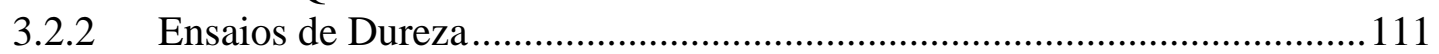

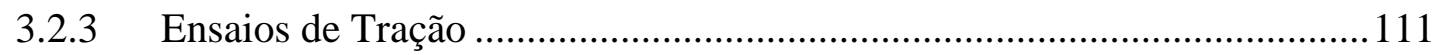

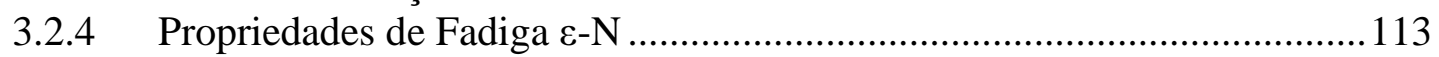

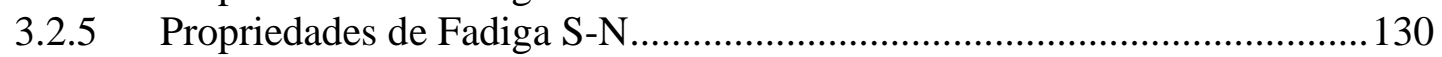

3.2.6 Considerações Gerais Sobre os Ensaios ..................................................135

3.2.7 Comparações entre os Comportamentos Monotônico e Cíclico.................. 140

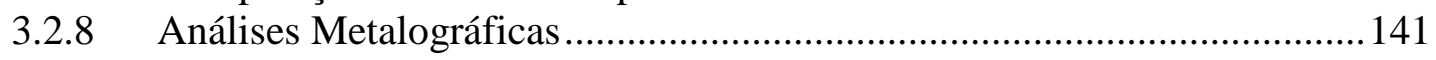

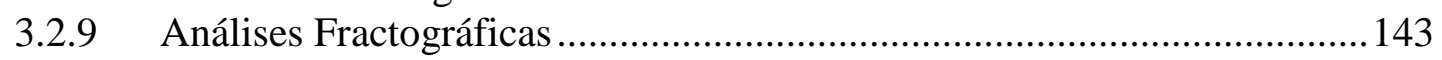

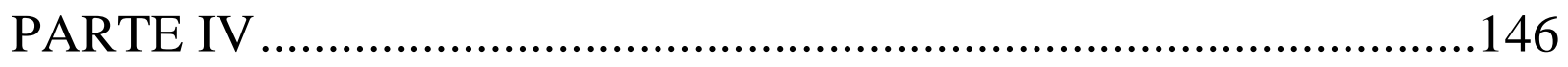

4.1 Propriedades Mecânicas dos Ferros Fundidos - Complemento da Literatura e $\mathrm{QI} \geq 80146$

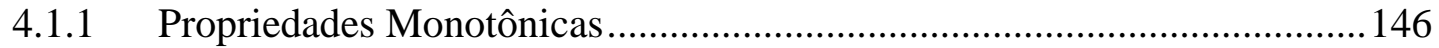

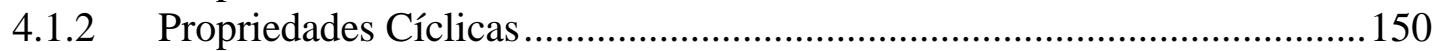

4.1.3 Correlação e Ajuste das Propriedades Mecânicas com a Dureza ...............155

4.1.4 Método Para Estimar as Propriedades Monotônicas .................................157

4.1.5 Método Para Estimar as Propriedades Cíclicas .......................................... 159

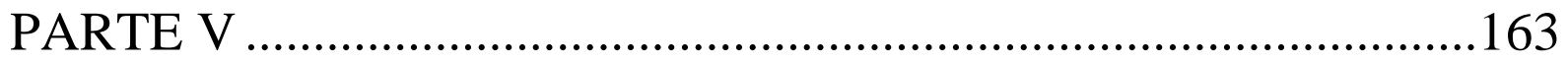

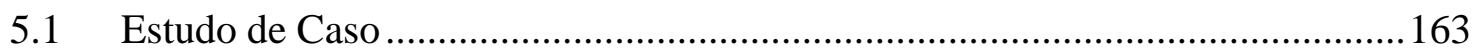

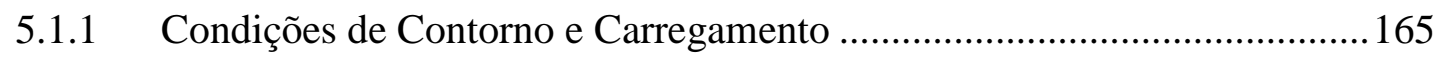

5.1.2 Conexões e Malha de Elementos Finitos .................................................166

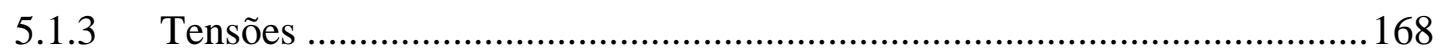

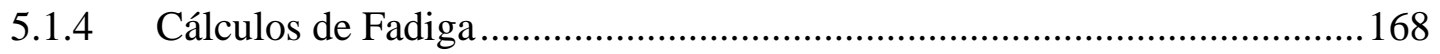

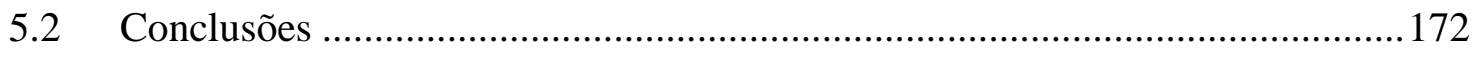

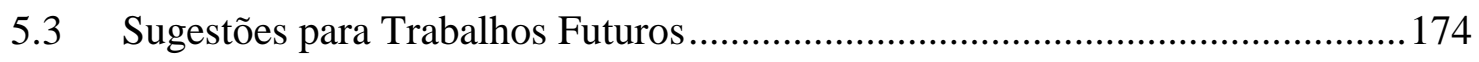

Referencias Bibliográficas ...................................................175 


\section{Resumo}

Magalhães, Elton F. (2011): "Caracterização e Proposição de Métodos Estimativos das Propriedades Monotônicas e Cíclicas dos Ferros Fundidos Nodulares”, 2011, Dissertação de Mestrado - Interunidades em Ciência e Engenharia dos Materiais, Universidade de São Paulo, São Carlos, 2011

Para o correto dimensionamento da maioria dos componentes estruturais é necessário informações sobre a resposta do material quando submetido à fadiga de alto e baixo ciclo, bem como conhecer as propriedades monotônicas (não-cíclicas) e cíclicas dos materiais. $\mathrm{Na}$ literatura são encontradas amplas divulgações de dados sobre diversos materiais de engenharia (Ex. SAE J1099 - Technical Report on Fatigue Properties). Porém, quando se trata de ferro fundido nodular estas informações são limitadas, sendo assim, visa-se neste trabalho caracterizar as propriedades monotônicas e cíclicas destes materiais em complemento aos trabalhos já publicados na literatura e propor métodos para a estimativa destas propriedades a partir da dureza. Faz-se necessário a proposição de métodos estimativos das propriedades mecânicas destes materiais baseados na dureza devido às suas grandes variações que são inerentes ao processo de fundição. Em um mesmo componente podem existir diferentes classes de ferro fundido, que apesar de possuir a mesma composição química, podem apresentar variações nas propriedades mecânicas devido à formação de diferentes estruturas metalúrgicas que são sensíveis às taxas de resfriamento do material que variam de acordo com as características geométricas da peça que está sendo fundida, principalmente a variação da espessura. Neste estudo a determinação das relações entre as propriedades monotônicas e cíclicas dos ferros fundidos nodulares foram obtidas a partir do tratamento dos dados publicados na literatura levando-se em consideração o índice de qualidade. Foi proposto um modelo contínuo com relação à dureza para a estimativa das propriedades monotônicas, do coeficiente de resistência cíclico e do expoente de encruamento cíclico e para a estimativa das propriedades cíclicas que experimentalmente demonstraram não ter correlação com a dureza foi proposto uma forma discreta, que consistiu na recomendação de valores típicos definidas por faixas de dureza.

\section{Palavras Chave:}

Ferro Fundido Nodular, Propriedades Monotônicas e Cíclicas, Fadiga de Baixo Ciclo, Estimativa Propriedades Mecânicas, Dureza 



\section{Abstract}

Magalhães, Elton F. (2011): "Characterization and Estimative Models of Monotonic and Cyclic Properties of Ductile Iron”, 2011, Master Degree in Sciences - Interunidades em Ciências e Engenharia dos Materiais, Universidade de São Paulo, São Carlos, 2011.

For the correct design of the most part of structural components is necessary to have information about the material response under both high cycle and low cycle fatigue, as well as the knowledge of monotonic and cyclic material's properties. In literature a major publication of several engineering material data can be found (e.g, SAE J1099 - Technical Report on Fatigue Properties), but regarding to ductile iron this information is quite limited. Therefore, this work aims to characterize the monotonic and cyclic properties of this material in complementing to the available data in the literature and also make a proposition of methods to estimate this properties from hardness. The mechanical properties estimation model from hardness is relevant to take into account the inherent variations of casting process, which for the same chemical composition can be found different grades in a same part. This fact occurs due to the formation of different metallurgical structures that is influenced by cooling ratio which changes accordingly to geometrical characteristic of the part, especially the thickness variation. In this study the determination of the relation between monotonic and cyclic properties from hardness has been determined from literature data processing taking into account the Quality Index. For monotonic properties, the cyclic strength coefficient and the cyclic strain hardening exponent estimation has been proposed a continuous method based on hardness and for the cyclic properties that experimentally showed to remain independent of hardness has been recommended one set of properties for specific hardness ranges.

Keywords:

Ductile Cast Iron, Monotonic and Cyclic Properties, Low Cycle Fatigue, Mechanical Properties Estimation from Hardness 



\section{Nomenclatura}

\begin{tabular}{ll}
$S_{u}$ & Resistência à tração \\
$S_{y}$ & Limite de Escoamento \\
$E L$ & Alongamento especifico até a ruptura (\%) \\
$R A$ & Redução de Área (\%) \\
$E$ & Módulo de Elasticidade \\
$K$ & Coeficiente de Resistência \\
$n$ & Expoente de Endurecimento por deformação \\
$Q I$ & Índice de Qualidade (Quality Index) \\
$D$ & Dano à fadiga \\
$a$ & Tamanho da trinca \\
$a_{o}$ & Tamanho inicial da trinca \\
$a_{f}$ & Tamanho crítico da trinca \\
$n_{i}$ & Número de ciclos de um carregamento $i$ \\
$N_{f}$ & Número de ciclos correspondentes ao tamanho crítico da trinca \\
$2 N$ & Número de reversos até a fratura \\
$\alpha_{f}$ & Expoente experimental da formula de Dano de Manson e Halford \\
$S_{r}$ & Faixa de tensão \\
$S_{a}$ & Amplitude de tensão \\
$S_{\text {max }}$ & Tensão máxima \\
$S_{\text {min }}$ & Tensão mínima \\
$S_{\mathrm{m}}$ & Tensão média \\
$A$ & Área da seção transversal \\
\hline & Momento de inércia \\
\hline &
\end{tabular}


$J \quad$ Momento de inércia polar

$y \quad$ Distância da linha neutra de uma seção até o ponto de interesse

$r$ Distância do centro de uma seção até o ponto de interesse

$\sigma_{y}^{\prime} \quad$ Limite de escoamento cíclico

$K^{\prime} \quad$ Coeficiente de resistência cíclico

$n \quad$ Expoente de encruamento cíclico

$\sigma_{f}^{\prime} \quad$ Coeficiente de resistência à fadiga

b Expoente de resistência à fadiga

$\mathcal{E}_{f} \quad$ Coeficiente de ductilidade à fadiga

c Expoente de ductilidade à fadiga

$S_{f}^{\prime} \quad$ Coeficiente de resistência à fadiga

$b^{\prime} \quad$ Expoente de resistência à fadiga 


\section{Lista de Figuras}

Figura 1 - Porcentagem de Carbono e Silício em Aços e Ferros Fundidos (WALTON 1981)

Figura 2: Tipos de Grafita conforme ASTM A247

Figura 3: Influência da matriz dos ferros fundidos nodulares nas suas propriedades mecânicas - neste caso na sua resistência a tração (LEE 2005)

Figura 4: Variações da Propriedades Mecânicas dos Ferros Fundidos de acordo com a Variação da Matriz (Dureza)

Figura 5: Curva Tensão-Deformação de Engenharia (LEE 2005).

Figura 6: Curva Verdadeira de Tensão-Deformação (LEE 2005)

Figura 7: Curva monotônica tensão verdadeira vs. deformação plástica verdadeira (LEE 2005)

Figura 8: Processo de fadiga em uma chapa fina sujeita a uma carga cíclica de tração (LEE 2005)

Figura 9: Bloco de carregamento com duas sequências de alto e baixo carregamento (LEE 2005)

Figura 10: Modelo linear de dano acumulado (LEE 2005) 64

Figura 11: Carregamentos e ciclos aplicados em ensaios de fadiga S-N (LEE 2005).......68

Figura 12: Resultados de um ensaio fadiga em flexão alternada de um aço normalizado (LEE 2005).

Figura 13: Conceito do método da deformação-vida local (COFFIN 1979) 72

Figura 14: Comportamento Transiente de endurecimento cíclico (SCHUBERT 1989) ...74 Figura 15: Comportamento Transiente de amolecimento cíclico (SCHUBERT 1989) ....75

Figura 16: Laço de Histerese (VISWANATHAN 1989) ................................................ 76

Figura 17: Curva tensão-deformação cíclica (CHRIST 1993) ........................................ 77

Figura 18: Comportamento da relação tensão-deformação monotônico e cíclico (MITCHELL 1996).

Figura 19: Curva da amplitude de deformação total vs. vida em reversos (MITCHELL 1996)

Figura 20: Variações das Propriedades dos Ferros Fundidos (SORELMETAL 2004) .....83 
Figura 21: Propriedades mecânicas do ferro fundido sem tratamento térmico (FOWLER 1984)

Figura 22: Propriedades mecânicas do ferro fundido após tratamento térmico de recozimento (FOWLER 1984)...

Figura 23: Propriedades mecânicas do ferro fundido com tratamento de normalização (FOWLER 1984) .86

Figura 24: Fatores que influenciam as propriedades mecânicas dos ferros fundidos .88

Figura 25: Relação entre o Índice de Qualidade dos Ferros Fundidos Nodulares e a Norma ASTM A536..

Figura 26: Fatores que influenciam as propriedades mecânicas dos ferros fundidos de alta qualidade $(\mathrm{QI}>80)$. .91

Figura 27: Relação do limite de resistência com a dureza - dados da literatura, R2=0,7294

Figura 28: Relação da tensão de escoamento com a dureza - dados da literatura, R2 $=0,82$

Figura 29: Relação do alongamento com a dureza - dados da literatura , R2 = 0,76......95

Figura 30: Relação do Coeficiente de Resistência com a Dureza - dados da literatura, R2 $=0,87$

Figura 31: Relação entre o expoente de encruamento e a dureza - dados da literatura, R2 $=0,74$ .96

Figura 32: Relação entre o coeficiente de resistência a fadiga e a dureza - dados da literatura, $\mathrm{R} 2=0,65$

Figura 33: Relação entre o Expoente de Resistência a Fadiga e a Dureza - dados da literatura, $\mathrm{R} 2=0,34$

Figura 34: Relação entre o Coeficiente de Ductilidade e a Dureza - dados da literatura, $\mathrm{R} 2=0,00$.

Figura 35: Relação entre o Expoente de Ductilidade e a Dureza - dados da literatura, R2 $=0,00$

Figura 36: Relação entre o coeficiente de resistência cíclico K' [MPa] e a dureza - dados da literatura, $\mathrm{R} 2=0,64$

Figura 37: Relação entre o expoente de encruamento cíclico n' e a dureza - dados da literatura, R2 $=0,48$.

Figura 38: Espaço Amostral Erro! Indicador não definido. 
Figura 39: Geometria e dimensões do corpo-de-prova de tração. Dimensões em mm ...105

Figura 40: Geometria e dimensões do corpo de prova utilizado para os ensaios de fadiga de baixo ciclo ( dimensões em $\mathrm{mm}$ )

Figura 41: Detalhe da garra e instalação do extensômetro no corpo de prova para o controle de deformação durante o ensaio de fadiga.

Figura 42: Configuração do ensaio de fadiga $\varepsilon-N$, (YANG 1994)

Figura 43: Comparação da Curva Tensão-Deformação de Engenharia e Verdadeira ....113

Figura 44: Curva deformação elástica vs. vida - classe A

Figura 45: Curva deformação plástica vs. vida - classe A

Figura 46: Curva amplitude de tensão vs. amplitude deformação plástica - classe A.....119

Figura 47: Curva de fadiga da Classe A - 130HB

Figura 48: Curva deformação elástica vs. vida - classe B

Figura 49: Curva deformação plástica vs. vida - classe B

Figura 50: Curva amplitude de tensão vs. amplitude deformação plástica - classe A.....124

Figura 51: Curva de fadiga da Classe B - 160HB

Figura 52: Curva deformação elástica vs. vida - classe B

Figura 53: Curva deformação plástica vs. vida - classe C .

Figura 54: Curva amplitude de tensão vs. amplitude deformação plástica - classe C .....129

Figura 55: Curva de fadiga da Classe C $-250 \mathrm{HB}$

Figura 56: Curva de amplitude de tensão vs. vida em fadiga - Classe A

Figura 57: Curva de amplitude de tensão vs. vida em fadiga - Classe B....

Figura 58: Curva de amplitude de tensão vs. vida em fadiga - Classe C.....

Figura 59: Comparação entre os laços de histerese para amplitude de deformação de $0,15 \%$

Figura 60: Comparação entre os laços de histerese para amplitude de deformação de $0,30 \%$

Figura 61: Comparação entre as curvas de fadiga das faixas de dureza de 135HB e 250HB 
Figura 62: Comparação entre as curvas de fadiga das faixas de dureza de $135 \mathrm{HB}$ e $250 \mathrm{HB}$

Figura 63: Comparação das curvas tensão-deformação monotônico e cíclico - amostra

Classe A

Figura 64: Amostras no qual foram realizada a análise micrográfica

Figura 65: Análise micrográfica de uma amostra da Classe A

Figura 66: Análise micrográfica de uma amostra da Classe B

Figura 67: Análise micrográfica de uma amostra da Classe C

Figura 68: Fractografia da amostra A

Figura 69: Fractografia da amostra B

Figura 70: Fractografia da amostra C

Figura 71: do limite de resistência com a dureza, $\mathrm{R} 2=0,98(\mathrm{QI} \geq 80)$. 148

Figura 72: Relação do limite de escoamento com a dureza, $\mathrm{R} 2=0,98(\mathrm{QI} \geq 80)$ 148

Figura 73: Relação do alongamento com a dureza, $\mathrm{R} 2=0,85(\mathrm{QI} \geq 80)$

Figura 74: Relação do coeficiente de resistência com a dureza, $\mathrm{R} 2=0,94(\mathrm{QI} \geq 80)$.

Figura 75: Relação entre o expoente de encruamento e a dureza, $\mathrm{R} 2=0,92(\mathrm{QI} \geq 80)$.... 150

Figura 76: Relação entre o coeficiente de resistência a fadiga e a dureza, $R 2=0,81$ $(\mathrm{QI} \geq 80)$

Figura 77: Relação entre o expoente de resistência a fadiga e a dureza, $R 2=0,0(\mathrm{QI} \geq 80)$

Figura 78: Relação entre o coeficiente de ductilidade e a dureza, $\mathrm{R} 2=0,00(\mathrm{QI} \geq 80) \ldots . .153$

Figura 79: Relação entre o expoente de ductilidade e a dureza, $\mathrm{R} 2=0,22(\mathrm{QI} \geq 80)$

Figura 80: Relação entre o coeficiente de resistência cíclico e a dureza, $R 2=0,94$ $(\mathrm{QI} \geq 80)$

Figura 81: Relação entre o expoente de encruamento cíclico e a dureza, $\mathrm{R} 2=0,88(\mathrm{QI} \geq 80)$

Figura 82: Método discreto para estimativa das propriedades cíclicas - exemplo coeficiente de resistência a fadiga.

Figura 83: Redutor de roda de uma colheitadeira - montagem 


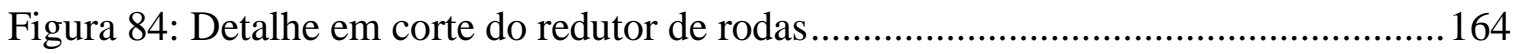

Figura 85: Carcaça de fixação do redutor no chassi - tampa do redutor...........................164

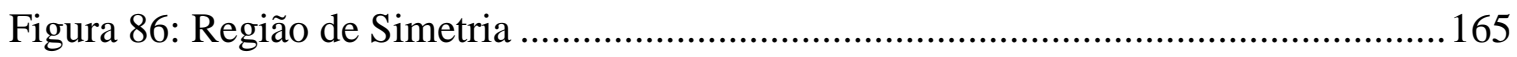

Figura 87: Condições de Contorno - restrição e esforço estrutural ...................................165

Figura 88: Modelamento das conexões entre os componentes ......................................166

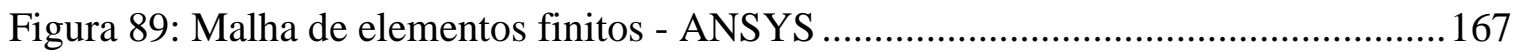

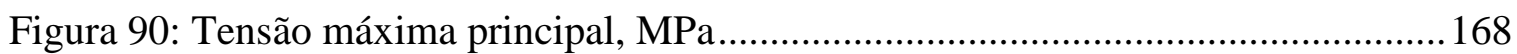

Figura 91: Vida estimada para a condição 1, Ciclos....................................................... 169

Figura 92: Vida estimada para a condição 2, Ciclos......................................................170

Figura 93: Vida estimada para a condição 3, Ciclos....................................................170 



\section{Lista de Tabelas}

Tabela 1: Composição Química dos Ferros Fundidos (ASTM A536) 50

Tabela 2: Classificação dos Ferros Fundidos Nodulares de Acordo com a ASTM A537.51

Tabela 3: Classificação dos Ferros Fundidos Nodulares de Acordo com a DIN EN 156351

Tabela 4: Evolução da Qualidade dos Ferros fundidos Nodulares QI - Quality Index (SORELMETAL 2004) 90

Tabela 5: Propriedades Monotônicas dos Ferros Fundidos 93

Tabela 6: Propriedades Cíclicas dos Ferros Fundidos Nodulares - dados da literatura ....97

Tabela 7: Avaliação da correlação das propriedades mecânicas com a dureza - dados da literatura

Tabela 8: Tipo de ensaio de acordo com a sua replicação (ASTM E739, 2004).............108

Tabela 9: Numero de níveis e amostras testadas em cada classe de material..... 109

Tabela 10: Replicação das classes testadas 109

Tabela 11: Composição química das classes A, B e C em \% em peso. 110

Tabela 12: Medidas da dureza das amostras de cada classe

Tabela 13: Resultado do ensaio de tração - classe A

Tabela 14: Resultado do ensaio de tração - classe A

Tabela 15: Resultado do ensaio de tração - classe A

Tabela 16: Resultados Individuais do Ensaio de Fadiga das Amostras da Classe A $135 \mathrm{HB}$

Tabela 17: Resultados individuais das amostras da classe B - $160 \mathrm{HB}$

Tabela 18: Resultados Individuais das Amostras da Classe C - $250 \mathrm{HB}$ 126

Tabela 19: Amplitudes de tensão e vidas determinadas no ensaio de fadiga $\varepsilon-\mathrm{N}$

Tabela 20: Resumo das propriedades monotônicas determinadas experimentalmente..135

Tabela 21: Resumo das propriedades cíclicas determinadas experimentalmente 136

Tabela 22: Propriedades Monotônicas dos Ferros Fundidos Nodulares - Complemento da Literatura 
Tabela 23: Propriedades Cíclicas dos Ferros Fundidos Nodulares - Complemento da literatura .

Tabela 24: Propriedades Cíclicas dos Ferros Fundidos Nodulares - Complemento da literatura

Tabela 25: Estimativa do coeficiente de resistência a fadiga ........................................161

Tabela 26: Estimativa do expoente de resistência a fadiga.............................................161

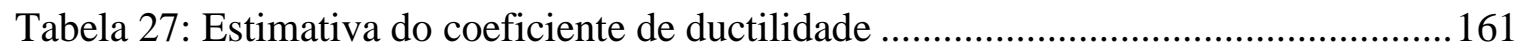

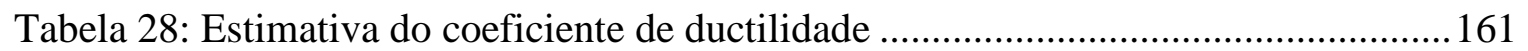

Tabela 29: Condições para os cálculos de fadiga e corresponde vida em fadiga .............168

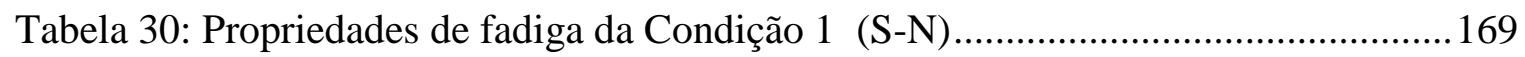

Tabela 31: Propriedades de fadiga das condições 2 e $3(\mathrm{e}-\mathrm{N})$..........................................169 


\section{Introdução}

Ferros fundidos, como objetos de arte, armamentos ou em forma de utensílios, são produzidos há mais de 2000 anos. Como processo comercial a produção de ferros fundidos é sem dúvida um processo de grande sucesso e que causou grande impacto na sociedade devido à sua grande utilização em peças de máquinas, automóveis, equipamentos e outros diversos itens utilizados pela sociedade.

O uso em grande escala deste tipo de material se deve à grande flexibilidade oferecida pelo processo de fundição que permite o emprego do Ferro Fundido em diversos componentes de engenharia, onde esta flexibilidade permite aos projetistas associar a forma às suas funções. Por exemplo, é possível adicionar metal em regiões de altas tensões para aumentar a capacidade de carga do componente e remover massa de regiões com baixas tensões de tal forma que haja um balanceamento entre o projeto funcional do componente e os seus custos.

Hoje em dia os engenheiros de projeto podem aperfeiçoar as formas do fundido a partir do uso de modelagem sólida 3D (CAD), avaliar seu processo de fundição a partir de softwares de simulação de fluxo de material e transformação de fases e avaliar seu desempenho com rapidez. Porém, quando se trata de avaliar a durabilidade estrutural de componentes de ferro fundido não é possível ter grande confiança nos cálculos (CAE elementos finitos) devido à falta de informações sobre as suas propriedades mecânicas, principalmente a falta de dados sobre o seu comportamento quando submetido à fadiga de baixo ciclo e também por que as suas características mecânicas são sensíveis à solidificação do metal e às características geométricas da peça. Podem ser encontradas diversas microestruturas e consequentes propriedades mecânicas diferentes em uma mesma peçam o que leva a uma grande divergência nas propriedades mecânicas inicialmente consideradas no dimensionamento estrutural do componente.

A presente investigação visa complementar os estudos sobre o comportamento dos Ferros Fundidos Nodulares principalmente quando submetidos à fadiga de baixo ciclo, bem como desenvolver métodos para a estimativa das propriedades mecânicas a partir da dureza, de tal forma que seja possível prever as propriedades mecânicas para diversas 
regiões de um mesmo componente e desta forma aumentar a confiabilidade nos cálculos de durabilidade estrutural destes componentes sem a necessidade de usar altos fatores de segurança.

Em termos gerais este trabalho pode ser dividido em cinco partes principais:

Parte I - Descrição sobre os ferros fundidos, apresentação do conceito do índice de qualidade de fundidos, descrição das propriedades mecânicas monotônicas e cíclicas, esta última com ênfase na revisão sobre fadiga de baixo ciclo;

Parte II - Revisão na literatura sobre as propriedades mecânicas dos ferros fundidos nodulares, processamento dos dados publicados na literatura e avaliação das relações das propriedades mecânicas com a dureza (monotônico e cíclico);

Parte III - Experimentos: caracterização das propriedades monotônicas e cíclicas de baixo ciclo dos ferros fundidos nodulares em complemento às publicações existentes na literatura, determinação das propriedades de fadiga de alto ciclo a partir dos dados do ensaio de fadiga de baixo ciclo e comparações entre os comportamentos monotônicos e cíclicos de baixo ciclo;

Parte IV - Proposição de um método contínuo com relação à dureza para estimar as propriedades monotônicas, o coeficiente de resistência cíclico e o expoente de encruamento cíclico e de um método discreto, baseado em faixas de dureza, para estimar as propriedades cíclicas dos ferros fundidos nodulares com qualidade satisfatória (índice de qualidade igual ou maior do que 80) que não apresentaram correlações com a dureza e

Parte V - Caso de estudo no qual foi exemplificado as divergências entre os métodos de calculo de fadiga e a influência da variação das propriedades metalúrgicas na vida em fadiga. Também se encontra nesta parte do trabalho as conclusões e as sugestões para os próximos trabalhos 


\section{PARTE I}

\subsection{Ferros Fundidos}

O termo "ferro fundido" refere-se não somente ao material em si, mas a uma família de materiais cujo principal constituinte é o ferro com importantes quantidades de carbono e silício (conforme figura 1). Desta forma, pode-se considerar o ferro fundido como um material compósito natural cujas propriedades são determinadas pelas microestruturas presentes - fases estáveis e metaestáveis que são formadas durante o processo de solidificação ou subsequente tratamento térmico. Os principais constituintes da microestrutura dos ferros fundidos são: a forma morfológica e química do carbono e a matriz metálica no qual o carbono e/ou carbetos são dispersos.

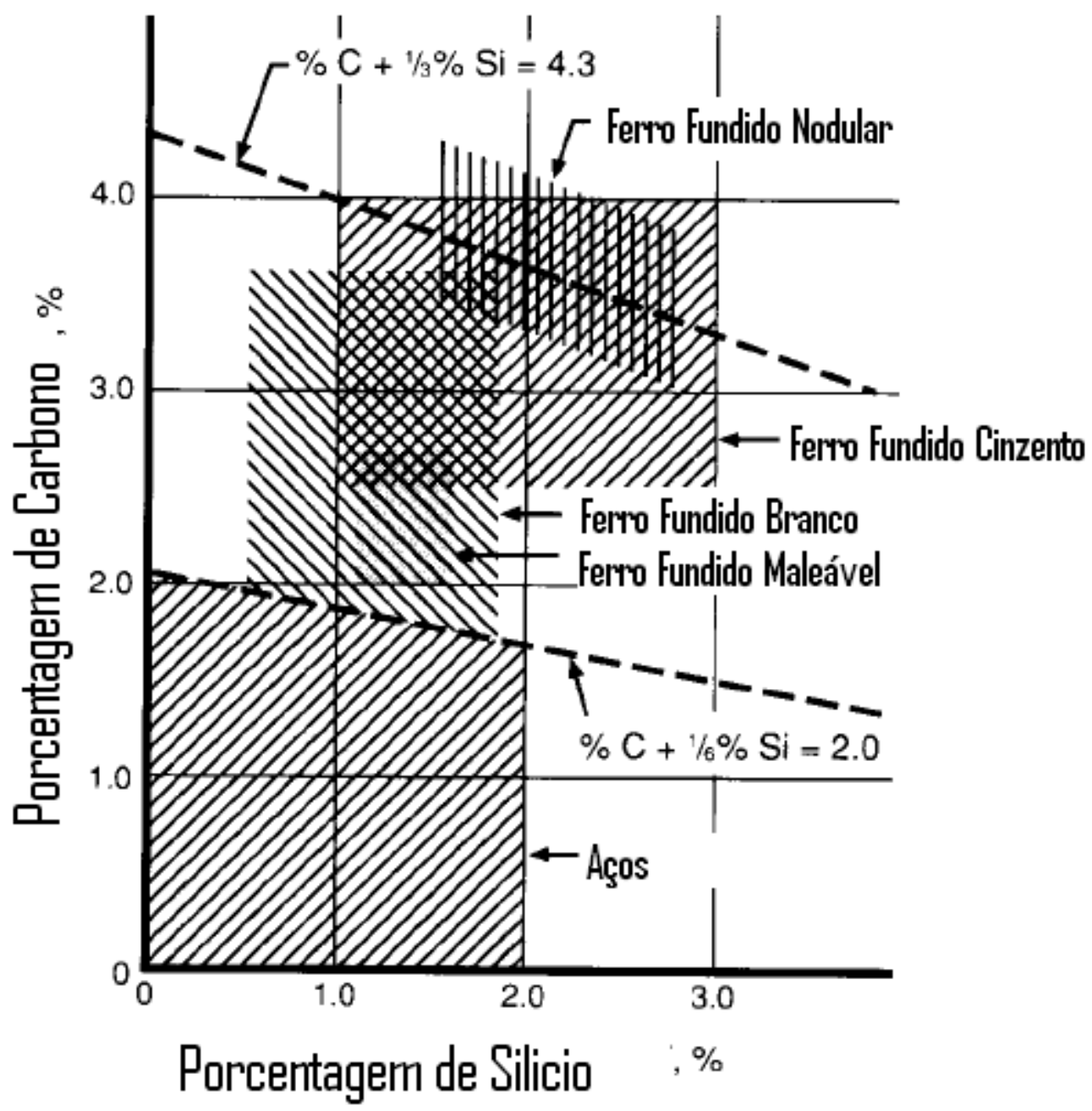

Figura 1 - Porcentagem de Carbono e Silício em Aços e Ferros Fundidos (WALTON 1981) 


\subsubsection{Componentes Microestruturais dos Ferros Fundidos}

\subsubsection{Grafita}

Esta é a forma estável do carbono puro no Ferro Fundido. Suas principais características físicas são: baixa densidade, baixa dureza, alta condutividade térmica e propriedades lubrificantes.

A forma da grafita que pode variar de veios à esferoidal tem uma grande influência na determinação das propriedades mecânicas dos ferros fundidos. A grafita em forma de veios age como trincas na matriz de ferro enquanto que na forma esferoidal (nodular) ela age como inibidora de trincas, dando ao respectivo ferro fundido propriedades mecânicas drasticamente diferentes.

\subsubsection{Carbeto}

Os carbetos constituem compostos duro e frágeis de carbono com ferro (cementita - $\mathrm{Fe}_{3} \mathrm{C}$ ) ou com outro elemento formador de carbetos, como, por exemplo, cromo, vanádio ou molibdênio. Grandes quantidades de carbetos aumentam a resistência ao desgaste dos ferros fundidos, porém, os tornam extremamente frágeis e difíceis de serem usinados. Carbetos dispersos na matriz de ferro tanto na forma de lamelas como na forma de nódulos influenciam na resistência mecânica e ao desgaste em ferros fundidos.

\subsubsection{Ferrita}

A ferrita é a forma mais pura do ferro no ferro fundido e é responsável por atribuir ao ferro fundido ductilidade e resiliência. É também responsável por abaixar a resistência mecânica e a dureza. 


\subsubsection{Perlita}

A Perlita é produzida a partir de uma reação eutetóide no qual é formada uma estrutura de cementita lamelar em uma matriz ferrítica. Como constituinte comum dos ferros fundidos a perlita é responsável pela combinação entre alta resistência com redução na ductilidade que atende a muitos requisitos nas aplicações engenharia.

\subsubsection{Martensita}

A Martensita é composta por uma solução sólida supersaturada de carbono no ferro produzida por um rápido resfriamento. Em condição não revenidas é muito dura e frágil. A Martensita é normalmente revenida - tratamento térmico para reduzir a porcentagem de carbono a partir da precipitação de carbetos - para propor uma combinação controlada de alta resistência mecânica e resistência ao desgaste.

\subsubsection{Austenita}

É normalmente uma fase formada a alta temperatura que consiste em carbono dissolvido no ferro, também pode existir na temperatura ambiente em ferros fundidos auteníticos e austemperados. Em ferros fundidos auteníticos a austenita é estabilizada para teores de níquel entre 18-36\%. Em ferros fundido austemperados (ADI Austempered Ductile Iron) a austenita pode existir na temperatura ambiente a partir de um rápido resfriamento com a supressão da formação de perlita e pela supersaturação de carbono durante a austêmpera que retarda o início da transformação de austenita para martensita para temperaturas abaixo da temperatura ambiente.

Em ferros fundidos austeníticos a matriz austenítica confere ductilidade e resiliência em todas as temperaturas, resistência à corrosão e boas propriedades mecânicas a altas temperaturas, especialmente sobre condições de carregamento térmico. 


\subsubsection{Bainita}

A bainita é uma mistura de ferrita e carbetos, que é produzida por adição de elementos de liga ou por tratamento térmico.

\subsubsection{Ausferrita}

A ausferrita consiste em uma mistura de ferrita acicular e austenita com carbono estabilizado formados durante a transformação isotérmica da austenita em temperaturas superiores a temperatura de início de formação da martensita, processo denominado por austêmpera.

\subsubsection{Tipos de Ferros Fundido}

A presença de elementos residuais (<100 parte por milhão), adição de elementos de liga, modificação do comportamento da solidificação e o tratamento térmico após a solidificação são usados para mudar a microestrutura dos ferros fundidos, com o objetivo de produzir propriedades mecânicas desejadas nos seguintes tipos de ferros fundidos:

\subsubsection{Ferro Fundido Branco}

O ferro fundido branco é composto pela matriz austenítica ou martensítica e por carbetos na sua forma final. A presença de carbono em diferentes formas de carbetos, produzidos por adição de elementos de liga faz com que os ferros fundidos branco sejam extremamente duros e muito resistentes ao desgaste, porém, são frágeis.

\subsubsection{Ferro Fundido Cinzento}

Este tipo de Ferro Fundido é sem dúvida a mais antiga e comum forma dos ferros fundidos, tanto que muitos consideram o termo "ferro fundido" e "ferro fundido cinzento" como termos intercambiáveis. A nomenclatura "cinzento" é devido à cor cinza que 
apresenta a sua fratura, que consiste em carbono na forma de veios de grafita em uma matriz de ferrita, perlita ou ainda uma mistura destas duas microestruturas.

Sua grande fluidez quando no estado líquido e a sua expansão durante a solidificação devido à formação da grafita tornou este material economicamente viável para aplicações no qual se deseja baixas distorções, tais como blocos de motores.

A forma de veios apresentada pela grafita neste tipo de ferro fundido exerce uma grande influência nas suas propriedades mecânicas. Os veios de Grafita funcionam como concentradores de tensões que podem induzir à formação de trincas prematuras na matriz a baixas tensões e gerar a fratura catastrófica quanto submetida a altas tensões sem apresentar um comportamento elástico e sem deformações plásticas significativas. A presença da grafita na forma de veios também confere a este tipo de ferro fundido excelente usinabilidade, características de amortecimento e propriedades de autolubrificação.

\subsubsection{Ferro Fundido Maleável}

Diferentemente de ferros fundidos cinzentos e nodulares o ferro fundido maleável é fundido como ferro fundido branco e posteriormente é submetido a um tratamento térmico de recozimento para converter os carbetos em grafita. A microestrutura deste tipo de ferro fundido é comporta por formas irregulares de nódulos de grafita chamadas de "carbono revenido" em uma matriz de ferrita ou perlita. A presença de grafita na forma mais compacta ou na forma de esferas faz com que o ferro fundido maleável apresente ductilidade e resistência equivalente a um aço de baixo carbono.

\subsubsection{Ferro Fundido Nodular}

Apesar do progresso alcançado durante a primeira metade do século passado no desenvolvimento de ferros fundidos cinzentos e maleáveis as fundições continuaram suas pesquisas para encontrar uma forma ideal de ferro fundido. Em 1943, no laboratório da Companhia Internacional de Pesquisas de Níquel, Keith Dwight Millis adicionou magnésio (na forma de uma liga de Cobre-Magnésio) ao ferro fundido cinzento e 
observou que o ferro fundido solidificado não continha mais os veios de gráfica e sim grafita em formas de nódulos, nascia então um novo tipo de ferro fundido que foi denominado por Ferro Fundido Nodular.

As vantagens dos ferros fundidos nodulares que alavancaram o seu sucesso podem ser resumidas como: versatilidade e alto desempenho a baixos custos. A versatilidade se deve principalmente na sua possibilidade de aplicação em componentes estruturais devido às suas propriedades mecânicas, que combinam altos valores de ductilidade aliados a alta resistência mecânica.

É justamente esta possibilidade de aplicação em componentes estruturais que tornam este tipo de ferro fundido como o vetor para os estudos e investigações presentes neste trabalho.

Este tipo de ferro fundido é comumente utilizado em componentes estruturais automotivos, industriais, agrícolas, de construção e em veículos comerciais, e.g., em componentes do sistema de direção, carcaças de redutores para usinas sucroalcooleiras, redutores de rodas para colheitadeiras, cubo de rodas de caminhões e carcaças de eixos para máquinas de construção e tratores, que por sua vez, geralmente falham por fadiga em regiões onde há concentração de tensões (plasticidade local). Torna-se, portanto, imprescindível o conhecimento da resposta deste material quando sujeito a fadiga de baixo ciclo, objetivo central deste trabalho.

O ferro fundido não é apenas um material, mas sim uma família de material que oferece extensas propriedades que são obtidas a partir do controle da sua microestrutura. Sua característica comum é a presença da grafita em nódulos praticamente esféricos que inibem a propagação de trincas tornando este material dúctil.

A família dos ferros fundidos nodulares é composta por ferros fundidos nodulares ferrítico, ferro fundido nodular ferrítico-perlítico, ferro fundido perlítico, ferro fundido nodular martensítico, ferro fundido nodular bainítico, ferro fundido nodular austenítico e ferro fundido nodular austemperado (ADI). 


\subsubsection{Classificação dos Ferros Fundido Nodulares}

Os ferros fundidos nodulares apresentam as faixas de composição química conforme mostrado na Tabela 1.

Tabela 1: Composição Química dos Ferros Fundidos (ASTM A536)

\begin{tabular}{|cc|}
\hline Elemento & Porcentagem \\
\hline Carbono & $(3,20-4,10) \%$ \\
Silício & $(1,80-3,00) \%$ \\
Manganês & $(0,10-1,00) \%$ \\
Fósforo & $0,050 \%$ Max. \\
Enxofre & $0,035 \%$ Max. \\
Magnésio & $(0,025-0,060) \%$ \\
\hline
\end{tabular}

Com relação à forma da Grafita é necessário que pelo menos $80 \%$ da grafita seja esferoidal dos Tipos I e II (ASTM A247) conforme mostrado na figura a seguir:

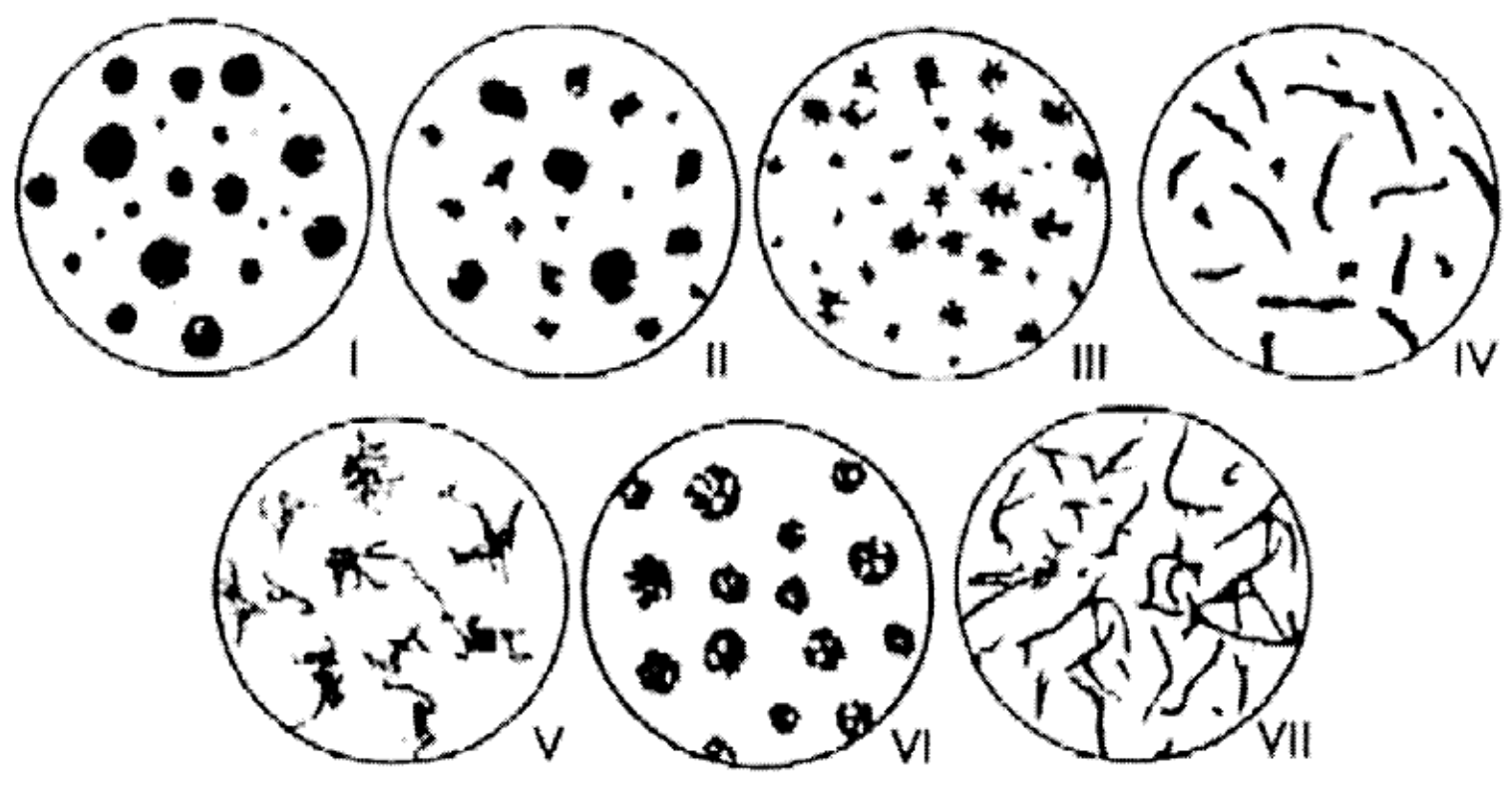

Figura 2: Tipos de Grafita conforme ASTM A247

A partir do atendimento da composição química e do tipo da forma da Grafita é possível classificar os ferros fundidos de acordo com a constituição da sua microestrutura, que por sua vez determina as suas propriedades mecânicas. 


\subsubsection{Classificação ASTM}

A ASTM A 536 classifica os ferros fundidos nodulares de acordo com a Tabela 2:

Tabela 2: Classificação dos Ferros Fundidos Nodulares de Acordo com a ASTM A537

\begin{tabular}{|c|c|c|c|c|}
\cline { 3 - 5 } \multicolumn{2}{c|}{} & \multicolumn{3}{c|}{ Propriedades Mecânicas Típicas - Tração } \\
\hline Designação SAE & Microestrutura & Su (MPa) & Sy (MPa) & El (\%) \\
\hline D4018 & Ferrita & 400 & 275 & 18 \\
\hline D4512 & Ferrita + Perlita & 450 & 310 & 12 \\
\hline D5006 & Ferrita + Perlita & 500 & 345 & 6 \\
\hline D5504 & Ferrita + Perlita & 550 & 380 & 4 \\
\hline D7003 & Perlita & 700 & 450 & 3 \\
\hline D8002 & Perlita + Martensita & 800 & 480 & 2 \\
\hline
\end{tabular}

\subsubsection{Classificação DIN EN}

A norma DIN EN 1563 classifica os ferros fundidos nodulares de acordo com a Tabela 3:

Tabela 3: Classificação dos Ferros Fundidos Nodulares de Acordo com a DIN EN 1563

\begin{tabular}{|c|c|c|c|c|}
\cline { 3 - 4 } \multicolumn{2}{c|}{} & \multicolumn{2}{c|}{ Propriedades Mecânicas Típicas - Tração } \\
\hline Designação DIN EN & Microestrutura & Su (MPa) & Sy (MPa) & El (\%) \\
\hline EN-GJS-400-18 & Ferrita & 400 & 250 & 18 \\
\hline EN-GJS-450-10 & Ferrita + Perlita & 400 & 250 & 15 \\
\hline EN-GJS-500-7 & Ferrita + Perlita & 450 & 310 & 10 \\
\hline EN-GJS-600-3 & Perlita & 500 & 320 & 7 \\
\hline EN-GJS-800-2 & Perlita + Martensita & 800 & 370 & 3 \\
\hline
\end{tabular}

\subsection{Propriedades Monotônicas}

Os ferros fundidos nodulares são constituídos por uma família de grande faixa de propriedades mecânicas que são obtidas a partir do controle da sua microestrutura. A microestrutura mais importante e distinguível de todos os ferros fundidos nodulares são os nódulos de grafita que funcionam como barreira para o crescimento de trincas e fornece ao ferro fundido nodular as propriedades de ductilidade e tenacidade superiores a qualquer outro tipo de ferro fundido e igual a muitos aços fundidos e forjados. A figura 3 mostra a grande influência que a matriz, no qual os nódulos de grafita estão inseridos, exerce sobre as características mecânicas dos ferros fundidos. 


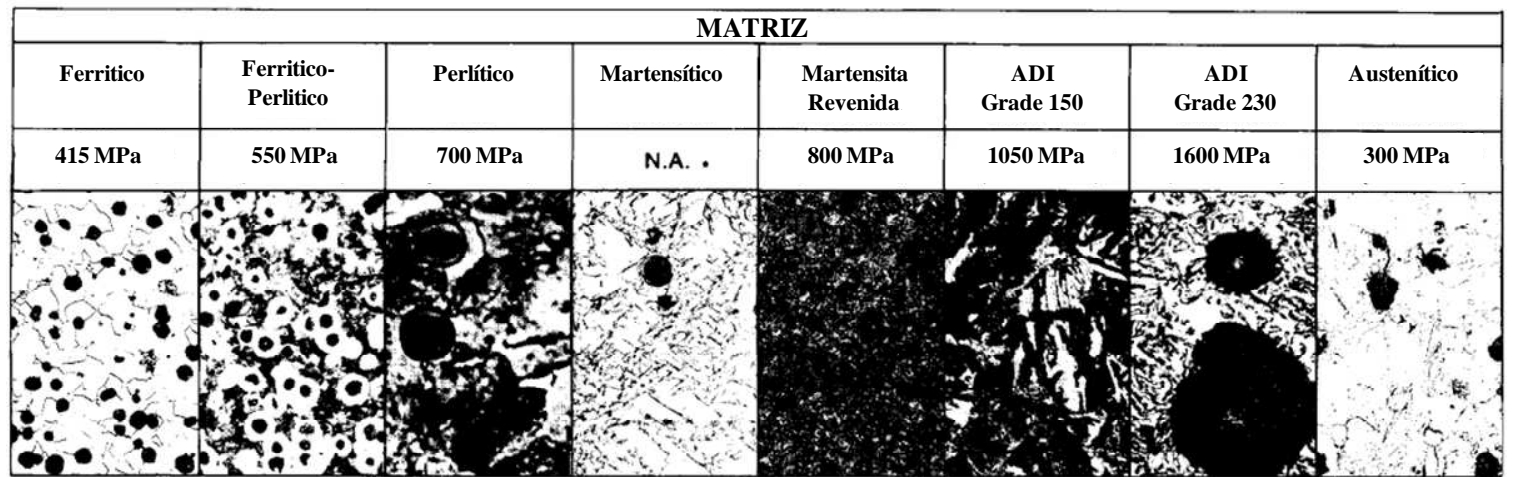

Figura 3: Influência da matriz dos ferros fundidos nodulares nas suas propriedades mecânicas neste caso na sua resistência a tração (LEE 2005)

O controle da matriz, obtido a partir da condição sem tratamento ("as-cast") ou através da combinação da composição, da geometria da peça, de controles da produção e de tratamentos térmicos possibilita ao projetista escolher a classe de ferro fundido que mais é adequada à sua aplicação.

A figura 4 ilustra, para as classes de ferros fundidos nodulares, a faixa de variação de resistência à tração, do limite de escoamento e do alongamento com relação à dureza

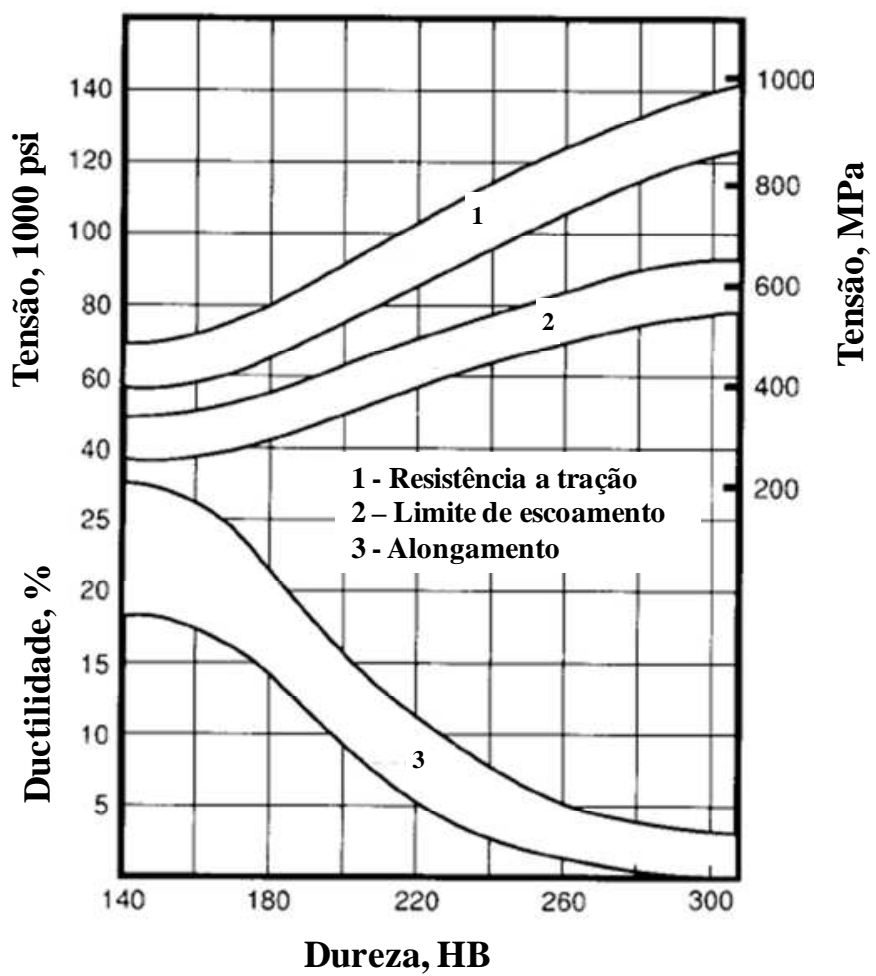

Figura 4: Variações das Propriedades Mecânicas dos Ferros Fundidos de acordo com a Variação da Matriz (Dureza) 
Os ferros fundidos ferríticos de alta ductilidade situados na parte esquerda do gráfico apresentam alongamento entre 18-30 \%, com resistência à tração equivalente aos aços de baixo carbono. Já os ferros fundidos perlíticos localizados na parte direita do gráfico exibem resistência à tração da ordem de $820 \mathrm{MPa}$, porém, com baixa ductilidade.

A seguir são descrito as principais propriedades mecânicas necessárias para a seleção de ferros fundidos nodulares para aplicações estruturais.

A norma ASTM E8M (ASTM, 2001) define os métodos e requisitos para a determinação da relação entre a tensão e a deformação para um material em um ensaio de tração monotônico. Os corpos de prova são fraturados em controle de deformação ou de deslocamento. Depois que o ensaio de tração é executado os corpos de prova fraturados são cuidadosamente encaixados e se faz então as medições do seu comprimento final, do diâmetro final e do diâmetro da estricção para se determinar a deformação final do corpo de prova.

A curva resultante do ensaio monotônico de tração é exibida na figura 5. Neste caso observa-se que a tensão de ruptura do material é menor do que a resistência a tração (tensão máxima) por que a redução da área (estricção) não é considerada durante o ensaio, esta curva é denominada curva tensão-deformação de engenharia.

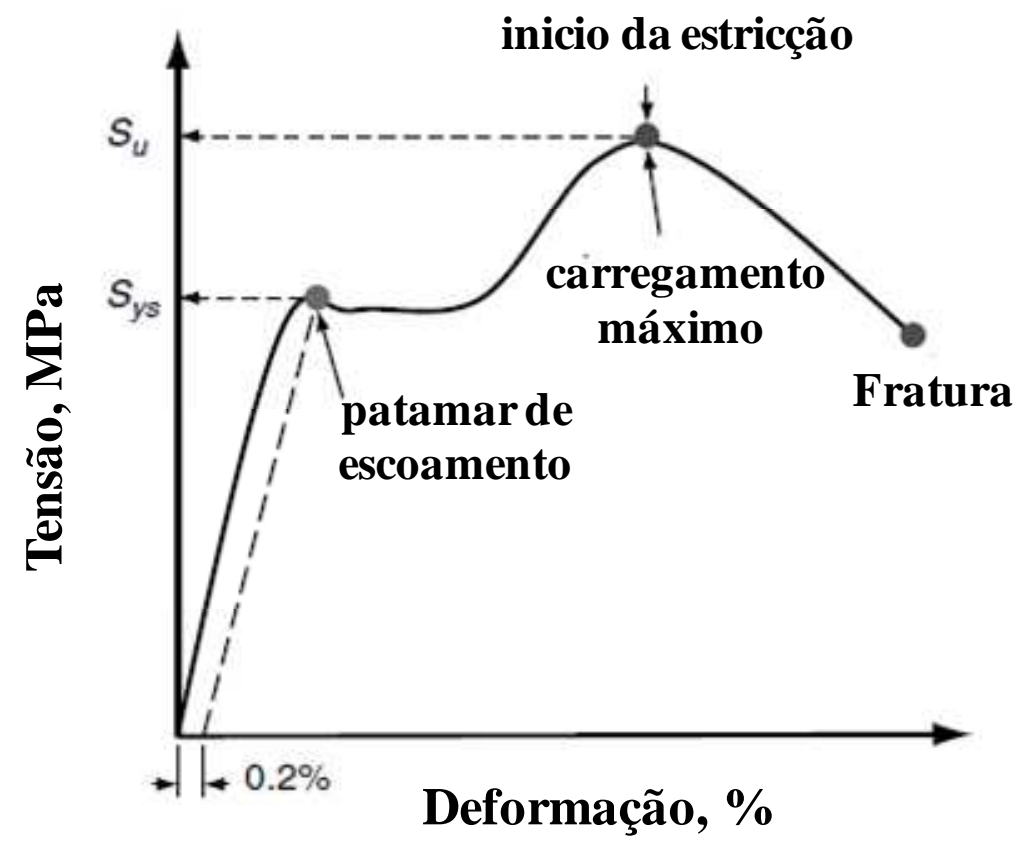

Figura 5: Curva Tensão-Deformação de Engenharia típica de um aço de baixo teor de carbono (LEE 2005) 
Considerando a variação da área durante a aplicação da força no ensaio de tração a curva verdadeira tensão-deformação obtida segue o formato conforme figura 6:

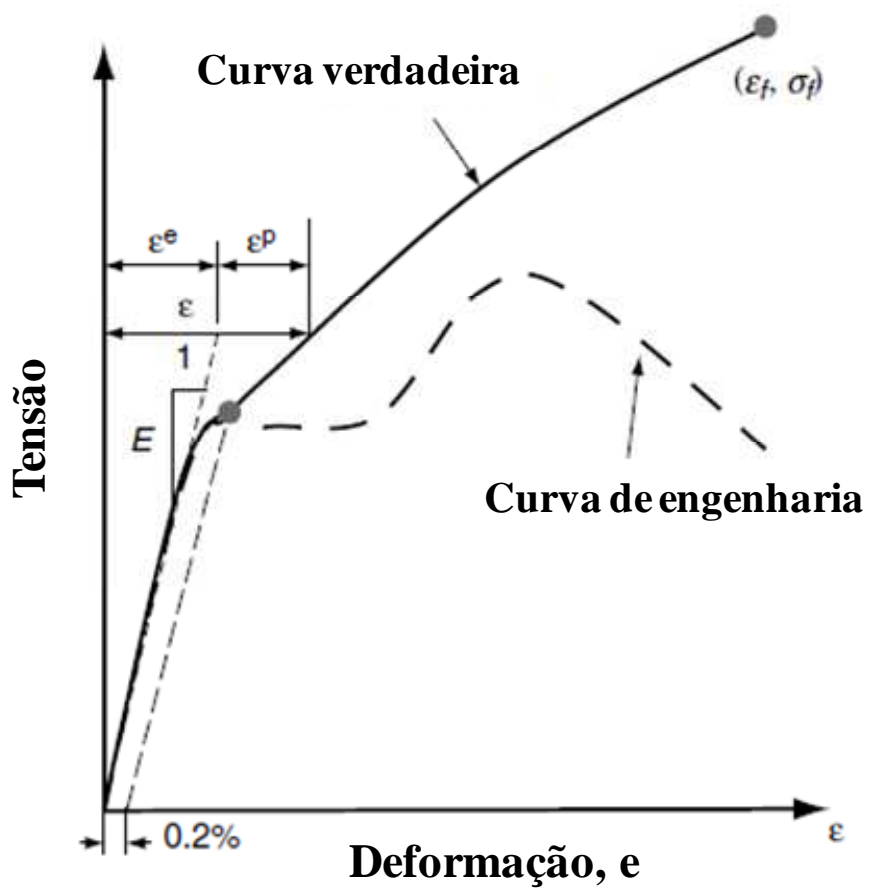

Figura 6: Curva tensão-deformação verdadeira e tensão-deformação de engenharia (LEE 2005) mecânicas:

A partir do ensaio de tração é possível determinar as seguintes propriedades $E$ = Módulo de elasticidade;

$v=$ Razão de Poisson;

$S_{y}=$ Limite de escoamento $(0,2 \%)$;

$S_{u}=$ Limite de resistência à tração;

$E L=$ Alongamento específico até a ruptura;

$K=$ Coeficiente de resistência monotônico;

$n=$ Expoente de encruamento monotônico;

$\sigma_{f}=$ Tensão verdadeira na fratura;

$\varepsilon_{f}=$ Deformação verdadeira na fratura; 
A tensão de engenharia (S) e a deformação de engenharia (e) são determinadas a partir do uso da seção original do corpo de prova $\left(\mathrm{A}_{0}\right)$ e do comprimento original $\left(l_{0}\right)$. A tensão de engenharia é dada por:

$$
S=\frac{P}{A_{0}}
$$

onde P é a carga aplicada.

A deformação de engenharia é dada pela variação do comprimento entre marcas do corpo de prova, que é dado por:

$$
e=\frac{l-l_{0}}{l_{0}}=\frac{\Delta l}{l_{0}}
$$

onde lé o comprimento instantâneo.

Ao invés de se utilizar as dimensões iniciais do corpo de prova é possível empregar as medidas instantâneas e desta maneira tem se a tensão verdadeira $(\sigma)$ e a deformação verdadeira ( $\varepsilon$ ) que são definidas nas expressões que se seguem:

$$
\begin{gathered}
\sigma=\frac{P}{A} \\
\varepsilon=\int_{l_{0}}^{l} \frac{d l}{l}=\ln \frac{l}{l_{0}}
\end{gathered}
$$

Assumindo-se que o volume do corpo de prova não se altera durante o ensaio de tração é possível estimar as tensões e a deformação verdadeira a partir das tensões e deformações de engenharia a partir de:

$$
\sigma=S(1+e)
$$




$$
\varepsilon=\ln (1+e)
$$

Estas relações têm validade somente até o início da estricção.

Observa-se que deformação total verdadeira mostrada na figura 6 é composta por uma parte elástica $\left(\varepsilon_{e}\right)$ e uma parte plástica $\left(\varepsilon_{p}\right)$ e a curva tensão-deformação verdadeira é geralmente descrita a partir da equação de Ramberg e Osgood (1943):

$$
\varepsilon=\varepsilon_{e}+\varepsilon_{p}=\frac{\sigma}{E}+\left(\frac{\sigma}{K}\right)^{1 / n}
$$

Onde "E" é o Módulo de Elasticidade e as constantes "K" e "n" são o coeficiente de resistência monotônico e o expoente de resistência monotônico, respectivamente, e ambos são empregados para descrever a curva monotônica de tensão-deformação plástica, que podem ser determinadas a partir do ajuste do gráfico $\log -\log$ ilustrado na figura 7 :

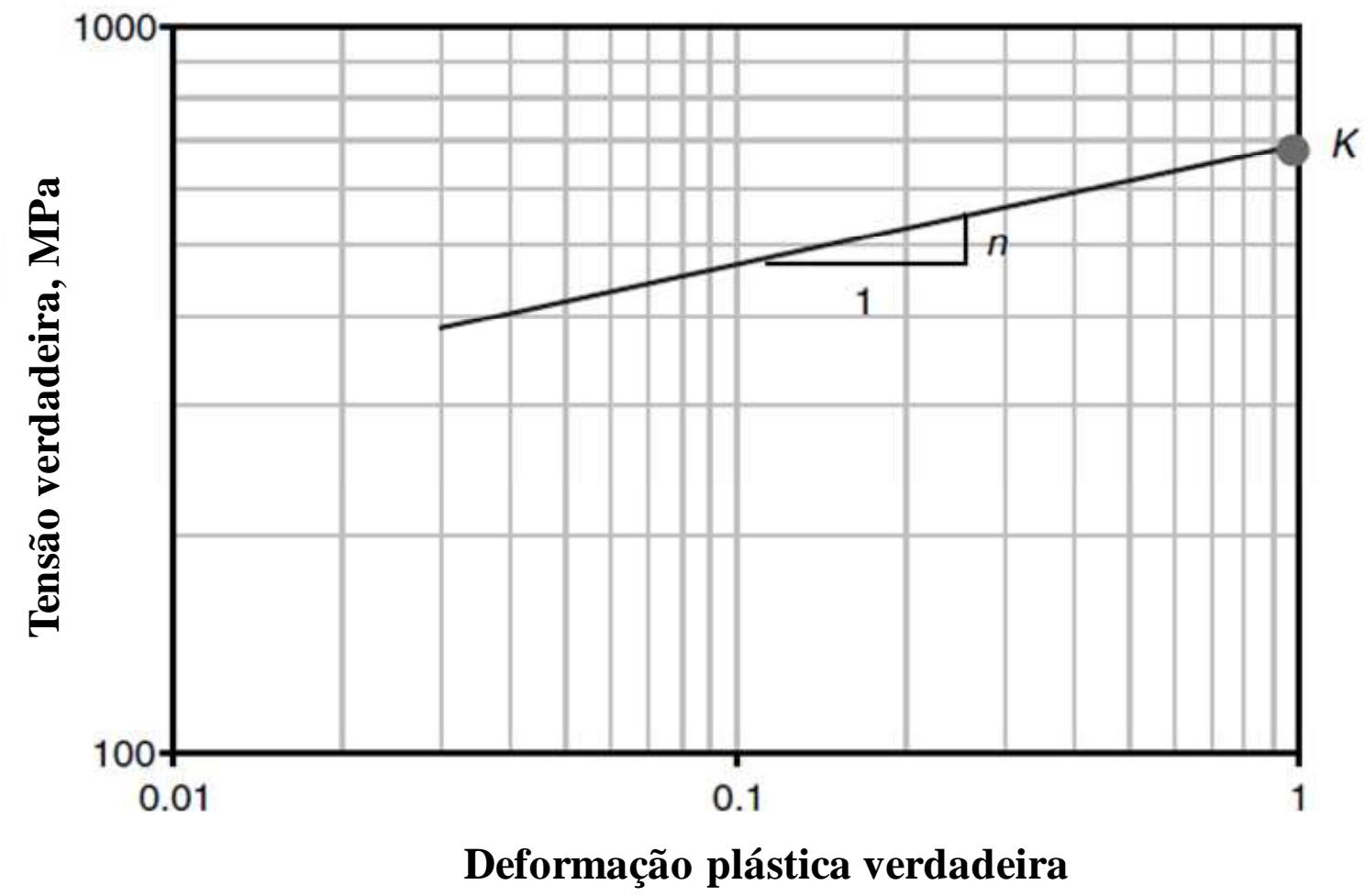

Figura 7: Curva monotônica tensão verdadeira em função da deformação plástica verdadeira (LEE 2005) 
Da equação (I.7) é possível notar que a tensão verdadeira é dada por:

$$
\sigma=K\left(\varepsilon^{p}\right)^{n}
$$

A resistência à fratura verdadeira $\left(\sigma_{f}\right)$ é a tensão verdadeira na fratura durante o ensaio de tração e deve ser corrigida devido à estricção através da aplicação do fator de correção de Bridgman (BRIDGMAN 1944):

$$
\sigma_{f}=\frac{P_{f} / A_{f}}{\left(1+4 R / D_{f}\right) \ln \left(1+D_{f} / 4 R\right)}
$$

onde $P_{f}$ é a carga na fratura, R é o raio da estricção e $D_{f}$ é o diâmetro da fratura. A deformação verdadeira na fratura $\left(\varepsilon_{f}\right)$ é devido à deformação até a fratura e é calculada como segue:

$$
\varepsilon_{f}=\ln \left(\frac{A_{0}}{A_{f}}\right)=\ln \left(\frac{100}{100-\% R A}\right)
$$

onde $\mathrm{A}_{\mathrm{f}}$ é a seção transversal no estricção.

\subsubsection{Módulo de Elasticidade}

Assim como observado na figuras 5 e 6 para baixas tensões existe uma relação linear entre a tensão e a deformação específica. Esta relação é conhecida como a lei de Hooke e a inclinação da reta é definida como sendo o módulo de elasticidade ou o módulo de young.

$$
E=\frac{\Delta S}{\Delta e}
$$

O módulo de elasticidade para ferros fundido nodulares é similar ao dos aços, porém, é limitado pelo início das deformações permanentes (plásticas). O valores típicos do Módulo de Elasticidade dos ferros fundidos varia entre 162 - 170GPa. 


\subsubsection{Razão de Poisson}

O coeficiente de Poisson é a relação entre as deformações elástica lateral e longitudinal medidas durante o ensaio de tração. O coeficiente típico dos ferros fundidos nodulares é 0,275 .

\subsubsection{Limite de Proporcionalidade}

O limite de proporcionalidade é máxima tensão no qual o material exibe comportamento elástico. Quando o material é sujeito a tensões menores que o limite de proporcionalidade, e a tensão é removida, a curva tensão-deformação retorna ao seu estado original - não existem mudanças permanentes nas dimensões.

\subsubsection{Limite de Escoamento}

O limite de escoamento é a tensão no qual o material apresenta deformação plástica significativa. Em ferros fundidos nodulares usa-se o método da reta paralela para se determinar a Limite de Escoamento, pois, este tipo de material não apresenta uma região de transição bem definida entre o seu comportamento linear e plástico. O valor do limite de escoamento é obtido traçando-se uma reta paralela à região linear do gráfico tensão-deformação e deslocado de 0,002 ou $0,2 \%$ no eixo da deformação. Os valores típicos para os ferros fundido são $275 \mathrm{MPa}$ para os ferros fundidos com matriz ferrítica, podendo chegar até aproximadamente $620 \mathrm{MPa}$ para as classes martensíticas.

\subsubsection{Resistência à Tração}

O limite de resistência à tração ou tensão máxima (UTS - Ultimate Tensile Strength) é a tensão correspondente à máxima carga aplicado durante o ensaio de tração e é uma tensão no qual o material pode não apresentar fratura. 


$$
S_{u}=\frac{P_{\max }}{A_{0}}
$$

Geralmente a resistência à tração dos ferros fundidos nodulares varia entre 400MPa para os ferríticos e 1400MPa para os martensíticos.

\subsubsection{Alongamento Específico até a Fratura e Redução de Área}

O alongamento define o aumento permanente da deformação que ocorre no comprimento do corpo de prova após o ensaio de tração, é expresso em porcentagem e é o indicador da ductilidade do material.

$$
\% E L=\frac{l_{f}-l_{0}}{l_{0}} \times 100
$$

Materiais frágeis como os ferros fundidos cinzentos geralmente fraturam no ensaio de tração sem apresentar alongamento significativo, já os ferros fundidos nodulares podem apresentar alongamentos na fratura superiores a $25 \%$.

Semelhantemente ao alongamento a redução de área define a redução percentual da seção do corpo de prova e também é usado para medir a ductilidade do material, é definido como:

$$
\% R A=\frac{A_{f}-A_{0}}{A_{0}} \times 100
$$

\subsubsection{Dureza}

A melhor maneira de se medir a dureza de ferros fundidos nodulares se dá pela utilização da escala Brinell, no qual consiste em pressionar sobre uma superfície plana do metal uma esfera, geralmente de aço rápido ou de carbeto de tungstênio, de $10 \mathrm{~mm}$ de diâmetro. A dureza é indicada como HB (Hardness Brinell). Pode ser empregada para o controle da produção ou como um ensaio auxiliar na medida de parâmetros mecânicos. 


\subsection{Propriedades Cíclicas}

As propriedades cíclicas definem a capacidade dos materiais de suportarem os danos causados por cargas cíclicas, denominado de fadiga, que é um processo cumulativo que ocorre desde o início da trinca, propagação, e a fratura final de um componente. Nesta seção do trabalho serão apresentados os conceitos básicos sobre o mecanismo da fadiga, a teoria de dano a fadiga (linear e não linear) e também as metodologias $\mathrm{S}-\mathrm{N}$ e $\varepsilon-\mathrm{N}$ usadas para a determinação da vida de fadiga.

O foco do presente trabalho é a metodologia baseada nas deformações cíclicas específicas $(\varepsilon-\mathrm{N})$, e consequentemente no estudo das propriedades cíclicas provenientes desta metodologia, também denominada de fadiga de baixo ciclo, porém, apesar de algumas limitações que serão discutidas faz-se necessário a apresentação da metodologia de determinação da vida em fadiga que é baseada na curva tensão $(\mathrm{S}-\mathrm{N})$ devido ao seu consagrado uso, por ser simples e por possuir com a metodologia $\varepsilon-\mathrm{N}$ diversos conceitos similares.

\subsubsection{Mecanismo da Fadiga}

Durante o carregamento cíclico pode ocorrer uma deformação plástica localizada na região de maior tensão. Esta deformação plástica induz a um dano permanente ao componente e uma trinca é desenvolvida (LEE 2005). Uma vez que o componente é sujeito a um aumento de números de ciclos de carregamentos, a comprimento da trinca cresce e desta forma também aumenta o dano causado à estrutura. Depois de determinado número de ciclos a trinca irá causar a falha do componente (separação em partes).

No geral tem-se observado que o processo de fadiga envolve os seguintes estágios: (1) nucleação da trinca, (2) crescimento de uma trinca curta, (3) crescimento de uma trinca longa e (4) fratura final. As trincas se iniciam nos planos de cisalhamento localizados próximos ou nas regiões de concentração de tensões. O plano de cisalhamento localizado geralmente ocorre na superfície ou nos contornos dos grãos. Nesta etapa, a 
nucleação da trinca, é o primeiro estágio no processo de fadiga. Uma vez que ocorreu a nucleação e o carregamento cíclico continua a trinca tende a crescer ao longo do plano de máxima tensão cisalhante e ao longo dos contornos dos grãos.

A figura abaixo é uma representação do processo de dano causado pela fadiga no qual mostra a nucleação da trinca na(s) região(ões) de concentração de tensão na região das bandas de escorregamento. A próxima etapa no processo de fadiga é o crescimento da trinca. Esta etapa é subdivida em dois estágios: Estágio I - nucleação e a propagação da trinca curta, que possuí comprimento da ordem de alguns grãos no plano de máxima tensão de cisalhamento. Neste estágio a plasticidade na ponta da trinca é muito influenciada pelas características microestruturais, tais como as bandas de escorregamento, tamanho do grão, orientação e nível de tensão, por que o tamanho da trinca é comparável com a microestrutura do material. Estagio II - neste estágio o crescimento da trinca refere-se ao crescimento ao longo do plano perpendicular ao plano de máxima tensão principal e na direção de máxima tensão de cisalhamento. Neste estágio as características da trinca longa são menos influenciadas pelas propriedades da microestrutura do que as trincas do estágio I (trincas curtas). Isto se deve por que a zona plástica na ponta da trinca no estágio II é muito maior do que a microestrutura do material.

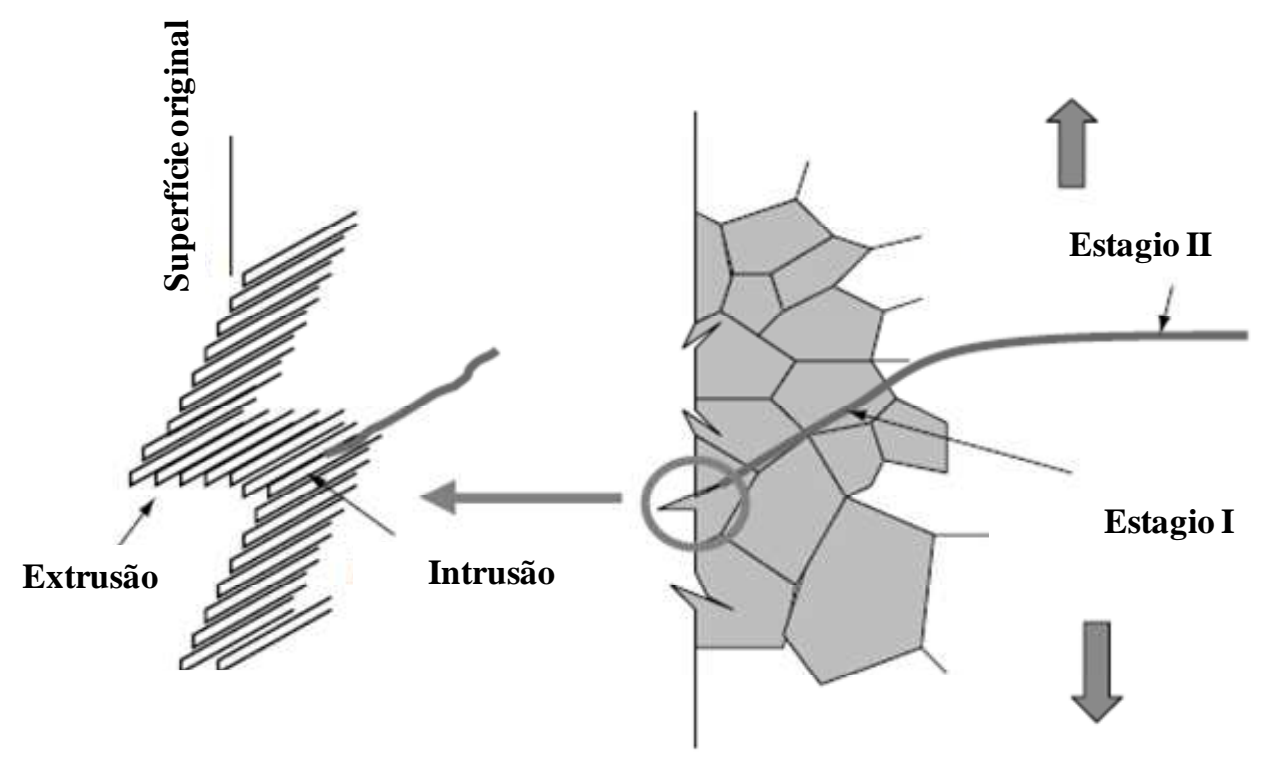

Figura 8: Processo de fadiga em uma chapa fina sujeita a uma carga cíclica de tração (LEE 2005)

Em aplicações de engenharia, a quantidade da vida usada na nucleação e crescimento de trinca curta é geralmente denominada de período de iniciação da trinca, enquanto que o período usado durante a propagação da trinca longa é denominado por 
período de propagação da trinca. Uma definição exata do período de transição entre a iniciação e a propagação é difícil de ser determinado.

\subsubsection{Dano à Fadiga}

O dano à fadiga (D) pode ser contabilizado a partir do acúmulo do comprimento da trinca $a$ com relação ao seu tamanho máximo permissível $a_{f}$ segundo a equação desenvolvida por Manson e Halford (1981), como segue:

$$
D=\frac{a}{a_{f}}=\frac{1}{a_{f}}\left[a_{0}+\left(a_{f}-a_{0}\right)\left(\frac{n}{N_{f}}\right)^{\alpha_{f}}\right]
$$

No qual $a_{0}$ representa o comprimento inicial de uma trinca e $n$ representa o número de ciclos de carregamentos necessários para se alcançar uma trinca de comprimento $a$ e $N_{f}$ representa o número de ciclos de carregamento necessários para se atingir uma trinca com comprimento $a_{f}$ na fratura, ou seja, $N_{f}$ é a vida em fadiga. A equação I.15 acima foi baseada em nos estudos inicias sobre Mecânica da Fratura a partir de ajustes de uma grande escala de informações de ensaios com dois níveis de vida e tensão. Da equação do dano pode inferir que a falha por fadiga ocorrerá quando $D$ for igual à unidade. $\mathrm{O}$ expoente $\alpha_{f}$ foi determinado empiricamente e é dado por:

$$
\alpha_{f}=\frac{2}{3} N_{f}^{0,4}
$$

Consider o carregamento de duas sequências, uma de alto carregamento seguido por outra de baixo carregamento, conforme figura 9. O número de ciclos $n_{1}$ denota os ciclos iniciais do carregamento com alta tensão e $n_{2, f}$ representa os ciclos remanescentes da eventual vida em fadiga com uma tensão menor. Os subscritos 1 e 2 referem-se à 
sequência de aplicação dos esforços, o índice 1 representa o primeiro e o índice 2 representa o segundo nível de esforços.

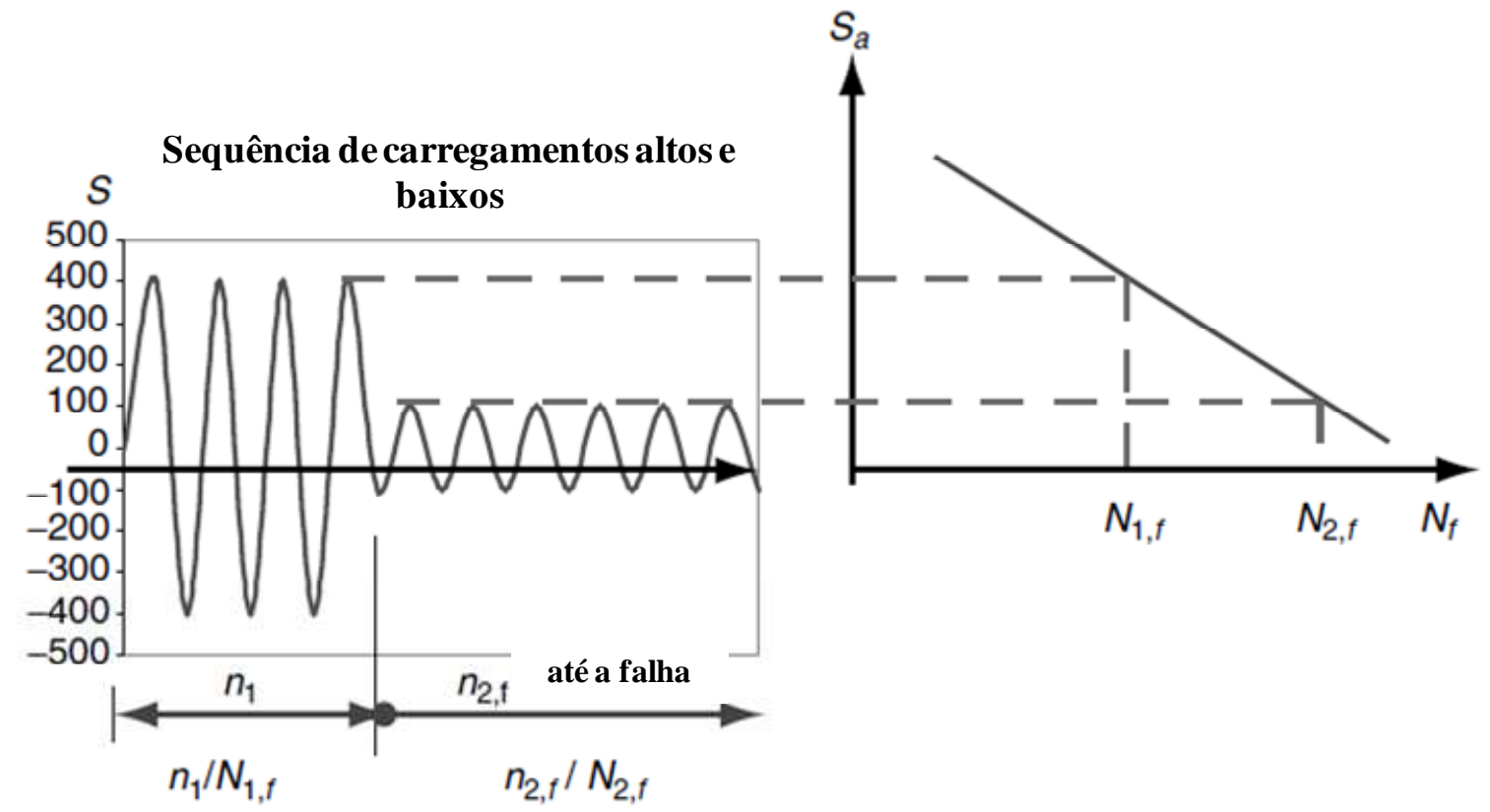

Figura 9: Bloco de carregamento com duas sequências de alto e baixo carregamento (LEE 2005)

Abaixo são mostradas as curvas não-lineares para dois carregamentos diferentes $N_{1, f}$ e $N_{2, f}$ para cada nível de carregamento. Cada uma destas curvas representa uma condição diferente de carregamento que induz a um tempo diferente para a falha (vida). Em cada nível de esforços, a relação entre o valor do dano e os ciclos aplicados ou a relação de ciclos segue a equação I.15. Caso uma relação de ciclo $n_{1} / N_{1, f}$ seja primeiramente aplicado ao longo da curva que representa o nível de vida $N_{1, f}$ ao ponto AO, o processo de dano acumulado será representado pela curva do nível de vida $N_{1, f}$ de zero até o ponto A. Caso um novo carregamento seja aplicado a partir deste ponto com um nível de vida $N_{2, f}$ então o processo de dano será representado do ponto A até o ponto A' a partir do mesmo valor de dano.

Caso um esforço correspondente à relação $n_{2} / N_{2, f}$ seja aplicado de A' até B' no nível de vida $N_{2, f}$, a falha, que ocorre quando $D=1$ é alcançada quando se atinge o ponto B'. A partir desta figura fica evidente que se um carregamento de alto esforço e com uma vida baixa, aplicado ao longo de $\mathrm{AO}$, for aplicado antes de um carregamento de 
baixo esforço e com uma vida alta ao longo de A'B' então a soma das razões entre os ciclos serão menores do que 1. Portanto, a vida em fadiga estimada depende da sequência do carregamento. Contudo, se um carregamento menor for aplicado ao longo de OA' antes de um carregamento maior aplicado ao longo de $\mathrm{AB}$, então a o somatório das relações dos ciclos serão maiores do que a unidade por que o segmento AA' será contabilizado duas vezes.

Quando a curva de dano é linearizada, ela pode ser representada por uma reta no domínio $n_{i} / N_{i, f}$ assim como mostrado na figura 10 :
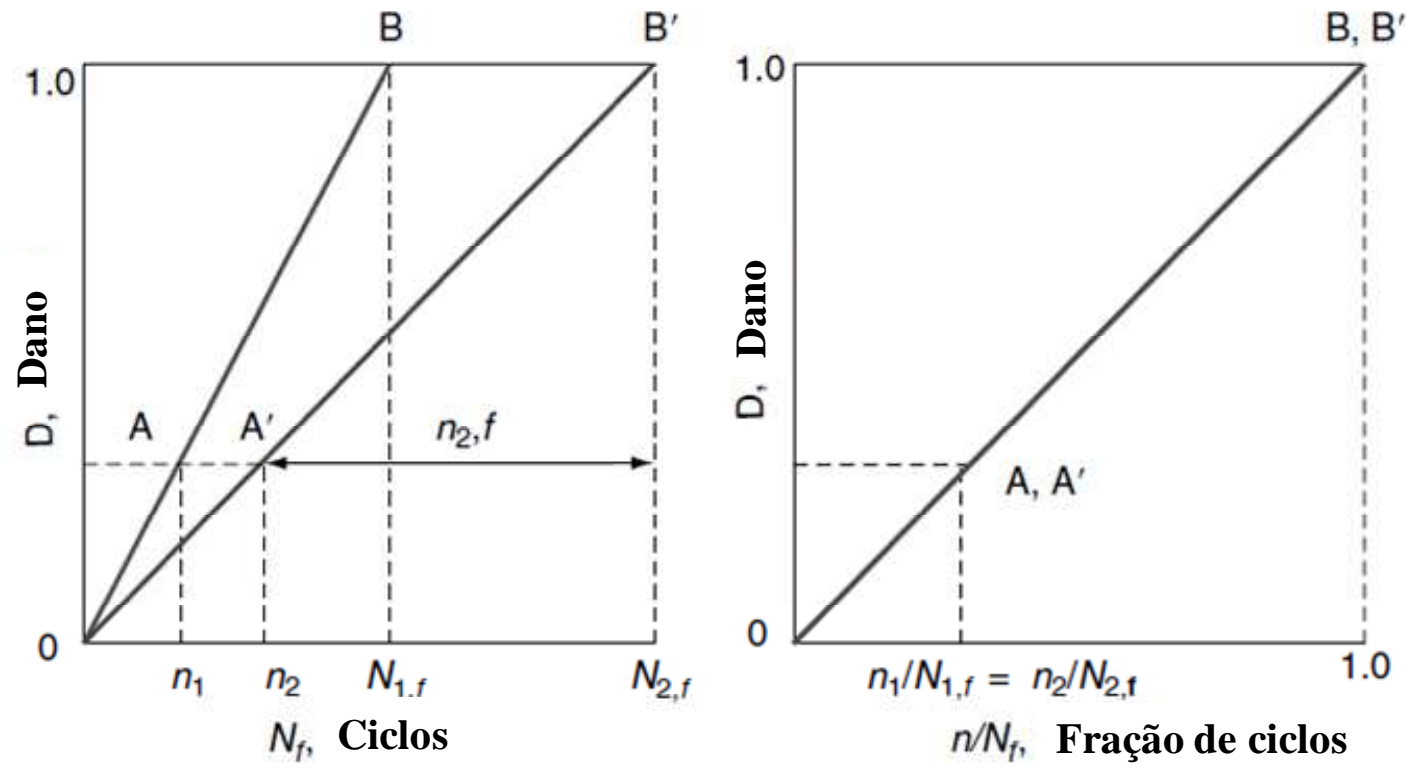

Figura 10: Modelo linear de dano acumulado (LEE 2005)

Neste caso o dano em fadiga tem uma relação linear única com a vida em fadiga $N_{i, f}$ independente do nível de tensão. Ou seja, para determinado nível de dano, a razão de vida para duas curvas diferentes de dano serão idênticas. Igualmente ao caso não linear a falha ocorrerá quando o dano for igual à unidade, porém, neste caso o dano por ser obtido simplesmente pela soma das razões de vida. Em termos matemáticos o modelo linear de dano por ser expresso por:

$$
D_{i}=\frac{n_{i}}{N_{i}}
$$


e a falha é prevista quando

$$
\sum D_{i}=\sum \frac{n_{i}}{N_{i}} \geq 1.0
$$

Este modelo universal de cálculo do dano foi primeiramente proposto por Palmgren (1924) para aplicações na indústria sueca de rolamentos de esferas. Langer (1937) trabalhando para a Westinghouse na indústria de geração de energia elétrica, independentemente propôs um modelo similar de um modelo linear para calculo do dano em vasos de pressão e componentes de tubos fabricados em aço. Miner (1945) da Douglas Aircraft trabalhou no trabalho de Langer aplicando o modelo linear da dano para dados experimentais de fadiga axial de tração para um revestimento aeronáutico feito em uma liga de Alumínio 24S AlCLAD. Miner demonstrou uma excelente correlação do modelo com os seus ensaios realizados, o garantiu a ele a grande associação do seu nome ao modelo linear de dano acumulado, tanto que comumente o modelo linear de cálculo de dano é denominado de modelo de Miner.

Portanto, uma vez conhecido o numero de ciclos referente a um carregamento $i$, de certa amplitude e uma tensão média (ou carregamento médio) é necessário agora definir a partir da metodologia $S-N$ (Tensão-Vida) ou $\varepsilon-N$ (Deformação Vida) a vida em fadiga $N_{i, f}$ para se calcular o dano sofrido pela estrutura, usando, por exemplo, o modelo linear de dano (regra de Miner).

\subsubsection{Metodologia S-N}

Assim como mostrado no item anterior o dano a fadiga é fortemente associado com a razão de vida $n_{i} / N_{i, f}$, onde $n_{i}$ e $N_{f}$, são, respectivamente, o numero de ciclos aplicados e a vida em fadiga para uma combinação de amplitude de tensão/deformação e tensão média. A contagem de ciclos $n_{i}$ pode ser feita a partir de um histórico de carregamento (variação do carregamento com o tempo) e a partir do emprego de diveRas técnicas, como por exemplo, a de Rainflow (DOWNING 1984). Nesta seção será dado foco principal em como determinar e estabelecer os dados de fadiga, determinação da vida em fadiga , $N_{f}$, baseados na metodologia tensão-vida $(\mathrm{S}-\mathrm{N})$. 
Entre 1852 e 1870, August Wöhler, um engenheiro ferroviário alemão, conduziu os primeiros ensaios sistemáticos investigativos de fadiga utilizando a metodologia $\mathrm{S}-\mathrm{N}$, no qual ciclos constantes de tensão com tensão média específica são aplicados em um corpo de prova. Em homenagem à sua contribuição, estes ensaios são denominados de ensaios de Wöhler. Este é o tipo mais comum de ensaios de fadiga. A partir deste ensaio é possível desenvolver a curva $\mathrm{S}-\mathrm{N}$ que representa a vida em fadiga de um componente ou de um corpo de prova. Independente da amostra usada, estes ensaios fornecem valiosas informações aos engenheiros durante o processo de desenvolvimento de um produto. Entretanto, é importante ressaltar que sempre existem limitações de tempo e custo, e que desta forma o número amostras ensaiadas para o levantamento das propriedades de fadiga são sempre limitadas, o que faz necessário conhecer os requisitos, as limitações e as abordagens do método.

Os dados de fadiga geralmente apresentam grande dispersão devido à não homogeneidade da microestrutura do material e acabamento superficial do componente ou do corpo de prova. No caso dos dados de fadiga S-N os resultados do ensaio de fadiga também são fortemente influenciados pelo tipo de carregamento (axial, flexão ou torção) e pelo efeito do tamanho da região sujeita à tensão crítica (KUGUEL, 1961). Algumas outras peculiaridades do método S-N são:

- o parâmetro que governa a falha por fadiga é a tensão;

- a falha ocorre em regimes de altos ciclos;

- existe pouca, ou nenhuma, deformação plástica ;

- é definido a partir de análises experimentais;

- limita-se ao uso somente para condições na qual a tensão aplicada é menor do que limite de escoamento

Durante o ensaio de fadiga o corpo de prova é submetido a carregamentos alternados até que ocorra a falha. O carregamento aplicado no corpo de prova é definido pela faixa de tensão $S_{r}$ ou pela amplitude constante de tensão $S_{a}$. A faixa de tensão é definida algebricamente pela diferença entre a tensão máxima $S_{\max }$ e tensão mínima $S_{\min }$ em um ciclo: 


$$
S_{r}=S_{\max }-S_{\min }
$$

No qual a amplitude de tensão é igual à metade da faixa de tensão,

$$
S_{a}=\frac{S_{r}}{2}=\frac{S_{\max }-S_{\min }}{2}
$$

Tipicamente, para analise de fadiga, é convenção considerar a tensão de tração como positiva e as tensões de compressão como negativas. A magnitude da faixa de tensão ou da amplitude de tensão é a variável controlável (independente) e o número de ciclos até a falha é a variável de resposta (dependente). O número de ciclos até a falha é definido como $N_{f}$ e cada ciclo é igual a dois reversos $2 N_{f}$.

Na maioria das vezes, os ensaios de fadiga S-N são conduzidos com carregamento completamente reverso. Isto indica que o carregamento é alternado sobre uma tensão média igual a zero. A tensão média é dada por:

$$
S_{m}=\frac{S_{\max }+S_{\min }}{2}
$$

Na figura abaixo 11 é possível visualizar estes parâmetros 


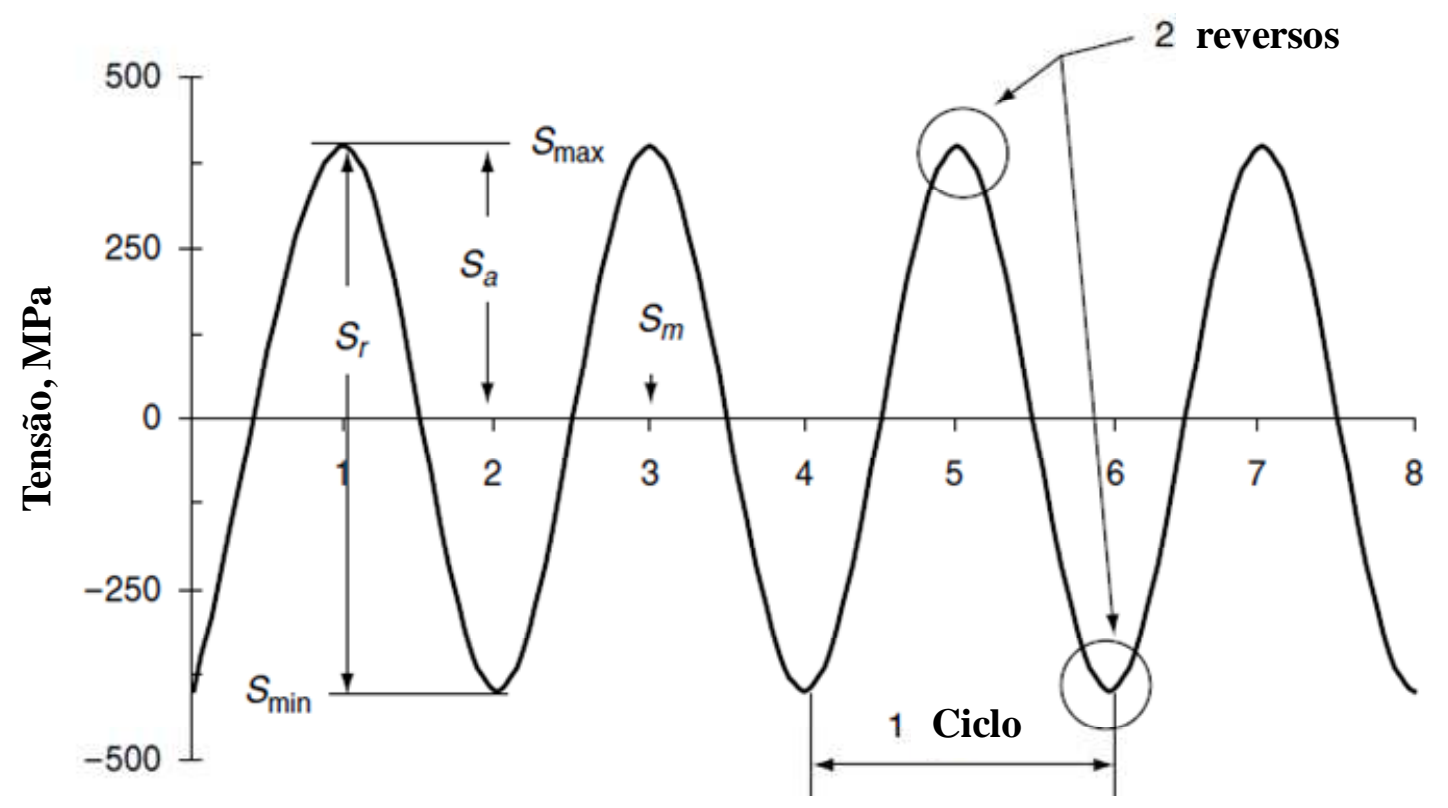

Figura 11: Carregamentos e ciclos aplicados em ensaios de fadiga S-N (LEE 2005)

Componentes estruturais reais geralmente estão sujeitos a carregamentos alternados com uma tensão média. Dois parâmetros, a razão de tensão $R$ e a amplitude de tensão são geralmente usadas para representar a tensão média à qual o componente está submetido. A razão de tensão é definida como a relação entre a tensão mínima e a tensão máxima,

$$
R=\frac{S_{\min }}{S_{\max }}
$$

A razão de amplitude é dada pela razão entre a tensão de amplitude pela tensão média,

$$
A=\frac{S_{a}}{S_{m}}=\frac{1-R}{1+R}
$$

Para gerar dados aplicáveis ao dimensionamento de fadiga é necessário realizar ensaios de fadiga com carregamento completamente reverso em vários corpos de prova em condições de diferentes amplitudes. Os resultados do ensaio de fadiga são geralmente traçados em escalas semi-log ou bi-log. A figura 12 abaixo mostra o resultado de um ensaio de fadiga de um aço normalizado, traçado em escala semi-log: 


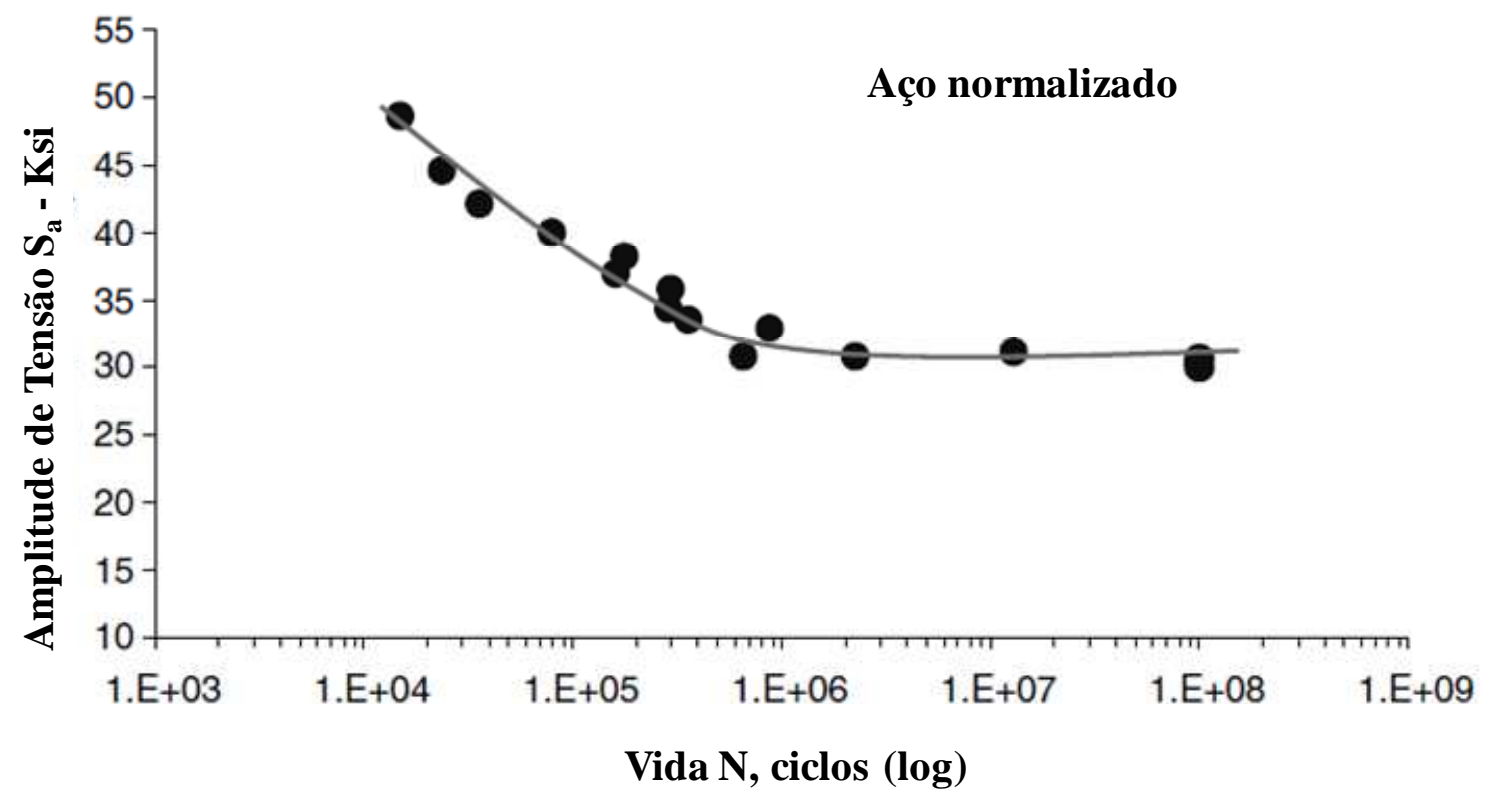

Figura 12: Resultados de um ensaio fadiga em flexão alternada de um aço normalizado (LEE 2005)

A curva mostrada na figura 12 representa o ajuste dos dados obtidos no ensaio de fadiga e é denominada de curva S-N ou curva de Wöhler, esta curva quando traçada na forma bi-log se torna linear. A parte da curva que apresenta inclinação negativa representa a região de vida finita e a região da curva horizontal representa a região de vida infinita. $\mathrm{O}$ valor da tensão no ponto de interseção destas duas retas é definido como o limite de fadiga do material.

Quando os dados obtidos no ensaio de fadiga S-N são traçados em escala bi-log a coordenada y é expressa em termos de amplitude de tensão ou faixa de tensão, enquanto que a abscissa x será expressa em termos do número de reversos para a falha ou o número de ciclos para a falha. Desta forma a vida em fadiga (ciclos ou reversos) refere-se à vida necessária para nuclear e propagar a trinca até a fratura. A equação I.24 representa a curva S-N

$$
S_{a}=S_{f}^{\prime}\left(2 N_{f}\right)^{b}
$$

onde $b$ é denominado de expoente de resistência a fadiga e $S_{f}^{\prime}$ é o coeficiente de resistência a fadiga. Esta expressão desenvolvida a partir de um gráfico bi-log é a equação 
mais utilização na metodologia baseada na tensão e é conhecida como a relação de Basquin (1910).

Nesta seção é de suma importância notar que na abordagem tensão-vida a tensão se refere à tensão nominal em função da vida em fadiga. A determinação da tensão nominal depende do carregamento e da geometria do corpo de prova. Os carregamentos mais comuns são os de força axial (P), flexão (M), ou torque (T). Estes carregamentos podem ser relacionados com a tensão nominal a partir do uso das equações tradicionais da teoria da elasticidade.

$$
\begin{gathered}
S=\frac{P}{A} \\
S=\frac{M \cdot c}{I} \\
S=\frac{T . r}{J}
\end{gathered}
$$

No qual $S$ é a tensão nominal normal ou tensão de cisalhamento, dependendo da equação utilizada e $A$ é a área da seção transversal, $I$ é o momento de inércia, $J$ é o momento de inércia polar, $c$ é a distância do eixo neutro até o ponto de interesse e $r$ é a distância do centro da seção até o ponto de interesse.

Uma curva S-N pode ser gerada para corpos de prova padrões sem entalhes, para componentes estruturais individuais manufaturados, para submontagens, ou para estruturas completas. Os corpos de prova padrão podem ser planos ou cilíndricos sem entalhes usinados com grande precisão apresentando superfícies polidas de forma a minimizar os efeitos da rugosidade superficial. Uma curva S-N fornece os dados de fadiga de referência para uma dada geometria, condição de carregamento e processo de fabricação para o uso no subsequente cálculo da vida e resistência à fadiga. Estes dados de referência podem ser ajustados para incorporar as condições reais do componente, tais como entalhes, tamanho, acabamento superficial, tratamentos superficiais, temperatura, tipos de carregamento e tensão média. 
Sob a perspectiva do carregamento aplicado, o dano em fadiga é fortemente relacionado com a amplitude de tensão ou faixa de tensão e também, de forma secundária, é afetado pela tensão média. A tensão média é responsável pela abertura e pelo fechamento de micro trincas, sendo que tensões médias trativas são prejudiciais por acelerem o crescimento da trinca e as tensões médias compressivas são benéficas por que retardam o crescimento da trinca. Estudos empíricos desenvolvidos por Gerber (1874), Goodman (1899), Haigh (1917) e Soderberg (1930) resultaram em modelos capazes de compensar os efeitos das tensões médias na resistência a fadiga de alto ciclo (S-N)

As curvas S-N obtidas para componentes ou estruturas reais representam o comportamento real de fadiga onde estão incluídos todos os parâmetros anteriormente mencionados. Contudo, quando há alguma mudança no projeto, é necessário refazer os ensaios para gerar uma nova curva S-N para incorporar os efeitos da mudança. Isto adiciona custos e tempo no processo de dimensionamento à fadiga. Em geral, a grande limitação do método S-N é a não contabilização da plasticidade local.

\subsubsection{Metodologia $\varepsilon-\mathrm{N}$}

Na seção anterior foi apresentado o método de projeto e análise da vida em fadiga baseado na tensão. Esta abordagem é limitada a situações nas quais só existem tensões e deformações elásticas. Contudo, a maioria dos componentes apresenta tensões e deformações cíclicas elásticas nominais. Entretanto, entalhes, soldas ou outros concentradores de tensão presentes no componente podem resultar em deformações cíclicas plásticas localizadas. Sob estas condições deve-se empregar outra abordagem de análise de fadiga que leva em conta a deformação localizada, este é o caso da abordagem deformação-vida que foi desenvolvido no final dos anos de 1950 e desde então tem se mostrado mais efetivo na determinação da vida em fadiga de um componente. Esta é a metodologia de interesse neste trabalho, que se destina a caracterizar as propriedades cíclicas de baixo ciclo (deformação-vida) e propor métodos estimativos destas propriedades a partir da dureza.

O método da deformação-vida localizado, também denominado por fadiga de baixo ciclo, é baseado na consideração de que a vida gasta para a nucleação e a propagação de uma pequena trinca de um componente entalhado pode ser aproximada por 
um corpo de prova submetido às mesmas condições de deformação cíclica na região de iniciação da trinca. Isto é ilustrado na figura a seguir:

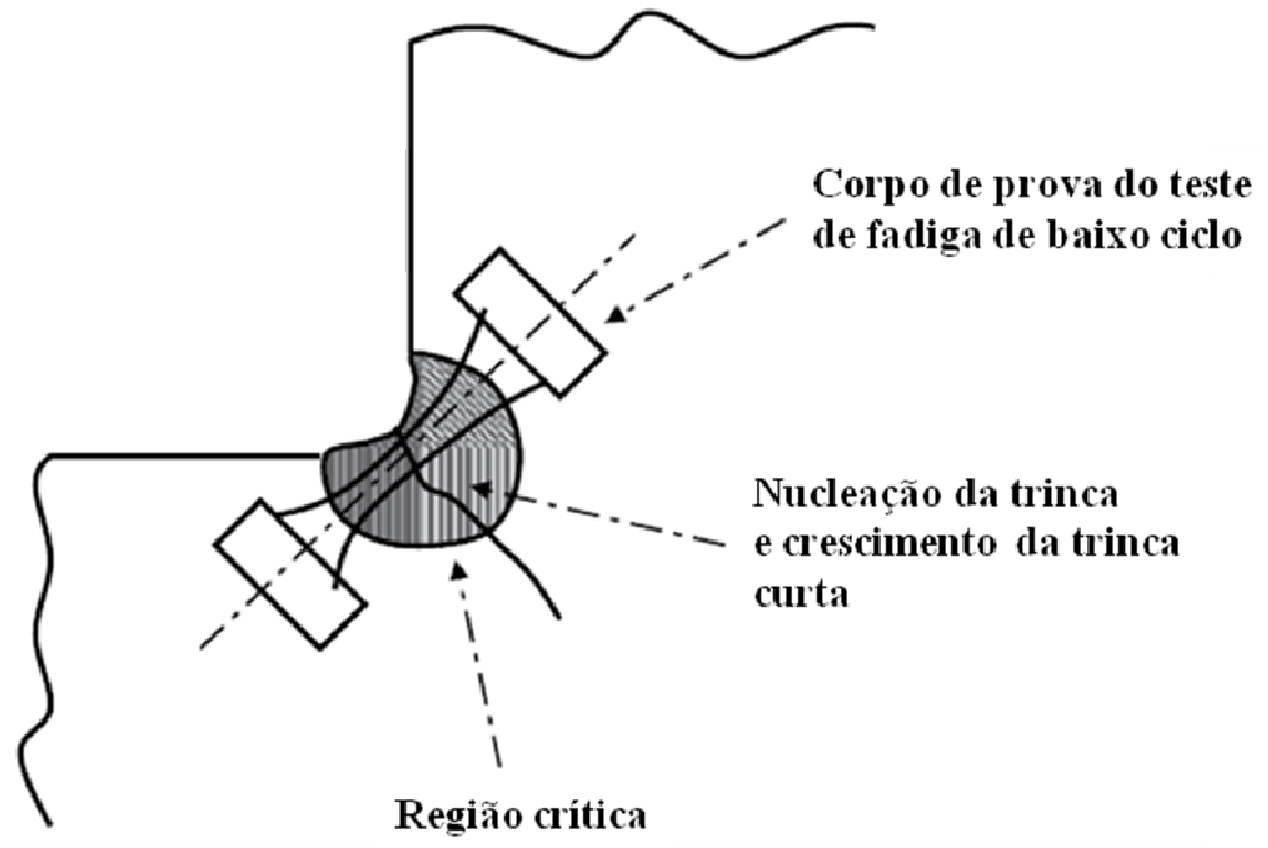

Figura 13: Conceito do método da deformação-vida local (COFFIN 1979)

Utilizando esta metodologia é possível determinar a vida em fadiga em um ponto de um componente carregado ciclicamente a partir do ensaio de um corpo de prova. Para isto basta conhecer a relação entre a deformação localizada e a vida em fadiga do corpo de prova. Esta relação entre a deformação e a vida em fadiga é geralmente representada por uma curva da deformação específica em função a vida em fadiga que é gerada a partir dos ensaios de fadiga com controle de deformação axial em um corpo de prova liso e polido. O ensaio de fadiga com controle de deformação axial é recomendado, pois, na raiz dos concentradores de tensão e entalhes de um componente pode haver deformações plásticas mesmo quando a maior parte do componente comporta-se elasticamente durante o carregamento.

O método da deformação-vida $(\varepsilon-\mathrm{N})$ pode ser usado no projeto de um componente logo nas etapas inicias do projeto sem a necessidade da existência do componente. A vida em fadiga pode ser estudada para várias configurações do produto e processo uma vez fornecidas as propriedades de fadiga de baixo ciclo. Isto faz com que haja redução na quantidade de iterações do projeto por meio da identificação e eliminação, logo nas etapas 
iniciais do projeto, das configurações insatisfatórias do produto quanto ao dimensionamento para suportar cargas cíclicas. Sendo assim, há uma redução do ciclo de projeto e encurtamento do tempo para o lançamento do produto. Além do mais esta metodologia de controle da deformação axial é geralmente preferencial quando o histórico de carregamento é irregular e randômico e quando existe a necessidade de contabilização da influência da tensão média e da sequência do carregamento. Este método também fornece uma abordagem racional para a identificação dos regimes de fadiga de alto e a baixo ciclo e inclui os efeitos da plasticidade localiza em concentradores de tensões e entalhes.

Devido ao fato de que as propriedades cíclicas de fadiga de baixo ciclo ser determinadas a partir de ensaios realizados em corpos de prova os efeitos do processo de fabricação no componente real, tais como o acabamento superficial e a rugosidade, as tensões residuais, as alterações devido a conformação a frio e a soldagem podem não ser corretamente contabilizados neste método de determinação da vida em fadiga. Recomenda-se nestes casos que o ensaio de fadiga seja feito sob controle de tensão no componente real, montagem ou mesmo toda a estrutura utilizando a metodologia de controle de tensão S-N.

\subsubsection{Resposta Cíclica Transiente}

A resposta cíclica transiente do material descreve a mudança na resistência a deformação devido a um carregamento cíclico. Quando um material é repetidamente submetido a um carregamento cíclico completamente reverso com controle de deformação o material pode responder das seguintes maneiras: endurecimento cíclico, amolecimento cíclico, permanecer estável ou apresentar uma combinação destas respostas.

As figuras 14 e 15 demonstram, respectivamente, o endurecimento e o amolecimento transiente cíclico sob o carregamento com controle de deformação. No endurecimento transiente cíclico a tensão correspondente a cada sucessão de reversos de deformação aumenta na medida em que o número de ciclos aumenta. No amolecimento transiente cíclico a tensão diminui à medida que o número de ciclos aumenta. Em ambos 
os casos, endurecimento e amolecimento transiente cíclico, a taxa de mudança da tensão gradualmente reduz e a magnitude da tensão atinge um nível constante (condição permanente) e permanece constante até o fim da vida em fadiga, quando ocorre a nucleação das primeiras trincas de fadiga.

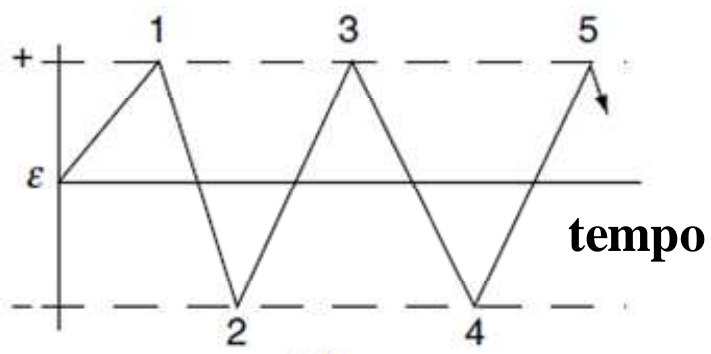

(a)

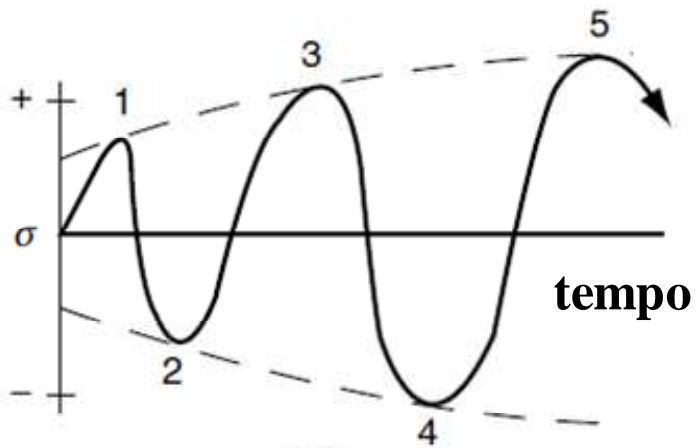

(b)

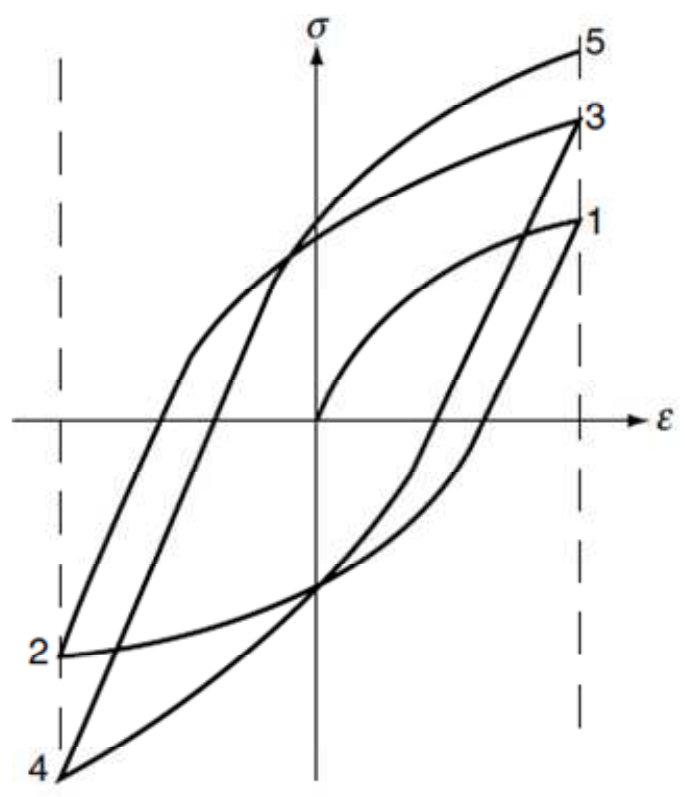

(c)

Figura 14: Comportamento Transiente de endurecimento cíclico (SCHUBERT 1989) 


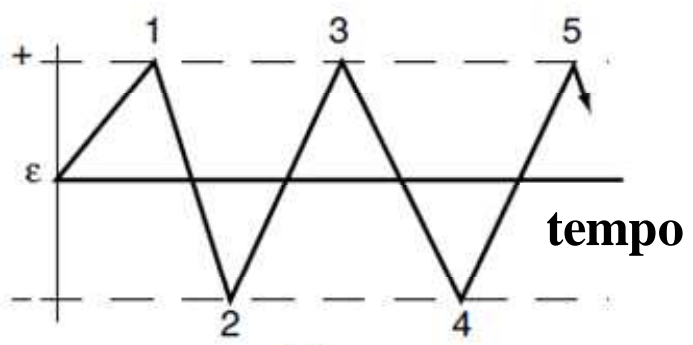

(a)

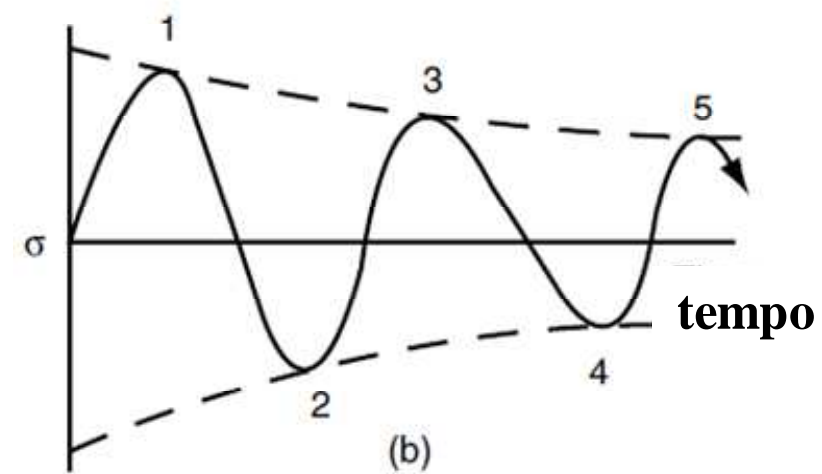

(b)

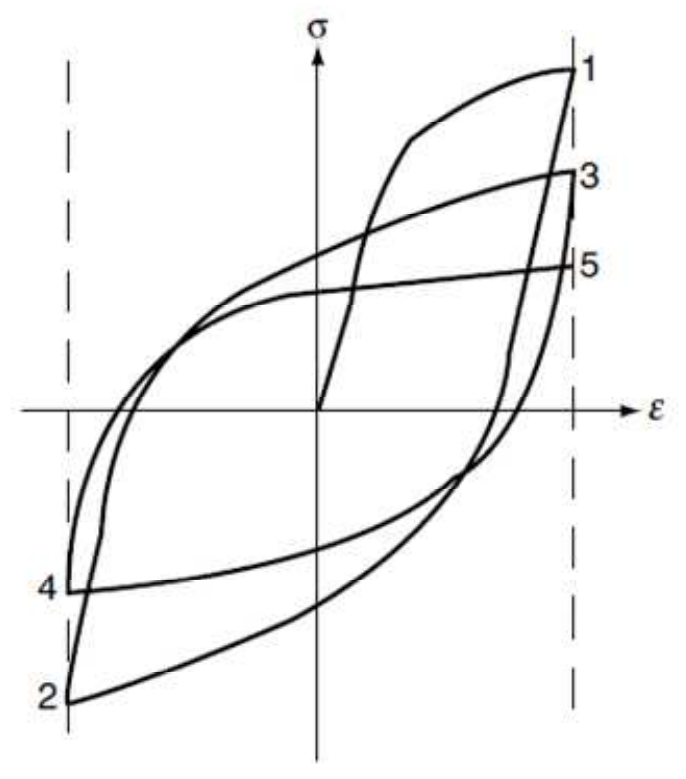

(c)

Figura 15: Comportamento Transiente de amolecimento cíclico (SCHUBERT 1989)

Acredita-se que o fenômeno de endurecimento e amolecimento cíclicos esteja associado à mudança da estrutura de discordância no interior dos grãos dos metais. De forma geral, metais com estrutura cúbica de face centrada (cfc), tais como ligas de alumínio, que possuem planos de escorregamento bem distribuídos no espaço e com alta densidade atômica, apresenta a tendência de endurecer ciclicamente, enquanto que materiais com estrutura cúbica de corpo centrado ( $\mathrm{ccc}$ ), como os aços, que apresentam baixa densidade atômica tendem a amolecer ciclicamente por apresentar planos de escorregamento de baixa densidade atômica. Em ambos os casos a taxa de endurecimento e amolecimento cíclico diminui com o aumento da ciclagem e um estado quase estável de deformação, conhecido como "saturação" é alcançado. .Uma vez que a saturação ocorre, a variação da resultante da tensão de cisalhamento com a resultante da deformação de cisalhamento não mais se alteram e o laço de histerese da $\sigma x \varepsilon$ atinge uma configuração estável. 


\subsubsection{Resposta Cíclica Permanente}

As propriedades determinadas quando se atinge o regime permanente cíclico da resposta do material quando sujeito a cargas cíclicas sob controle de deformação são:

$\sigma_{y}^{\prime}:$ Limite de escoamento cíclico;

$K^{\prime}$ : Coeficiente de resistência cíclico;

$n^{\prime}$ : Expoente de encruamento cíclico;

A vida em fadiga pode ser caracterizada pelo comportamento permanente por que para o ensaio com controle de deformação a relação tensão-deformação se torna estável após rápido endurecimento ou amolecimento cíclico que ocorre logo após os ciclos iniciais. O ciclo de tensão-deformação estável é denominado como laço de histerese e pode ser visualizado na figura 16 :

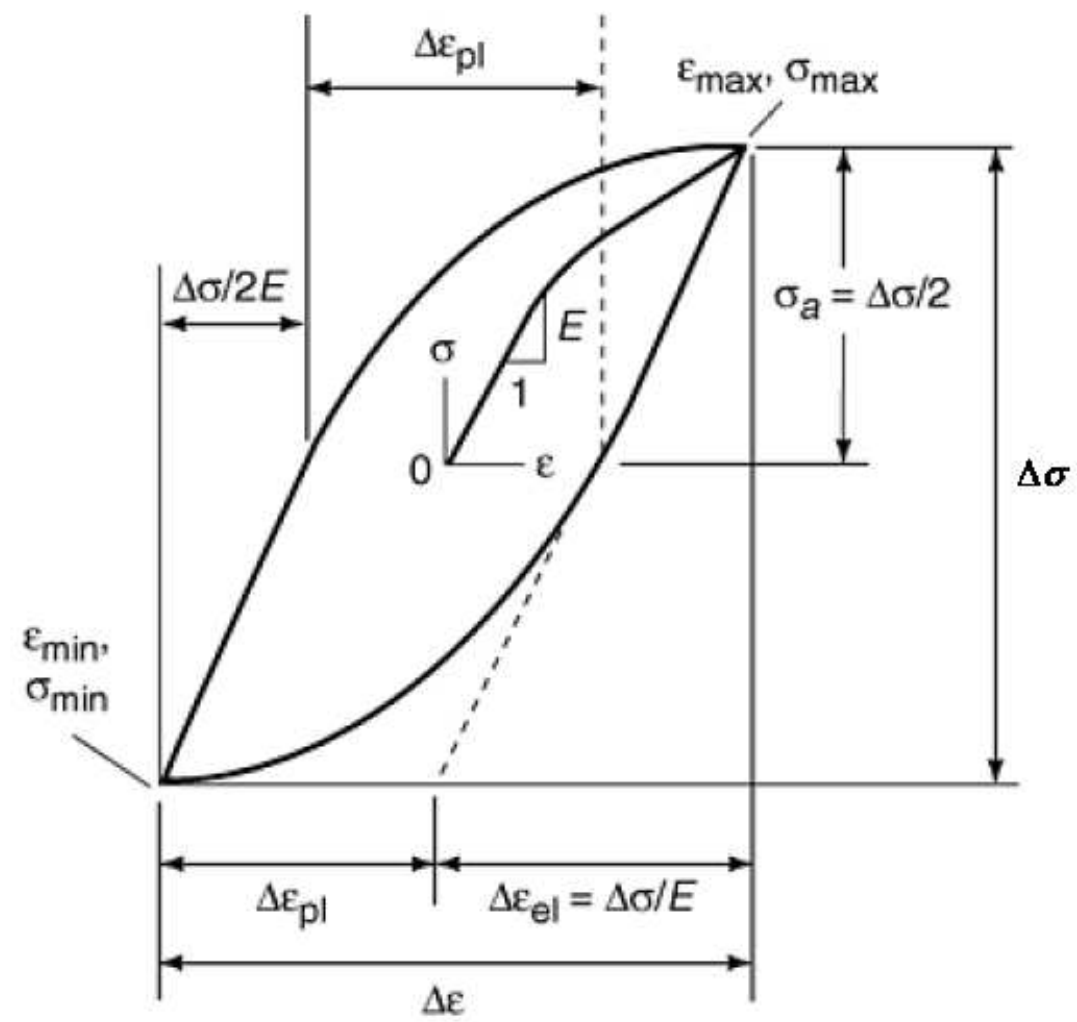

Figura 16: Laço de Histerese (VISWANATHAN 1989) 
O laço de histerese é definido pela variação total da deformação $(\Delta \mathcal{E})$ e pela variação total da tensão $(\Delta \sigma)$ que representa o trabalho elástico e plástico do material sujeito ao carregamento e ao descarregamento. Geralmente adota-se o laço de histerese estabilizado como o ciclo que ocorre na metade da vida em fadiga observada durante o ensaio.

Quando uma família de laços de histerese com vários níveis de amplitudes de deformação são representadas em um mesmo gráfico assim como mostrado na figura 17 , é possível formar uma curva de tensão-deformação definida pelas extremidades de cada laço de histerese. Esta curva possui o formato similar à curva de tensão-deformação monotônica desenvolvida por Ramberg e Osgood (1945):

$$
\varepsilon=\varepsilon_{e}+\varepsilon_{p}=\frac{\sigma}{E}+\left(\frac{\sigma}{K^{\prime}}\right)^{1 / n^{\prime}}
$$

no qual o simbolo ' representa o parâmetro relacionado com o comportamento cíclico do material para diferenciar com os parâmetros relacionado ao comportamento monotônico.

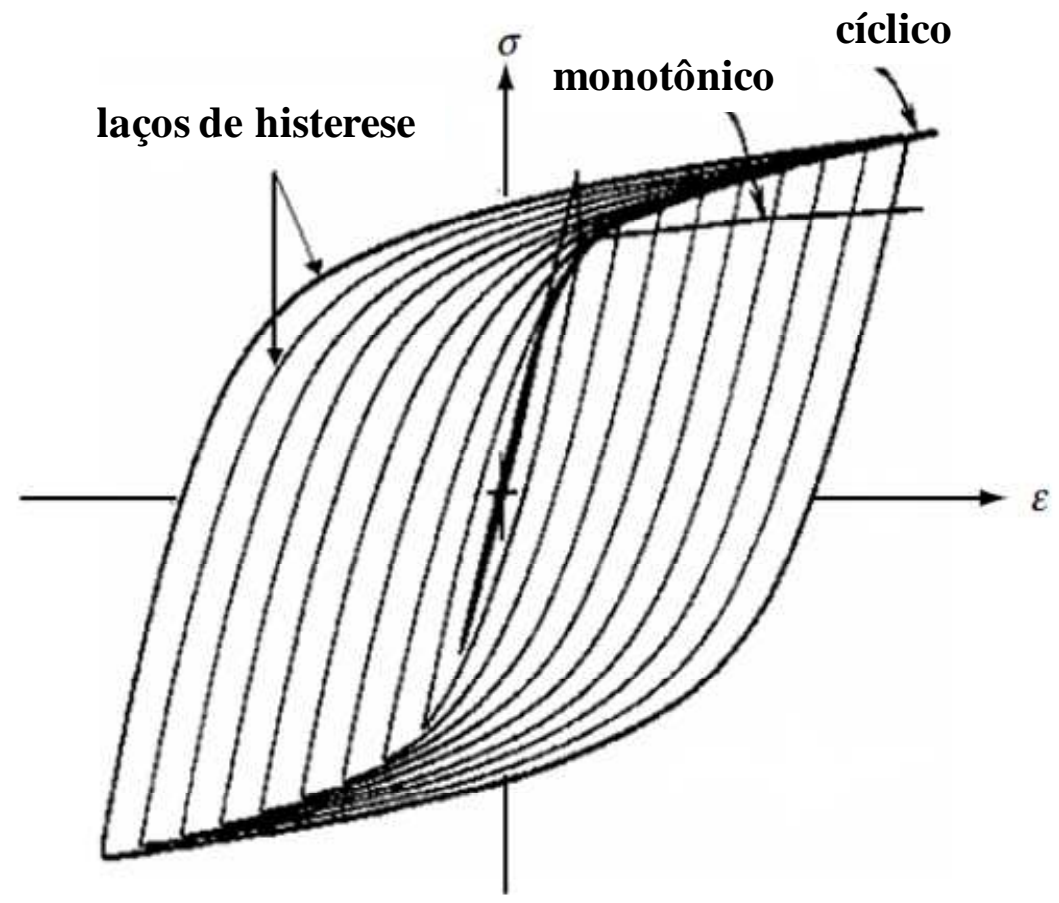

Figura 17: Curva tensão-deformação cíclica (CHRIST 1993) 
A limite de escoamento cíclica $\sigma_{y}^{\prime}$ é a tensão a $0,2 \%$ de deformação plástica em uma curva tensão-deformação cíclica. Este valor é obtido a partir da construção de uma reta com um deslocamento de deformação de $0,2 \%$ a partir do ponto de tensão nula. A tensão no qual a reta intercepta a curva tensão-deformação cíclica é a tensão de escoamento cíclica.

Segundo as considerações de Masing (1976) a curva da amplitude de tensão em função da amplitude de deformação pode ser descrita pela curva de tensão-deformação cíclica,

$$
\varepsilon_{a}=\varepsilon_{e}+\varepsilon_{p}=\frac{\sigma_{a}}{E}+\left(\frac{\sigma_{a}}{K^{\prime}}\right)^{1 / n}
$$

E também, no caso de materiais que possuem comportamento simétrico em tensão e compressão, maioria dos metais homogêneos, pode-se reescrever a equação I.27 como

$$
\frac{\Delta \varepsilon}{2}=\frac{\Delta \varepsilon_{e}}{2}+\frac{\Delta \varepsilon_{p}}{2}=\frac{\Delta \sigma}{2 E}+\left(\frac{\Delta \sigma}{2 K^{\prime}}\right)^{1 / n^{\prime}}
$$

que pode ser reduzida na equação do laço de histerese estabilizado

$$
\Delta \varepsilon=\frac{\Delta \sigma}{E}+2 \cdot\left(\frac{\Delta \sigma}{2 K^{\prime}}\right)^{1 / n}
$$

a equação I.28 tem sido amplamente usada para descrever e monitorar o comportamento da tensão-deformação sob condições de carregamentos com amplitude variáveis.

O coeficiente de resistência cíclico $K^{\prime}$ e o expoente de encruamento $n^{\prime}$ correspondem à intersecção e a inclinação da reta de interpolação, respectivamente, do gráfico da amplitude da tensão verdadeira $\Delta \sigma / 2$ em função da amplitude deformação plástica verdadeira $\Delta \varepsilon^{p} / 2$ traçado na escala log-log: 


$$
\frac{\Delta \sigma}{2}=K^{\prime}\left(\frac{\Delta \varepsilon_{p}}{2}\right)^{n^{\prime}}
$$

em que a amplitude de deformação plástica verdadeira é calculada a partir da seguinte expressão:

$$
\frac{\Delta \varepsilon^{p}}{2}=\frac{\Delta \varepsilon_{e}}{2}-\frac{\Delta \sigma}{2 E}
$$

Quando é feito o ajuste para a interpolação da curva para determinar $K^{\prime}$ e $n^{\prime}$, o logarítmico da amplitude de deformação plástica verdadeira é a variável independente e o logarítmico da amplitude de tensão verdadeira é a variável dependente. É recomendado (Williams, 2003) que as amplitudes de deformações plásticas menores do que 0,0005 $\mathrm{mm} / \mathrm{mm}$ sejam negligenciados na análise da regressão linear.

A curva de tensão-deformação cíclica representa a resistência do material em deformar ciclicamente e pode ser diferente da curva tensão-deformação monotônica assim como mostrado na figura 18 : 

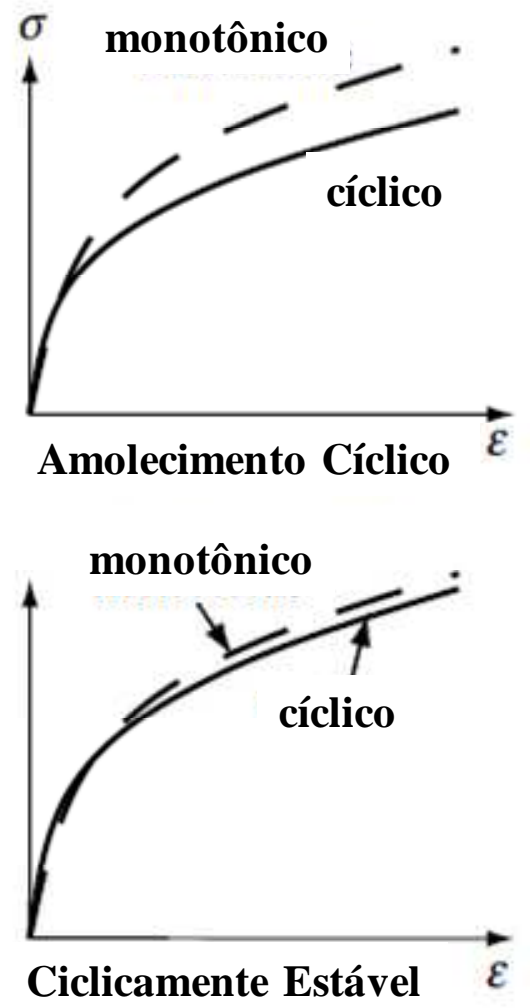
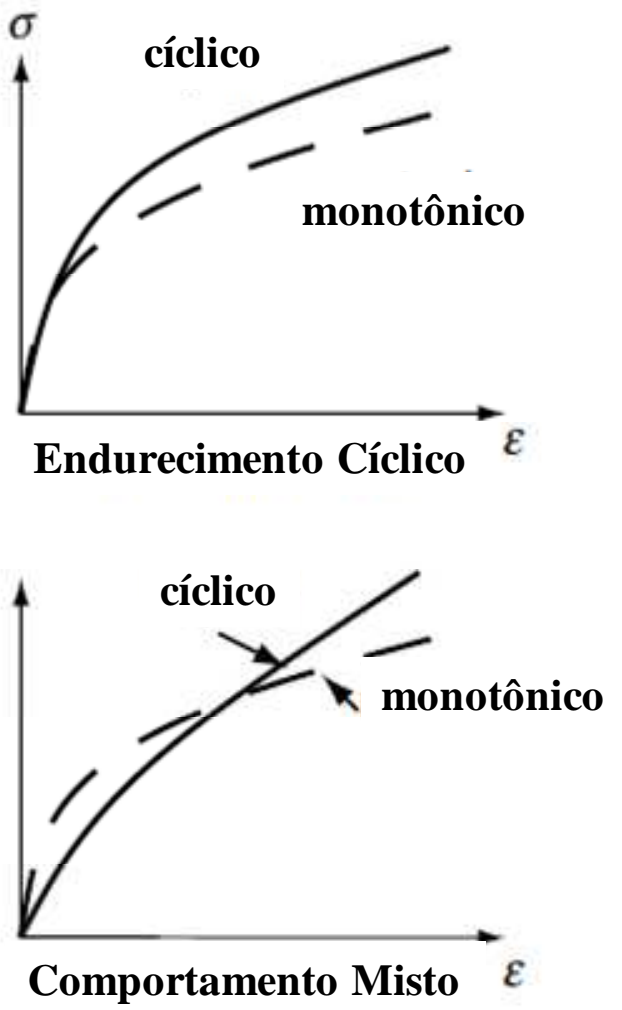

Figura 18: Comportamento da relação tensão-deformação monotônico e cíclico (MITCHELL 1996)

As propriedades determinadas a partir do laço de histerese estabilizado são:

$\sigma_{f}^{\prime}:$ coeficiente de resistência à fadiga;

$b$ : expoente de resistência à fadiga;

$\mathcal{E}_{f}^{\prime}:$ coeficiente de ductilidade à fadiga;

$c: \quad$ expoente de ductilidade à fadiga;

Geralmente é adotado como base para a determinação destes parâmetros o laço de histerese correspondente à meia vida, neste trabalho foi usada esta abordagem. 
Baseado na proposição de Morrow (1965) a relação da amplitude total de deformação ( $\mathcal{E}_{a}$ ) e vida em fadiga, dada em números de reversos para a falha ( $2 N_{f}$ ), é dada por:

$$
\varepsilon_{a}=\varepsilon_{e}+\varepsilon_{p}=\frac{\sigma_{f}^{\prime}}{E}\left(2 N_{f}\right)^{b}+\varepsilon_{f}^{\prime}\left(2 N_{f}\right)^{c}
$$

Esta equação (I.34) é chamada da equação vida-deformação e é a base para a metodologia $\varepsilon-\mathrm{N}$. Ela é composta por duas curvas: a curva da amplitude de deformação elástica vs. vida $\left(\varepsilon_{a}^{e}-2 N_{f}\right)$ e a curva de amplitude de deformação plástica vs. vida $\left(\varepsilon_{a}^{p}\right.$ $\left.2 N_{f}\right)$

Dividindo a equação de Basquin (1910) pela módulo de elasticidade resulta na equação da curva da amplitude de deformação elástica-vida

$$
\varepsilon_{a}=\frac{\Delta \varepsilon^{e}}{2}=\frac{\sigma_{f}^{\prime}}{E}\left(2 N_{f}\right)^{b}
$$

Simultaneamente Manson (1953) e Coffin (1954) propuseram a equação da curva amplitude de deformação plática-vida:

$$
\varepsilon_{a}^{p}=\frac{\Delta \varepsilon^{p}}{2}=\varepsilon_{f}^{\prime}\left(2 N_{f}\right)^{c}
$$

Estas duas curvas em escala log-log resultam em curvas lineares assim como mostrado na figura 19: 


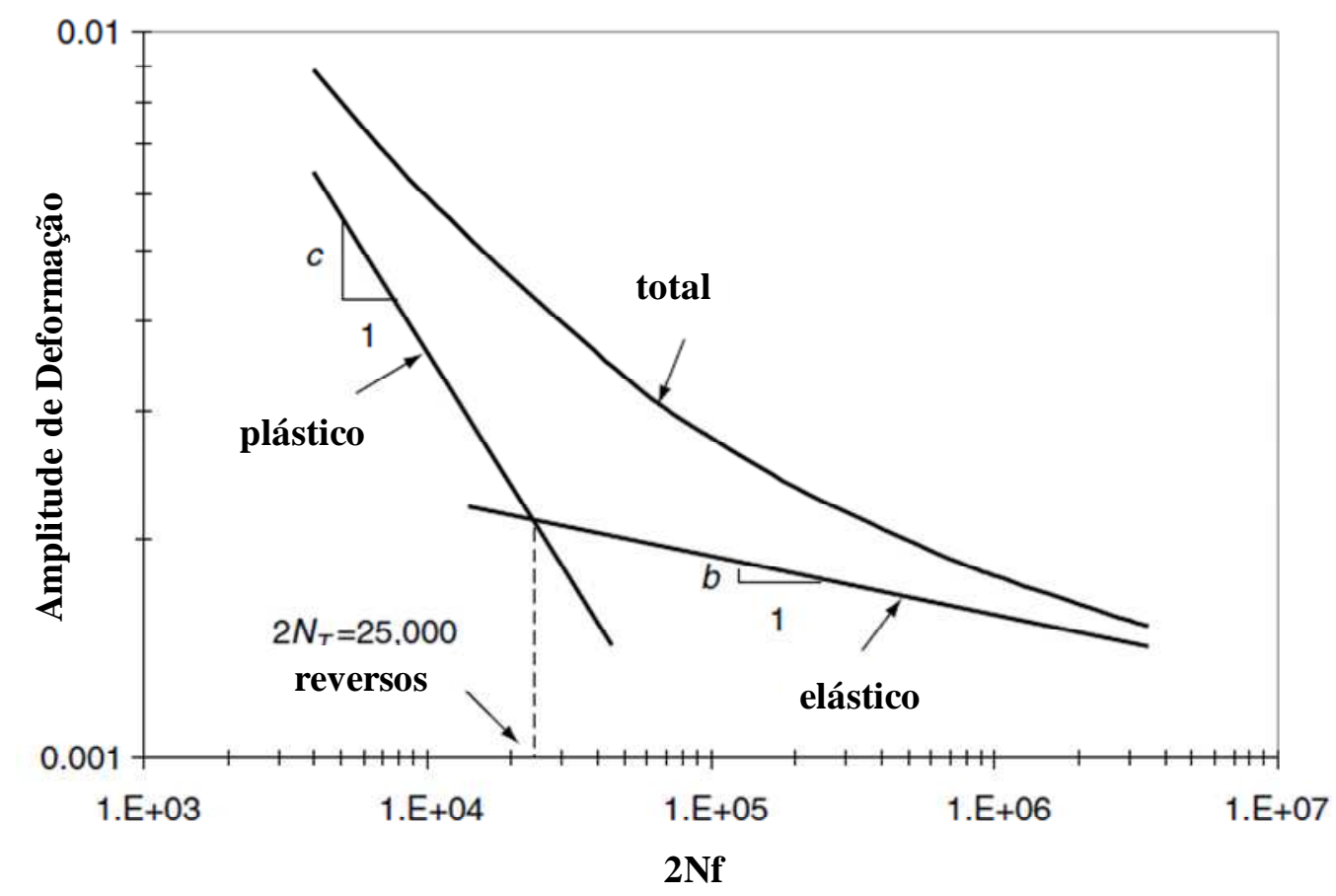

Figura 19: Curva da amplitude de deformação total vs. vida em reversos (MITCHELL 1996)

Portanto, um método para a determinação dos parâmetros de fadiga $\varepsilon-\mathrm{N}$ é o uso dos parâmetros das regressões comparados com as equações I.35 e I.36. Esta será a metodologia empregada neste estudo para a determinação das propriedades cíclicas.

\section{4 Índice de Qualidade}

O comportamento mecânico dos ferros fundidos é afetado por diversas características microestruturais (metalográficas) que por sua vez possuem estreita relação com as suas propriedades químicas e processo de fabricação, especialmente relativas às variações de processo e à sua taxa de resfriamento que é influenciada também pela geometria da peça.

A figura 20 mostra as variações da resistência à tração e ao alongamento devido à microestrutura dos ferros fundidos nodulares no qual é possível notar também a influência do tratamento térmico de austêmpera. 


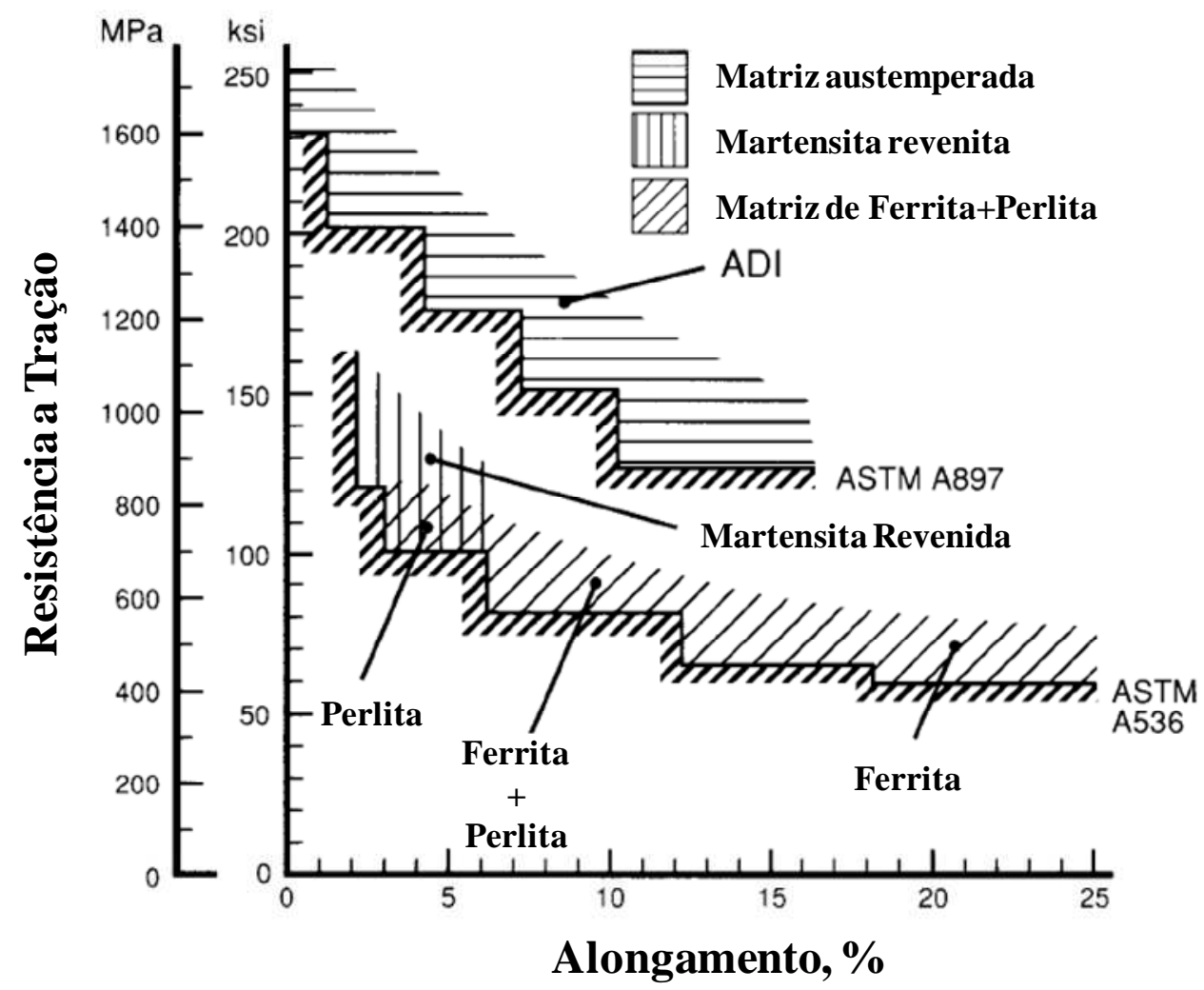

Figura 20: Variações das Propriedades dos Ferros Fundidos (SORELMETAL 2004)

Dentre os inúmeros fatores que contribuem para as variações das propriedades mecânicas dos ferros fundidos, cabe salientar:

- Formato da Grafita: a grande diferença entre as propriedades mecânicas dos ferros fundidos cinzentos e nodulares se deve principalmente ao formato da grafita. Nos ferros fundidos cinzentos a grafita é encontrada na forma de lamelas que podem ser consideradas como trincas, já nos ferros fundidos nodulares a grafita se encontra na forma de nódulos que são barreiras para o crescimento da trinca. Isto justifica as melhores características estruturais dos ferros fundidos nodulares em relação aos cinzentos;

- Quantidade de nódulos: geralmente expressa em número de nódulos $/ \mathrm{mm}^{2}$ a quantidade de nódulos de grafita também influencia as propriedades mecânica dos ferros fundidos. Geralmente uma grande quantidade de nódulos por área significa uma boa qualidade metalúrgica, mas existe uma quantidade adequada de nódulos para cada tamanho da seção fundida 
- Volume da grafita: aumentando a porcentagem de carbono, no qual se aumenta o volume de grafita tem-se a diminuição do módulo de elasticidade dinâmico dos ferros fundidos (DEM - Dynamic Elastic Modulus) para uma mesma seção. A seção do fundido pode influenciar tanto a fração de volume quanto o tamanho do nódulo da grafita. Aumentando-se o tamanho da seção reduz-se a taxa de resfriamento do fundido acarretando em uma maior precipitação de carbono na fase de estável de grafita ao invés da fase de Carbeto favorecida por altas taxas de resfriamento;

- Quantidade de Carbetos: a quantidade de carbetos tem efeitos tanto diretos como indiretos nas propriedades mecânicas dos ferros fundidos. O seu aumento faz com que haja aumento do módulo de elasticidade, porém, reduz se a resistência à tração dos ferros fundidos nodulares e também o alongamento. A formação de carbetos é também responsável pela formação de porosidade nos ferros fundidos, uma vez que por reduzir a expansão da grafita durante a solidificação;

- Efeito da Matriz: a matriz dos ferros fundidos determina as suas propriedades mecânicas quando a nodularidade é consistente, existe uma quantidade de nódulos adequada, existe baixa porosidade e baixa porcentagem de carbetos. Na maioria dos ferros fundidos nodulares a matriz é composta por ferrita e/ou perlita. A ferrita é a forma pura do ferro na ferro fundido, ela tem baixa resistência e dureza, mas alta ductilidade e boa usinabilidade. Já a perlita é uma mistura de cementita lamelar em uma matriz de ferrita. Comparada com a ferrita a perlita confere ao ferro fundido alta resistência e dureza e uma baixa ductilidade. Desta forma as propriedades mecânicas dos ferros fundidos nodulares são determinadas pelo equilíbrio entre a quantidade de ferrita e perlita na matriz. Esta relação é controlada pela porcentagem de carbono levando em consideração também a taxa de resfriamento do fundido. Também pode ser controlado pelo tratamento de recozimento (ou ferritização) para a produção de uma matriz puramente ferrítica ou de normalização para maximizar a porcentagem de perlita.

- Influência dos elementos Cu e Sn: os efeitos do Cobre e do Estanho no ferro fundido são divergentes. Adicionando-se $\mathrm{Cu}$ (cobre) a uma matriz completamente perlítica em uma liga $\mathrm{Cu}-\mathrm{Mn}$ resulta um aumento tanto no limite de escoamento quanto na resistência a tração, provavelmente devido ao aumento de resistência da solução sólida. A adição de Sn (estanho) em uma matriz completamente perlítica não altera a tensão de escoamento, mas resulta na diminuição da resistência a tração. 
- Tratamento térmico: as figuras abaixo evidenciam as relações entre as propriedades mecânicas de tração e a quantidade de ferrita e perlita dos ferros fundidos sem tratamento térmico (Figura 21 - As-cast), recozidos (Figura 22 - Annealed) e normalizados (Figura 23 - Normalized). Nestas figuras é possível também analisar os efeitos da quantidade dos elementos Cobre (copper) e Estanho (tin).

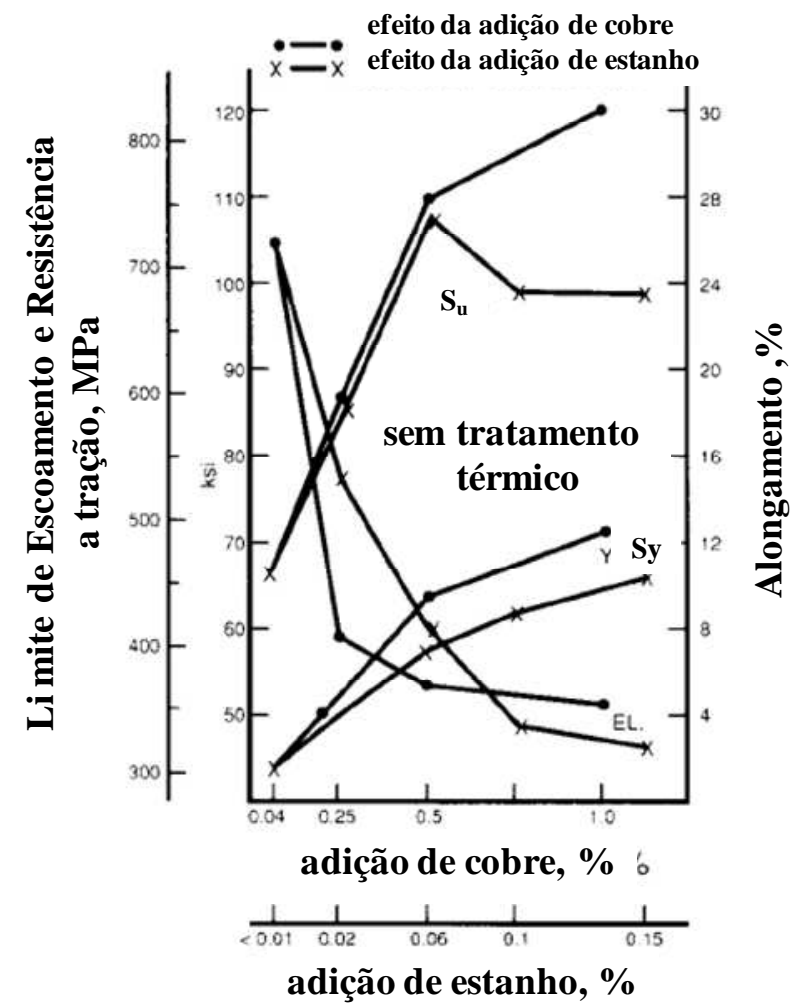

Figura 21: Propriedades mecânicas do ferro fundido sem tratamento térmico (FOWLER 1984) 


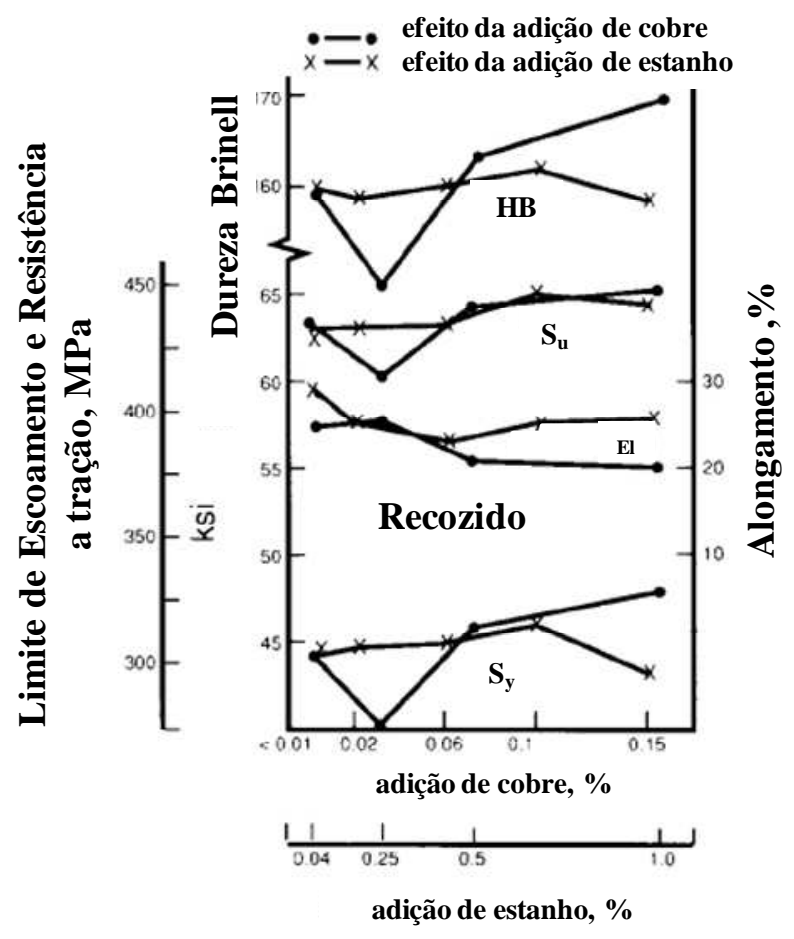

Figura 22: Propriedades mecânicas do ferro fundido após tratamento térmico de recozimento (FOWLER 1984)

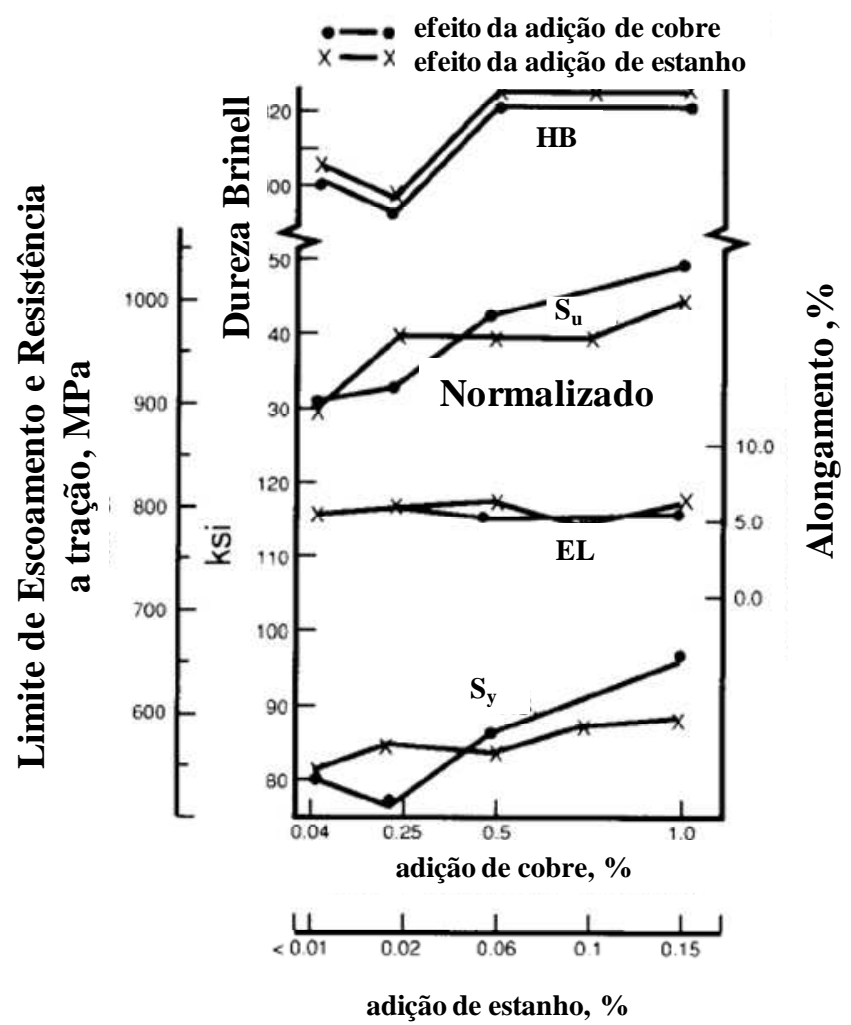

Figura 23: Propriedades mecânicas do ferro fundido com tratamento de normalização (FOWLER 1984) 
Visto os principais fatores que afetam as propriedades mecânicas é possível notar como é difícil estabelecer um único parâmetro para medir a qualidade dos ferros fundidos.

Em todas as normas de ferros fundidos existem requisitos mínimos de atendimento das propriedades mecânicas, tais como a resistência à tração, limite de escoamento, dureza e porcentagem de alongamento total.

O fato de se usar mais do uma característica para a especificação de um ferro fundido (geralmente a resistência à tração e o alongamento) é a tentativa do uso de um padrão para a avaliação da qualidade do material, pois, sem exceções, nos ferros fundidos, assim como nos metais em geral, estas propriedades possuem comportamentos inversos entre si, ou seja, quanto maior a resistência à tração menor é o alongamento do material e vice-versa (observe o comportamento destas características nas Tabelas 2 e 3 e também na Figura 4).

De modo geral os componentes estruturais são dimensionados para não falharem quando submetidos a carregamentos cíclicos, não terem sua geometria alteradas após sofrerem determinado esforço (deformação plástica) e finalmente que não falhem quando submetidos a esforços repentinos, ou seja, é necessário que o material tenha, respectivamente, níveis aceitáveis de resistência à fadiga, resistência ao escoamento e resistência ao impacto (tenacidade).

Em síntese assim como já descrito as propriedades dos ferros fundidos são influenciadas por diversos fatores, que afetam as suas propriedades mecânicas que for sua vez determinam o seu comportamento quando submetido aos esforços estruturais. Observa-se, portanto que é necessária uma ligação entre os fatores que influenciam as propriedades dos ferros fundidos e as suas propriedades em si de tal forma que seja possível prever o seu comportamento ao ser submetido aos esforços estruturais. A figura 24 mostra a relação destas características. 


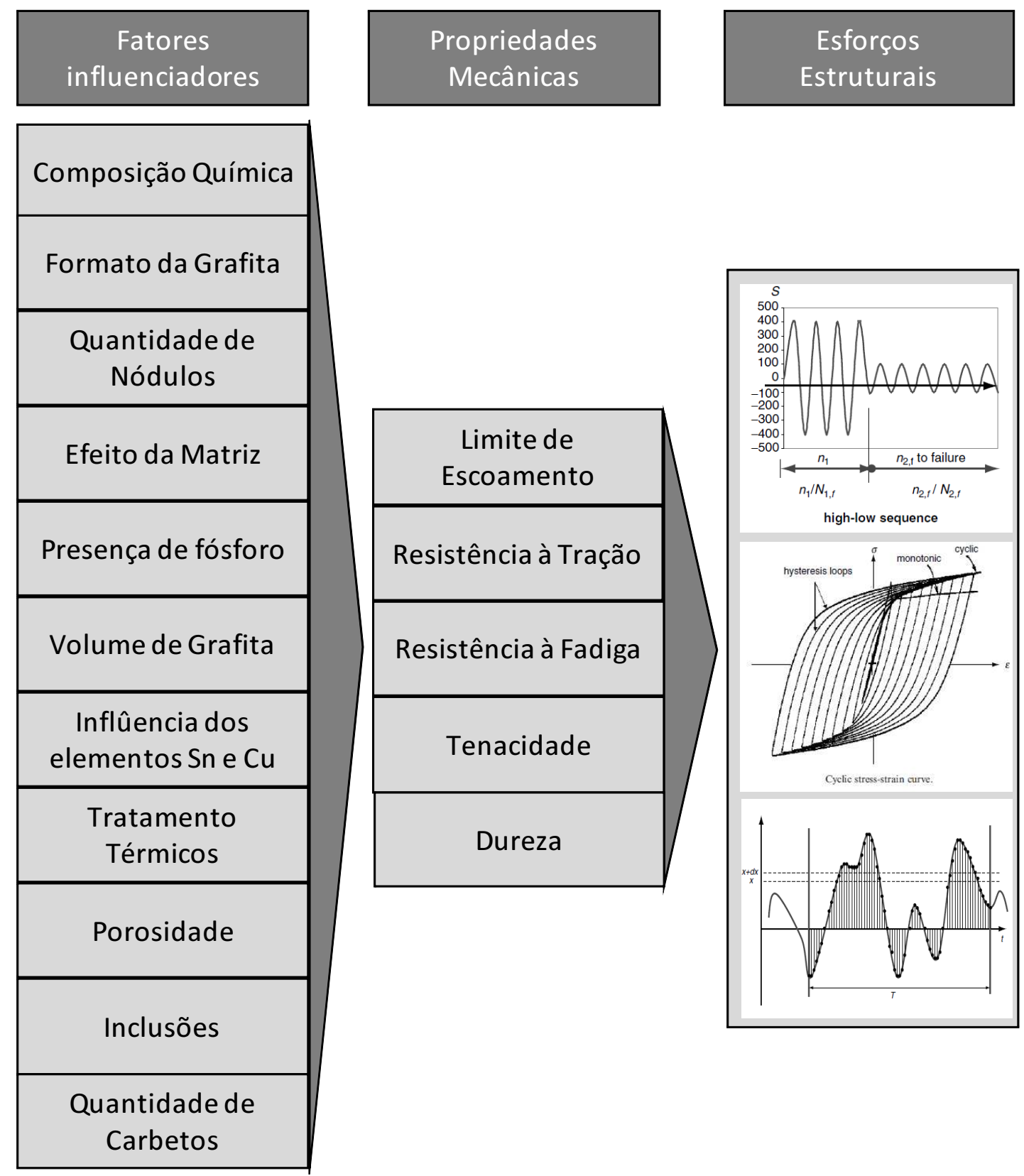

Figura 24: Fatores que influenciam as propriedades mecânicas dos ferros fundidos

A grande influência da morfologia da grafita e da estrutura da matriz produz uma grande correlação destas características com as propriedades mecânicas dos ferros fundidos.

W, Siefer e K, Orths (1970) em um estudo estatístico das propriedades mecânicas de uma grande amostra de ferros fundidos identificou uma relação entre a resistência à tração e o alongamento, como segue: 


$$
\frac{\left[S_{u}(k s i)\right]^{2} \cdot E l}{1000}=Q
$$

onde "Q" uma constante.

Um grande valor de Q indica uma combinação de grande resistência a tração e grande alongamento, ou seja, um material com grande desempenho. Crews (1974) definiu “Q” como sendo o Índice de Qualidade (QI) para os ferros fundidos nodulares.

$$
Q I=\frac{\left[S_{u}(k s i)\right]^{2} \cdot E l}{1000}
$$

Tanto o QI como a relação estabelecida entre o limite de resistência à tração e o alongamento contribuíram para a quantificação da qualidade entre os diferentes ferros fundidos nodulares e permitiram a possibilidade obter a combinação de várias propriedades. Altos valores de QI mostraram que são resultados de alta nodularidade (alta porcentagem de grafita no formato esférico ou próximo ao esférico, abstenção de grafita intercelular degenerativa, grande quantidade de nódulos, baixo volume de carbetos, baixa porcentagem de fósforo $(<0,03 \%)$ e ausência de porosidade). Ferros fundidos com altos índices de qualidade podem ser produzidos por Fundições competentes e modernas, que possuem controle dos diversos parâmetros de produção que afetam as características do material.

A figura 25 demonstra a relação entre resistência à tração e o alongamento e para diferentes Índices de Qualidade (QI) dos ferros fundidos nodulares. 


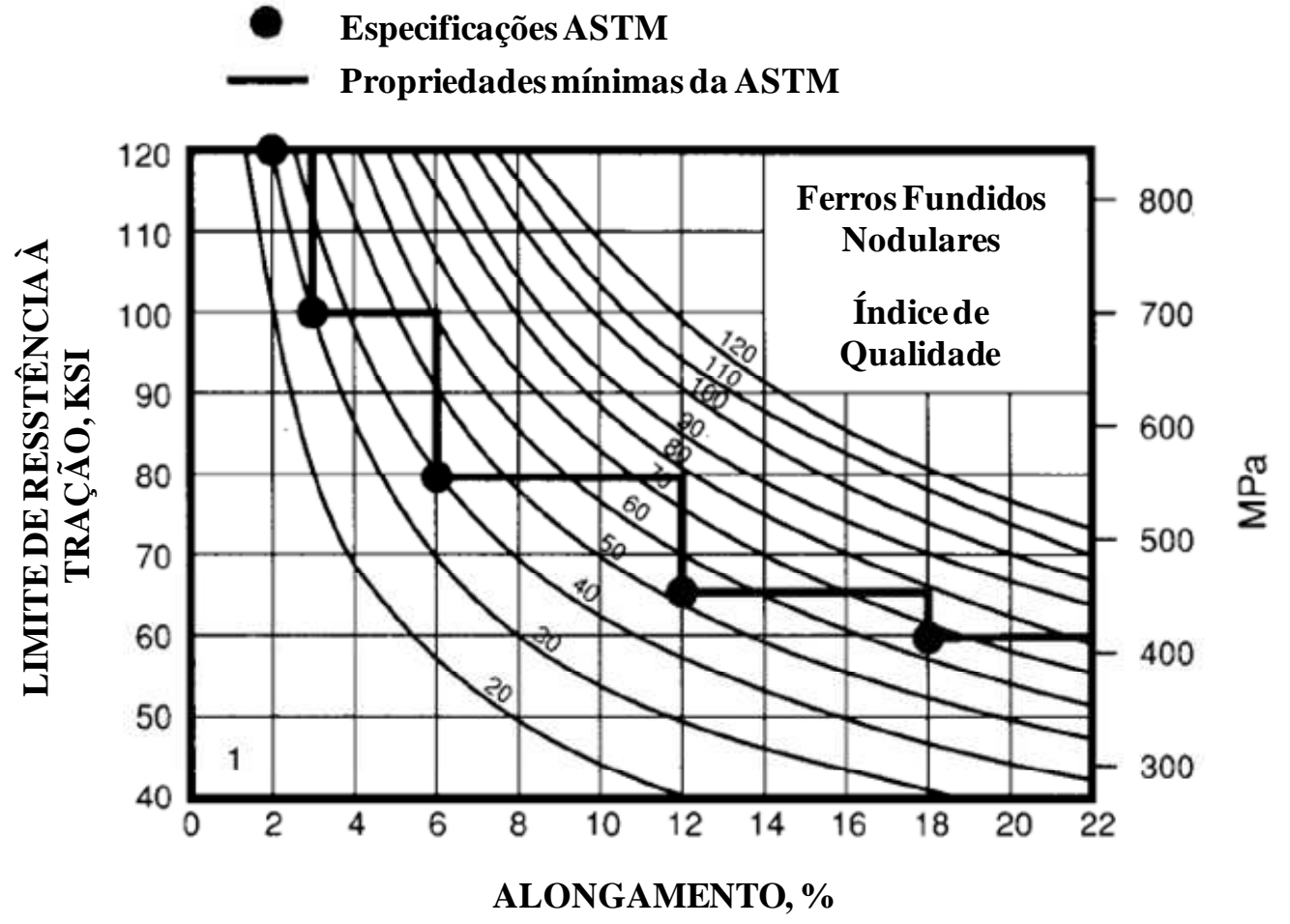

Figura 25: Relação entre o Índice de Qualidade dos Ferros Fundidos Nodulares e a Norma ASTM A536

Cada linha na figura acima se refere a um material de mesma qualidade ao longo da qual os valores de resistência à tração e alongamento podem ser modificados por tratamentos térmicos de recozimento ou normalização que alteram a matriz ferrítica: porcentagem de perlita.

A Tabela 4 comparativa a seguir releva a evolução da qualidade dos ferros fundidos nodulares nos últimos 20 anos provenientes das modernizações no processo produtivo e melhoria do controle de qualidade.

\begin{tabular}{|c|c|c|}
\cline { 2 - 3 } \multicolumn{1}{c|}{} & $\begin{array}{c}\text { Siefer e Orths } \\
(\mathbf{1 9 7 0 )}\end{array}$ & $\begin{array}{c}\text { Venugopalan e Alagarsamy } \\
(\mathbf{1 9 9 0 )}\end{array}$ \\
\hline $\mathbf{Q I}_{\mathbf{9 9 . 5}}$ & 120 & 129 \\
\cline { 2 - 3 } $\mathbf{Q I}_{\mathbf{5 0 , 0}}$ & 60 & 90 \\
\hline
\end{tabular}

Tabela 4: Evolução da Qualidade dos Ferros fundidos Nodulares QI - Quality Index (SORELMETAL 2004)

Visto a evolução da qualidade dos ferros fundidos é proposto neste presente trabalho o estudo somente dos ferros fundidos de alta qualidade, definidos neste trabalho 
como ferros fundidos com Índice de Qualidade maior do que 80. Observa-se que este valor é factível com a Tabela 4.

O objetivo de se usar apenas ferros fundidos de alta qualidade é a eliminação dos diversos fatores que influenciam as propriedades mecânicas dos ferros fundidos de tal forma que seja possível avaliar somente o efeito da composição da matriz no comportamento estrutural do ferro fundido (quantidade de ferrita e perlita), a figura 24 torna-se:

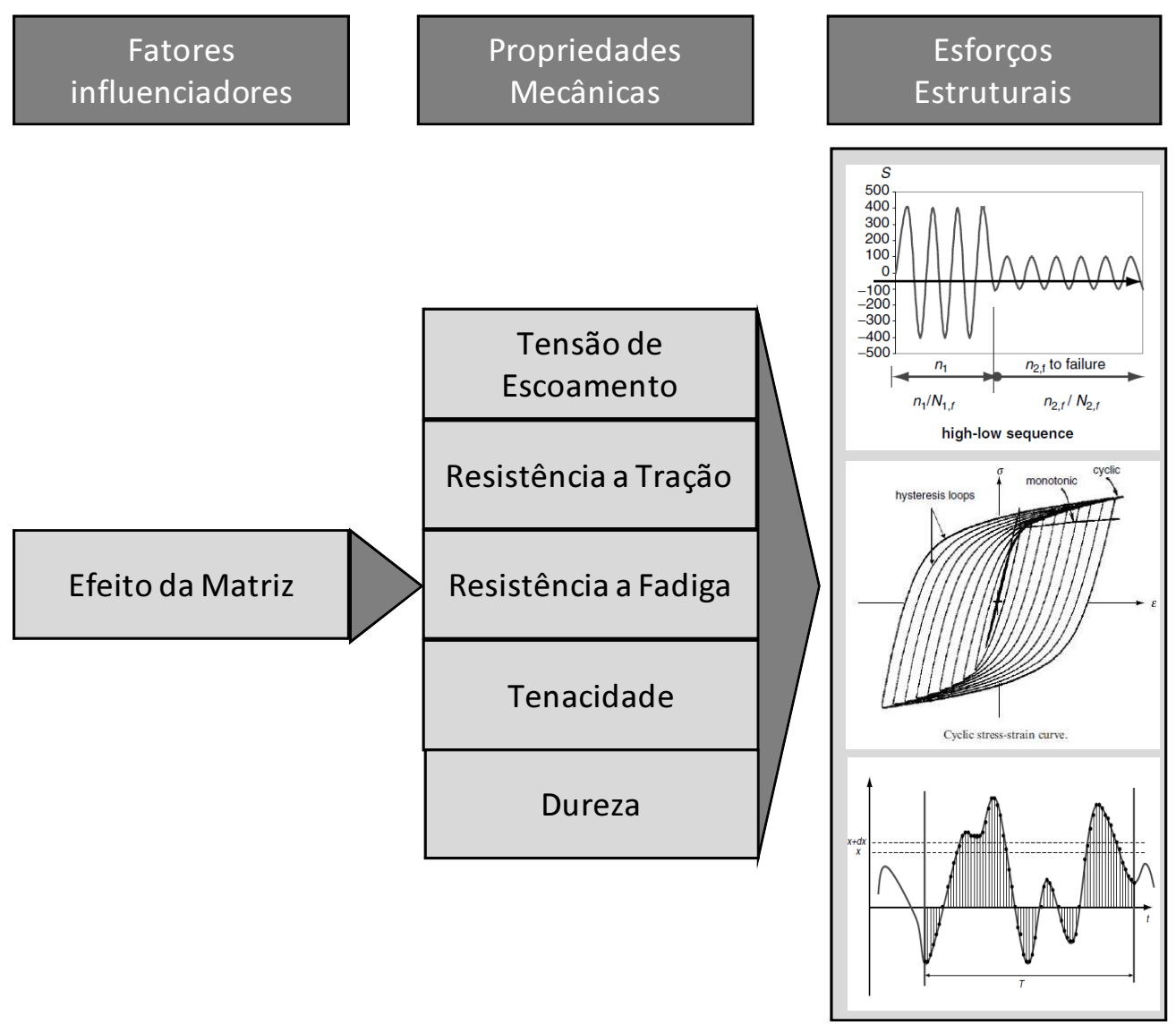

Figura 26: Fatores que influenciam as propriedades mecânicas dos ferros fundidos de alta qualidade (QI >80) 


\section{PARTE II}

\subsection{Propriedades Mecânicas dos Ferros Fundidos - Dados da Literatura}

Foi realizado um amplo estudo das publicações existentes na literatura no qual havia informações sobre as propriedades mecânicas e as durezas dos ferros fundidos, as principais fontes encontradas foram os estudos feitos por TARTAGLIA (2000) nas publicações realizadas no Ductile Iron Society (DIS), TUCKER (1975) e MORTON (1980). As seguintes seções deste trabalho concentram-se na apresentação das relações entre as propriedades mecânicas dos ferros fundidos com a dureza.

\subsubsection{Propriedades Monotônicas}

A Tabela 5 resume as propriedades monotônicas encontradas na literatura onde havia informações sobre a dureza dos materiais ensaiados. Foi possível separar as informações em classes de dureza. No trabalho apresentado no Dutile Iron Society (TARTAGLIA, 2000) o autor da pretendia caracterizar apenas o ferro fundido SAE D5506, porém, verificando os valores de dureza e alongamento obtido por ele nota-se que o estudo foi mais amplo do que o pretendido, pois, o estudo envolveu a caracterização parcial da faixa de dureza do ferro fundido SAE 4512, caracterização de toda a faixa de dureza do SAE D5006 e do D5504 e caracterização parcial da faixa de dureza do SAE7003. 

Tabela 5: Propriedades Monotônicas dos Ferros Fundidos

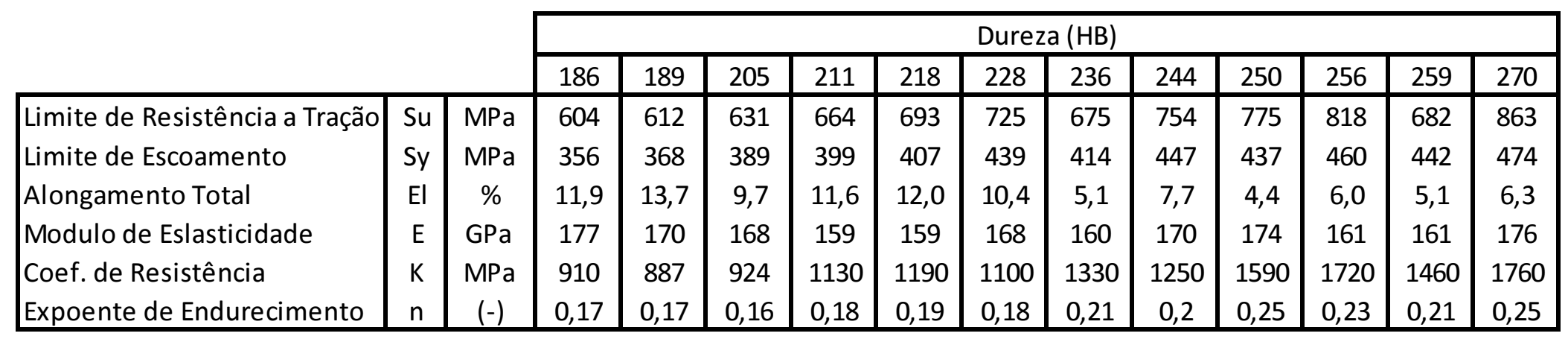

\begin{tabular}{|l|c|c|c|c|c|c|c|c|c|c|c|c|c|c|}
\hline Indice de Qualidade & QI & $(-)$ & 91 & 108 & 81 & 108 & 121 & 115 & 49 & 92 & 56 & 84 & 50 & 99 \\
\hline
\end{tabular}

\begin{tabular}{|l|c|c|c|c|c|c|c|c|c|c|c|c|}
\hline \multirow{2}{*}{ Referências } & 1 & 1 & 1 & 2 & 2 & 1 & 2 & 1 & 1 & 2 & 2 & 1 \\
\cline { 2 - 7 } & \multicolumn{10}{|c|}{ 1. Tartaglia, 2000} \\
\hline
\end{tabular}


A partir dos dados da Tabela 5 foi possível, assim como já realizado por outros autores (TARTAGLIA, 2000), definir uma relação entre as propriedades monotônicas e a dureza como segue:

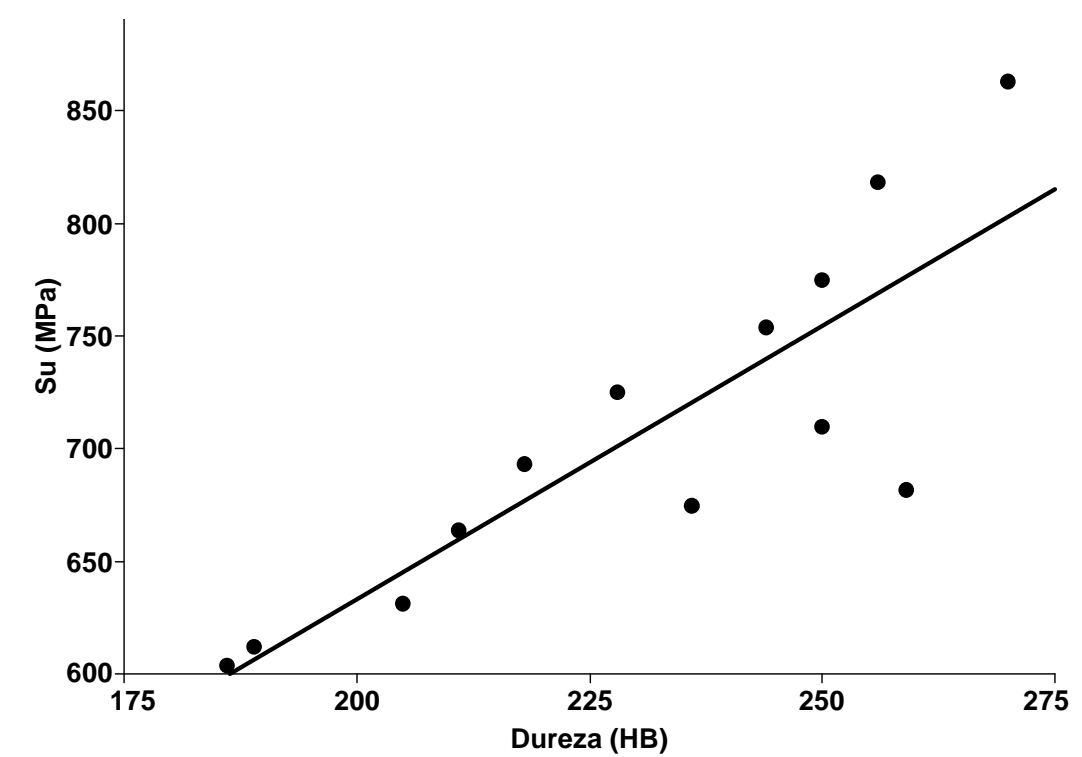

Figura 27: Relação do limite de resistência com a dureza - dados da literatura, $\mathbf{R}^{2}=0,72$

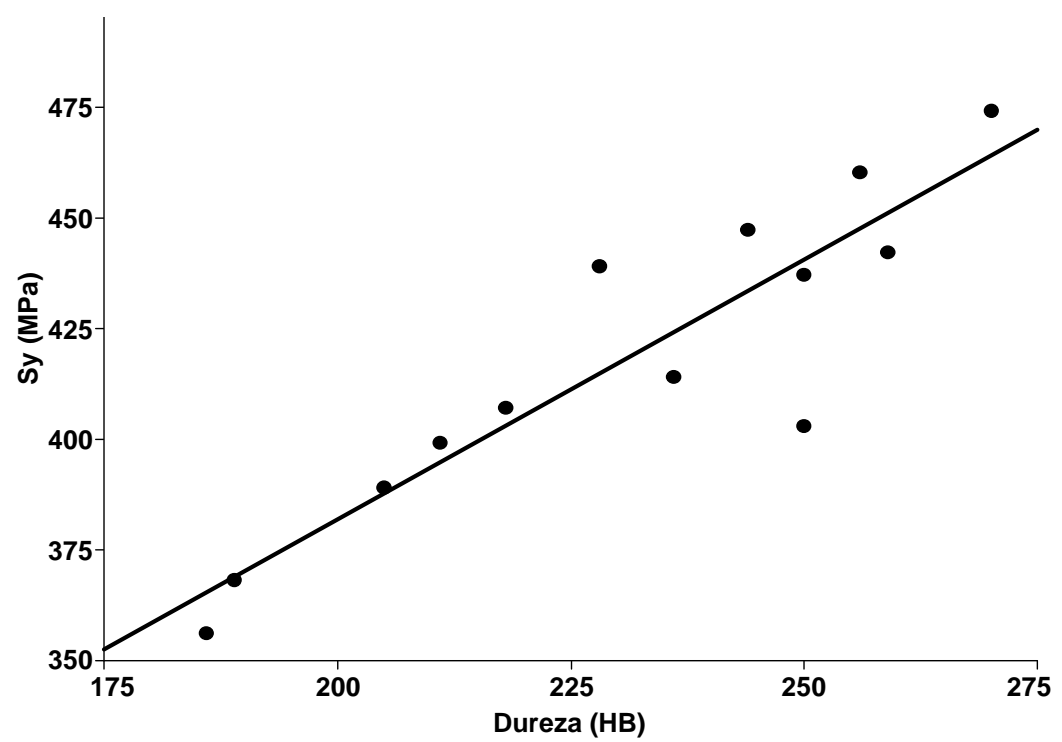

Figura 28: Relação da tensão de escoamento com a dureza - dados da literatura, $R^{2}=0,82$ 


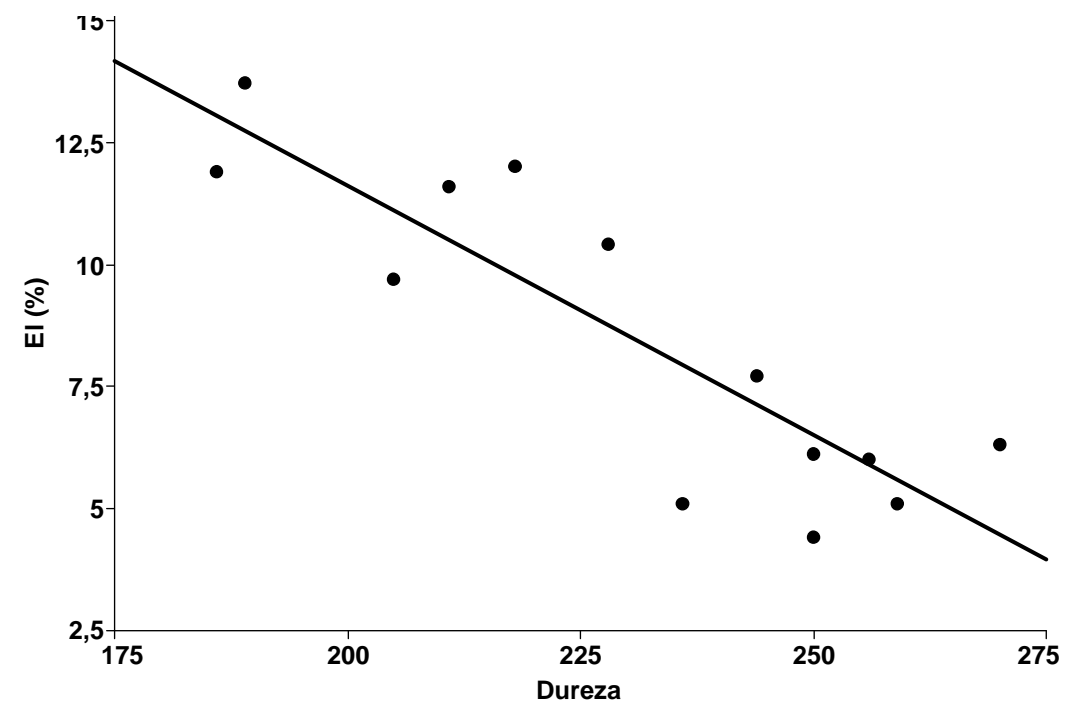

Figura 29: Relação do alongamento com a dureza - dados da literatura, $\mathbf{R}^{2}=\mathbf{0 , 7 6}$

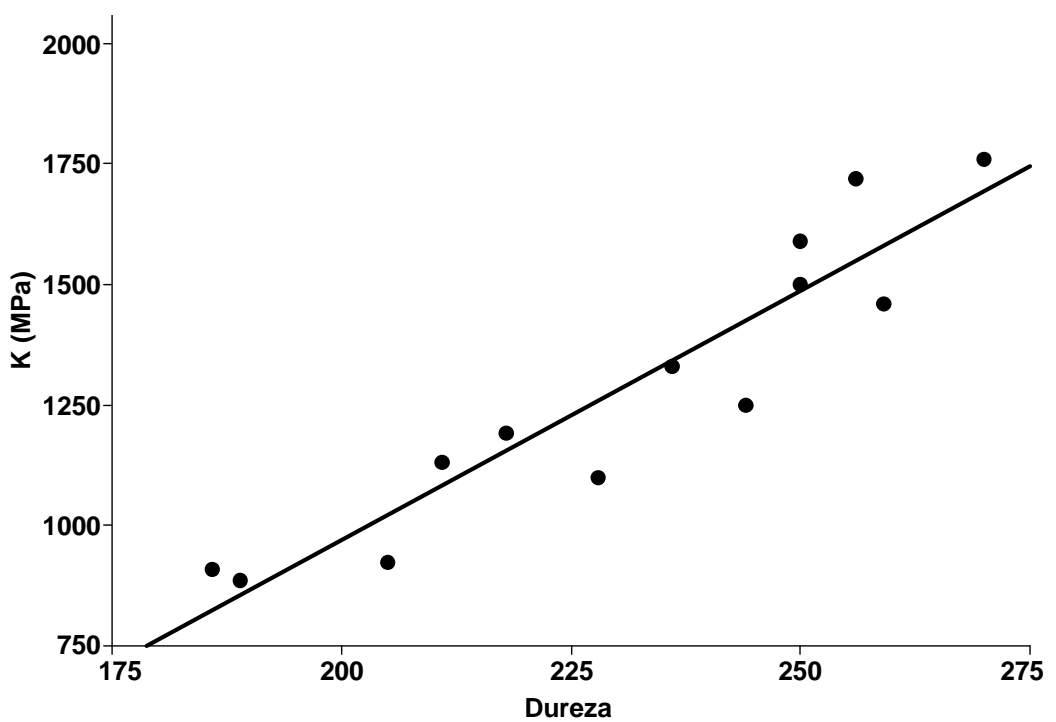

Figura 30: Relação do Coeficiente de Resistência com a Dureza - dados da literatura, $R^{2}=0,87$ 


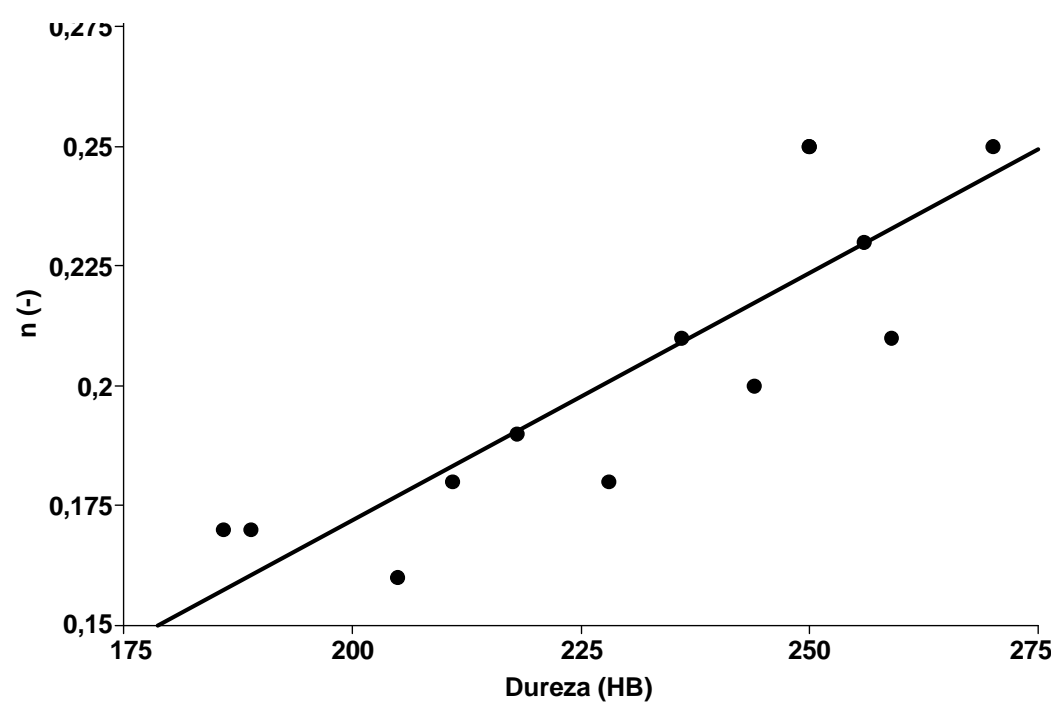

Figura 31: Relação entre o expoente de encruamento e a dureza - dados da literatura, $\mathbf{R}^{2}=0,74$

Analisando os resultados apresentados acima é possível concluir que existe correlação entre as propriedades monotônicas dos ferros fundidos com a dureza, porém, esta correlação é moderada, pois, o $\mathrm{R}^{2}$ varia entre 0,70 e 0,90 . Para que houvesse uma forte correlação entre as variáveis independentes (propriedades monotônicas) com a variável dependente (dureza) seria necessário que o fator de correlação fosse maior do 0,90 (Peter, 2001)

\subsubsection{Propriedades Cíclicas}

Analogamente ao estudo sobre as publicações sobre as propriedades monotônicas foi feito uma pesquisa sobre as publicações nas quais havia informações sobre as propriedades cíclicas e a dureza e a partir do uso das mesmas fontes literárias usadas na seção anterior foi construída a Tabela 6 : 
Tabela 6: Propriedades Cíclicas dos Ferros Fundidos Nodulares - dados da literatura

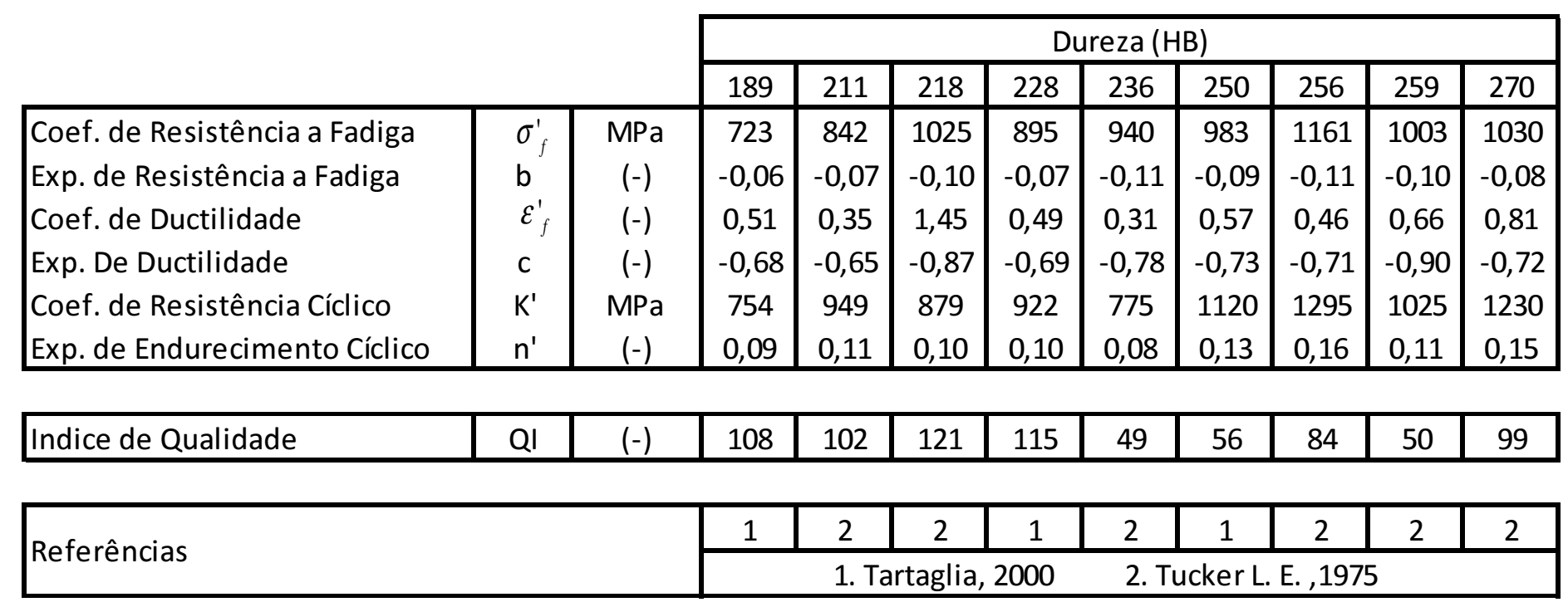




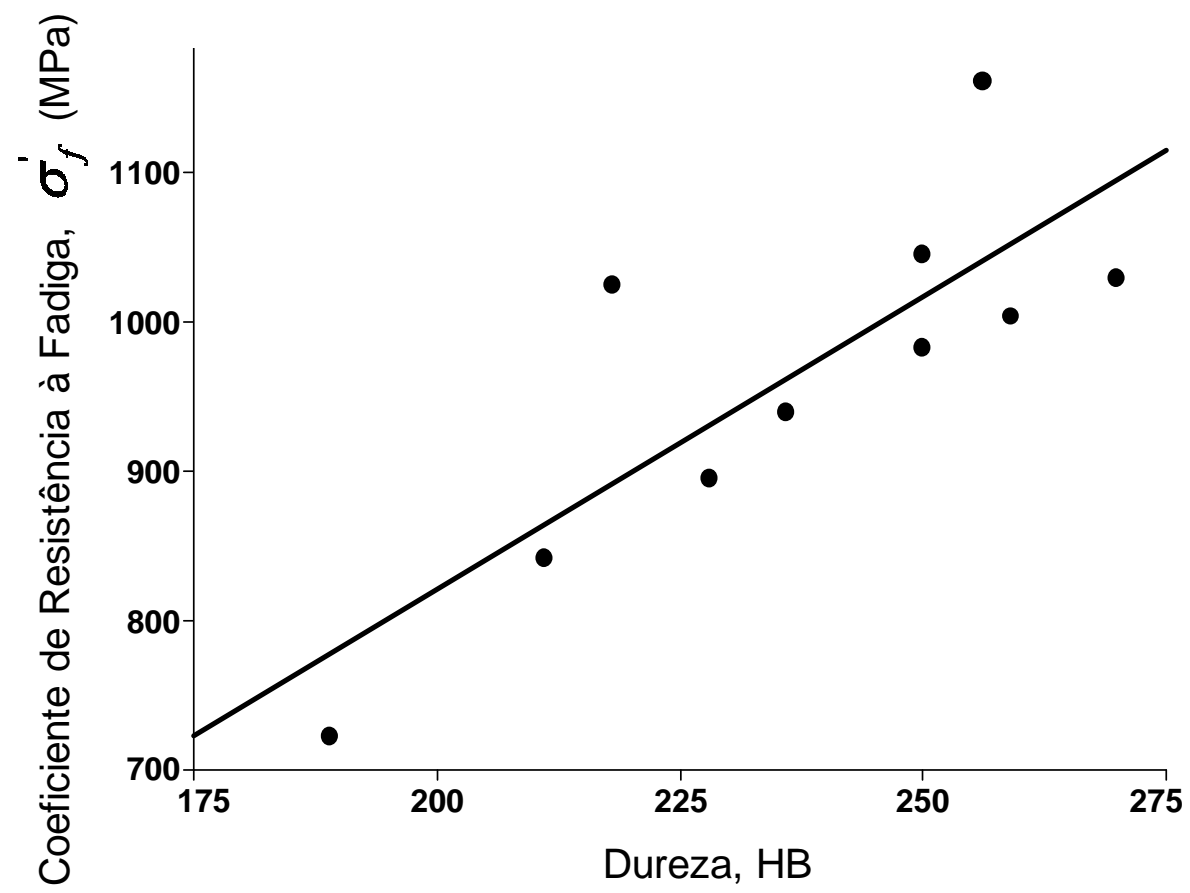

Figura 32: Relação entre o coeficiente de resistência a fadiga e a dureza - dados da literatura , $R^{2}=0,65$

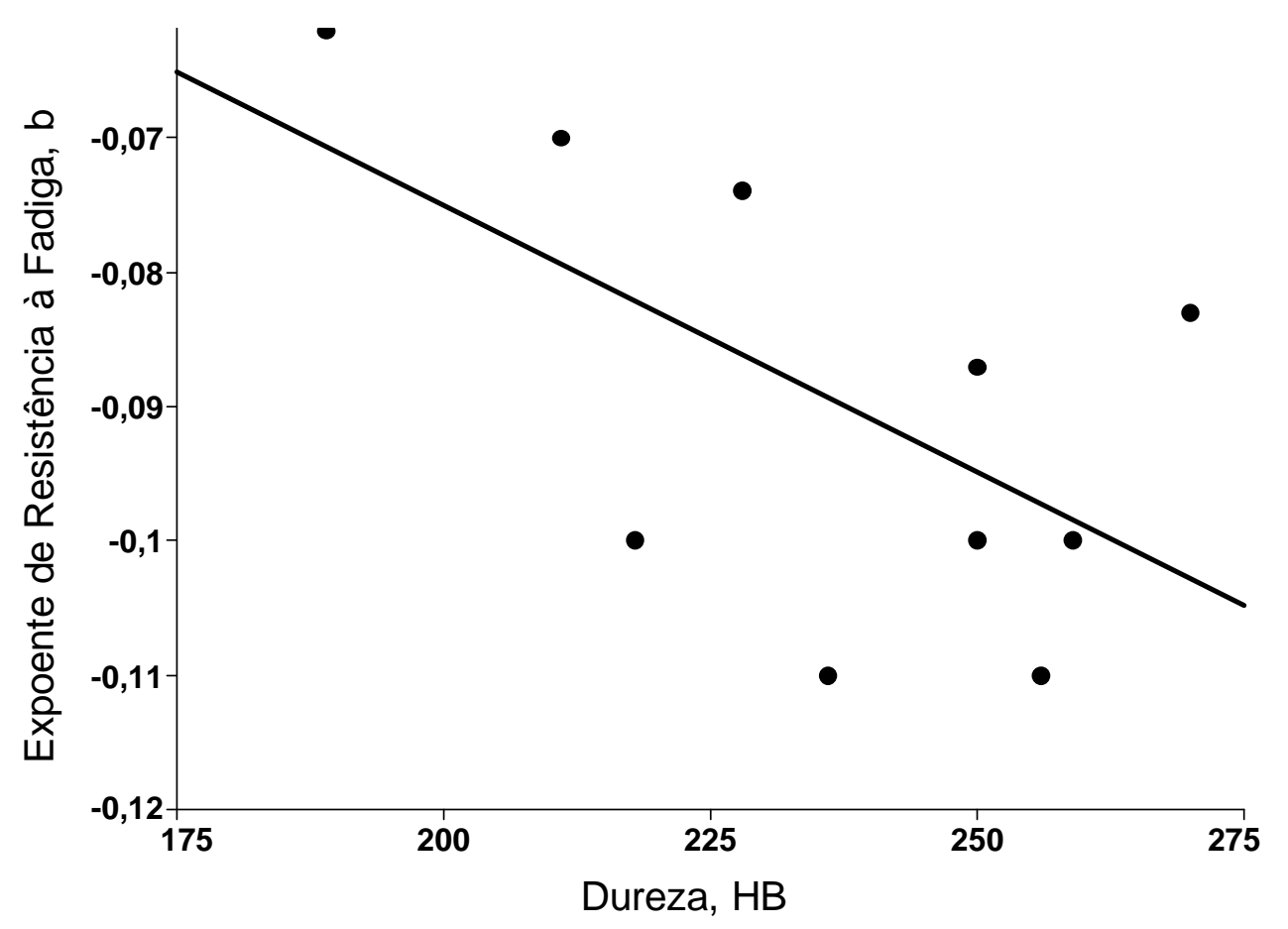

Figura 33: Relação entre o Expoente de Resistência a Fadiga e a Dureza - dados da literatura, $R^{2}=0,34$ 


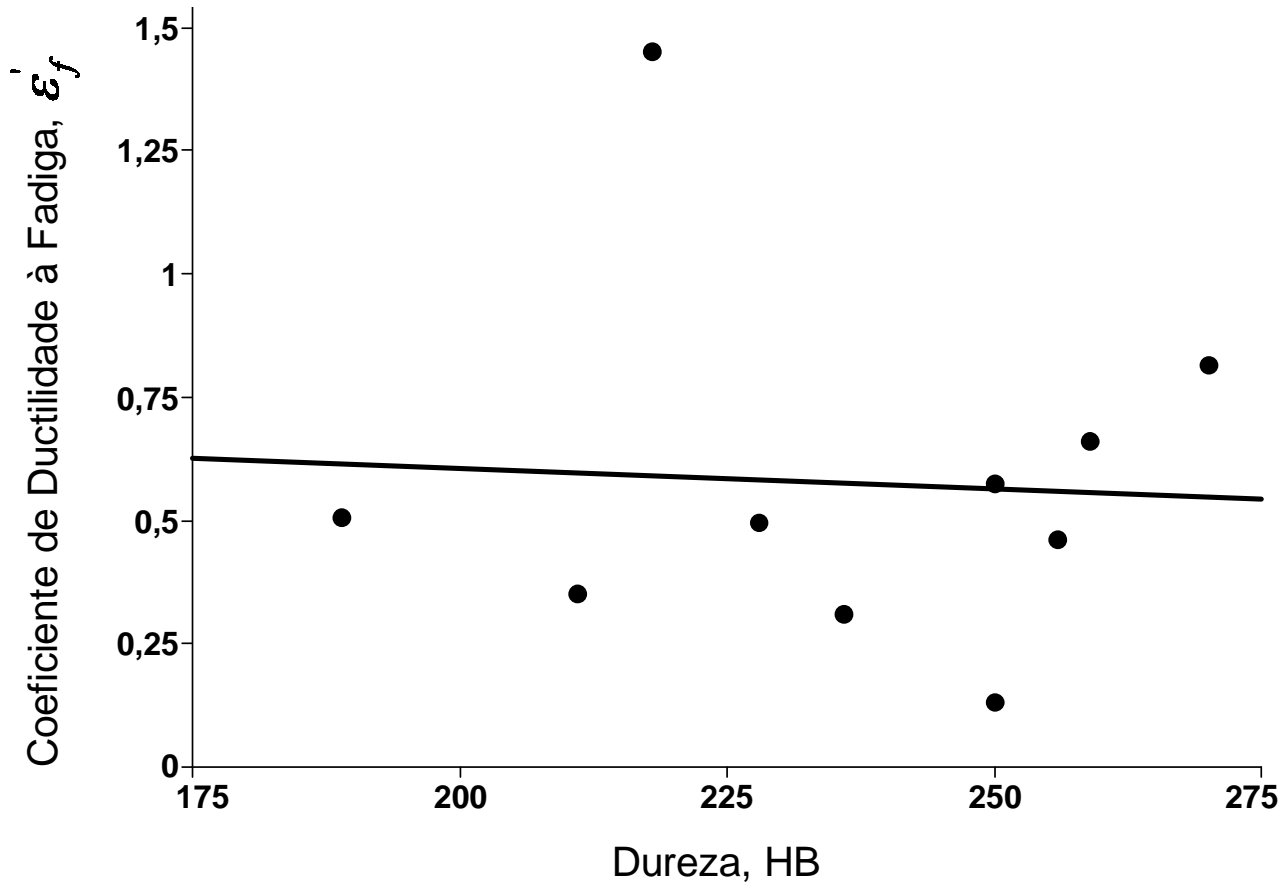

Figura 34: Relação entre o Coeficiente de Ductilidade e a Dureza - dados da literatura, $\mathbf{R}^{2}=0,00$

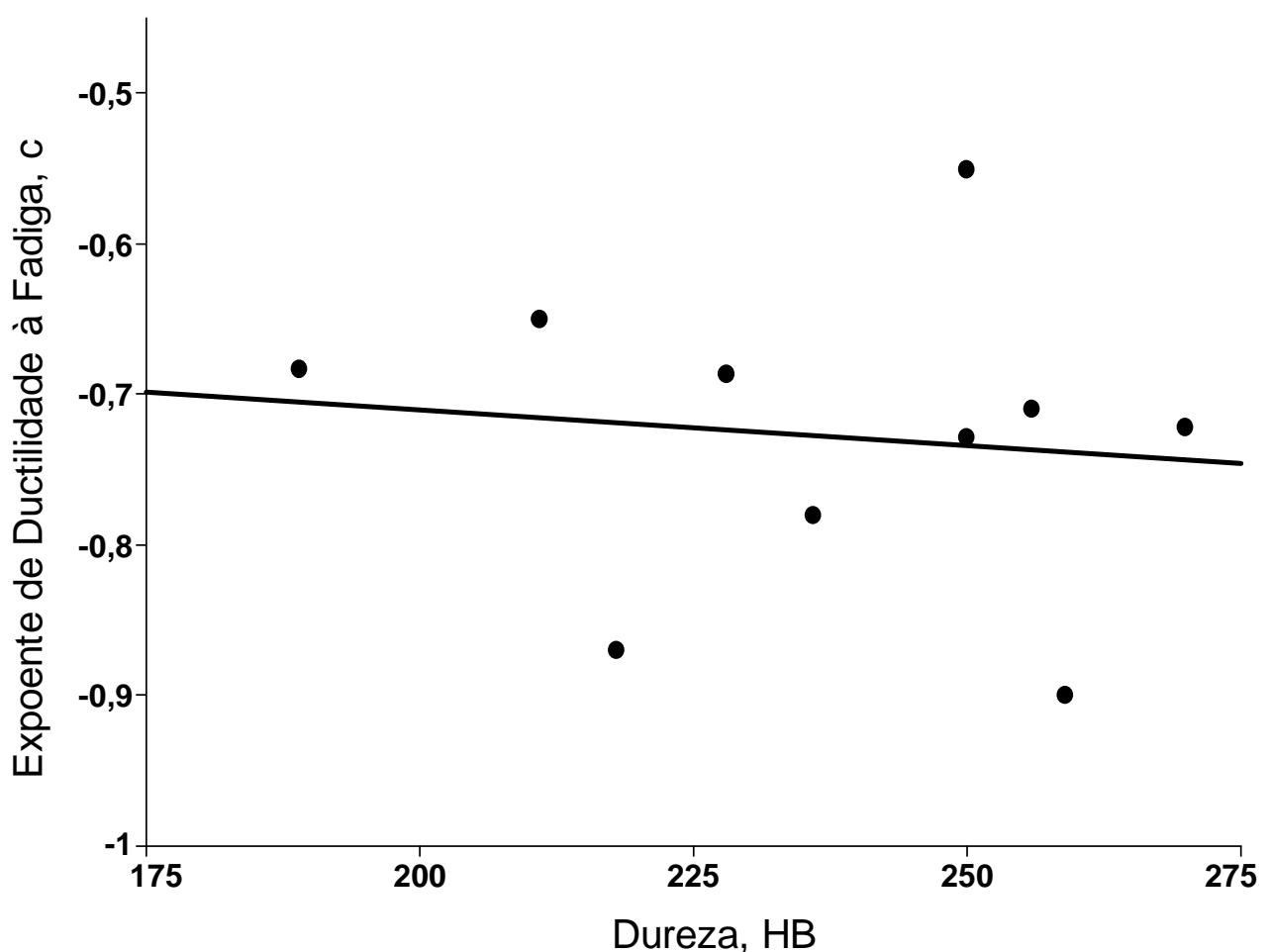

Figura 35: Relação entre o Expoente de Ductilidade e a Dureza - dados da literatura, $R^{2}=0,00$ 


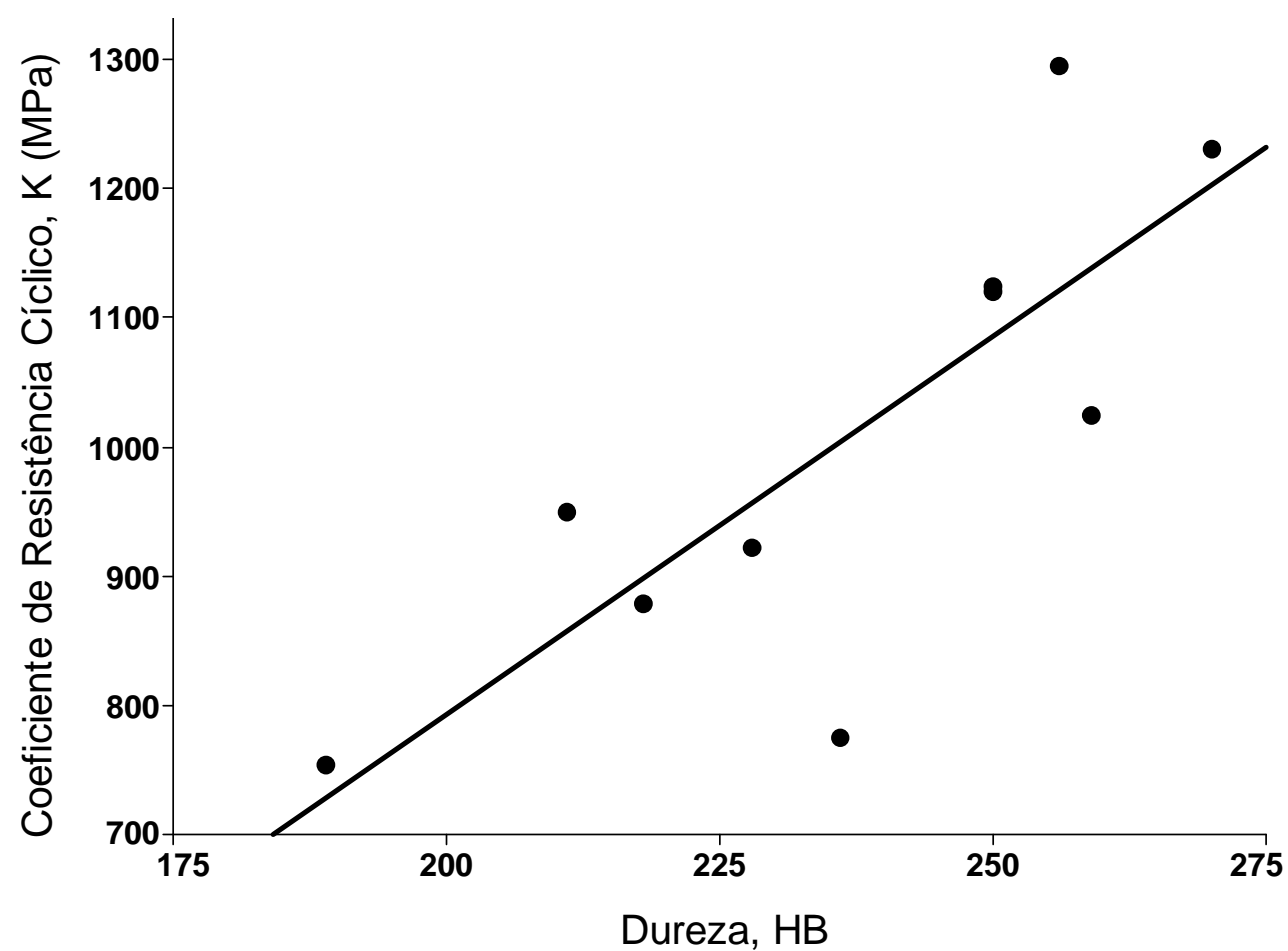

Figura 36: Relação entre o coeficiente de resistência cíclico K' [MPa] e a dureza - dados da literatura $\mathbf{R}^{2}=\mathbf{0 , 6 4}$

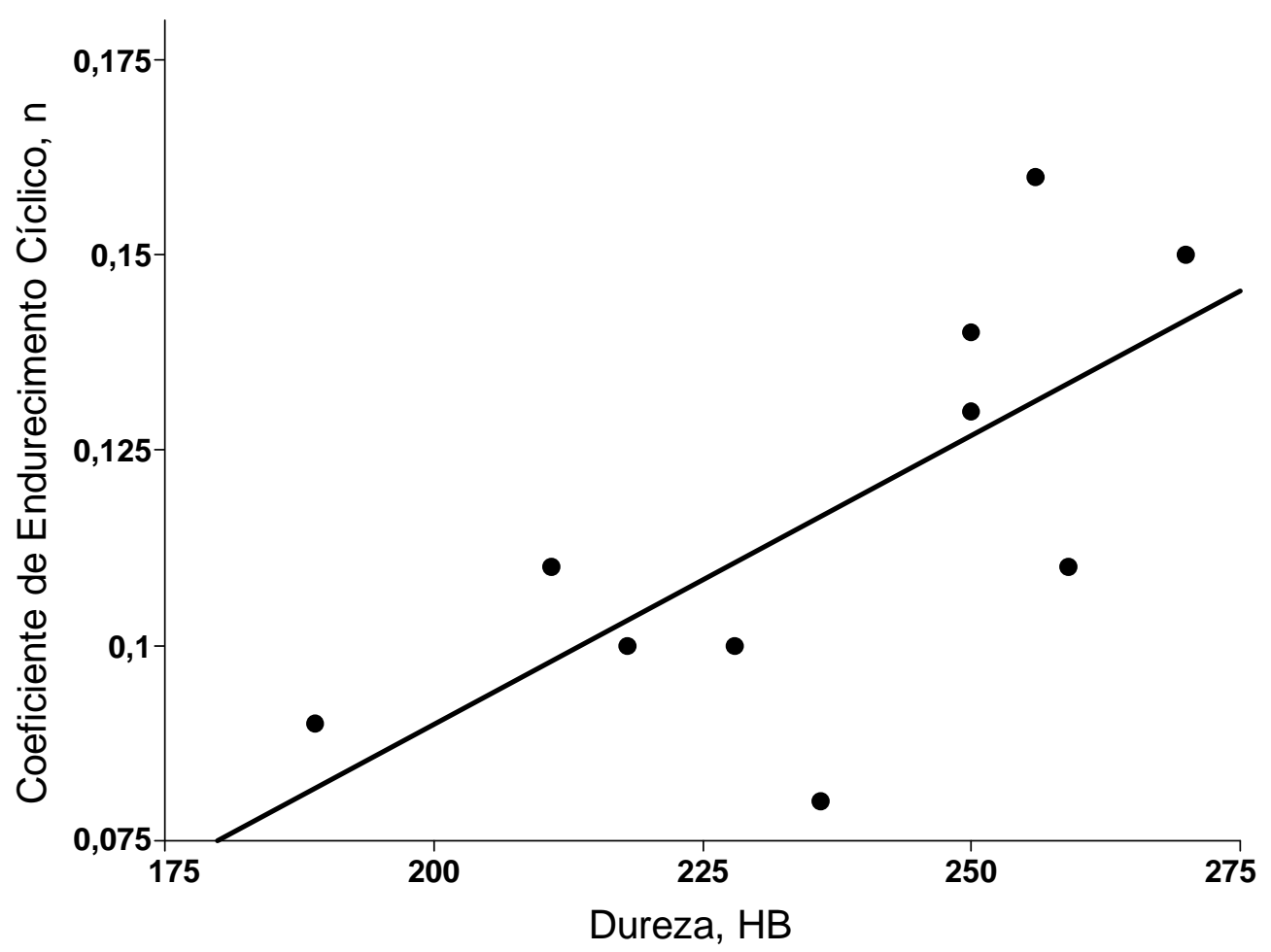

Figura 37: Relação entre o expoente de encruamento cíclico n' e a dureza - dados da literatura , $\mathbf{R}^{2}=\mathbf{0 , 4 8}$ 


\subsubsection{Correlação das Propriedades Mecânicas com a Dureza - Dados da Literatura}

Desta forma, referindo às relações das propriedades mecânicas com a dureza determinadas com base nos dados da literatura foi construída a Tabela 7 que resume a avaliação dos ajustes destas correlações:

Tabela 7: Avaliação da correlação das propriedades mecânicas com a dureza - dados da literatura

\begin{tabular}{|c|c|c|c|c|c|c|}
\hline & & & & Antes do Estud & \\
\hline & & & & $\mathrm{R}^{2}$ & $\begin{array}{c}\text { Correlação } \\
\text { com a Dureza }\end{array}$ & Ajuste \\
\hline \multirow{11}{*}{ 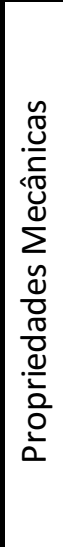 } & \multirow{5}{*}{ 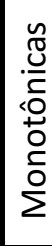 } & Limite de Resistência & $\mathrm{Su}$ & 0,72 & $\operatorname{sim}$ & fraco \\
\hline & & Limite de Escoamento & Sy & 0,82 & sim & fraco \\
\hline & & Alongamento & El & 0,76 & $\operatorname{sim}$ & fraco \\
\hline & & Coeficiente de Resistência & K & 0,87 & sim & fraco \\
\hline & & Expoente de Endurecimento & $\mathrm{n}$ & 0,74 & sim & fraco \\
\hline & \multirow{6}{*}{ 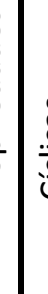 } & Coef. de Resistência a Fadiga & $\sigma_{f}^{\prime}$ & 0,65 & sim & fraco \\
\hline & & Exp. de Resistência a Fadiga & $b$ & 0,34 & não & - \\
\hline & & Coef. de Ductilidade & $\varepsilon_{f}^{\prime}$ & 0,00 & não & - \\
\hline & & Expoente de Ductilidade & c & 0,00 & não & - \\
\hline & & Coeficiente de Resistência Cíclico & $\mathrm{K}^{\prime}$ & 0,64 & $\operatorname{sim}$ & fraco \\
\hline & & Expoente de Endurecimento Cíclico & $\mathrm{n}^{\prime}$ & 0,48 & $\operatorname{sim}$ & fraco \\
\hline
\end{tabular}

Portanto, avaliando o ajuste das relações entre o coeficiente de resistência à fadiga $\left(\mathrm{R}^{2}=0,65\right)$, do coeficiente de resistência cíclico $\left(\mathrm{R}^{2}=0,64\right)$ e do expoente de encruamento cíclico $\left(\mathrm{R}^{2}=0,48\right)$ com a dureza que são maiores do que 0,30 e menores do que 0,70 é possível afirmar que existe correlação destas propriedades com a dureza, porém elas são correlações consideradas fracas. Com relação do expoente de resistência a fadiga $\left(\mathrm{R}^{2}=0,34\right)$ e ao coeficiente de ductilidade e ao expoente de ductilidade, ambos com $\mathrm{R}^{2}=0,00$, pode-se afirmar que estes parâmetros não se correlacionam com a dureza. 


\section{PARTE III}

\subsection{Metodologias Experimentais}

\subsubsection{Definição do Espaço Amostral}

Visto a falta de dados na literatura contemplando relações das propriedades monotônicas e cíclicas dos ferros fundidos nodulares com a dureza e a necessidade aumentar o espaço amostral para a se fazer uma melhor avaliação da relação das propriedades mecânicas destes materiais com a dureza fez-se necessário o planejamento de um experimento que ampliasse os estudos já publicados na literatura de forma que todas as classes de ferros fundidos nodulares fossem estudadas a partir de toda a faixa de dureza que os ferros fundidos podem apresentar de acordo com a constituição metalográfica da sua matriz (ferrita e perlita).

$\mathrm{Na}$ Parte II deste trabalho, a partir das publicações feitas na literatura, nota-se que algumas classes de ferros fundido possuem informações sobre as suas propriedades mecânicas relacionadas com a dureza, este é o caso das classes SAE D5504 e parcialmente das classes dos ferros fundidos SAE D4512 e SAE D7003 que foram estudados por Tartaglia (2000), apesar do interesse inicial do autor ter sido concentrado nos estudos da classe SAE D5506. O autor Tucker (1975) apresentou os resultados para a classe SAE D5504, portanto, para se completar o estudo de forma que toda a gama de ferro fundido nodulares seja contemplada faltam amostras que representassem a dureza destes materiais que foram estudados parcialmente, amostras que representassem o ferro fundido SAE D4018 e o D800.

Uma premissa para a escolha das amostras dos ensaios foi atender ao requisito de possuir o índice de qualidade maior do que 80 e desta forma garantir uma qualidade satisfatória, que seja isenta dos possíveis defeitos inerentes ao processo de fabricação. Esta exigência dever ser cumprida para que haja amostras suficientes para a avaliação das suas propriedades mecânicas com a dureza sem que haja a influência destes defeitos.

Observando esta necessidade de ter amostras de ferro fundido com qualidade satisfatória para poder fazer os estudos de correlação das suas propriedades mecânicas 
com a dureza nota-se que é necessário refazer o estudo para a classe de dureza com 250 $\mathrm{HB}$ visto que as amostras escolhidas para representar esta categoria de dureza tanto no estudo publicado no DIS (Dutile Iron Society) por Tartaglia (2000) quanto no estudo apresenta por Turcker (1975) não atenderam o critério da qualidade mínima exigida no presente trabalho (Índice de Qualidade $\geq 80$ ). Isto pode ser observado na Tabela 6.

Portanto, confrontando estas necessidades para ampliar o estudo com o grau de utilização destes materiais na indústria foi escolhido representar a classe D4018 com duas categorias de dureza, 135 e $160 \mathrm{HBS}$, denominadas neste estudo por Classe A e Classe B, respectivamente e refazer o estudo com a dureza de $250 \mathrm{HBS}$, denominada por Classe C.

As categorias de material SAE D7003 e o D800, devido sua baixa utilização na fabricação de componentes estruturais, não foram incluídas neste estudo. Foi necessário fazer esta escolha por que os ensaios de caracterização cíclica têm custos elevados e consomem um tempo considerável. Na figura 38 é possível visualizar a distribuição das amostras escolhidas no presente trabalho com relação às amostras estudas na Parte II deste trabalho. 


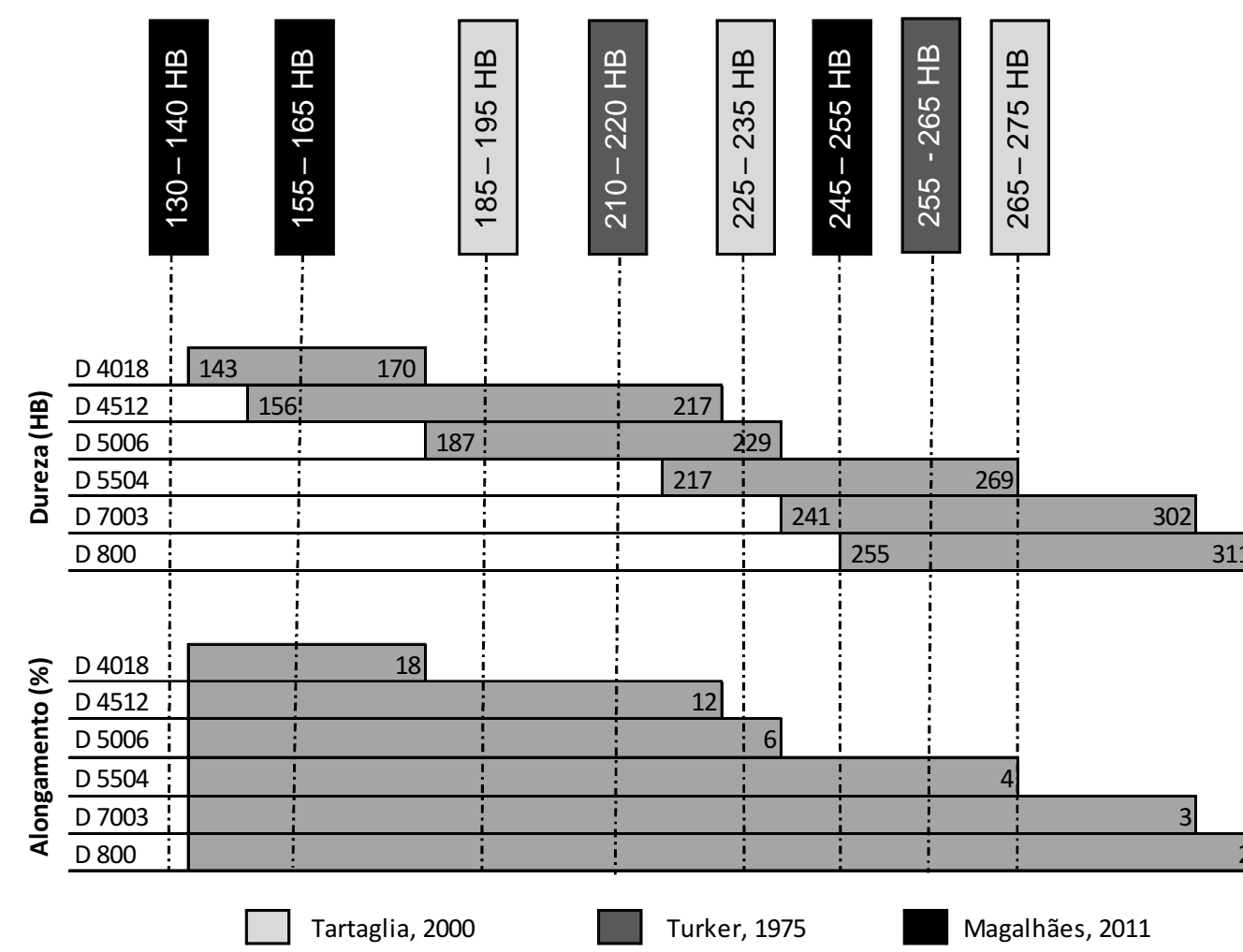

$130-140 \mathrm{HB}$

Classe A

$155-165 \mathrm{HB}$

- Classe B

$245-255 \mathrm{HB}$

- Classe C

Figura 38: Espaço Amostral

As três classes especificadas foram fornecidas pela empresa Schulz Automotiva, localizada na cidade Joinville - SC. Já na forma de corpos de prova usinados.

\subsubsection{Análise Química}

As análises químicas dos elementos químicos das ligas das classes A, B e C, com exceção dos elementos $\mathrm{C}$ e $\mathrm{S}$ que foram analisados por combustão foram realizadas pela técnica de espectrometria por emissão ótica em amostras retiradas de corpos de prova fraturados nos ensaios de fadiga de baixo ciclos e refundidas em atmosfera protetora e vazadas em coquilha resfriada à água. 


\subsubsection{Ensaios de Dureza}

Para a determinação da dureza foi realizada na parte chanfrada dos corpos de prova próxima a cabeça rosqueada dos corpos de prova pelo o método medida Brinell, utilizado carga de 187,5 $\mathrm{kgf}$ e esfera de $\mathrm{W}$ de $2,5 \mathrm{~mm}$ de diâmetro. O procedimento adotado foi de acordo norma ASTM E 10 (2010), foram realizadas cinco medidas em cada grupo de corpo de prova ao longo do plano de laminação do material. Para as medidas utilizou-se uma máquina de dureza universal da marca Wolpert.

\subsubsection{Ensaio de Tração}

Os ensaios de tração foram realizados em corpos de prova usinados a partir do material na condição de como-recebido. Os procedimentos dos ensaios foram realizados segundo as normas ASTM E8/E8M-09. Os ensaios de tração foram realizados em uma máquina servo-hidráulica MTS LANDMARK com capacidade para $100 \mathrm{kN}$, equipada com um controlador digital MTS FlexTest GT, com velocidade de deslocamento do pistão de $0,5 \mathrm{~mm} / \mathrm{min}$ até $0,5 \%$ de deformação e aumentada para $5 \mathrm{~mm} / \mathrm{min}$ acima desta deformação. Todos os equipamentos descritos acima estão alocados nos Laboratórios de Propriedades Mecânicas do Departamento de Engenharia de Materiais da EESC-USP.

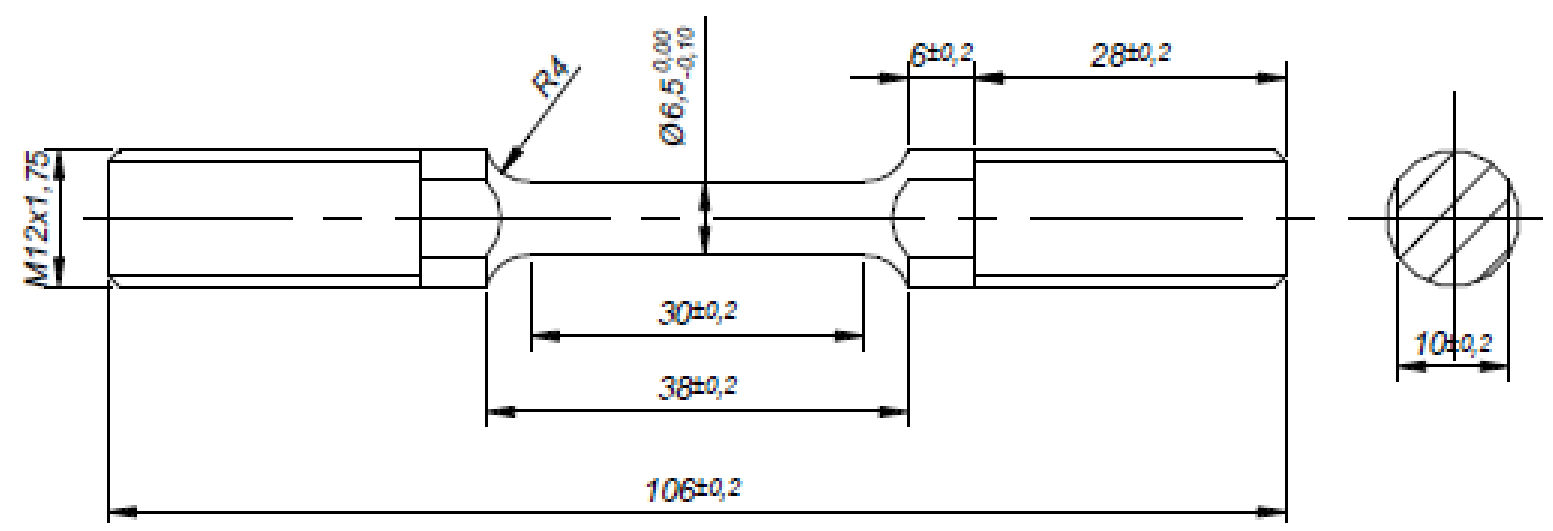

Figura 39: Geometria e dimensões do corpo-de-prova de tração. Dimensões em mm

\subsubsection{Ensaio de Fadiga $\varepsilon-\mathrm{N}$}

Os ensaios de fadiga de baixo ciclo foram realizados sob controle de deformação e monitorados pelo programa MPT da MTS, programado de acordo com a norma ASTM E606 - 04. 
Os corpos de prova das classes A, B e C com diferentes durezas foram especificados de tal forma que se possa complementar os dados já publicados na literatura cobrindo desta forma toda a faixa de dureza dos Ferros Fundidos Nodulares geralmente empregados em componentes estruturais, de acordo com a norma.

As dimensões e geometria dos corpos de prova utilizados neste tipo de ensaio são mostradas na figura 40:

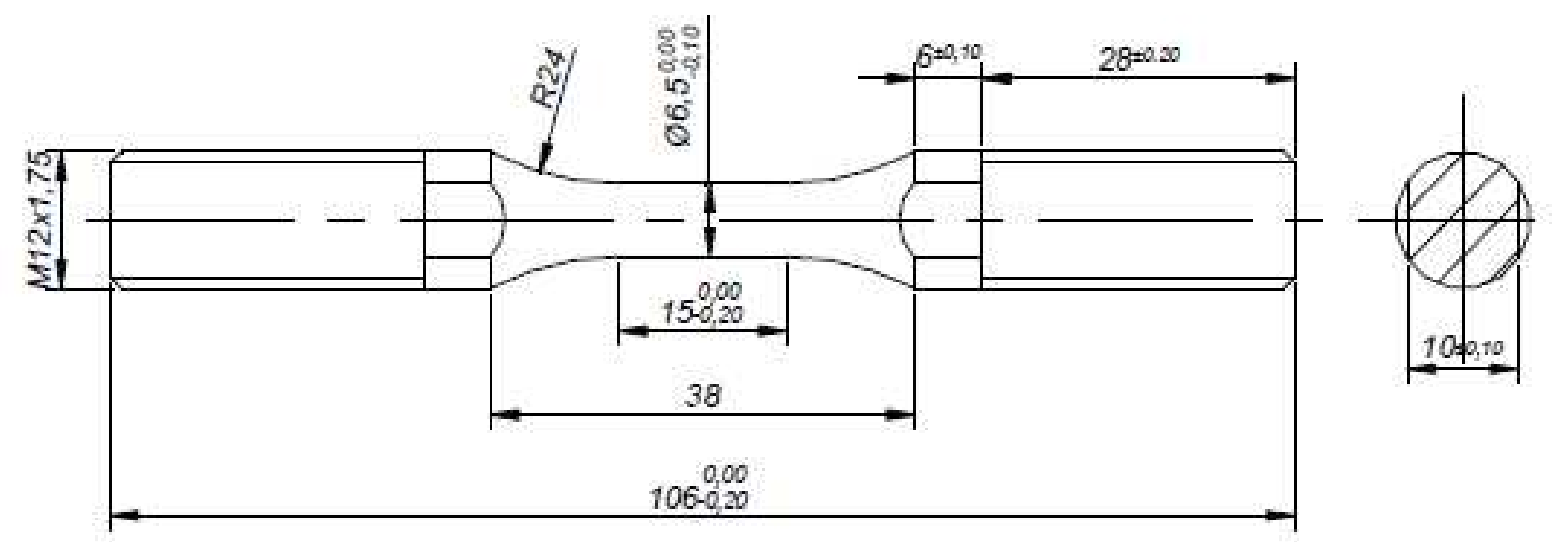

Figura 40: Geometria e dimensões do corpo de prova utilizado para os ensaios de fadiga de baixo ciclo ( dimensões em mm)

Utilizou-se, para controle de deformação, um extensômetro MTS 632.26F-20 (ver figura 41) com distância inicial entre facas de $8,0 \mathrm{~mm}$. Os ensaios foram realizados em uma máquina servo-hidráulica MTS LANDMARK de 100kN de capacidade máxima , em onda senoidal, com frequência variando entre $0,5 \mathrm{~Hz}$ a $3 \mathrm{~Hz}$, dependendo do nível de deformação imposto, isto é, para altas amplitudes de deformação foram empregadas baixas frequências e vice-versa. As amplitudes de deformação variaram de 0,15\% a 0,45\%. Devido ao risco de flambagem dos corpos de prova durante o ensaio foram evitados deformações maiores do que $0,45 \%$. Os ensaios foram realizados com a razão de deformação variando em forma de onda senoidal. 


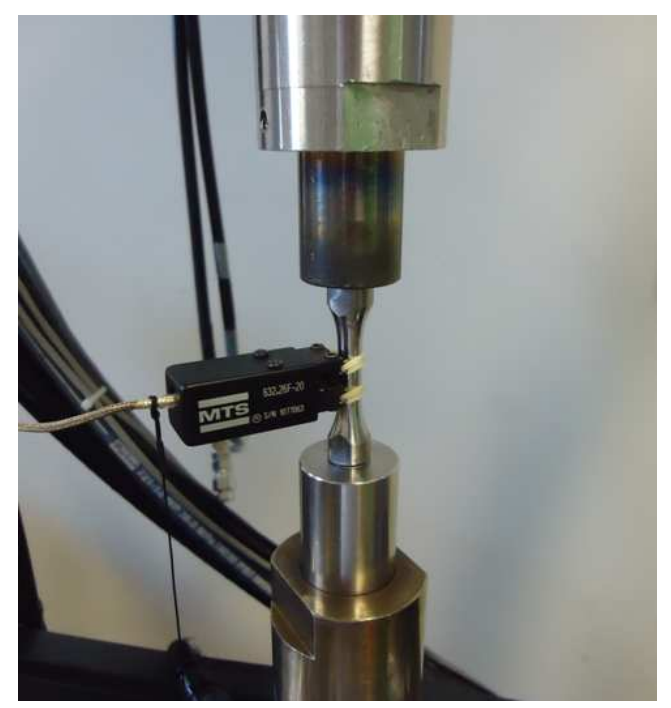

Figura 41: Detalhe da garra e instalação do extensômetro no corpo de prova para o controle de deformação durante o ensaio de fadiga

A figura 42 mostra esquematicamente a configuração do sistema MTS para ensaio dinâmico que foi utilizada para a realização dos ensaios de fadiga de baixo ciclo.

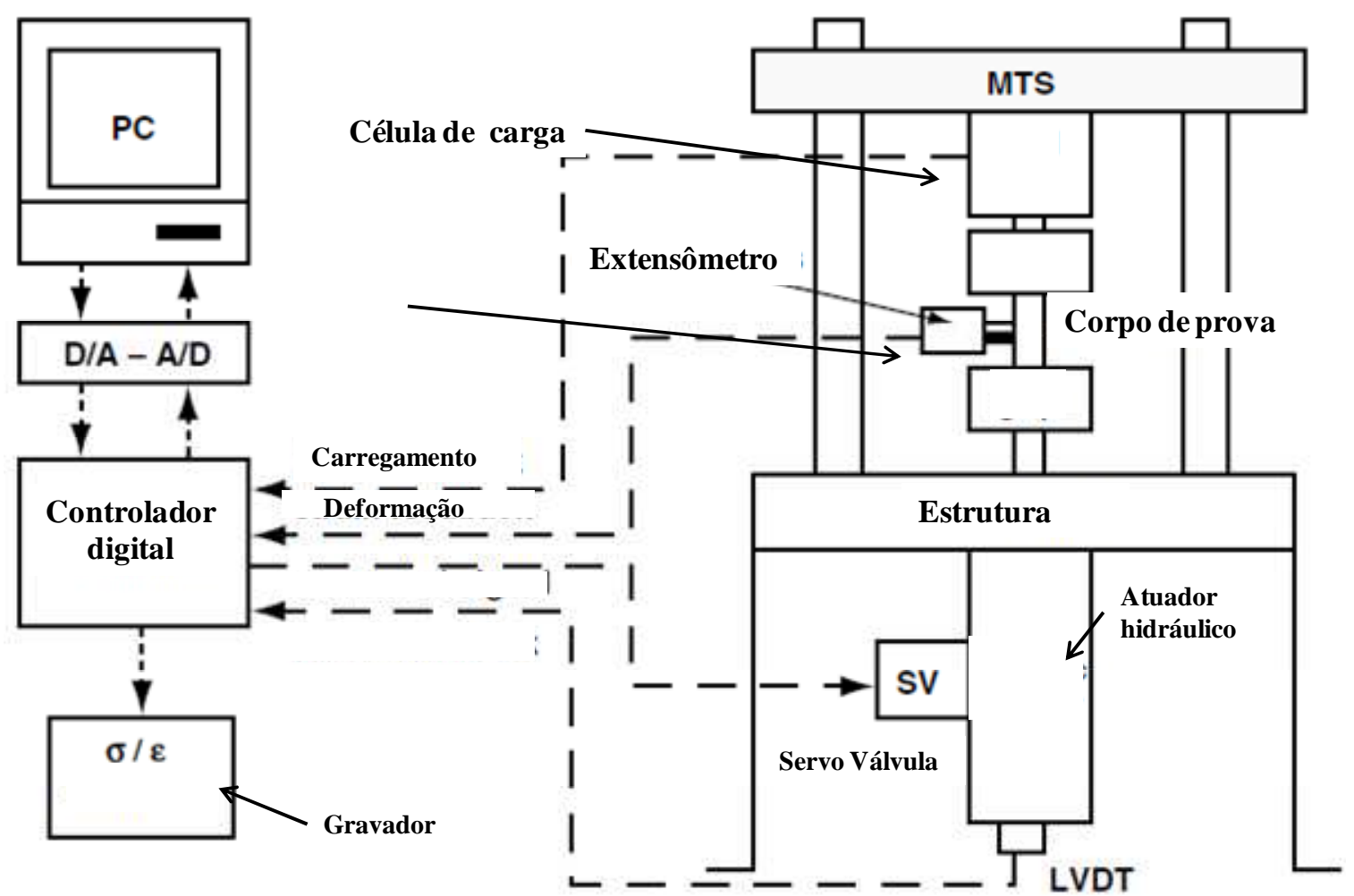

Figura 42: Configuração do ensaio de fadiga $\varepsilon-N$, (YANG 1994) 
A equação que descreve o comportamento do material quando submetido à fadiga de baixo ciclo, ou fadiga $\varepsilon-\mathrm{N}$, e os parâmetros relacionadas a este método de determinação da vida em fadiga foram explorados na revisão bibliográfica apresentada na Parte I deste trabalho.

O procedimento adotado neste trabalho para a escolha do tamanho da amostragem utilizada para a obtenção da curva deformação-vida, foi baseado no tipo de ensaio do programa de obtenção de dados para projeto, conforme descrito no item 7 da norma ASTM E739-10, que está apoiado no Manual sobre Planejamento Estatístico e Análises para Experimentos em Fadiga, proposto na STP 588 , que se fundamenta nos valores das faixas de porcentagens de replicações apresentadas na Tabela 8.

Tabela 8: Tipo de ensaio de acordo com a sua replicação (ASTM E739, 2004)

\begin{tabular}{|l|c|}
\hline \multicolumn{1}{|c|}{ Tipo do Teste } & Replicação (\%) \\
\hline Teste preliminar e exploratório (testes de pesquisa e desenvolvimento) & de 17 até 33 \\
\hline Teste de pesquisa e desenvolvimento de componentes e espécimes & de 33 até 50 \\
\hline Dados permissíveis para projeto & de 50 até 75 \\
\hline Dados confiáveis & de 75 até 88 \\
\hline
\end{tabular}

O cálculo da replicação é dado pela equação III.1, como segue:

Replicação $(\%)=100 *[1-(n \circ$ o total de níveis diferentes de deformação ou tensão/ no total de amostras testadas)]

A Tabela 9 lista o número total de níveis diferentes de deformação usados nos ensaios e a quantidade de amostras testadas em cada nível para as três classes de materiais testados: 
Tabela 9: Numero de níveis e amostras testadas em cada classe de material

\begin{tabular}{|c|c|c|c|}
\cline { 2 - 4 } \multicolumn{1}{c|}{} & \multicolumn{3}{c|}{ Numero de Amostras } \\
\hline Nivel Deformação (\%) & Classe A & Classe B & Classe C \\
\hline 0,15 & 3 & 2 & 1 \\
\hline 0,20 & 3 & 3 & 3 \\
\hline 0,25 & 4 & 3 & - \\
\hline 0,30 & 3 & 3 & 3 \\
\hline 0,35 & 3 & 3 & 3 \\
\hline 0,40 & 3 & 1 & 2 \\
\hline 0,45 & - & - & 3 \\
\hline no total de níveis & 6 & 6 & 6 \\
\hline no total de amostras & 19 & 15 & 15 \\
\hline
\end{tabular}

Substituindo as informações da Tabela 9 na equação III.1 pode-se calcular a replicação das amostras, a Tabela 10 resume esta avaliação:

Tabela 10: Replicação das classes testadas

\begin{tabular}{|c|c|}
\hline Classe & Replicação (\%) \\
\hline Classe A & 68 \\
\hline Classe B & 60 \\
\hline Classe C & 60 \\
\hline
\end{tabular}

Portanto, uma vez que as \% replicações utilizadas ficaram entre a faixa de porcentagem de 50 a 75\%, pode-se então concluir, que o tamanho da amostragem adotada neste trabalho forneceu uma \% de replicação considerada adequada para obtenção de dados do comportamento de fadiga de baixo ciclos, permitidos para utilização em projetos de componentes.

\subsubsection{Metalografia}

As amostras destinadas às analises por microscopia óptica foram obtidas da região seção transversal da cabeça rosqueada dos corpos de prova fraturados nos ensaios de tração e embutidas em resina polimérica, lixadas (lixas 120, 240, 320, 400 e 600, respectivamente) e polidas com alumina $0,05 \mu \mathrm{m}$. O ataque químico foi feito com Nital $2 \%$, que revela os contornos de grão ferríticos e escurece o microconstituinte perlita. As 
microestruturas foram observadas e fotografadas em um microscópio óptico Olympus BX60M, equipado com máquina fotográfica digital Sony Cyber-shot 14.1 Megapixels.

\subsubsection{Análises Fratográficas}

As análises fratográficas foram realizadas nas superfícies de fratura de três corpos de prova das classes A, B e C, fraturados em fadiga de baixo ciclos em níveis de deformação total de $0,30 \%$. Antes das análises, as amostras foram limpas por ultra som em álcool isopropílico.

Para análise do das superfícies de fratura pela técnica de microscopia eletrônica de varredura (MEV), foi utilizado um microscópio eletrônico marca Zeiss, modelo DMS 960, com a finalidade de se determinar os aspectos morfológicos da superfície fraturada nas regiões de nucleação, propagação estável e fratura final.

\subsection{Resultados Experimentais e Discussões}

\subsubsection{Análise Química}

Segue na Tabela 11 o resumo das composições em \% de peso de cada elemento químico encontrado nas classes de material especificados para os ensaios.

Tabela 11: Composição química das classes A, B e C em \% em peso

\begin{tabular}{|c|c|c|c|c|c|c|c|c|c|c|c|c|c|}
\cline { 2 - 11 } \multicolumn{1}{c|}{} & $\mathrm{C}$ & $\mathrm{Si}$ & $\mathrm{Mn}$ & $\mathrm{P}$ & $\mathrm{S}$ & $\mathrm{Al}$ & $\mathrm{Cu}$ & $\mathrm{Mg}$ & $\mathrm{Cr}$ & $\mathrm{Mo}$ & $\mathrm{Ni}$ & $\mathrm{Ti}$ & $\mathrm{CE}^{*}$ \\
\hline Classe A & 3,46 & 2,33 & 0,29 & 0,022 & 0,019 & 0,026 & 0,13 & 0,031 & 0,04 & $\mathrm{ND}$ & 0,025 & $\mathrm{ND}$ & 4,24 \\
Classe B & 3,60 & 2,35 & 0,3 & 0,020 & 0,024 & 0,023 & 0,3 & 0,035 & 0,05 & $\mathrm{ND}$ & 0,034 & $\mathrm{ND}$ & 4,39 \\
Classe C & 3,50 & 2,41 & 0,35 & 0,021 & 0,022 & 0,029 & 0,36 & 0,057 & 0,04 & $\mathrm{ND}$ & 0,04 & $\mathrm{ND}$ & 4,31 \\
\hline
\end{tabular}

Observação: * CE (Carbono Equivalente)= \% C + 1/3 (\%Si + \%P) 


\subsubsection{Ensaios de Dureza}

Foram realizadas medidas de dureza em cinco corpos de prova de tração de cada classe. Os valores médios encontrados estão apresentados na Tabela 12.

Tabela 12: Medidas da dureza das amostras de cada classe

\begin{tabular}{|c|c|c|c|c|c|}
\hline \multicolumn{2}{|c|}{ Classe A } & \multicolumn{2}{c|}{ Classe B } & \multicolumn{2}{c|}{ Classe C } \\
\hline Amostra & $\begin{array}{c}\text { Dureza } \\
\text { (HBS) }\end{array}$ & Amostra & $\begin{array}{c}\text { Dureza } \\
\text { (HBS) }\end{array}$ & Amostra & $\begin{array}{c}\text { Dureza } \\
\text { (HBS) }\end{array}$ \\
\hline AT1 & 138 & BT1 & 154 & CT1 & 242 \\
AT2 & 139 & BT2 & 153 & CT2 & 257 \\
AT3 & 137 & BT3 & 164 & CT3 & 255 \\
AT4 & 137 & BT4 & 161 & CT4 & 253 \\
AT5 & 141 & BT5 & 161 & CT5 & 253 \\
\hline Media & 138 & Media & 159 & Media & 252 \\
\hline
\end{tabular}

\subsubsection{Ensaios de Tração}

As tabelas 13, 14 e 15 apresentam os resultados dos cálculos das propriedades monotônicas determinadas a partir do ensaio de tração realizadas nas classes A, B e C, respectivamente.

Tabela 13: Resultado do ensaio de tração - classe A

\begin{tabular}{|c|c|c|c|c|c|c|c|}
\hline \multicolumn{8}{|c|}{ Classe A (135 HB) } \\
\hline CDP & El (\%) & Su (MPa) & Sy (MPa) & E (MPa) & K & $\mathbf{n}$ & QI \\
AT1 & 18,4 & 409 & 285 & 166118 & 667 & 0,19 & 65 \\
AT2 & 29,5 & 405 & 274 & 165246 & 648 & 0,18 & 102 \\
AT3 & 29,5 & 406 & 280 & 165023 & 653 & 0,18 & 102 \\
\hline Media & 25,8 & 407 & 280 & 165462 & 656 & 0,18 & 90 \\
\hline
\end{tabular}


Tabela 14: Resultado do ensaio de tração - classe A

\begin{tabular}{|c|c|c|c|c|c|c|c|}
\hline \multicolumn{7}{|c|}{ Classe B (160 HB) } \\
\hline CDP & El (\%) & Sr (Mpa) & Sy (Mpa) & E (Mpa) & K & $\mathbf{n}$ & QI \\
BT1 & 25,3 & 430 & 323 & 182112 & 699 & 0,19 & 98 \\
BT2 & 22,8 & 449 & 301 & 167685 & 709 & 0,18 & 97 \\
BT3 & 24,4 & 449 & 305 & 160508 & 694 & 0,17 & 103 \\
\hline Media & 24,2 & 443 & 310 & 170102 & 700 & 0,18 & 100 \\
\hline
\end{tabular}

Tabela 15: Resultado do ensaio de tração - classe A

\begin{tabular}{|c|c|c|c|c|c|c|c|}
\hline \multicolumn{7}{|c|}{ Classe C (250 HB) } \\
\hline CDP & El (\%) & Sr (Mpa) & Sy (Mpa) & E (Mpa) & K & $\mathbf{n}$ & QI \\
CT1 & 7,9 & 672,9 & 368 & 156119 & 1433 & 0,26 & 75 \\
CT2 & 4,5 & 713,9 & 430 & 171556 & 1491 & 0,24 & 48 \\
CT3 & 6 & 745,3 & 412 & 176708 & 1582 & 0,26 & 70 \\
\hline Media & 6,1 & 711 & 403 & 168128 & 1502 & 0,25 & 65 \\
\hline
\end{tabular}

A partir da determinação do limite de resistência $\mathrm{Su}(\mathrm{MPa})$ e do alongamento El (\%) foram calculados os índices de qualidade das amostras segundo a equação I.36, cujo valores médios de cada classe estão listados na ultima coluna das Tabelas 13, 14 e 15. Observa-se que as amostras da classe A e B atenderam ao requisito de qualidade exigido (Indice de Qualidade $\geq 80$ ), pois, apresentaram médias do QI de 90 e 100, respectivamente, enquanto que as amostras da classe $\mathrm{C}$ tiveram média do QI igual a 65 e, portanto, não atenderam ao requisito de qualidade mínima exigida.

A figura 43 é um exemplo das curvas tensão-deformação obtidas durante o ensaio de tração, no qual é possível evidenciar as diferenças entre as curvas tensão-deformação de engenharia (área inicial do corpo de prova permanece constante ao longo da aplicação dos esforços) e a curva tensão-deformação verdadeira que contabiliza a redução da área transversal do corpo de prova à medida que os esforços são aplicados durante o ensaio. 


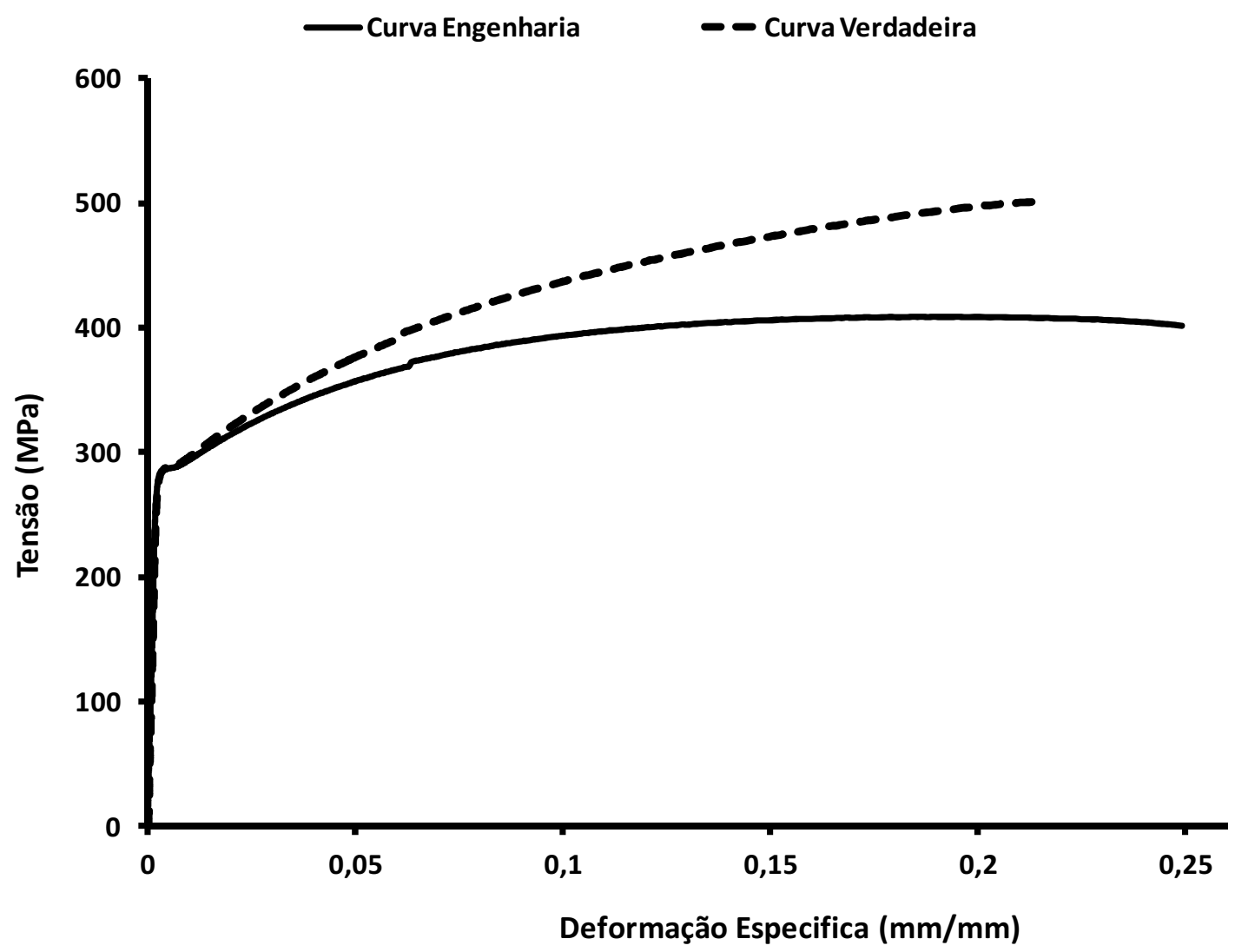

Figura 43: Comparação da curva tensão-deformação de engenharia e curva tensão-deformação verdadeira para uma amostra da classe A ensaiada

\subsubsection{Propriedades de Fadiga $\varepsilon-\mathrm{N}$}

Nesta seção serão mostrados os resultados dos ensaios de fadiga realizados sob controle de deformação realizados nas três classes de dureza definidos para complementar as informações divulgadas na literatura, que são as a Classe A, Classe B e Classe C, com durezas médias de $135 \mathrm{HB}, 160 \mathrm{HB}$ e $250 \mathrm{HB}$, respectivamente.

A média da qualidade das amostras da Classe $\mathrm{C}$ não atenderam ao requisito mínimo recomendado neste trabalho, $(\mathrm{QI} \geq 80)$, porém, visando aumentar a quantidade de informações sobre o comportamento em fadiga sob controle de deformação deste material, que também é um dos objetivos principais deste estudo (caracterização do ferro fundido nodular), foi decidido realizar os ensaios desta classe de amostras mesmo ela não atendendo ao requisito mínimo de qualidade proposto.

Visando reduzir o tempo do ensaio em alguns casos de amplitude de deformação de $0,15 \%$ (menor deformação ensaiada) após a estabilização do ciclo de histerese o ensaio 
passou a ser feito sobre controle de tensão (carregamento) a uma frequência maior, neste caso, a indicação da frequência utilizada no ensaio aparecerá indicado nas tabelas como, por exemplo, na Tabela $16,3 \mathrm{~Hz} / 20 \mathrm{~Hz}$, que indica que o ensaio foi realizado a $3 \mathrm{~Hz}$ sob controle de deformação até a estabilização do laço de histerese e depois ele passou a ser controlado pelo controle do carregamento com frequência de $20 \mathrm{~Hz}$.

\subsubsection{Classe $\mathrm{A}-135 \mathrm{HB}$}

A Tabela 16 a seguir contém o resumo dos resultados de todas as amostras da Classe A 
Tabela 16: Resultados Individuais do Ensaio de Fadiga das Amostras da Classe A - 135HB

\begin{tabular}{|c|c|c|c|c|c|c|c|c|c|c|c|c|c|c|c|c|c|}
\hline \multirow[b]{2}{*}{ CDP } & \multirow[b]{2}{*}{$\begin{array}{l}\text { Freq. } \\
(\mathrm{Hz})\end{array}$} & \multirow[b]{2}{*}{$\Delta \varepsilon_{t} / 2$} & \multirow[b]{2}{*}{$\Delta l_{t} / 2$} & \multirow[b]{2}{*}{$\begin{array}{c}d_{0} \\
(\mathrm{~mm})\end{array}$} & \multirow[b]{2}{*}{$\begin{array}{c}A_{0} \\
\left(\mathrm{~mm}^{\wedge} 2\right)\end{array}$} & \multirow[b]{2}{*}{$\begin{array}{c}\text { Tempo } \\
\mathrm{s} \\
\end{array}$} & \multirow[b]{2}{*}{$\begin{array}{l}N_{f} \\
\text { Ciclos }\end{array}$} & \multicolumn{7}{|c|}{ Meia Vida } & \multirow[b]{2}{*}{$\Delta \mathcal{E}_{e} / 2$} & \multirow[b]{2}{*}{$\Delta \varepsilon_{p} / 2$} & \multirow[b]{2}{*}{$\begin{array}{c}2 N_{f} \\
\text { Reversos }\end{array}$} \\
\hline & & & & & & & & $\begin{array}{c}N_{f} / 2 \\
\text { Meia Vida }\end{array}$ & $\begin{array}{l}F_{\max } \\
(\mathrm{kN})\end{array}$ & $\begin{array}{l}\sigma_{\max } \\
(\mathrm{MPa})\end{array}$ & $\begin{array}{l}F_{\min } \\
(\mathrm{kN})\end{array}$ & $\begin{array}{l}\sigma_{\min } \\
(\mathrm{MPa})\end{array}$ & $\begin{array}{l}\Delta \sigma / 2 \\
(\mathrm{MPa})\end{array}$ & $\begin{array}{c}E \\
(\mathrm{MPa})\end{array}$ & & & \\
\hline A1 & 2 & $0,200 \%$ & 0,0160 & 6,49 & 33,08 & 13261 & 26522 & 13261 & 9,97 & 301,4 & $-10,1$ & $-305,9$ & 303,6 & 161286 & $0,1883 \%$ & $0,0117 \%$ & 53044 \\
\hline A2 & 2 & $0,200 \%$ & 0,0160 & 6,43 & 32,47 & 11176 & 22352 & 11176 & 9,15 & 281,9 & $-10,1$ & $-311,6$ & 296,7 & 160543 & $0,1848 \%$ & $0,0152 \%$ & 44704 \\
\hline A3 & 3 & $0,150 \%$ & 0,0120 & 6,45 & 32,67 & 75171 & 225513 & 112756,5 & 7,29 & 223,0 & $-8,7$ & $-266,4$ & 244,7 & 166273 & $0,1472 \%$ & $0,0028 \%$ & 451026 \\
\hline A4 & 2 & $0,200 \%$ & 0,0160 & 6,49 & 33,08 & 16662 & 33324 & 16662 & 9,98 & 301,7 & $-10,7$ & $-322,8$ & 312,3 & 169113 & $0,1847 \%$ & $0,0153 \%$ & 66648 \\
\hline A5 & 1 & $0,400 \%$ & 0,0320 & 6,51 & 33,29 & 1388 & 1388 & 694 & 12,12 & 364,2 & $-12,4$ & $-372,4$ & 368,3 & 159862 & $0,2304 \%$ & $0,1696 \%$ & 2776 \\
\hline A6 & 1 & $0,350 \%$ & 0,0280 & 6,50 & 33,18 & 1508 & 1508 & 754 & 11,14 & 335,6 & $-12,6$ & $-379,3$ & 357,4 & 165952 & $0,2154 \%$ & $0,1346 \%$ & 3016 \\
\hline A7 & 2 & $0,300 \%$ & 0,0240 & 6,47 & 32,88 & 1129 & 2258 & 1129 & 11,65 & 354,4 & $-11,7$ & $-356,7$ & 355,6 & 154152 & $0,2307 \%$ & $0,0693 \%$ & 4516 \\
\hline A8 & 2 & $0,300 \%$ & 0,0240 & 6,48 & 32,98 & 916 & 1832 & 916 & 11,39 & 345,5 & $-11,6$ & $-352,9$ & 349,2 & 167160 & $0,2089 \%$ & $0,0911 \%$ & 3664 \\
\hline A9 & 2 & $0,300 \%$ & 0,0240 & 6,50 & 33,18 & 1893 & 3786 & 1893 & 11,60 & 349,7 & $-12,4$ & $-374,1$ & 361,9 & 159275 & $0,2272 \%$ & $0,0728 \%$ & 7572 \\
\hline A10 & 1 & $0,350 \%$ & 0,0280 & 6,49 & 33,08 & 1838 & 1838 & 919 & 12,39 & 374,4 & $-12,7$ & $-384,5$ & 379,5 & 172709 & $0,2197 \%$ & $0,1303 \%$ & 3676 \\
\hline A11 & 1 & $0,350 \%$ & 0,0280 & 6,51 & 33,29 & 2248 & 2248 & 1124 & 12,48 & 374,8 & $-13,1$ & $-392,4$ & 383,6 & 171288 & $0,2240 \%$ & $0,1260 \%$ & 4496 \\
\hline A12 & 1 & $0,400 \%$ & 0,0320 & 6,39 & 32,07 & 968 & 968 & 484 & 11,57 & 360,8 & $-12,3$ & $-382,2$ & 371,5 & 161265 & $0,2303 \%$ & $0,1697 \%$ & 1936 \\
\hline A13 & 3 & $0,247 \%$ & 0,0198 & 6,45 & 32,67 & 4100 & 12300 & 6150 & 11,37 & 348,1 & $-10,8$ & $-330,9$ & 339,5 & 177246 & $0,1915 \%$ & $0,0555 \%$ & 24600 \\
\hline A14 & 1 & $0,400 \%$ & 0,0320 & 6,47 & 32,88 & 2891 & 2891 & 1445,5 & 11,77 & 357,8 & $-12,2$ & $-369,8$ & 363,8 & 155864 & $0,2334 \%$ & $0,1666 \%$ & 5782 \\
\hline A15 & 3 & $0,250 \%$ & 0,0200 & 6,48 & 32,98 & 2836 & 8508 & 4254 & 11,05 & 335,0 & $-11,2$ & $-340,4$ & 337,7 & 160700 & $0,2101 \%$ & $0,0399 \%$ & 17016 \\
\hline A16 & $3 / 20$ & $0,150 \%$ & 0,0120 & 6,41 & 32,27 & 60562 & 206966 & 103483 & 7,85 & 243,2 & $-8,6$ & $-266,3$ & 254,8 & 173772 & $0,1466 \%$ & $0,0034 \%$ & 413932 \\
\hline A17 & 2 & $0,150 \%$ & 0,0120 & 6,47 & 32,88 & 53686 & 107372 & 53686 & 6,82 & 207,5 & $-9,2$ & $-281,3$ & 244,4 & 164461 & $0,1486 \%$ & $0,0014 \%$ & 214744 \\
\hline A18 & 3 & $0,250 \%$ & 0,0200 & 6,47 & 32,88 & 3100 & 9300 & 4650 & 10,62 & 323,1 & $-11,8$ & $-358,4$ & 340,7 & 154512 & $0,2205 \%$ & $0,0295 \%$ & 18600 \\
\hline A19 & 3 & $0,250 \%$ & 0,0200 & 6,46 & 32,78 & 2835 & 8505 & 4252,5 & 11,60 & 353,8 & $-12,2$ & $-372,0$ & 362,9 & 170253 & $0,2132 \%$ & $0,0368 \%$ & 17010 \\
\hline
\end{tabular}

\begin{tabular}{|c|c|c|c|c|c|c|c|c|c|c|c|c|c|c|c|c|c|c|}
\hline A16_1 & 3 & $0,150 \%$ & 0,0120 & 6,41 & 32,27 & 60562 & 181686 & 90843 & \multirow{2}{*}{7,85} & \multirow{2}{*}{243,2} & \multirow{2}{*}{$-8,6$} & \multirow{2}{*}{$-266,3$} & \multirow{2}{*}{254,8} & \multirow{2}{*}{173772} & \multirow{2}{*}{$0,1466 \%$} & \multirow{2}{*}{\multicolumn{2}{|c|}{$0,0034 \%$}} & 363372 \\
\hline A16_2 & 20 & $0,150 \%$ & 0,0120 & 6,41 & 32,27 & 1264 & 25280 & 12640 & & & & & & & & & & 50560 \\
\hline
\end{tabular}


Com base nos resultados individuais das amostras da classe A fez-se a determinação dos parâmetros de fadiga a partir das curvas bi-log de amplitude de deformação elásticas e plásticas vs. numero de reversos e a partir da curva amplitude de tensão vs. amplitude de deformação plástica, como segue:

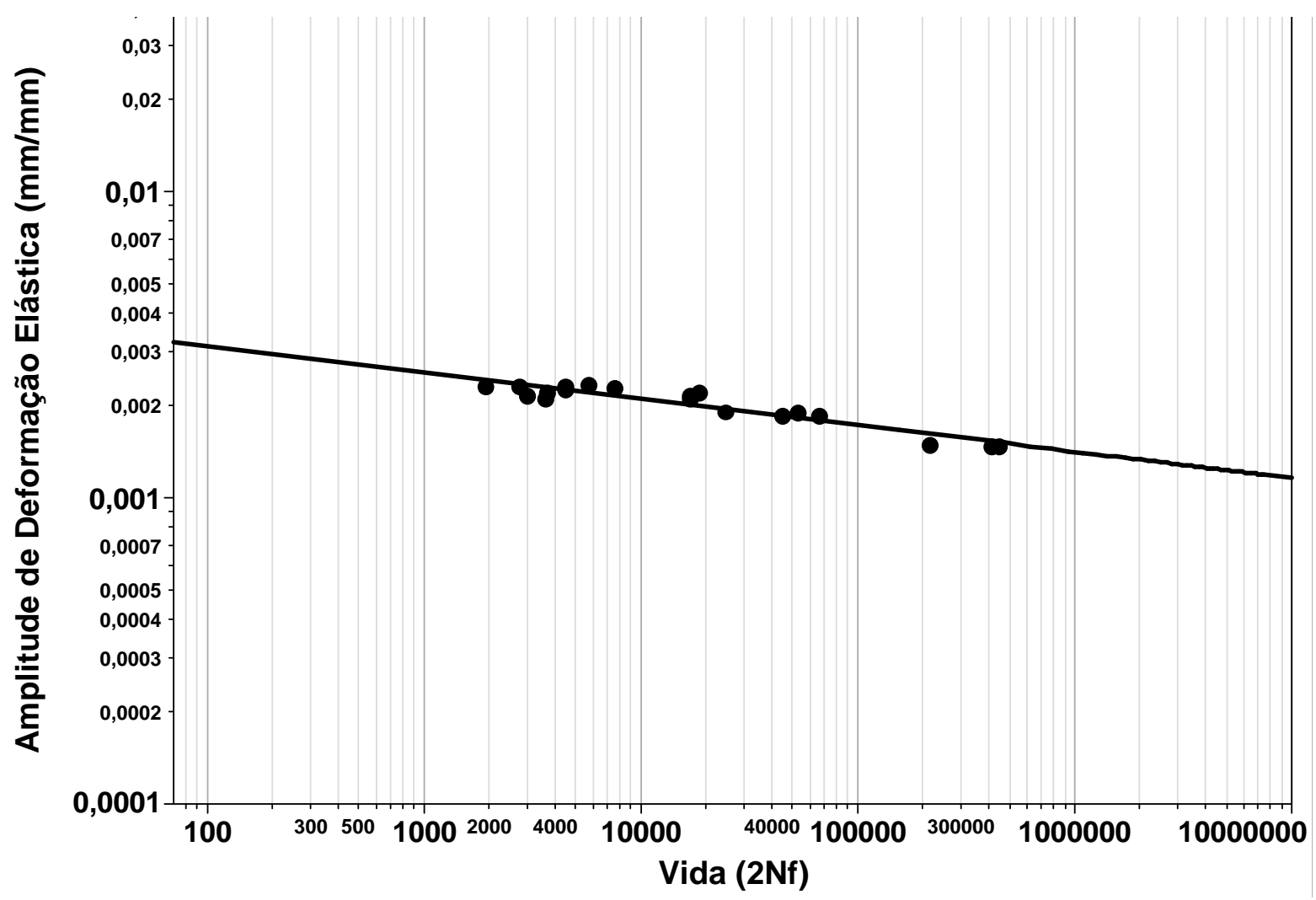

Figura 44: Curva deformação elástica vs. vida - classe A

A partir da curva de amplitude de deformação elástica versus a vida (2Nf), cuja função de interpolação logarítmica é dado por:

$$
\log \left(\frac{\Delta \varepsilon^{e}}{2}\right)=-2,3348-0,086 \log \left(2 N_{f}\right)
$$

e a partir da comparação com a equação I.34 e usando a média do módulo de elasticidade dos laços de histerese de meia vida das amostras desta classe ensaiada

$$
E=164511 \mathrm{MPa}
$$


tem-se que o coeficiente de resistência a fadiga e o expoente de resistência a fadiga, serão, respectivamente:

$$
\begin{aligned}
& \sigma_{f}^{\prime}=761 \mathrm{MPa} \\
& b=-0,09
\end{aligned}
$$

A figura 45 mostra a relação entre a amplitude de deformação plástica e a vida (2Nf), a partir da qual é possível determinar o coeficiente de ductilidade e o expoente de ductilidade como segue.

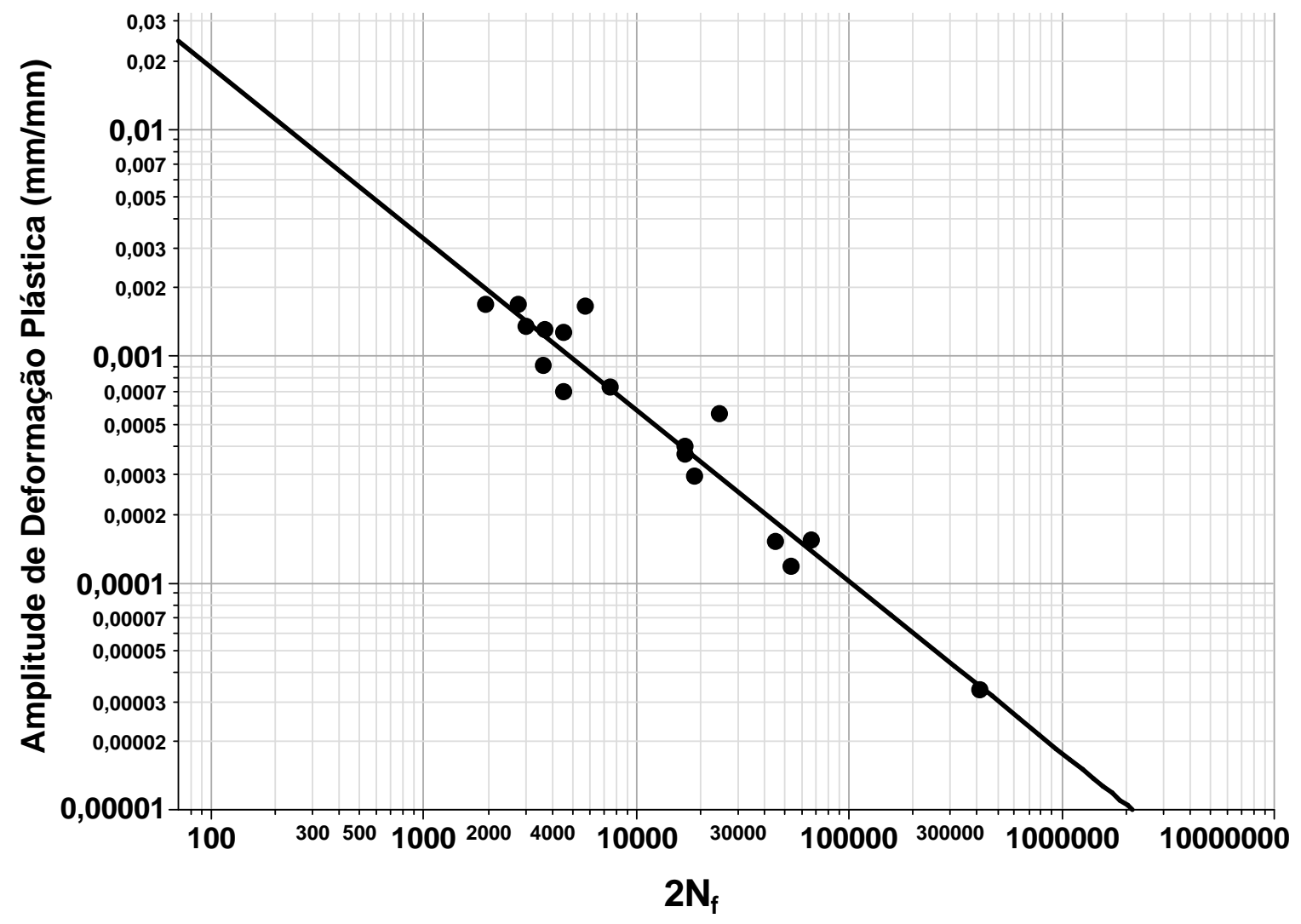

Figura 45: Curva deformação plástica vs. vida - classe A 
Sendo a função de interpolação:

$$
\log \left(\frac{\Delta \varepsilon^{p}}{2}\right)=-0,214670-0,75617 \log \left(2 N_{f}\right)
$$

Portanto, comparando com a equação I.34 tem-se que:

$$
\begin{aligned}
& \varepsilon_{f}^{\prime}=0,61 \\
& c=-0,76
\end{aligned}
$$

Agora, substituindo o módulo de elasticidade (III.3), e os parâmetros de fadiga de baixo ciclo determinados em III.4, III.5, III.7 e III.8 na equação de deformação-vida apresentado na equação I.34, tem-se para esta faixa de dureza que:

$$
\frac{\Delta \varepsilon_{t}}{2}=0,00462 \cdot\left(2 N_{f}\right)^{-0,09}+0,61 \cdot\left(2 N_{f}\right)^{-0,76}
$$

Da mesma forma a partir da função de interpolação logarítmica da amplitude de tensão pela amplitude de deformação plástica, figura 46, é possível determinar o coeficiente de resistência cíclico e o expoente de encruamento 


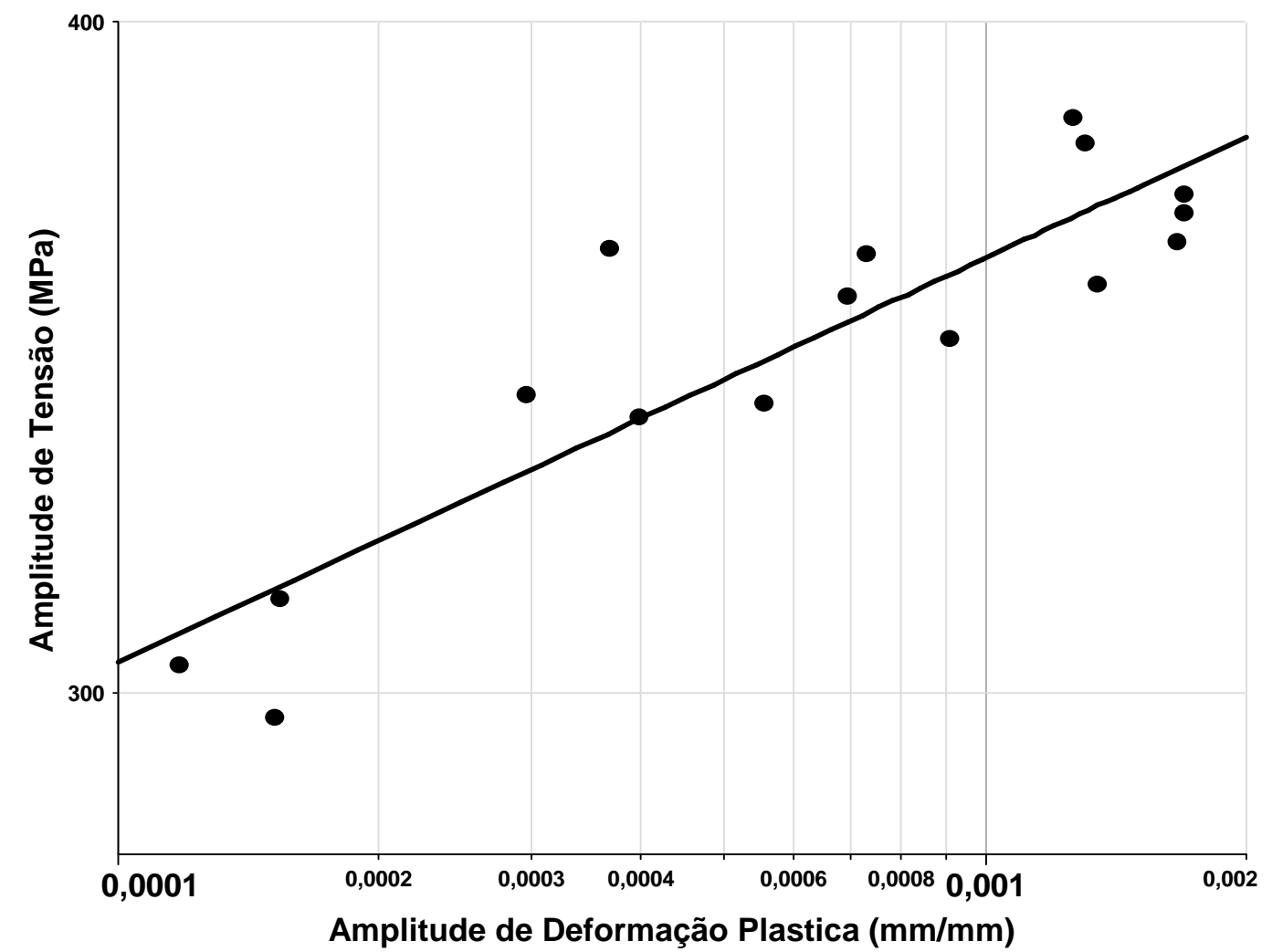

Figura 46: Curva amplitude de tensão vs. amplitude deformação plástica - classe A

Sendo, portanto, a função de interpolação dada por:

$\log \left(\frac{\Delta \sigma}{2}\right)=2,783311-0,07508 \log \left(\frac{\Delta \varepsilon^{p}}{2}\right)$

comparando com as equação I.8 tem-se que:

$K^{\prime}=607 M P a$

$n^{\prime}=0,08$

Finalmente é possível traçar a curva de fadiga da faixa de dureza de $135 \mathrm{HB}$ substituindo os valores das propriedades cíclicas na equação de Morrow (1965), equação I.34, cujo gráfico resultante é dado na figura 47: 


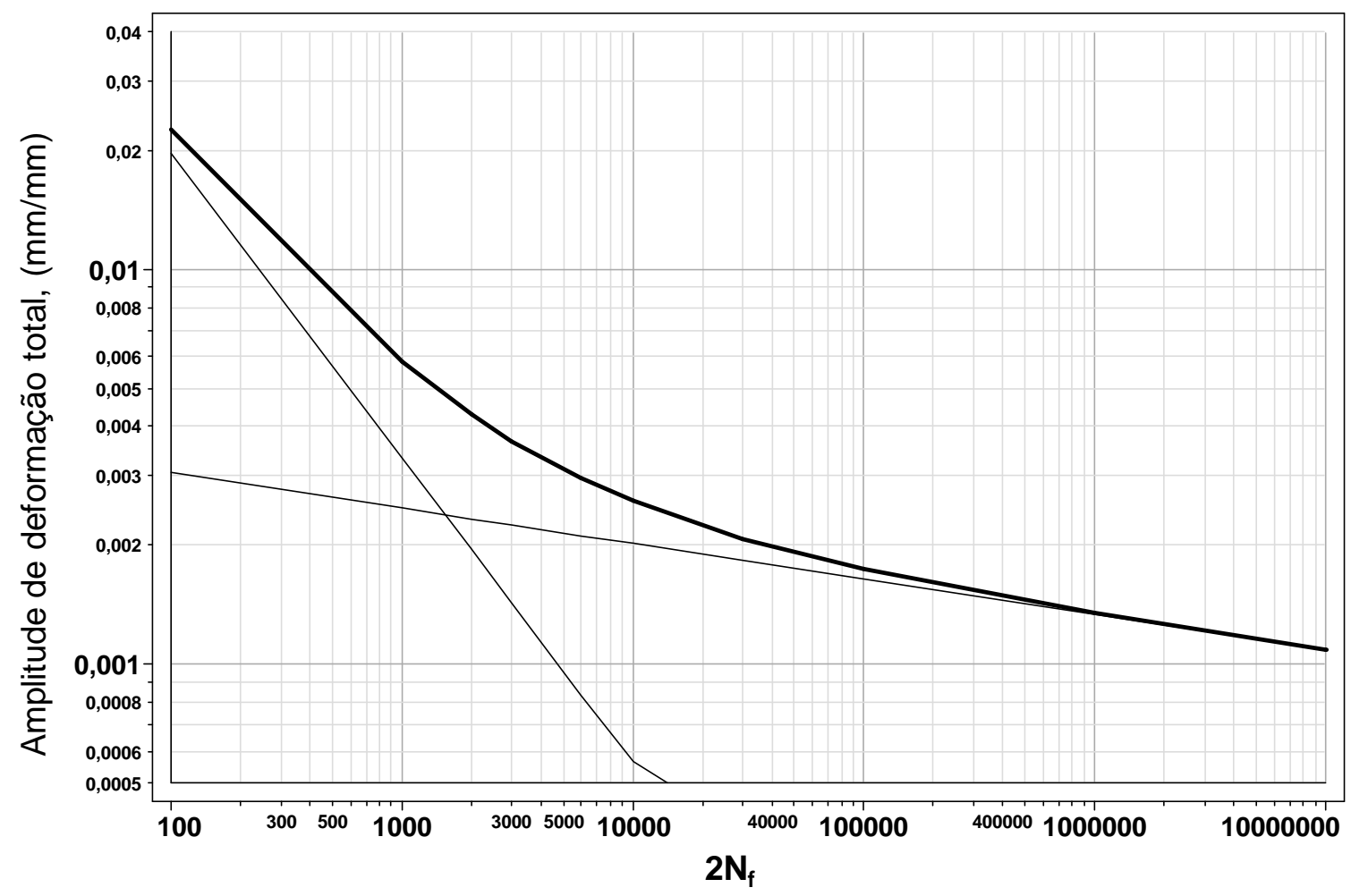

--. Curva Elástica $135 \mathrm{HE} \quad$ - Curva Plástica $135 \mathrm{HE}$ - Curva Total $135 \mathrm{HB}$

Figura 47: Curva de fadiga da Classe A - 130HB

Seguindo esta metodologia fez-se também a determinação dos parâmetros de fadiga para as demais classes (classe B e classe C) conforme mostrado nos próximos itens.

\subsubsection{Classe B - $160 \mathrm{HB}$}

O resumo dos resultados do ensaio nas amostras da Classe B estão listados na Tabela 17 a seguir: 
Tabela 17: Resultados individuais das amostras da classe B - 160 HB

\begin{tabular}{|c|c|c|c|c|c|c|c|c|c|c|c|c|c|c|c|c|c|}
\hline \multirow[b]{2}{*}{ CDP } & \multirow[b]{2}{*}{$\begin{array}{l}\text { Freq. } \\
(\mathrm{Hz})\end{array}$} & \multirow[b]{2}{*}{$\Delta \varepsilon_{t} / 2$} & \multirow[b]{2}{*}{$\Delta l_{t} / 2$} & \multirow[b]{2}{*}{$\begin{array}{c}d_{0} \\
(\mathrm{~mm})\end{array}$} & \multirow[b]{2}{*}{$\begin{array}{c}A_{0} \\
\left(\mathrm{~mm}^{\wedge} 2\right)\end{array}$} & \multirow[b]{2}{*}{$\begin{array}{c}\text { Tempo } \\
\mathrm{s} \\
\end{array}$} & \multirow[b]{2}{*}{$\begin{array}{l}N_{f} \\
\text { Ciclos } \\
\end{array}$} & \multicolumn{7}{|c|}{ Meia Vida } & \multirow[b]{2}{*}{$\Delta \varepsilon_{e} / 2$} & \multirow[b]{2}{*}{$\Delta \varepsilon_{p} / 2$} & \multirow[b]{2}{*}{$\begin{array}{c}2 N_{f} \\
\text { Reversos }\end{array}$} \\
\hline & & & & & & & & $\begin{array}{c}N_{f} / 2 \\
\text { Meia Vida }\end{array}$ & $\begin{array}{l}F_{\max } \\
(\mathrm{kN}) \\
\end{array}$ & $\begin{array}{l}\sigma_{\max } \\
(\mathrm{MPa}) \\
\end{array}$ & $\begin{array}{l}F_{\min } \\
(\mathrm{kN})\end{array}$ & $\begin{array}{l}\sigma_{\min } \\
(\mathrm{MPa})\end{array}$ & $\begin{array}{l}\Delta \sigma / 2 \\
(\mathrm{MPa}) \\
\end{array}$ & $\begin{array}{c}E \\
(\mathrm{MPa})\end{array}$ & & & \\
\hline B13 & $1 / 20$ & $0,150 \%$ & 0,0120 & 6,53 & 33,49 & 116379 & 555203 & 277602 & 7,1877 & 214,6 & $-9,5$ & -284 & 249,3 & 174797 & $0,1426 \%$ & $0,0074 \%$ & 1110406 \\
\hline B16 & $1 / 20$ & $0,150 \%$ & 0,0120 & 6,50 & 33,18 & 72246 & 124211 & 62106 & 8,4360 & 254,2 & $-7,6$ & -230 & 242,2 & 165841 & $0,1460 \%$ & $0,0040 \%$ & 248422 \\
\hline BO & 1 & $0,200 \%$ & 0,0160 & 6,50 & 33,18 & 9484 & 9484 & 4742 & 10,3029 & 310,5 & $-10,3$ & -309 & 309,8 & 176622 & $0,1754 \%$ & $0,0246 \%$ & 18968 \\
\hline B4 & 1 & $0,200 \%$ & 0,0160 & 6,49 & 33,08 & 22012 & 22012 & 11006 & 10,2684 & 310,4 & $-10,3$ & -313 & 311,5 & 165144 & $0,1886 \%$ & $0,0114 \%$ & 44024 \\
\hline B8 & 1 & $0,200 \%$ & 0,0160 & 6,45 & 32,67 & 28970 & 28970 & 14485 & 10,1990 & 312,1 & $-10,4$ & -319 & 315,8 & 169627 & $0,1862 \%$ & $0,0138 \%$ & 57940 \\
\hline B12 & 1 & $0,250 \%$ & 0,0200 & 6,49 & 33,08 & 7571 & 7571 & 3786 & 11,1384 & 336,7 & $-11,6$ & -349 & 343,0 & 175025 & $0,1960 \%$ & $0,0540 \%$ & 15142 \\
\hline B3 & 1 & $0,250 \%$ & 0,0200 & 6,45 & 32,67 & 11183 & 11183 & 5592 & 11,0819 & 339,2 & $-11,5$ & -352 & 345,4 & 162158 & $0,2130 \%$ & $0,0370 \%$ & 22366 \\
\hline B2 & 1 & $0,250 \%$ & 0,0200 & 6,54 & 33,59 & 3599 & 3599 & 1800 & 10,3626 & 308,5 & $-12,0$ & -356 & 332,2 & 170741 & $0,1946 \%$ & $0,0554 \%$ & 7198 \\
\hline B1 & 1 & $0,300 \%$ & 0,0240 & 6,45 & 32,67 & 1805 & 1805 & 903 & 11,6115 & 355,4 & $-12,2$ & -372 & 363,7 & 170548 & $0,2133 \%$ & $0,0867 \%$ & 3610 \\
\hline B6 & 1 & $0,300 \%$ & 0,0240 & 6,50 & 33,18 & 3054 & 3054 & 1527 & 12,8109 & 386,1 & $-12,8$ & -385 & 385,7 & 185632 & $0,2078 \%$ & $0,0922 \%$ & 6108 \\
\hline B17 & 1 & $0,300 \%$ & 0,0240 & 6,47 & 32,88 & 4467 & 4467 & 2234 & 12,4745 & 379,4 & $-12,1$ & -368 & 373,5 & 169467 & $0,2204 \%$ & $0,0796 \%$ & 8934 \\
\hline B18 & 1 & $0,350 \%$ & 0,0280 & 6,48 & 32,98 & 5170 & 5170 & 2585 & 12,1180 & 367,4 & $-12,5$ & -379 & 373,3 & 165972 & $0,2249 \%$ & $0,1251 \%$ & 10340 \\
\hline $\mathrm{B} 10$ & 0,5 & $0,350 \%$ & 0,0280 & 6,42 & 32,37 & 4925 & 2463 & 1231 & 12,1900 & 376,6 & $-12,4$ & -383 & 379,8 & 158409 & $0,2398 \%$ & $0,1102 \%$ & 4925 \\
\hline B14 & 0,5 & $0,350 \%$ & 0,0280 & 6,48 & 32,98 & 5200 & 2600 & 1300 & 12,2852 & 372,5 & $-12,6$ & -381 & 376,6 & 156297 & $0,2410 \%$ & $0,1090 \%$ & 5200 \\
\hline B9 & 1 & $0,400 \%$ & 0,0320 & 6,48 & 32,98 & 886 & 886 & 443 & 12,1087 & 367,2 & $-12,9$ & -390 & 378,7 & 156828 & $0,2415 \%$ & $0,1585 \%$ & 1772 \\
\hline
\end{tabular}

\begin{tabular}{|c|c|c|c|c|c|c|c|c|c|c|c|c|c|c|c|c|c|}
\hline B13_1 & 1 & \multirow{2}{*}{$0,150 \%$} & \multirow{2}{*}{0,0120} & \multirow{2}{*}{6,53} & \multirow{2}{*}{33,49} & 93283 & 93283 & 46641,5 & \multirow{2}{*}{7,1877} & \multirow{2}{*}{214,6} & \multirow{2}{*}{$-9,5$} & \multirow{2}{*}{-284} & \multirow{2}{*}{249,3} & \multirow{2}{*}{174797} & \multirow{2}{*}{$0,1426 \%$} & \multirow{2}{*}{$0,0074 \%$} & \multirow{2}{*}{$\begin{array}{l}186566 \\
923840\end{array}$} \\
\hline B13_2 & 20 & & & & & 23096 & 461920 & 230960 & & & & & & & & & \\
\hline B16_1 & 1 & & & & & 69511 & 69511 & 34755,5 & & & & & & & & & 139022 \\
\hline B16_2 & 20 & 0,150\% & 0,0120 & 6,50 & 33,18 & 2735 & 54700 & 27350 & 8,4360 & 254,2 & $-7,6$ & -230 & 242,2 & 165841 & $0,1460 \%$ & $0,0040 \%$ & 109400 \\
\hline
\end{tabular}


Na figura 48 tem-se a relação entre amplitude de deformação elástica e o número de reversos $(2 \mathrm{Nf})$ :

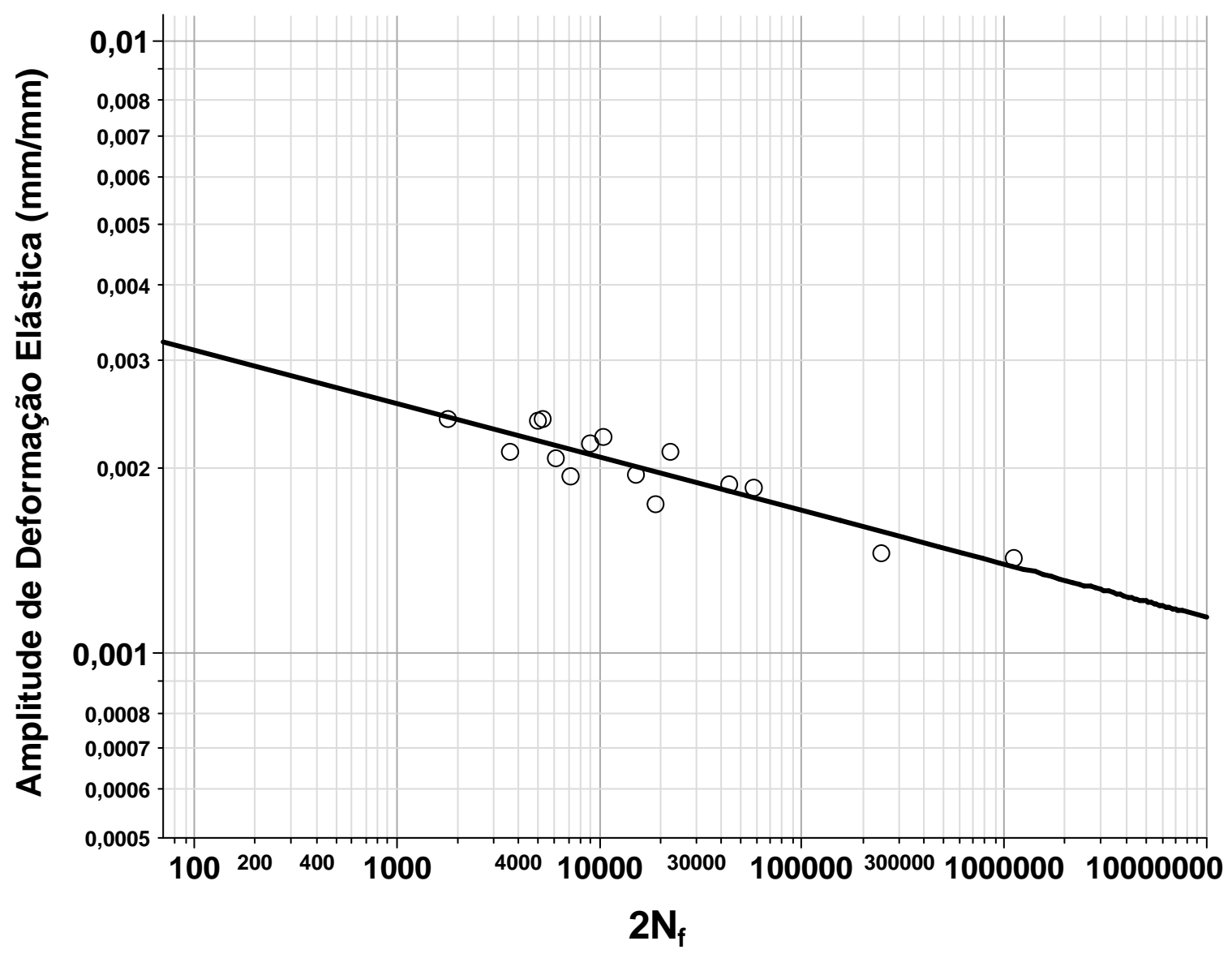

Figura 48: Curva deformação elástica vs. vida - classe B

Cuja função de interpolação é:

$\log \left(\frac{\Delta \varepsilon^{e}}{2}\right)=-2,329863-0,087 \log \left(2 N_{f}\right)$

E considerando o módulo de elasticidade médio dos ciclos estabilizados de meia vida desta classe de amostra igual a

$$
E=168204 M P a
$$

Portanto, comparando com a equação I.34 tem-se que: 
$\sigma_{f}^{\prime}=787 \mathrm{MPa}$

$b=-0,09$

Agora a partir da função de interpolação logarítmica da amplitude de deformação plástica pela vida (2Nf), figura 49 , tem-se:

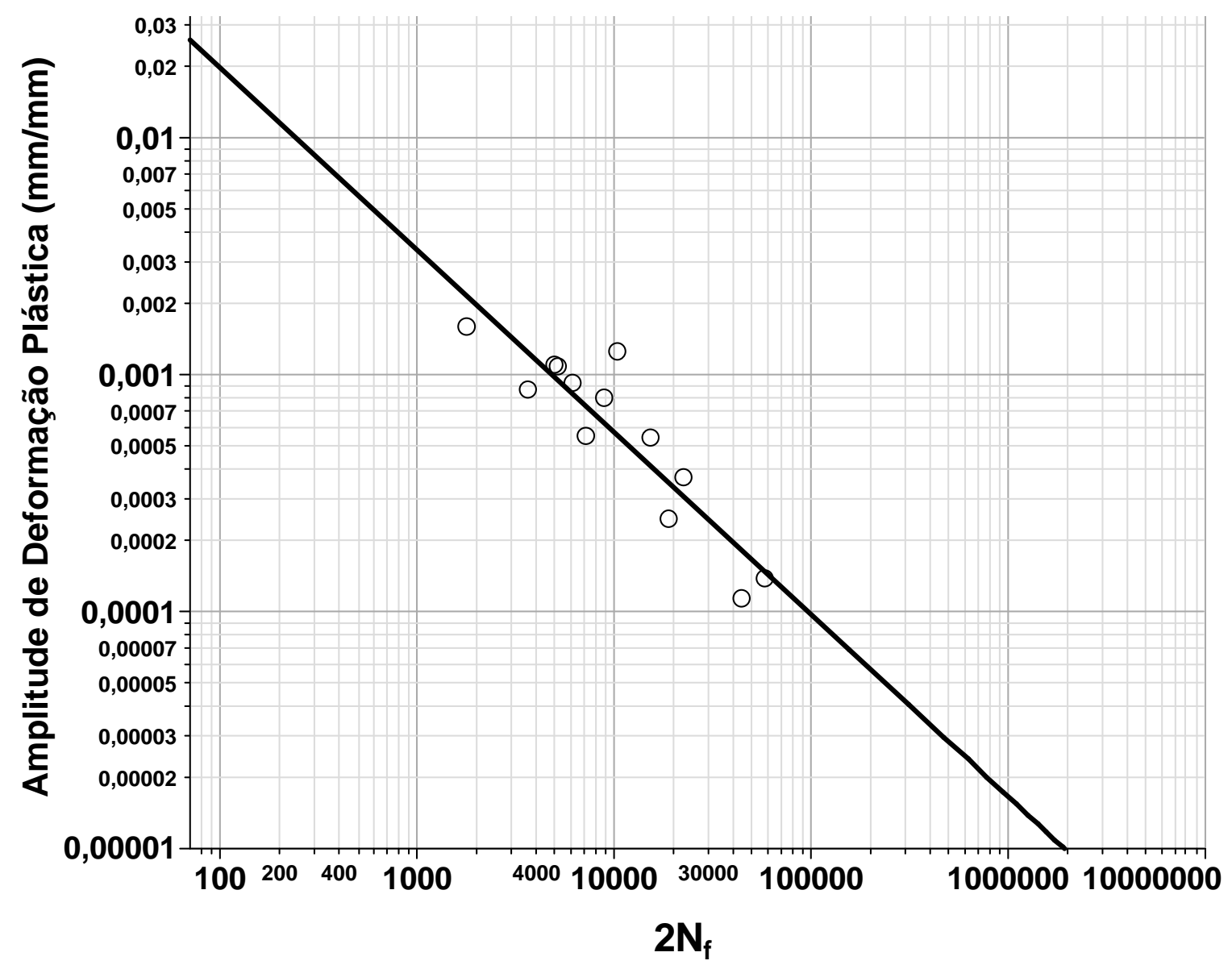

Figura 49: Curva deformação plástica vs. vida - classe B

$\log \left(\frac{\Delta \varepsilon^{p}}{2}\right)=-0,167491-0,769577 \log \left(2 N_{f}\right)$

Portanto, comparando com as equação I.34, tem-se que:

$\varepsilon_{f}^{\prime}=0,68$ 
Da mesma forma como feito na seção anterior para as amostras classe A, de dureza média igual a $135 \mathrm{HB}$, é possível determinar a equação deformação-vida para estas amostras da classe B, como segue na equação III.20:

$\frac{\Delta \mathcal{E}_{t}}{2}=0,00468 \cdot\left(2 N_{f}\right)^{-0,09}+0,68 \cdot\left(2 N_{f}\right)^{-0,77}$

A partir da função de interpolação logarítmica da amplitude de tensão pela amplitude de deformação plástica, figura 50, tem-se:

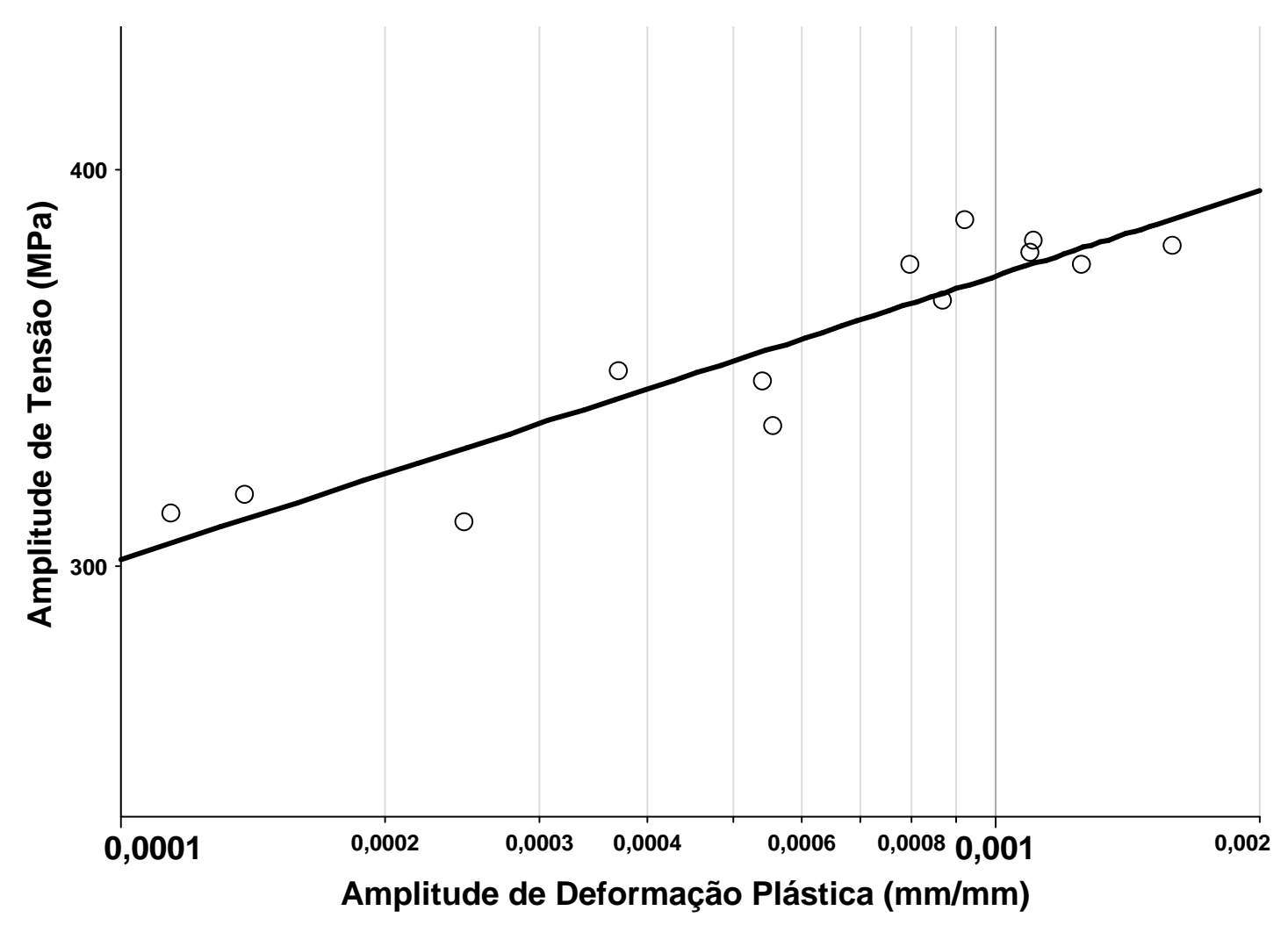

Figura 50: Curva amplitude de tensão vs. amplitude deformação plástica - classe A

$$
\log \left(\frac{\Delta \sigma}{2}\right)=2,8361-0,089244 \log \left(\frac{\Delta \varepsilon^{p}}{2}\right)
$$

comparando com a equação I.8 tem-se que: 
$K^{\prime}=686 \mathrm{MPa}$

$n^{\prime}=0,09$

Finalmente é possível traçar a curva de fadiga da faixa de dureza de $160 \mathrm{HB}$ a partir da equação deformação-vida determinada em III., cujo gráfico resultante é dado na figura 51:

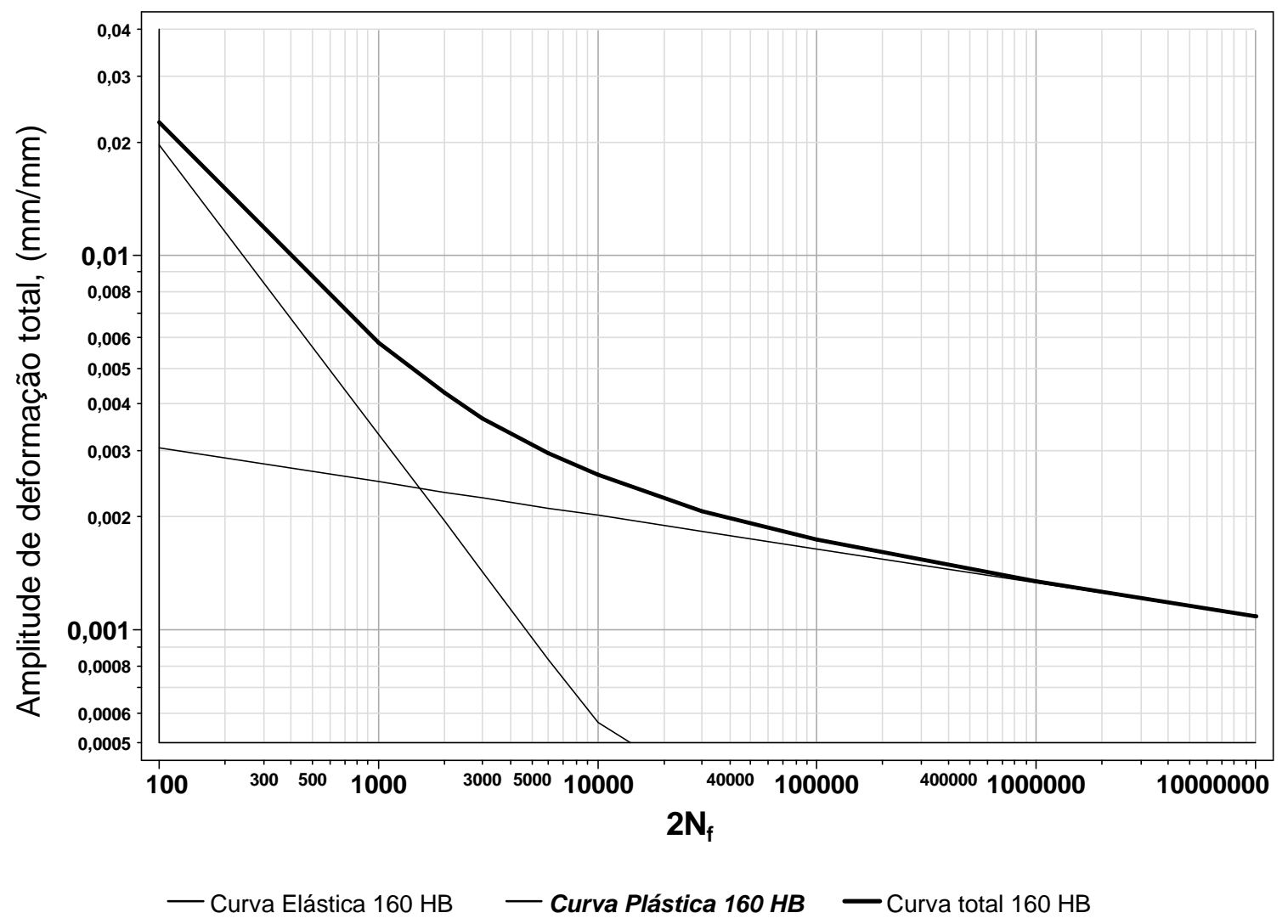

Figura 51: Curva de fadiga da Classe B - 160HB

\subsubsection{Classe C - 250 HB}

O resumo dos resultados do ensaio nas amostras da Classe $\mathrm{C}$ está listado na Tabela 18: 
Tabela 18: Resultados Individuais das Amostras da Classe C - 250 HB

\begin{tabular}{|c|c|c|c|c|c|c|c|c|c|c|c|c|c|c|c|c|c|}
\hline \multirow[b]{2}{*}{ CDP } & \multirow[b]{2}{*}{$\begin{array}{l}\text { Freq. } \\
(\mathrm{Hz})\end{array}$} & \multirow[b]{2}{*}{$\Delta \varepsilon_{t} / 2$} & \multirow[b]{2}{*}{$\Delta l_{t} / 2$} & \multirow[b]{2}{*}{$\begin{array}{c}d_{0} \\
(\mathrm{~mm})\end{array}$} & \multirow[b]{2}{*}{$\begin{array}{c}A_{0} \\
\left(\mathrm{~mm}^{\wedge} 2\right)\end{array}$} & \multirow[b]{2}{*}{$\begin{array}{c}\text { Tempo } \\
\mathrm{s}\end{array}$} & \multirow[b]{2}{*}{$\begin{array}{l}N_{f} \\
\text { Ciclos }\end{array}$} & \multicolumn{7}{|c|}{ Meia Vida } & \multirow[b]{2}{*}{$\Delta \mathcal{E}_{e} / 2$} & \multirow[b]{2}{*}{$\Delta \mathcal{E}_{p} / 2$} & \multirow[b]{2}{*}{$\begin{array}{c}2 N_{f} \\
\text { Reversos }\end{array}$} \\
\hline & & & & & & & & $\begin{array}{c}N_{f} / 2 \\
\text { Meia Vida }\end{array}$ & $\begin{array}{l}F_{\max } \\
(\mathrm{kN})\end{array}$ & $\begin{array}{l}\sigma_{\max } \\
(\mathrm{MPa})\end{array}$ & $\begin{array}{l}F_{\min } \\
(\mathrm{kN})\end{array}$ & $\begin{array}{l}\sigma_{\min } \\
(\mathrm{MPa})\end{array}$ & $\begin{array}{r}\Delta \sigma / 2 \\
(\mathrm{MPa})\end{array}$ & $\begin{array}{c}E \\
(\mathrm{MPa})\end{array}$ & & & \\
\hline $\mathrm{C1}$ & 2 & $0,200 \%$ & 0,0160 & 6,50 & 33,18 & 33309 & 66618 & 33309 & 11,06 & 333,3 & $-10,86$ & $-327,4$ & 330,3 & 179721 & $0,1838 \%$ & $0,0162 \%$ & 133236 \\
\hline $\mathrm{C} 2$ & 2 & $0,200 \%$ & 0,0160 & 6,48 & 32,98 & 46592 & 93184 & 46592 & 9,45 & 286,5 & $-11,04$ & $-334,9$ & 310,7 & 156064 & $0,1991 \%$ & $0,0009 \%$ & 186368 \\
\hline C3 & 2 & $0,200 \%$ & 0,0160 & 6,51 & 33,29 & 36788 & 73576 & 36788 & 9,33 & 280,4 & $-11,77$ & $-353,7$ & 317,0 & 173691 & $0,1825 \%$ & $0,0175 \%$ & 147152 \\
\hline $\mathrm{C4}$ & $2 / 20$ & $0,150 \%$ & 0,0120 & 6,55 & 33,70 & 83412 & 735444 & 367722 & 7,32 & 217,2 & $-10,03$ & $-297,8$ & 257,5 & 172838 & $0,1490 \%$ & $0,0010 \%$ & \begin{tabular}{|l|l}
1470888 \\
\end{tabular} \\
\hline C5 & 2 & $0,300 \%$ & 0,0240 & 6,40 & 32,17 & 5583 & 11166 & 5583 & 12,68 & 394,0 & $-12,57$ & $-390,8$ & 392,4 & 161742 & $0,2426 \%$ & $0,0574 \%$ & 22332 \\
\hline $\mathrm{C6}$ & 2 & $0,300 \%$ & 0,0240 & 6,51 & 33,29 & 3555 & 7110 & 3555 & 13,23 & 397,5 & $-14,08$ & $-422,9$ & 410,2 & 170448 & $0,2407 \%$ & $0,0593 \%$ & 14220 \\
\hline $\mathrm{C7}$ & 2 & $0,300 \%$ & 0,0240 & 6,46 & 32,78 & 3803 & 7606 & 3803 & 12,72 & 388,1 & $-13,54$ & $-413,2$ & 400,6 & 174742 & $0,2293 \%$ & $0,0707 \%$ & 15212 \\
\hline $\mathrm{C} 8$ & 1 & $0,350 \%$ & 0,0280 & 6,49 & 33,08 & 3753 & 3753 & 1876,5 & 13,54 & 409,2 & $-15,29$ & $-462,2$ & 435,7 & 172428 & $0,2527 \%$ & $0,0973 \%$ & 7506 \\
\hline C9 & 1 & $0,350 \%$ & 0,0280 & 6,50 & 33,18 & 3956 & 3956 & 1978 & 13,86 & 417,8 & $-14,39$ & $-433,7$ & 425,7 & 171827 & $0,2478 \%$ & $0,1022 \%$ & 7912 \\
\hline C10 & 1 & $0,350 \%$ & 0,0280 & 6,48 & 32,98 & 4609 & 4609 & 2304,5 & 13,54 & 410,7 & $-13,72$ & $-416,0$ & 413,3 & 174460 & $0,2369 \%$ & $0,1131 \%$ & 9218 \\
\hline C11 & 1 & $0,400 \%$ & 0,0320 & 6,51 & 33,29 & 2703 & 2703 & 1351,5 & 14,89 & 447,3 & $-15,10$ & $-453,7$ & 450,5 & 167944 & $0,2682 \%$ & $0,1318 \%$ & 5406 \\
\hline $\mathrm{C} 12$ & 1 & $0,400 \%$ & 0,0320 & 6,46 & 32,78 & 3600 & 3600 & 1800 & 11,70 & 357,0 & $-15,43$ & $-470,7$ & 413,8 & 165457 & $0,2501 \%$ & $0,1499 \%$ & 7200 \\
\hline C15 & 1 & $0,450 \%$ & 0,0360 & 6,50 & 33,18 & 1195 & 1195 & 597,5 & 13,99 & 421,6 & $-15,67$ & $-472,2$ & 446,9 & 147048 & $0,3039 \%$ & $0,1461 \%$ & 2390 \\
\hline C16 & 1 & $0,450 \%$ & 0,0360 & 6,46 & 32,78 & 770 & 770 & 385 & 14,36 & 438,2 & $-15,22$ & $-464,2$ & 451,2 & 161118 & $0,2801 \%$ & $0,1699 \%$ & 1540 \\
\hline C17 & 1 & $0,450 \%$ & 0,0360 & 6,53 & 33,49 & 1380 & 1380 & 690 & 14,78 & 441,4 & $-16,44$ & $-490,8$ & 466,1 & 161932 & $0,2878 \%$ & $0,1622 \%$ & 2760 \\
\hline
\end{tabular}

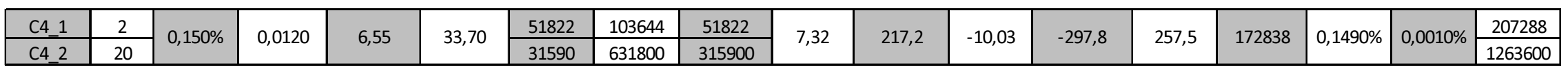


Na figura 52 tem-se a relação entre amplitude de deformação elástica e o número de reversos $(2 \mathrm{Nf})$ :

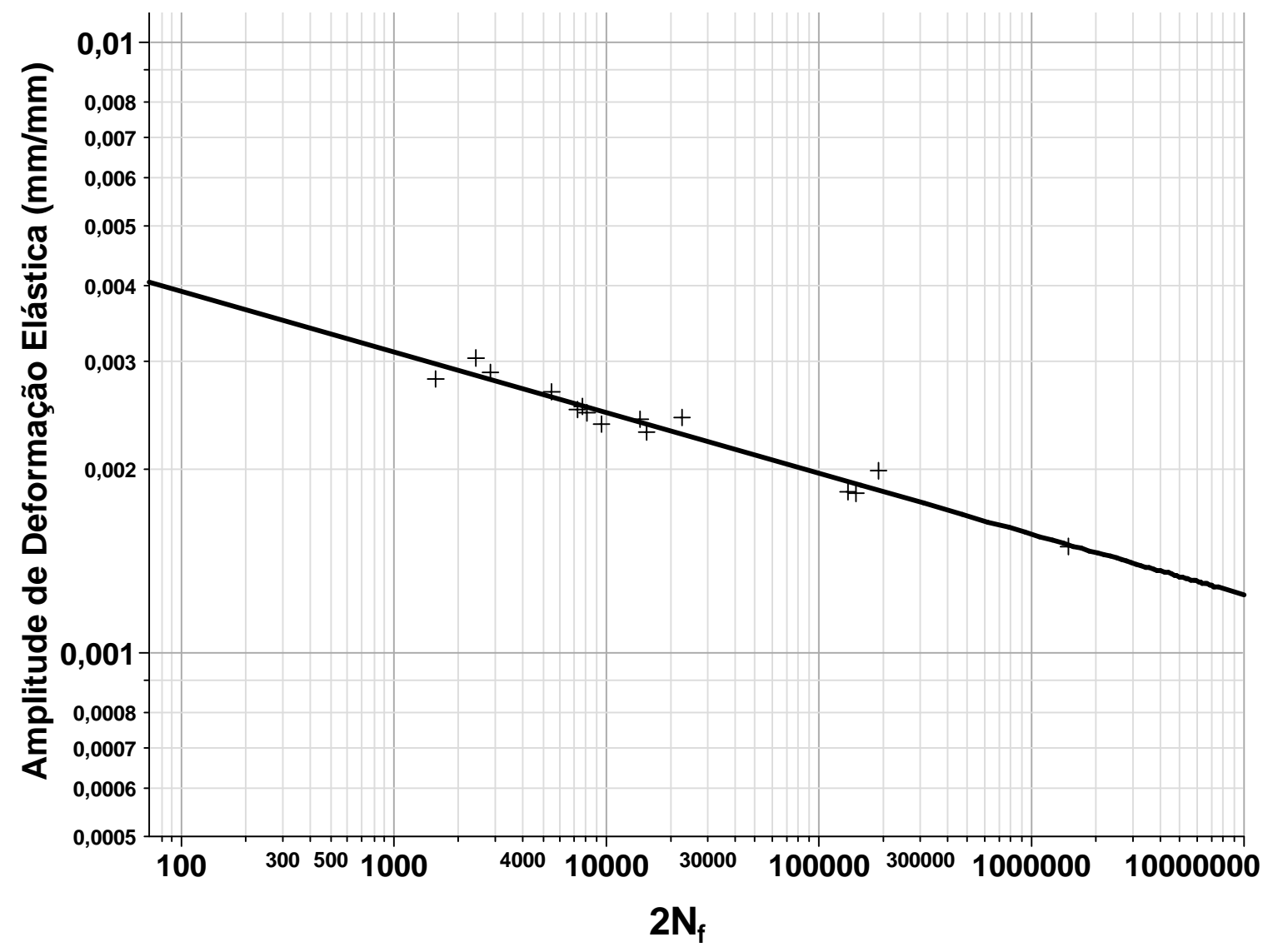

Figura 52: Curva deformação elástica vs. vida - classe B

Cuja função de interpolação é:

$\log \left(\frac{\Delta \varepsilon^{e}}{2}\right)=-2,211579-0,09906 \log \left(2 N_{f}\right)$

E considerando o módulo de elasticidade médio dos ciclos estabilizados de meia vida desta classe de amostra igual a

$$
E=170096 \mathrm{MPa}
$$

Portanto, comparando com as equação I.34 tem-se que:

$$
\sigma_{f}^{\prime}=1045 \mathrm{MPa}
$$


$b=-0,10$

Agora a partir da função de interpolação logarítmica da amplitude de deformação plástica pela vida (2Nf), figura 53, tem-se:

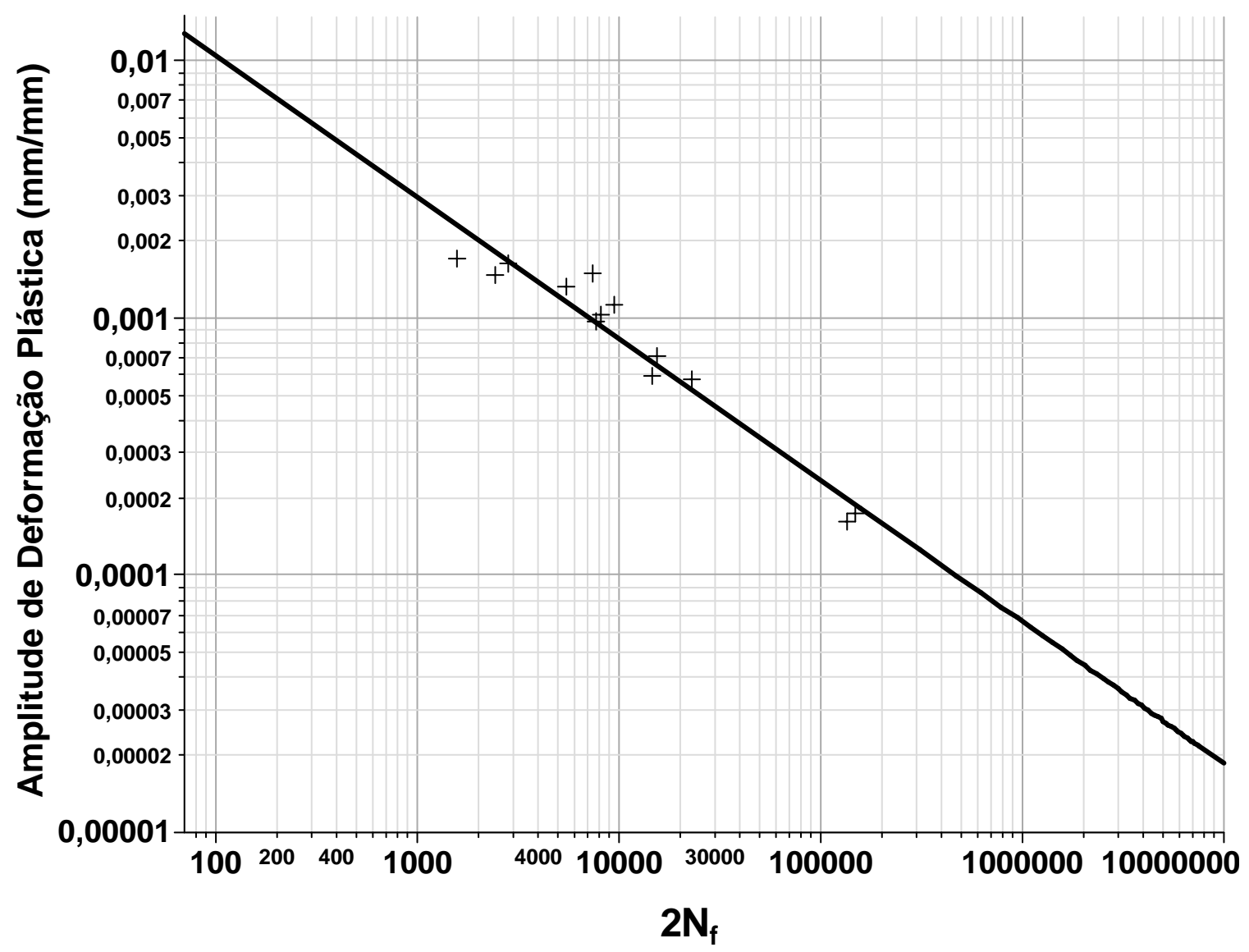

Figura 53: Curva deformação plástica vs. vida - classe C

$\log \left(\frac{\Delta \varepsilon^{p}}{2}\right)=-0,88605-0,55086 \log \left(2 N_{f}\right)$

Portanto, comparando com as equações I.34 tem-se que:

$$
\begin{aligned}
& \varepsilon_{f}^{\prime}=0,13 \\
& c=-0,55
\end{aligned}
$$


A equação III. que representa a relação deformação-vida foi determinada assim como para as demais classes a partir do módulo de elasticidade e dos parâmetros de fadiga de baixo ciclo:

$$
\frac{\Delta \mathcal{E}_{t}}{2}=0,00614 .\left(2 N_{f}\right)^{-0,10}+0,13 \cdot\left(2 N_{f}\right)^{-0,55}
$$

A partir da função de interpolação logarítmica da amplitude de tensão pela amplitude de deformação plástica, figura 54, tem-se:

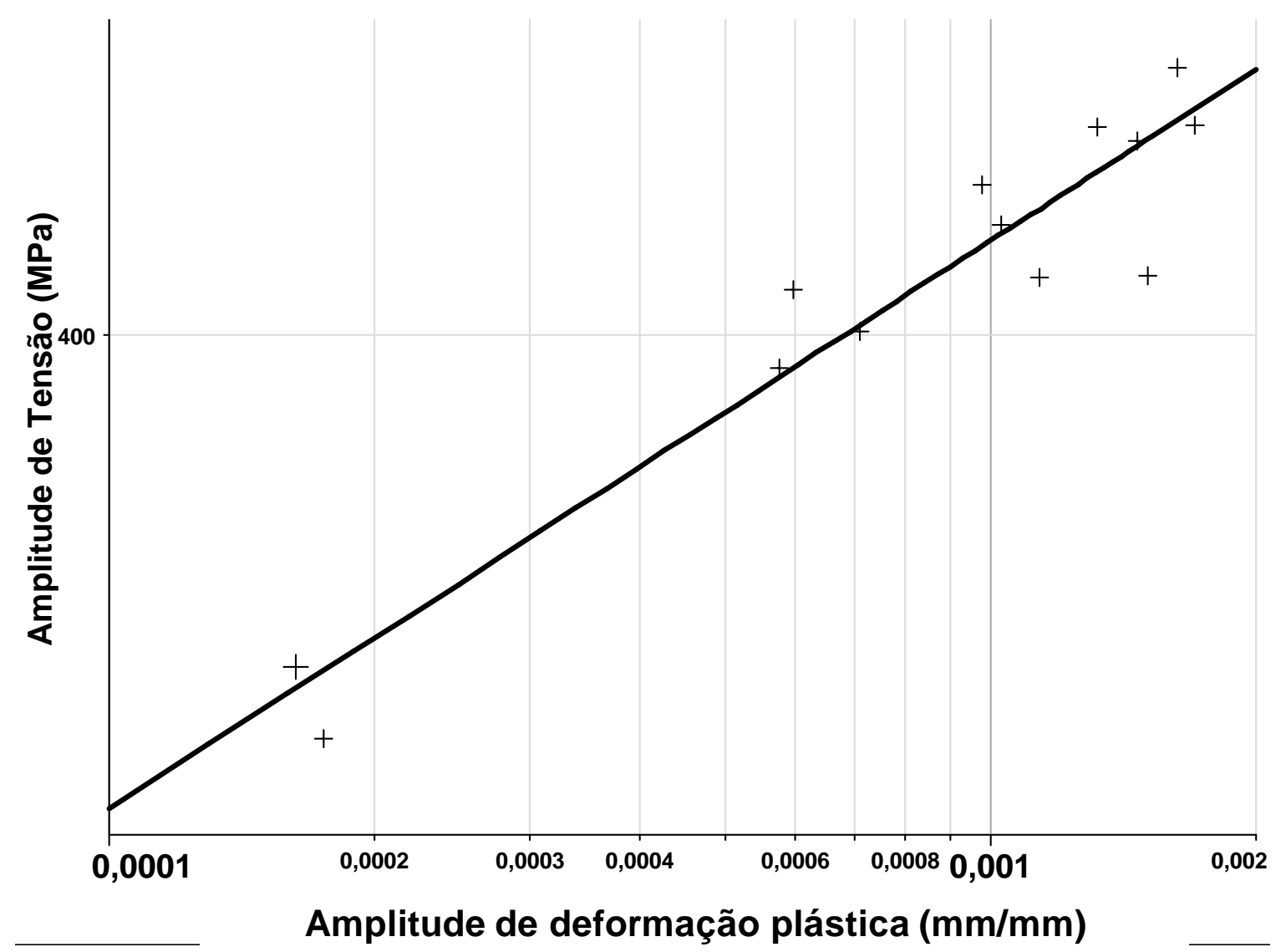

Figura 54: Curva amplitude de tensão vs. amplitude deformação plástica - classe C

$$
\log \left(\frac{\Delta \sigma}{2}\right)=3,050837-0,141815 \log \left(\frac{\Delta \varepsilon^{p}}{2}\right)
$$

comparando com a equação I.8 tem-se que: 


$$
\begin{aligned}
& K^{\prime}=1124 M P a \\
& n^{\prime}=0,14
\end{aligned}
$$

Finalmente é possível traçar a curva de fadiga da faixa de dureza de $160 \mathrm{HB}$ a partir da equação III.24, cujo gráfico resultante é dado na figura 55:

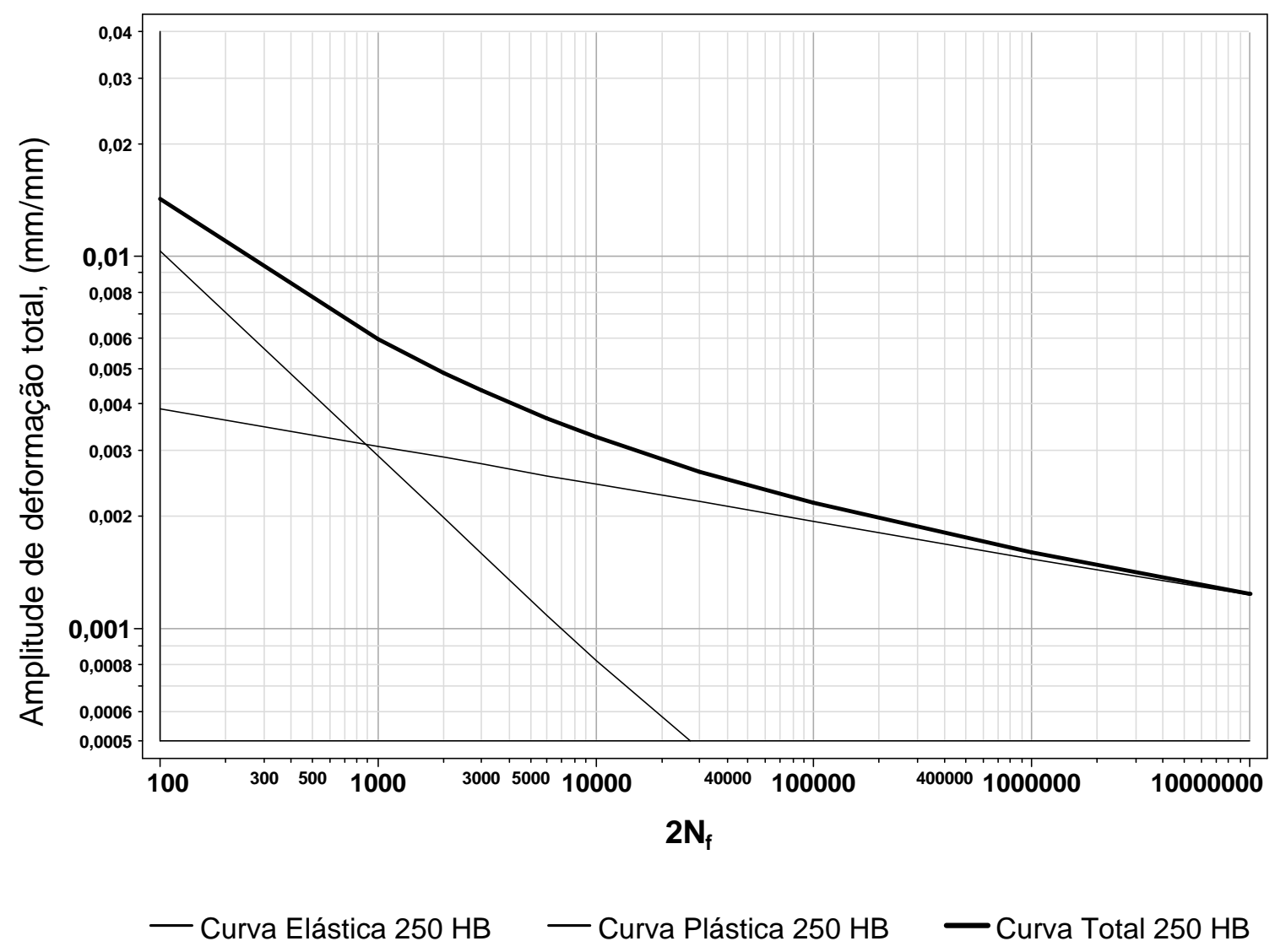

Figura 55: Curva de fadiga da Classe C $-250 \mathrm{HB}$

\subsubsection{Propriedades de Fadiga S-N}

A partir das relações entre a amplitude de tensão e a vida em fadiga $\left(2 \mathrm{~N}_{\mathrm{f}}\right)$ determinadas nos ensaios de fadiga de baixo ciclo (Tabela 19) é possível determinar as propriedades de fadiga de alto ciclo (sob controle de tensão). Estas propriedades foram determinadas para cada classe de dureza do material a partir da comparação dos 
coeficientes da curva de interpolação da amplitude de tensão e a vida em fadiga com a equação I.24.

Tabela 19: Amplitudes de tensão e vidas determinadas no ensaio de fadiga $\varepsilon$-N

\begin{tabular}{|c|c|c|c|c|c|}
\hline \multicolumn{2}{|c|}{ Classe A } & \multicolumn{2}{|c|}{ Classe B } & \multicolumn{2}{|c|}{ Classe C } \\
\hline $\begin{array}{c}\Delta \sigma / 2 \\
(\mathrm{MPa})\end{array}$ & $\begin{array}{c}2 N_{f} \\
\text { Ciclos }\end{array}$ & $\begin{array}{c}\Delta \sigma / 2 \\
(\mathrm{MPa})\end{array}$ & $\begin{array}{c}2 N_{f} \\
\text { Ciclos }\end{array}$ & $\begin{array}{c}\Delta \sigma / 2 \\
(\mathrm{MPa})\end{array}$ & $\begin{array}{c}2 N_{f} \\
\text { Ciclos }\end{array}$ \\
\hline 303,6 & 53044 & 249,3 & 1110406 & 330,3 & 133236 \\
\hline 296,7 & 44704 & 242,2 & 248422 & 310,7 & 186368 \\
\hline 244,7 & 451026 & 309,8 & 18968 & 317,0 & 147152 \\
\hline 312,3 & 66648 & 311,5 & 44024 & 257,5 & 1470888 \\
\hline 368,3 & 2776 & 315,8 & 57940 & 392,4 & 22332 \\
\hline 357,4 & 3016 & 343,0 & 15142 & 410,2 & 14220 \\
\hline 355,6 & 4516 & 345,4 & 22366 & 400,6 & 15212 \\
\hline 349,2 & 3664 & 332,2 & 7198 & 435,7 & 7506 \\
\hline 361,9 & 7572 & 363,7 & 3610 & 425,7 & 7912 \\
\hline 379,5 & 3676 & 385,7 & 6108 & 413,3 & 9218 \\
\hline 383,6 & 4496 & 373,5 & 8934 & 450,5 & 5406 \\
\hline 371,5 & 1936 & 373,3 & 10340 & 413,8 & 7200 \\
\hline 339,5 & 24600 & 379,8 & 4925 & 446,9 & 2390 \\
\hline 363,8 & 5782 & 376,6 & 5200 & 451,2 & 1540 \\
\hline 337,7 & 17016 & 378,7 & 1772 & 466,1 & 2760 \\
\hline 254,8 & 413932 & & & & \\
\hline 244,4 & 214744 & & & & \\
\hline 340,7 & 18600 & & & & \\
\hline 362,9 & 17010 & & & & \\
\hline
\end{tabular}

\subsubsection{Classe A - $135 \mathrm{HB}$}

Traçando a amplitude de tensão em função da vida em fadiga dos dados do material da classe A tem-se a figura 56: 


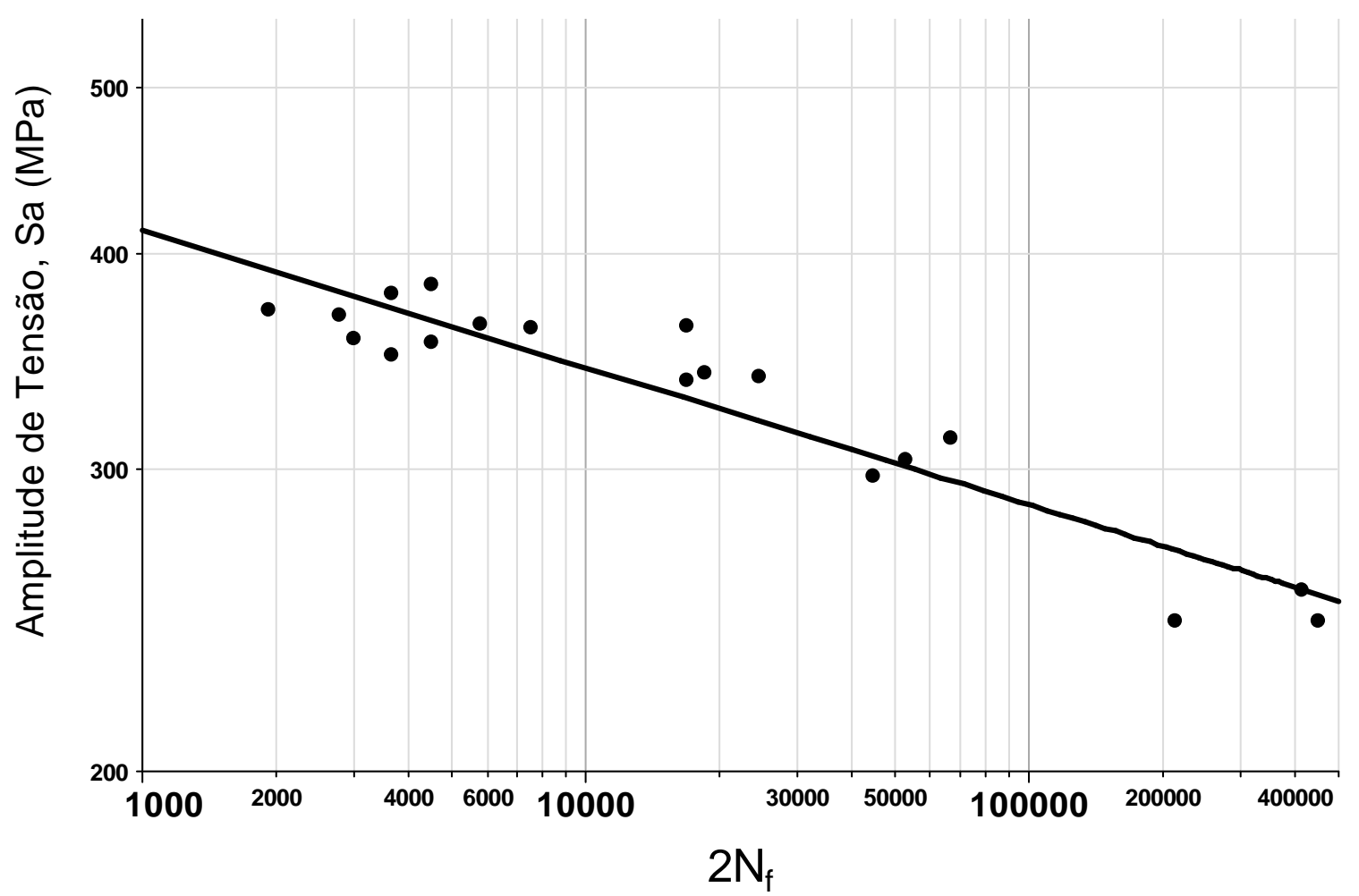

Figura 56: Curva de amplitude de tensão vs. vida em fadiga - Classe A

A equação de interpolação, em escala logarítmica, é dada por:

$\log S_{a}=2,8553-0,0798 \log \left(2 N_{f}\right)$

Portanto, comparando a equação III.26 com a equação I.24, tem-se que os parâmetros de fadiga de alto ciclo $(\mathrm{S}-\mathrm{N})$ são dados por:

$$
S_{f}{ }_{f}=716 M P a
$$

$b^{\prime}=-0,08$

A equação S-N da Classe A é então dada por:

$$
S_{a}=716 .\left(2 N_{f}\right)^{0,08}
$$

\subsubsection{Classe B - $160 \mathrm{HB}$}


Traçando a amplitude de tensão em função da vida em fadiga dos dados do material da classe B tem-se a figura 57:

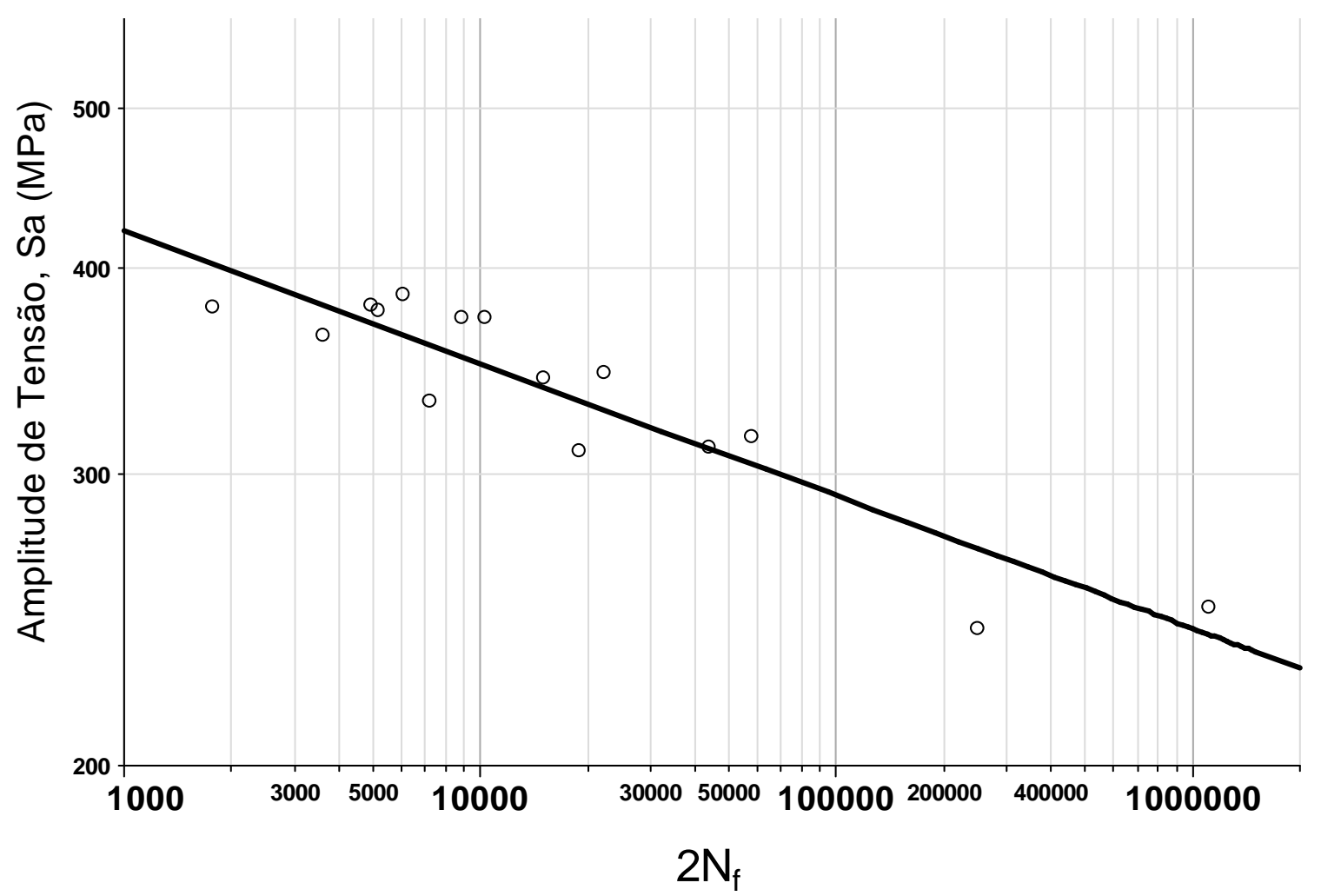

Figura 57: Curva de amplitude de tensão vs. vida em fadiga - Classe B

A equação de interpolação, em escala logarítmica, é dada por:

$$
\log S_{a}=2,8646-0,0808 \log \left(2 N_{f}\right)
$$

Portanto, comparando a equação III.30 com a equação I.24, tem-se que os parâmetros de fadiga de alto ciclo $(\mathrm{S}-\mathrm{N})$ são dados por:

$$
\begin{aligned}
& S_{f}{ }_{f}=732 \mathrm{MPa} \\
& b^{\prime}=-0,08
\end{aligned}
$$

A equação S-N da Classe B é então dada por:

$$
S_{a}=732 \cdot\left(2 N_{f}\right)^{-0,08}
$$




\subsubsection{Classe C - 250 HB}

Traçando a amplitude de tensão em função da vida em fadiga dos dados do material da Classe $\mathrm{C}$ tem-se a figura 58:

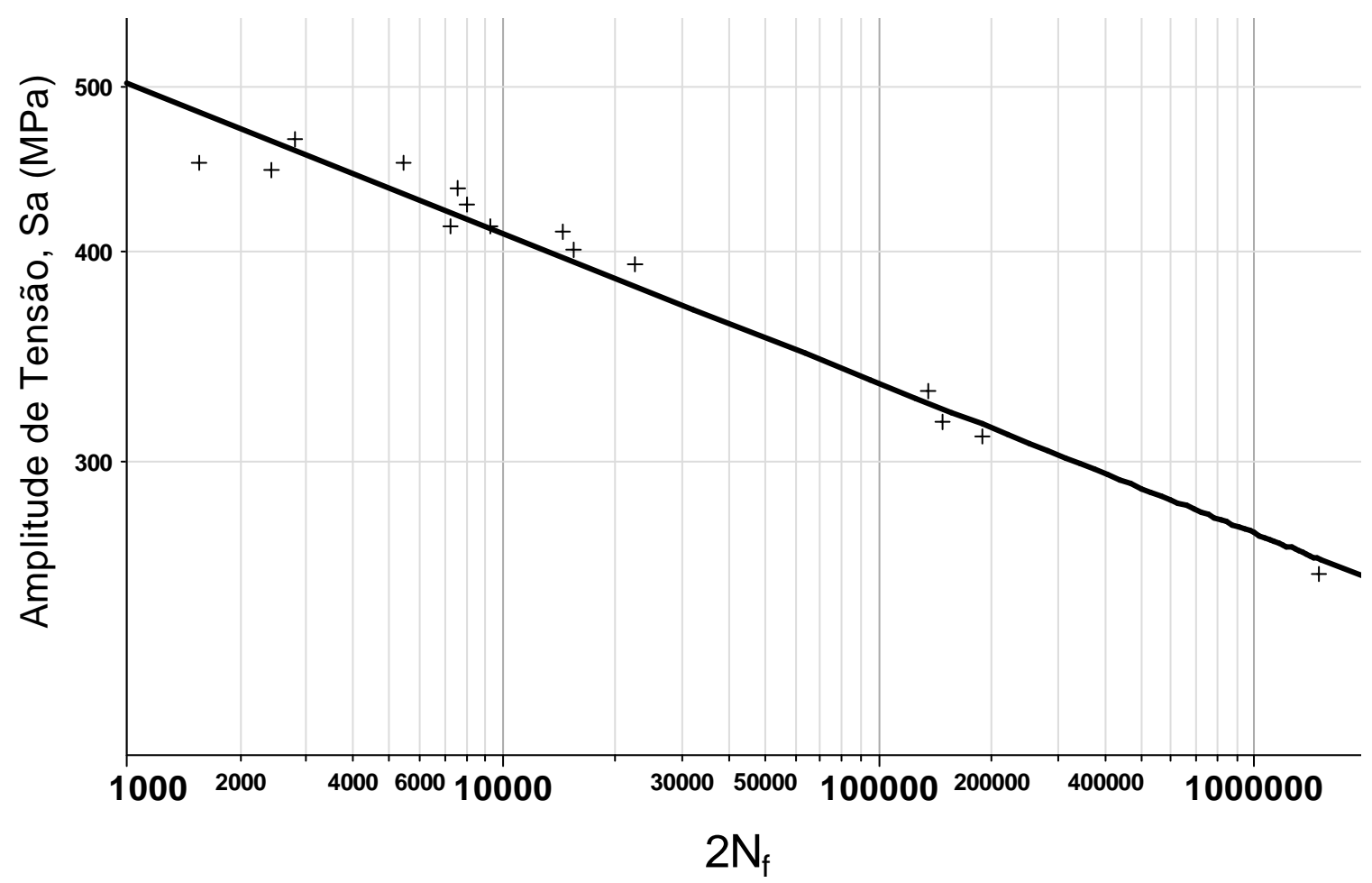

Figura 58: Curva de amplitude de tensão vs. vida em fadiga - Classe C

A equação de interpolação, em escala logarítmica, é dada por:

$$
\log S_{a}=2,9679-0,08875 \log \left(2 N_{f}\right)
$$

Portanto, comparando a equação III.34 com a equação I.24, tem-se que os parâmetros de fadiga de alto ciclo (S-N) são:

$$
\begin{aligned}
& S_{f}{ }_{f}=928 \mathrm{MPa} \\
& b^{\prime}=-0,09
\end{aligned}
$$

A equação S-N da Classe C é então dada por: 


$$
S_{a}=928 \cdot\left(2 N_{f}\right)^{-0,09}
$$

\subsubsection{Considerações Gerais Sobre os Ensaios}

As Tabelas 20 e 21 resumem, respectivamente, os valores das propriedades monotônicas e cíclicas determinadas para cada faixa de dureza ensaiada:

Tabela 20: Resumo das propriedades monotônicas determinadas experimentalmente

\begin{tabular}{|l|c|c|c|c|c|}
\cline { 3 - 5 } \multicolumn{2}{c}{} & \multicolumn{4}{c|}{ Dureza (HB) } \\
\cline { 4 - 6 } \multicolumn{2}{c}{} & & $\begin{array}{c}\text { Faixa A } \\
130\end{array}$ & $\begin{array}{c}\text { Faixa B } \\
160\end{array}$ & $\begin{array}{c}\text { Faixa C } \\
250\end{array}$ \\
\hline Resistência a Tração & $\mathrm{Su}$ & $\mathrm{MPa}$ & 407 & 442 & 710 \\
Tensão de Escoamento & $\mathrm{Sy}$ & $\mathrm{MPa}$ & 280 & 310 & 403 \\
Alongamento & $\mathrm{El}$ & $\%$ & 25,8 & 24,1 & 6,1 \\
Modulo de Eslasticidade & $\mathrm{E}$ & $\mathrm{GPa}$ & 165 & 170 & 168 \\
Coef. de Resistência & $\mathrm{K}$ & $\mathrm{MPa}$ & 656 & 700 & 1501 \\
Expoente de Endurecimento & $\mathrm{n}$ & $(-)$ & 0,18 & 0,18 & 0,25 \\
\hline
\end{tabular}


Tabela 21: Resumo das propriedades cíclicas determinadas experimentalmente

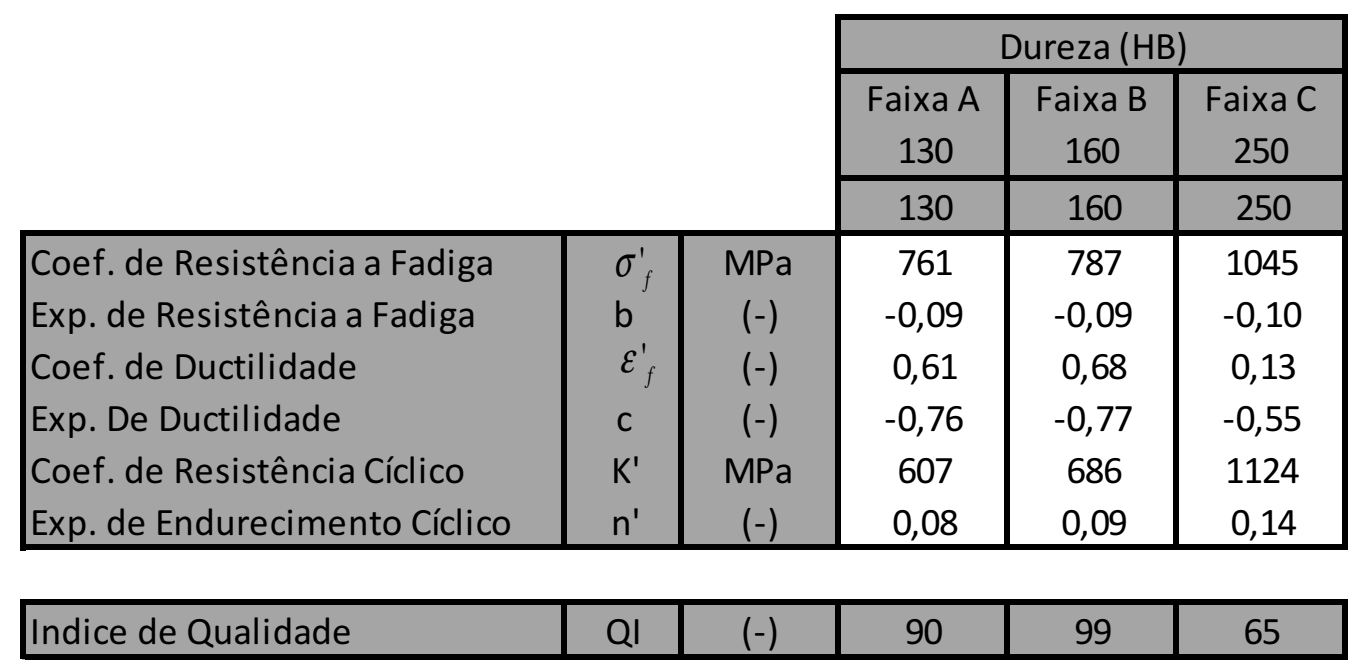

Na figura 59 abaixo é possível visualizar as diferenças entre os laços de histerese entre as faixas de dureza ensaiadas para diferentes amplitudes deformação total

A figura abaixo mostra o ciclo de meia vida para cada amostra obtida durante os ensaios e que foram utilizados como referencia para os cálculos das propriedades cíclicas desta classe 


\section{A3 - Histerese na Meia Vida}

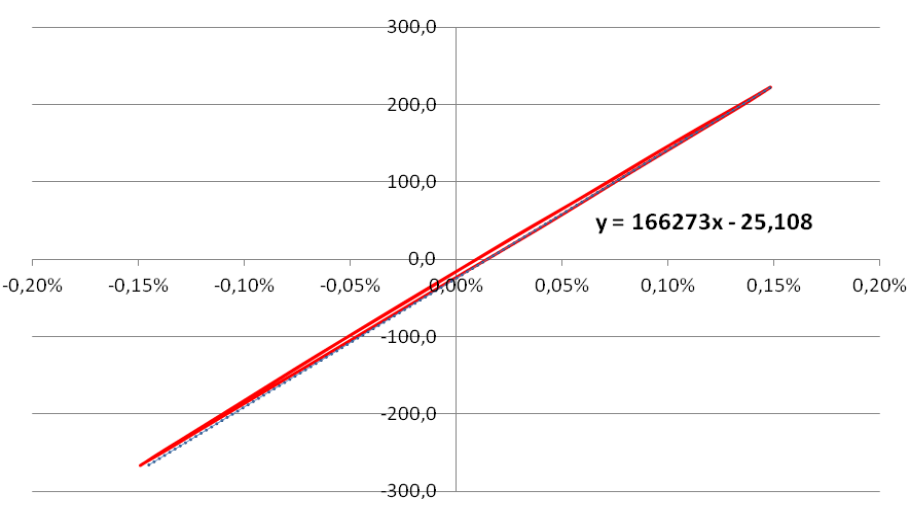

B13 - Histerese na Meia Vida

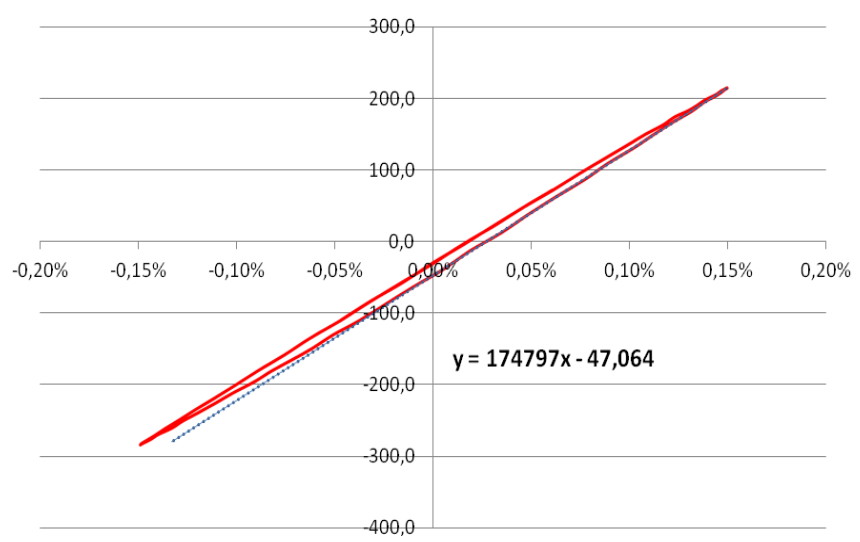

\section{C4 - Histerese na Meia Vida}

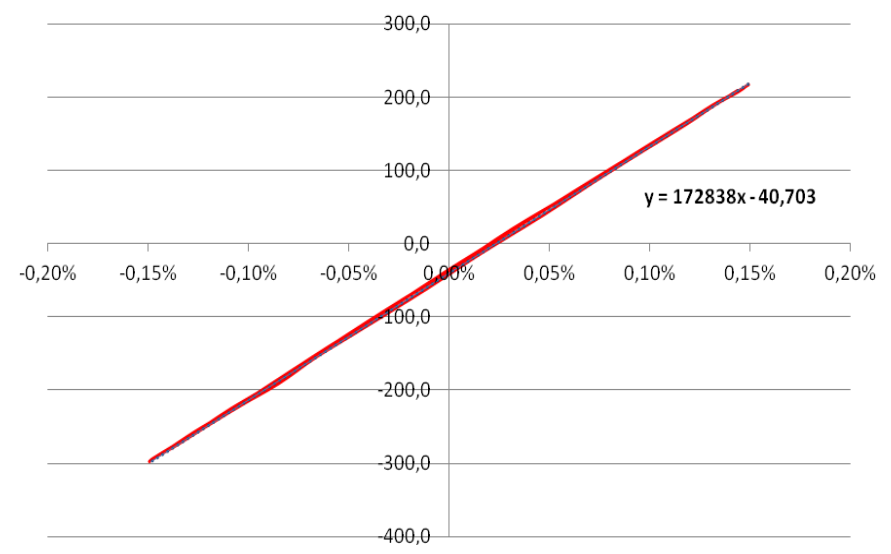

Figura 59: Comparação entre os laços de histerese para amplitude de deformação de 0,15\% 


\section{A7 - Histerese na Meia Vida}

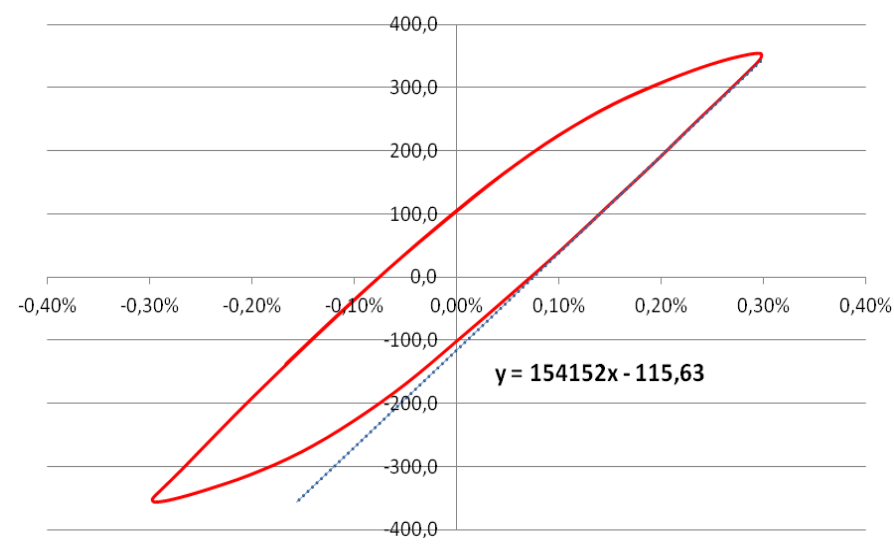

B6 - Histerese na Meia Vida

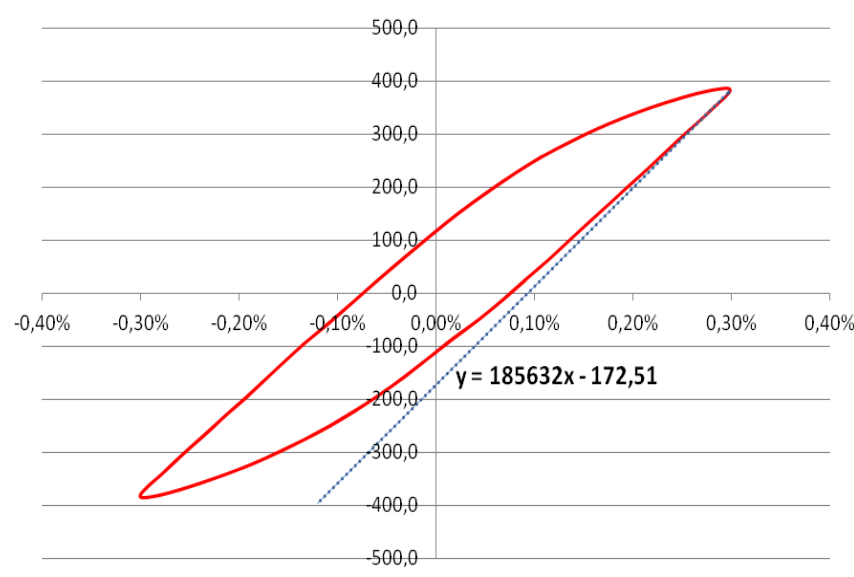

\section{C5 - Histerese na Meia Vida}

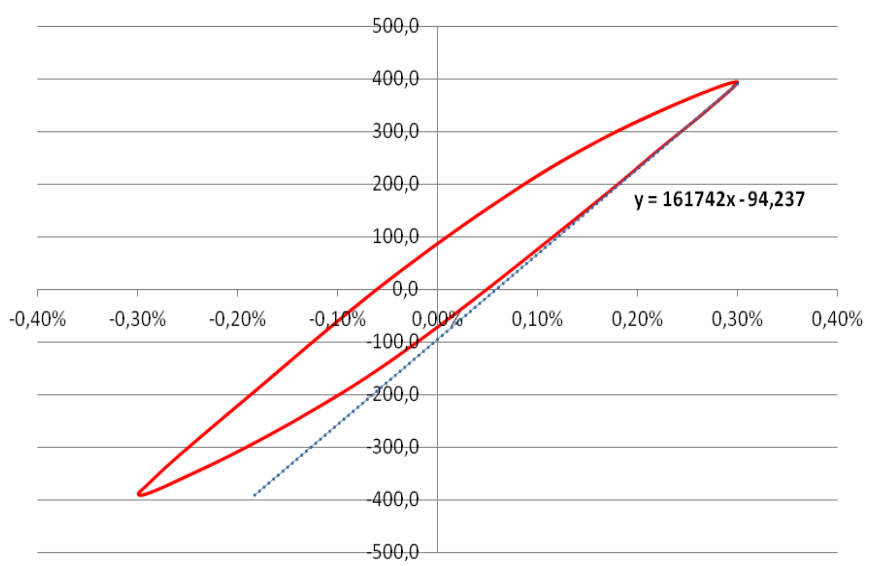

Figura 60: Comparação entre os laços de histerese para amplitude de deformação de 0,30\% 
É possível observar nas figuras 59 e 60 a influência do limite de escoamento no comportamento sobre controle de deformação. Na comparação feita a $0,15 \%$ observa-se que a amostra com faixa de dureza de 250 HB não atingiu o seu limite de escoamento e, portanto, o seu laço de histerese se reduz a uma reta e na comparação feita a $0,30 \%$ observa-se como as amplitudes de deformações plásticas na amostra com dureza de 135 e 160 HB são maiores do que as amplitudes de deformações plásticas na com dureza de 250 HB.

As curvas de fadiga de baixo ciclo $(\varepsilon-\mathrm{N})$ das faixas de dureza de $135 \mathrm{HB}$ e $160 \mathrm{HB}$ são muito semelhantes, como pode ser notado na figura 58
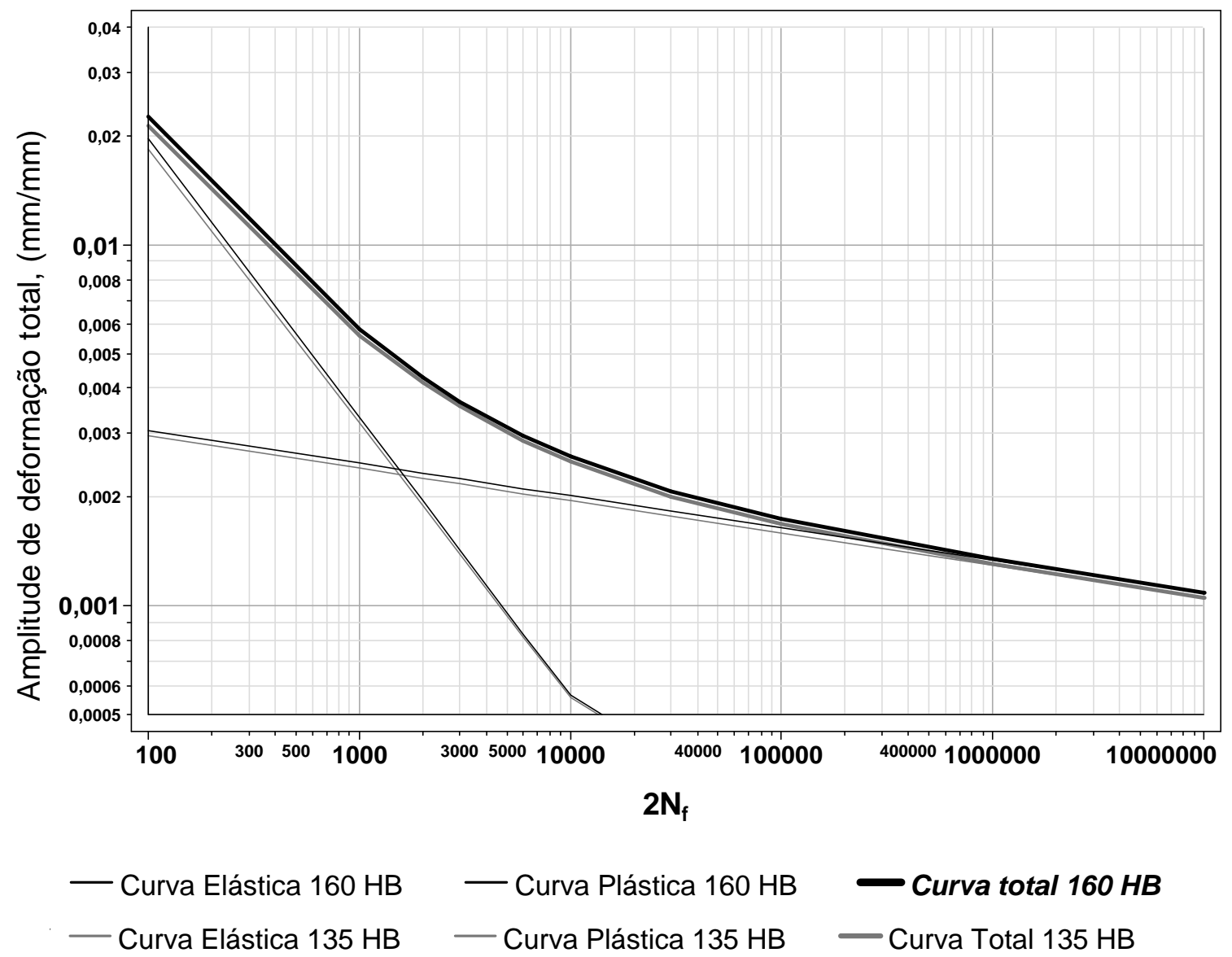

Figura 61: Comparação entre as curvas de fadiga das faixas de dureza de $135 \mathrm{HB}$ e $250 \mathrm{HB}$

Comparando as curvas de fadiga da faixa de dureza de $135 \mathrm{HB}$ com a de $250 \mathrm{HB}$ observa-se que existe uma região de transição na qual a classe de maior dureza se torna mais resistente à fadiga do que a classe de menor dureza, esta região de transição, que ocorre em aproximadamente 700 ciclos é devido a diferença de inclinação das curvas de 
amplitude de deformação plástica, pois, as curvas de amplitude de deformação elástica são paralelas. Isto pode ser observado na figura 59. A maior resistência à fadiga da classe de menor dureza na fase inicial é por que nesta região os parâmetros que governam o comportamento do material quando submetidos à fadiga são os parâmetros de ductilidade, enquanto que para níveis menores de deformação (consequentemente vidas maiores) os parâmetros que predominam são os de resistência a fadiga.

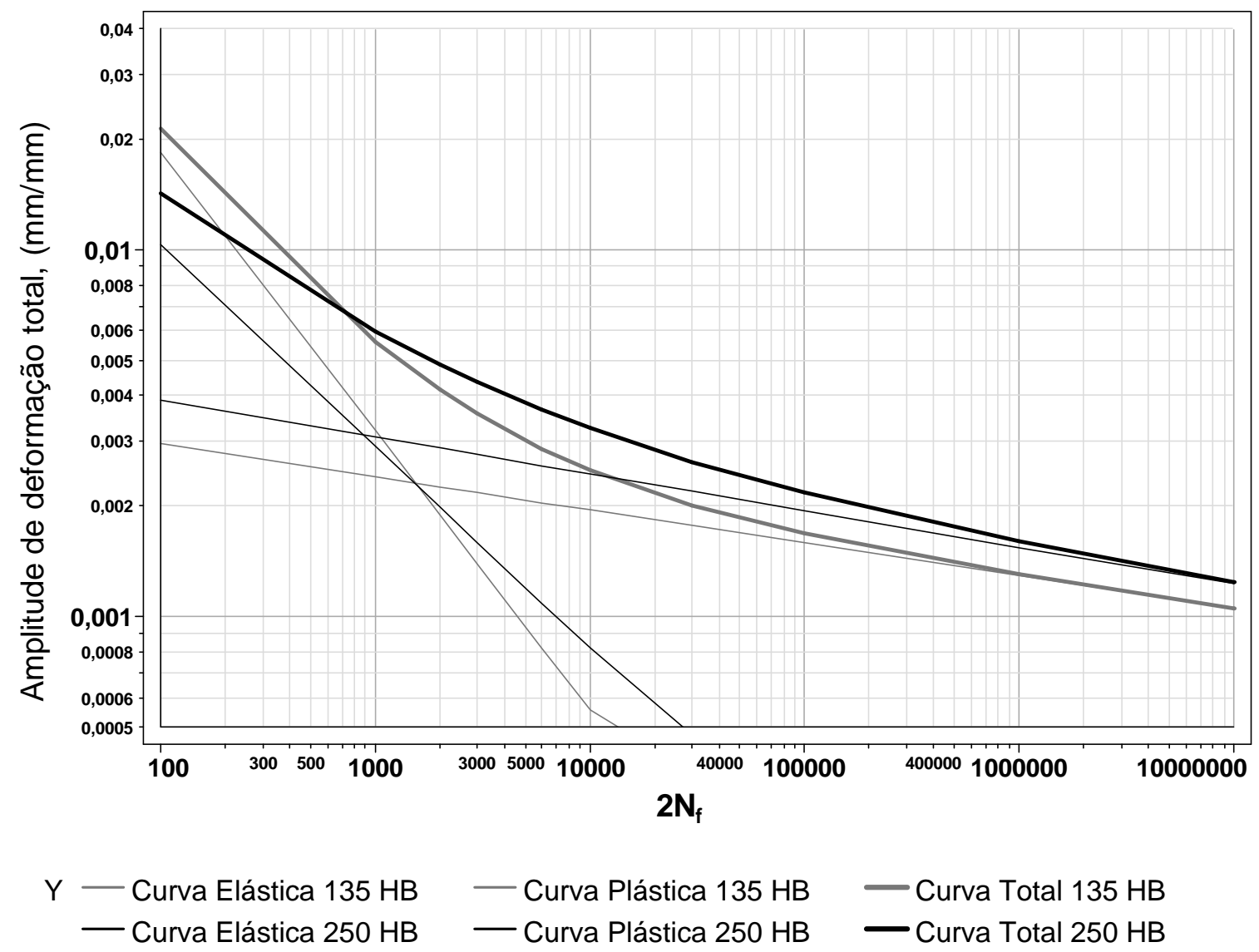

Figura 62: Comparação entre as curvas de fadiga das faixas de dureza de $135 \mathrm{HB}$ e $250 \mathrm{HB}$

\subsubsection{Comparações entre os Comportamentos Monotônico e Cíclico}

Comparando as curvas monotônica e cíclica de uma das amostras, como por exemplo de uma da faixa de dureza de $135 \mathrm{HB}$ (figura 60) é possível notar que o ferro fundido nodular é um material que apresenta endurecimento cíclico 


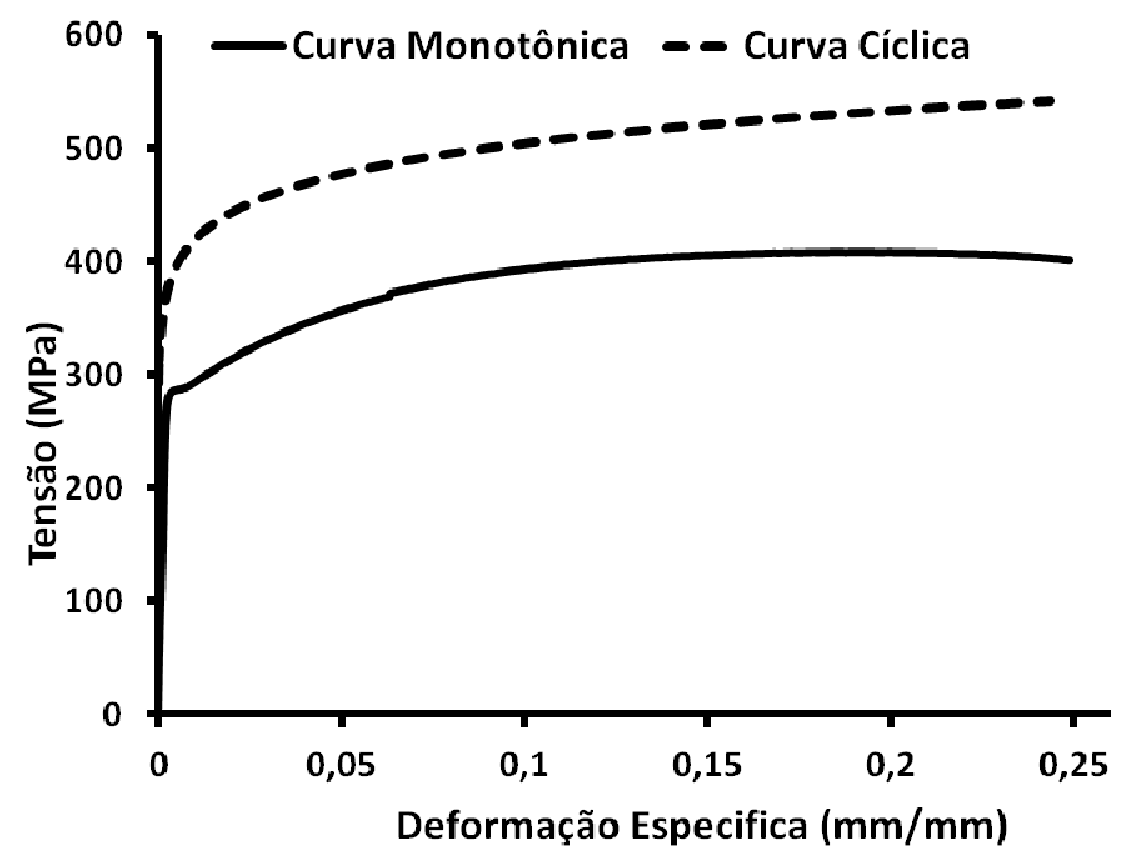

Figura 63: Comparação das curvas tensão-deformação monotônico e cíclico - amostra Classe A

\subsubsection{Análises Metalográficas}

Após a realização dos ensaios de tração e de fadiga sob controle de deformação ( $\varepsilon$ N) foram realizadas as análises metalográficas várias amostras. A figura 64 mostra alguns exemplares dos corpos de prova ensaiados.

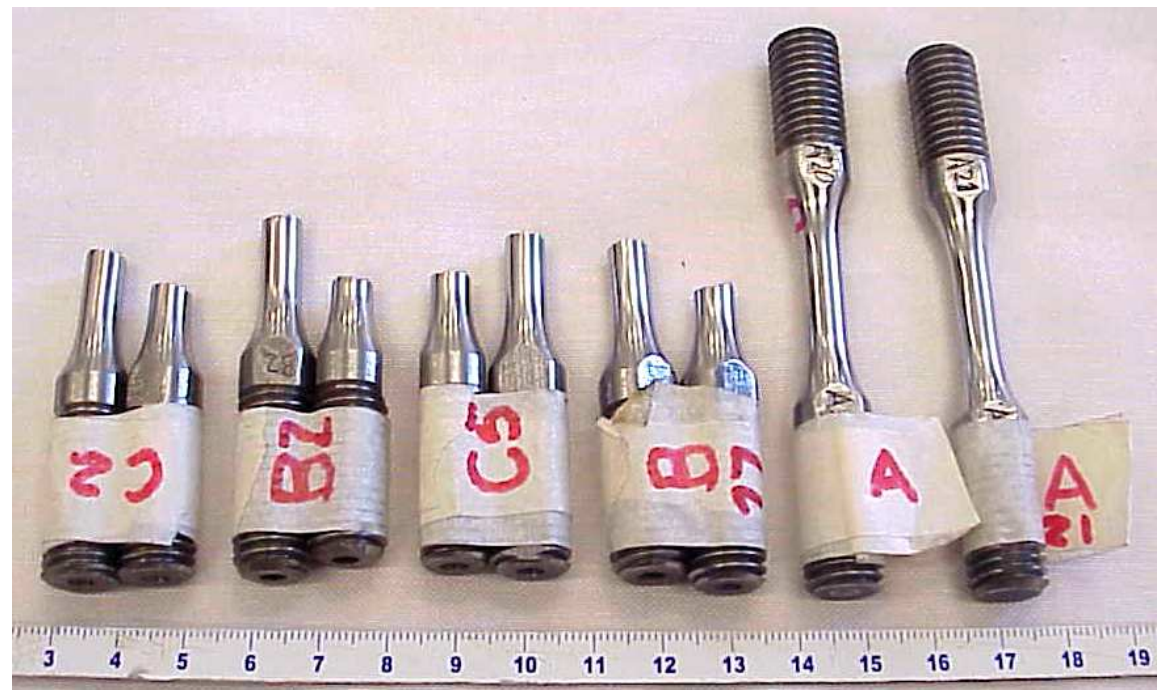

Figura 64: Amostras no qual foram realizada a análise micrográfica 
Nota-se pela análise micrográfica nas classes A e B que houve a presença de praticamente $100 \%$ de ferrita nas suas matrizes (figura 65 e figura 66) e que na matriz do material da classe $\mathrm{C}$ houve predominante de $100 \%$ de perlita (figura 67). Para a obtenção da classe A, que possui dureza média de $135 \mathrm{HB}$, foi necessário realizar o tratamento térmico de ferritização, que foi responsável pela redução do tamanho dos nódulos de grafita e aumento da sua dispersão por área da matriz ferrítica.

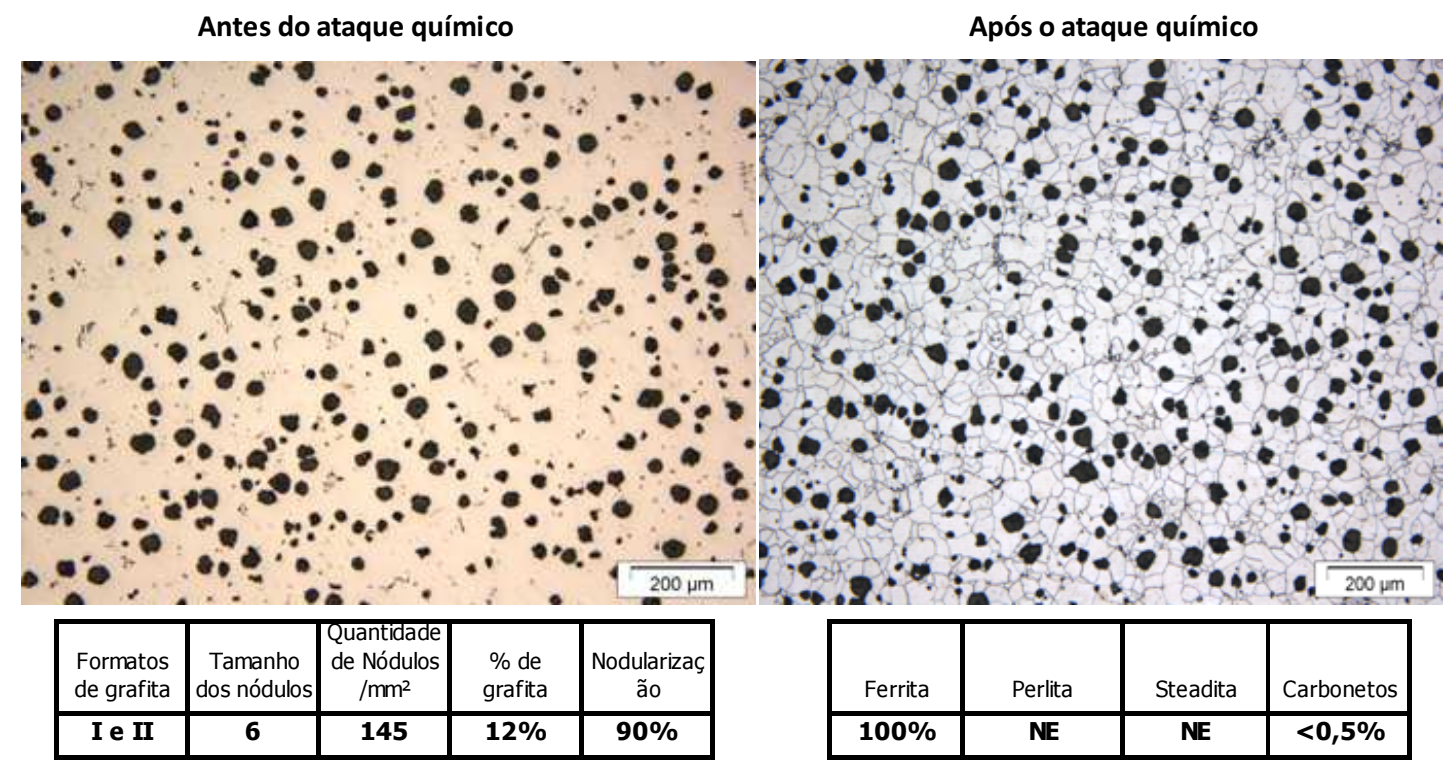

Figura 65: Análise micrográfica de uma amostra da Classe A

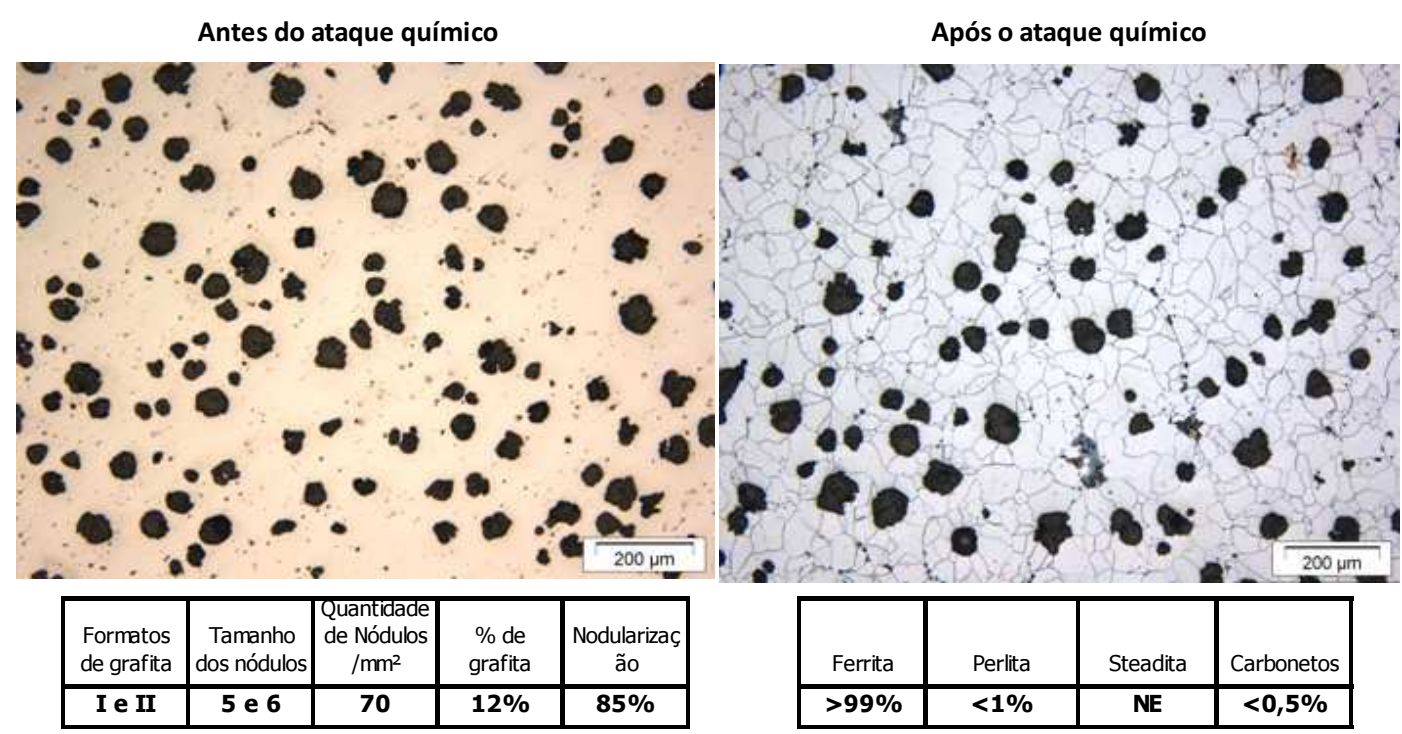

Figura 66: Análise micrográfica de uma amostra da Classe B 


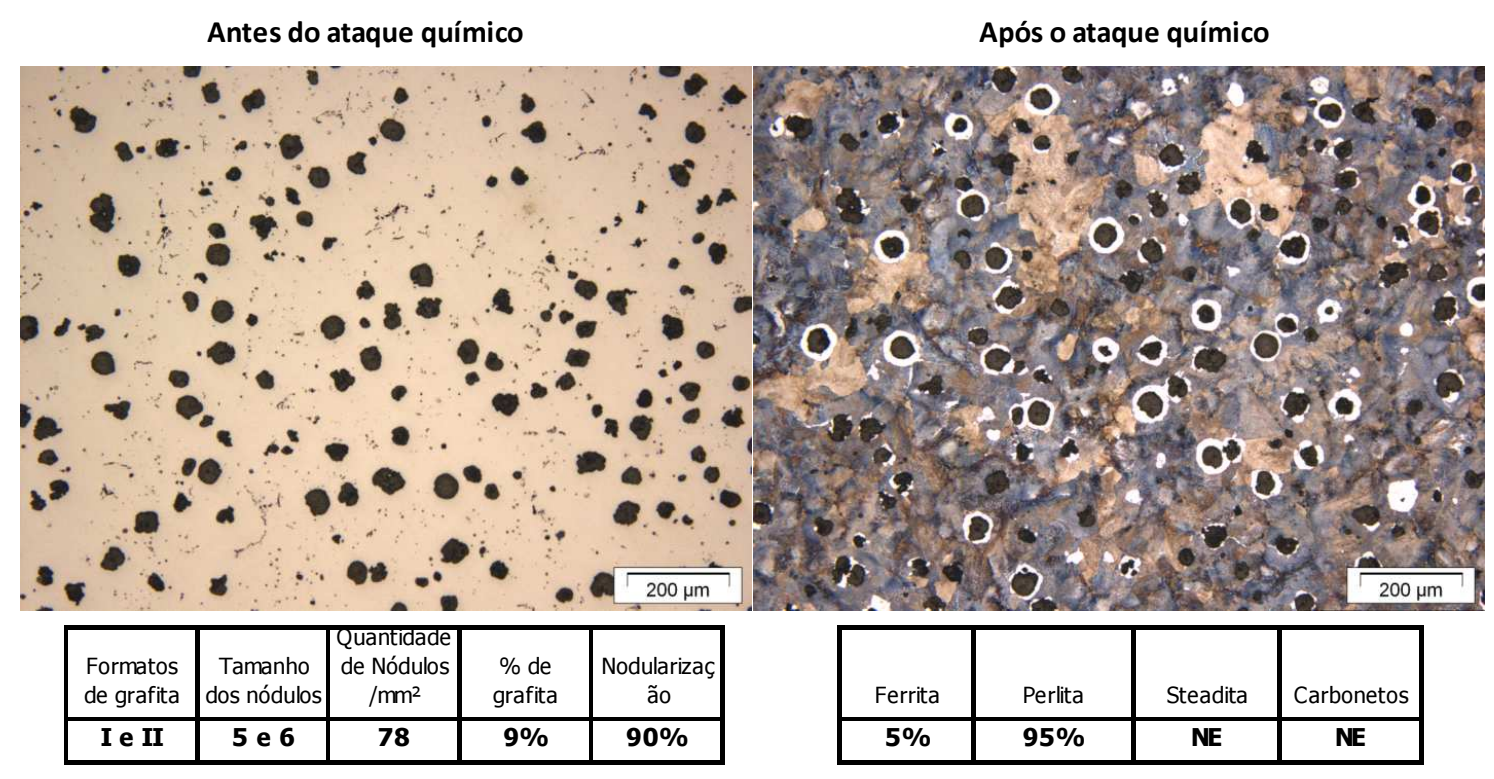

Figura 67: Análise micrográfica de uma amostra da Classe C

\subsubsection{Análises Fractográficas}

As figuras abaixo mostram os aspectos macrográficos e micrográficos das superfícies de fratura obtidas pela técnica de elétrons retro-espalhados. Nestas figuras estão indicadas as regiões prováveis da ocorrência de nucleação da trinca $(\mathrm{N})$, de propagação estável (PE) e de propagação instável (PI). Em todas as superfícies de fratura examinadas pode-se observar a existência de uma grande quantidade de microvazios onde se localizavam os nódulos de grafita. 

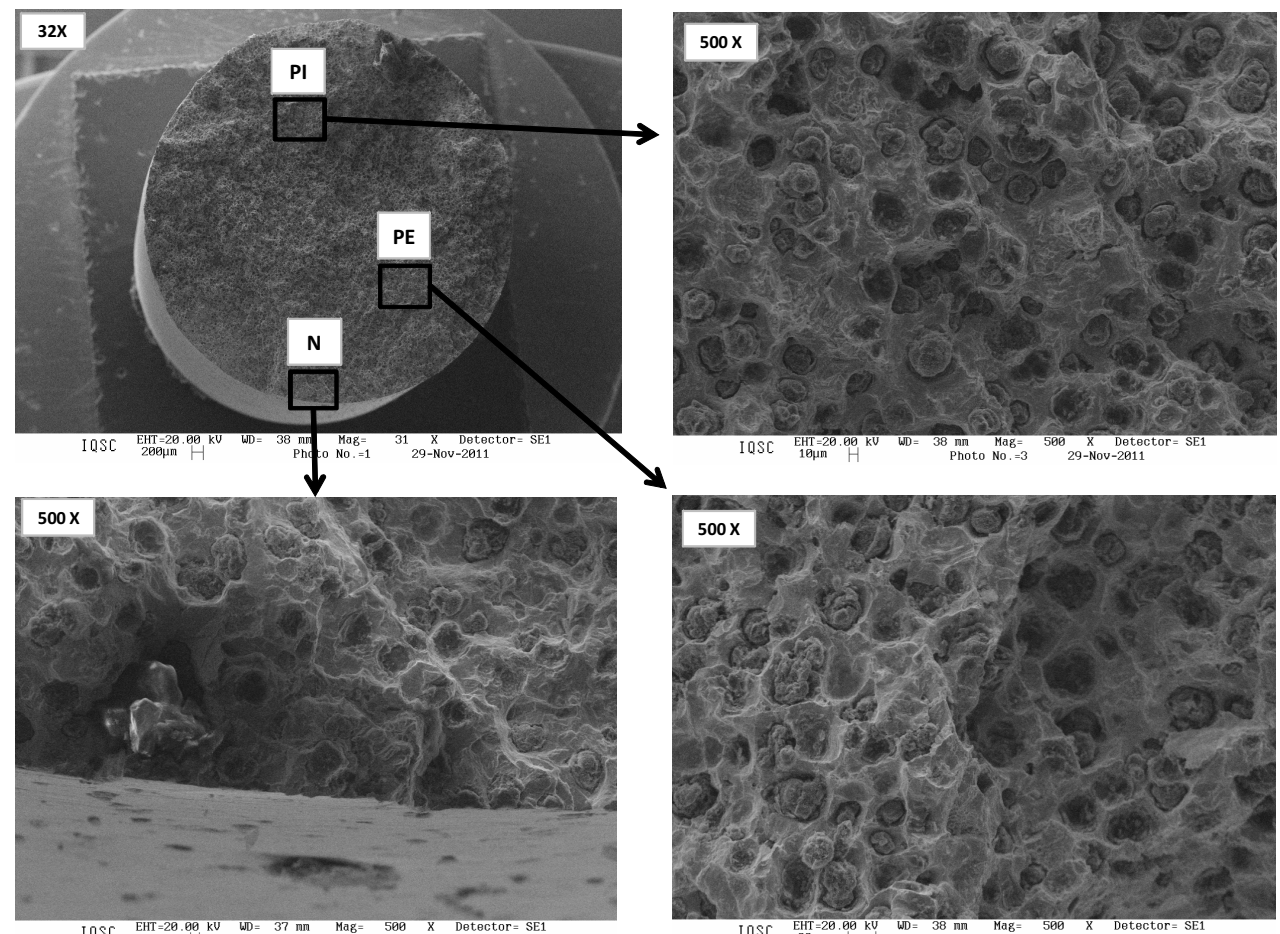

Figura 68: Fractografia da amostra A

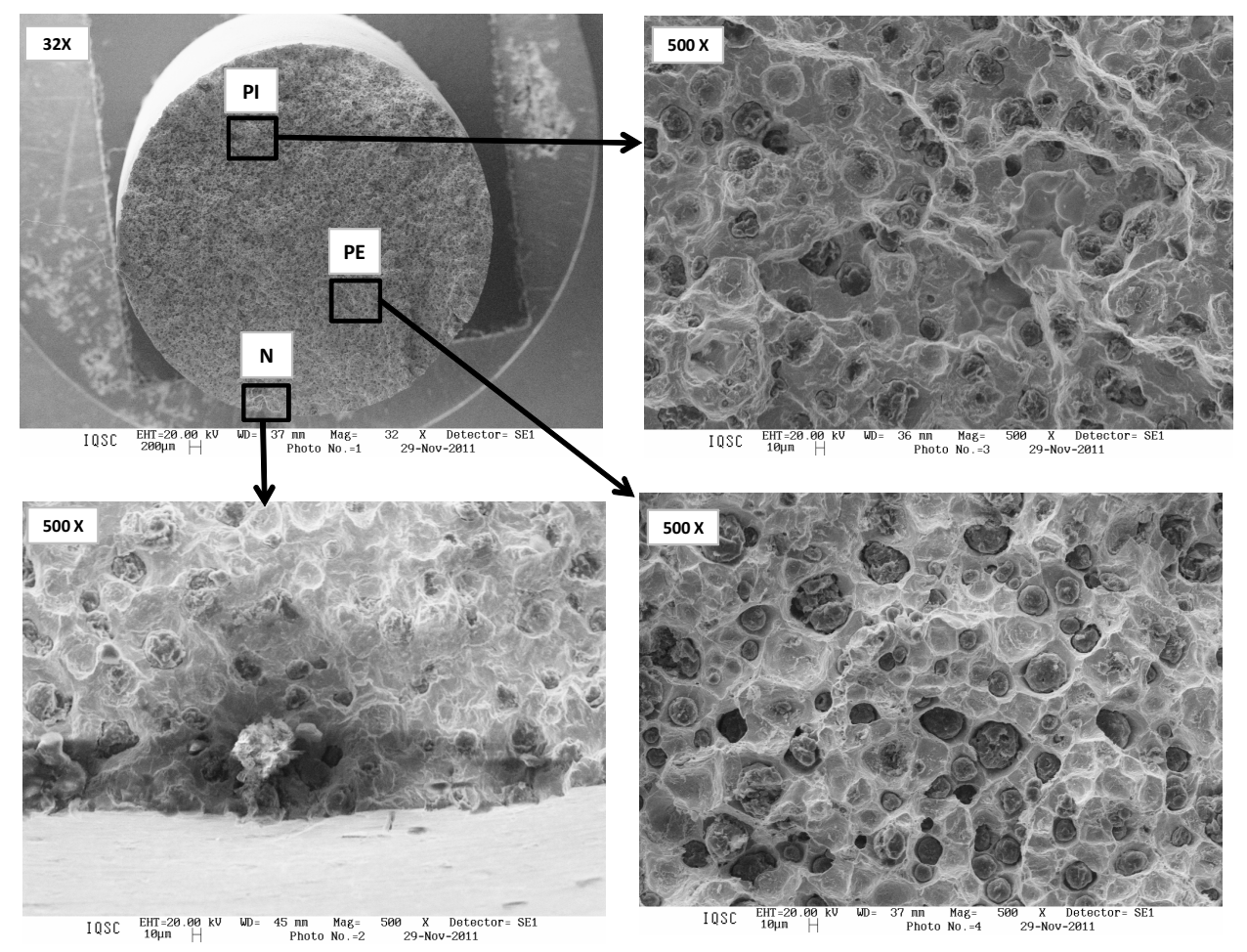

Figura 69: Fractografia da amostra B 


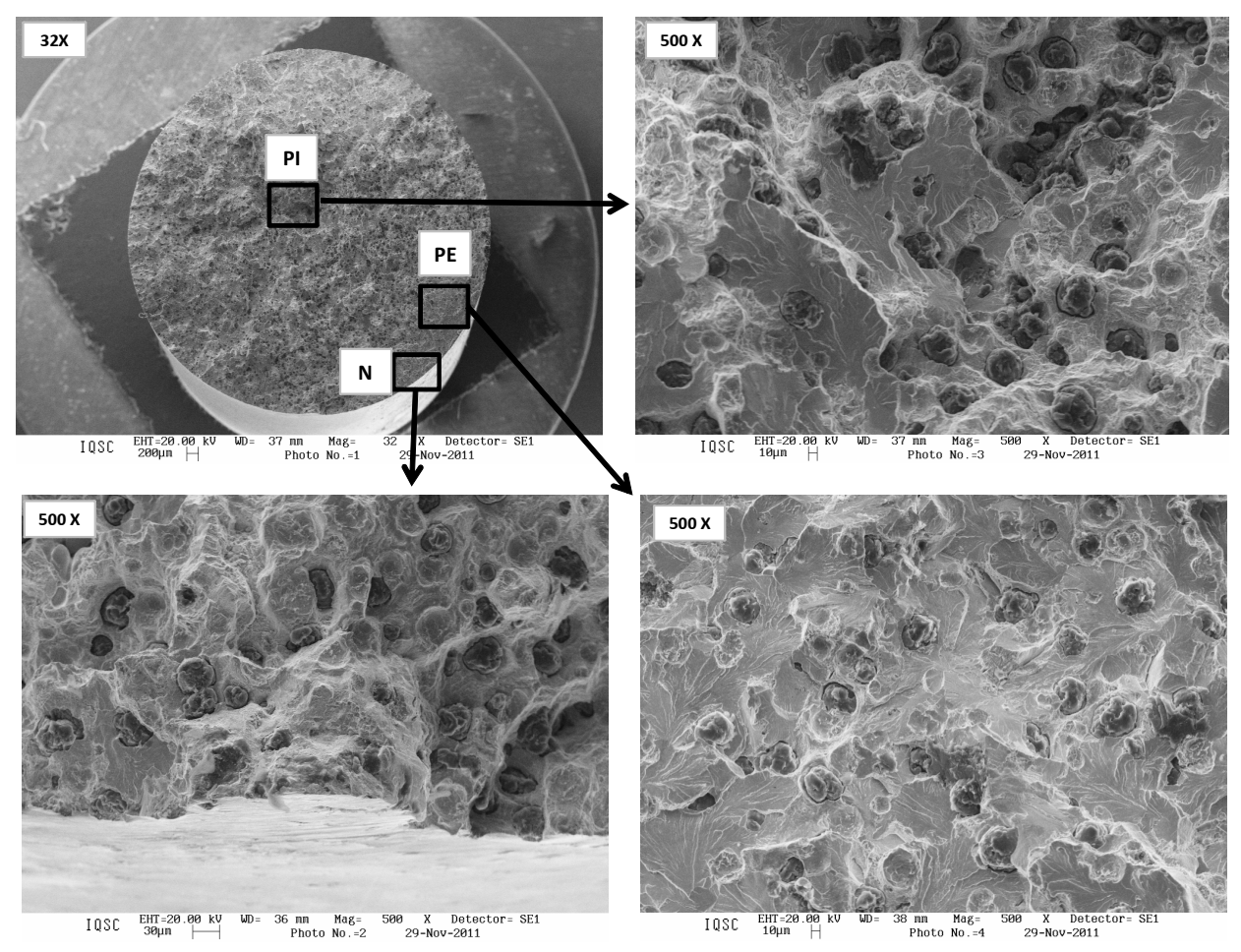

Figura 70: Fractografia da amostra C 


\section{PARTE IV}

\subsection{Propriedades Mecânicas dos Ferros Fundidos - Complemento da Literatura e $\mathrm{QI} \geq 80$}

A proposta para se correlacionar as propriedades monotônicas e cíclica parte do princípio que quando se trata de ferros fundidos deve-se utilizar como base de comparação materiais cuja qualidade seja equivalente ou que esteja dentro de uma faixa de qualidade no qual a correlação com a dureza não seja afetada, neste caso, baseado na revisão dos encontrados na literatura e incluindo os resultados experimentais obtidos neste estudo é proposto fazer a correlação para ferros fundidos cuja qualidade, expressa a partir do Índice de Qualidade, seja igual ou superior a 80. Desta forma foram excluídas as categorias de dureza que não atenderam a este requisito por apresentarem qualidade inferior a 80, assim garantiu-se que o restante das amostras estavam dentro da qualidade pretendida.

\subsubsection{Propriedades Monotônicas}

Outra premissa para se propor o modelo de correlação das propriedades monotônicas com a dureza foi adotar que os parâmetros que representam o comportamento não linear do material, neste caso o coeficiente de resistência e o expoente de endurecimento, se relacionam com a dureza a partir de um polinômio de segunda ordem. Esta premissa partiu da análise da distribuição dos dados após a exclusão das categorias de materiais que tinham o Índice de Qualidade inferior a 80.

A Tabela 22 mostra os dados disponíveis para as análises depois dos ensaios. Observe que foram excluídas do estudo quatro faixas de dureza por que elas não atendiam ao requisito mínimo de qualidade exigido neste estudo. 
Tabela 22: Propriedades Monotônicas dos Ferros Fundidos Nodulares - Complemento da Literatura

\begin{tabular}{|c|c|c|c|c|c|c|c|c|c|c|c|c|c|c|c|c|c|}
\hline & & & \multicolumn{15}{|c|}{ Dureza (HB) } \\
\hline & & & 135 & 160 & 186 & 189 & 205 & 211 & 218 & 228 & 236 & 244 & 250 & 250 & 256 & 259 & 270 \\
\hline Limite de Resistência a Tração & Su & $\mathrm{MPa}$ & 407 & 442 & 604 & 612 & 631 & 664 & 693 & 725 & 675 & 754 & 710 & 775 & 818 & 682 & 863 \\
\hline Limite de Escoamento & Sy & $\mathrm{MPa}$ & 280 & 310 & 356 & 368 & 389 & 399 & 407 & 439 & 414 & 447 & 403 & 437 & 460 & 442 & 474 \\
\hline Alongamento total & $\mathrm{El}$ & $\%$ & 25,8 & 24,1 & 11,9 & 13,7 & 9,7 & 11,6 & 12,0 & 10,4 & 5,1 & 7,7 & 6,1 & 4,4 & 6,0 & 5,1 & 6,3 \\
\hline Modulo de Eslasticidade & $\mathrm{E}$ & $\mathrm{GPa}$ & 165 & 170 & 177 & 170 & 168 & 159 & 159 & 168 & 160 & 170 & 168 & 174 & 161 & 161 & 176 \\
\hline Coef. de Resistência & $\mathrm{K}$ & $\mathrm{MPa}$ & 656 & 700 & 910 & 887 & 924 & 1130 & 1190 & 1100 & 1330 & 1250 & 1501 & 1590 & 1720 & 1460 & 1760 \\
\hline Expoente de Endurecimento & $\mathrm{n}$ & $(-)$ & 0,18 & 0,18 & 0,17 & 0,17 & 0,16 & 0,18 & 0,19 & 0,18 & 0,21 & 0,2 & 0,25 & 0,25 & 0,23 & 0,21 & 0,25 \\
\hline
\end{tabular}

\begin{tabular}{|l|c|c|c|c|c|c|c|c|c|c|c|c|c|c|c|c|c|}
\hline Indice de Qualidade & QI & $(-)$ & 90 & 99 & 91 & 108 & 81 & 108 & 121 & 115 & 49 & 92 & 65 & 56 & 84 & 50 & 99 \\
\hline
\end{tabular}

\begin{tabular}{|c|c|c|c|c|c|c|c|c|c|c|c|c|c|}
\hline \multirow{2}{*}{ Referências } & 3 & 3 & 1 & 1 & 1 & 2 & 2 & 1 & 2 & 1 & 3 & 1 & 2 \\
\cline { 2 - 6 } & \multicolumn{8}{|c|}{ 2. Tartaglia, 2000} & 1 \\
\hline
\end{tabular}

$\square$ Dados eliminados por não atenderem ao requisito de qualidade proposto no estudo $(\mathrm{Q} I \geq 80)$ 
A partir das dados foi possível traçar novas relações das propriedades mecânicas com a dureza, como segue:

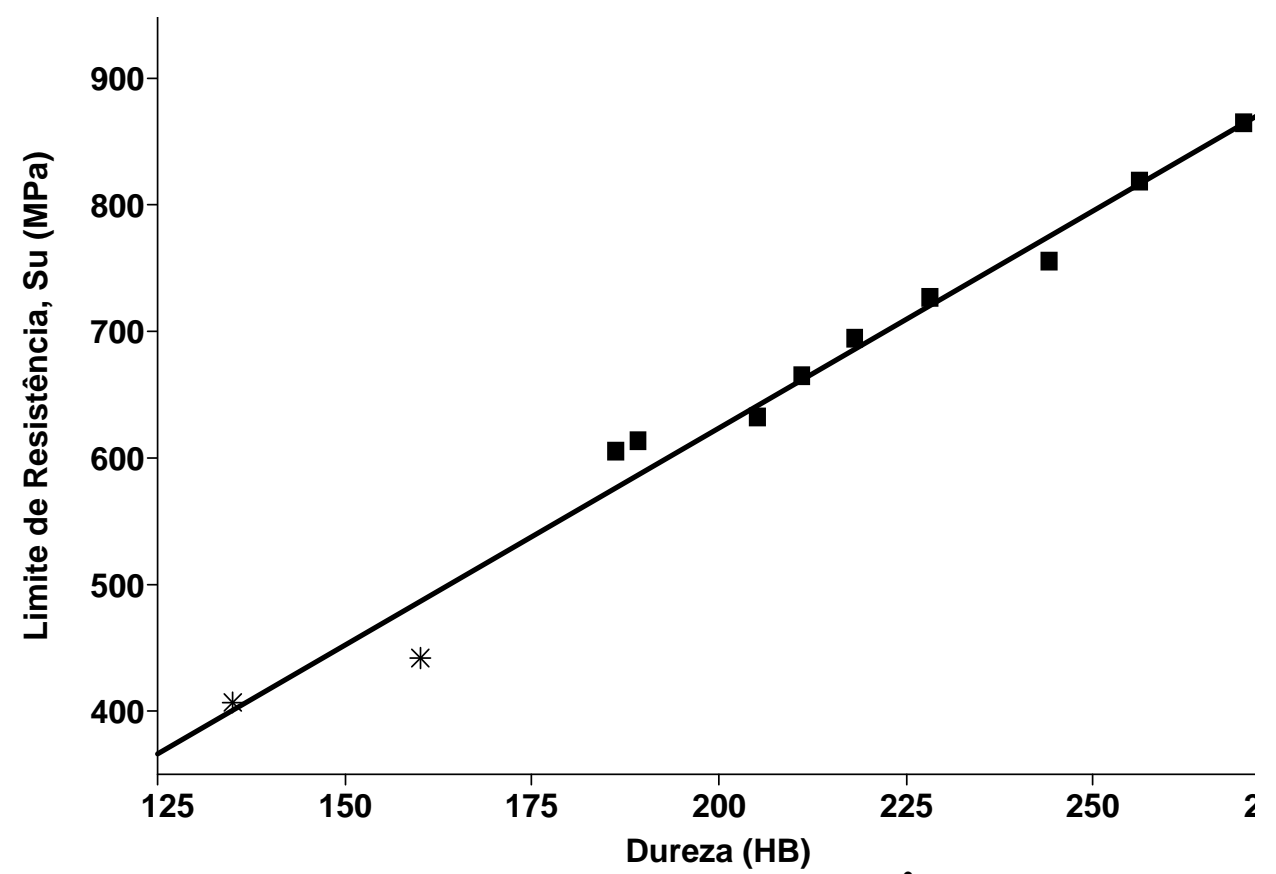

Figura 71: do limite de resistência com a dureza, $R^{2}=0,98(Q I \geq 80)$

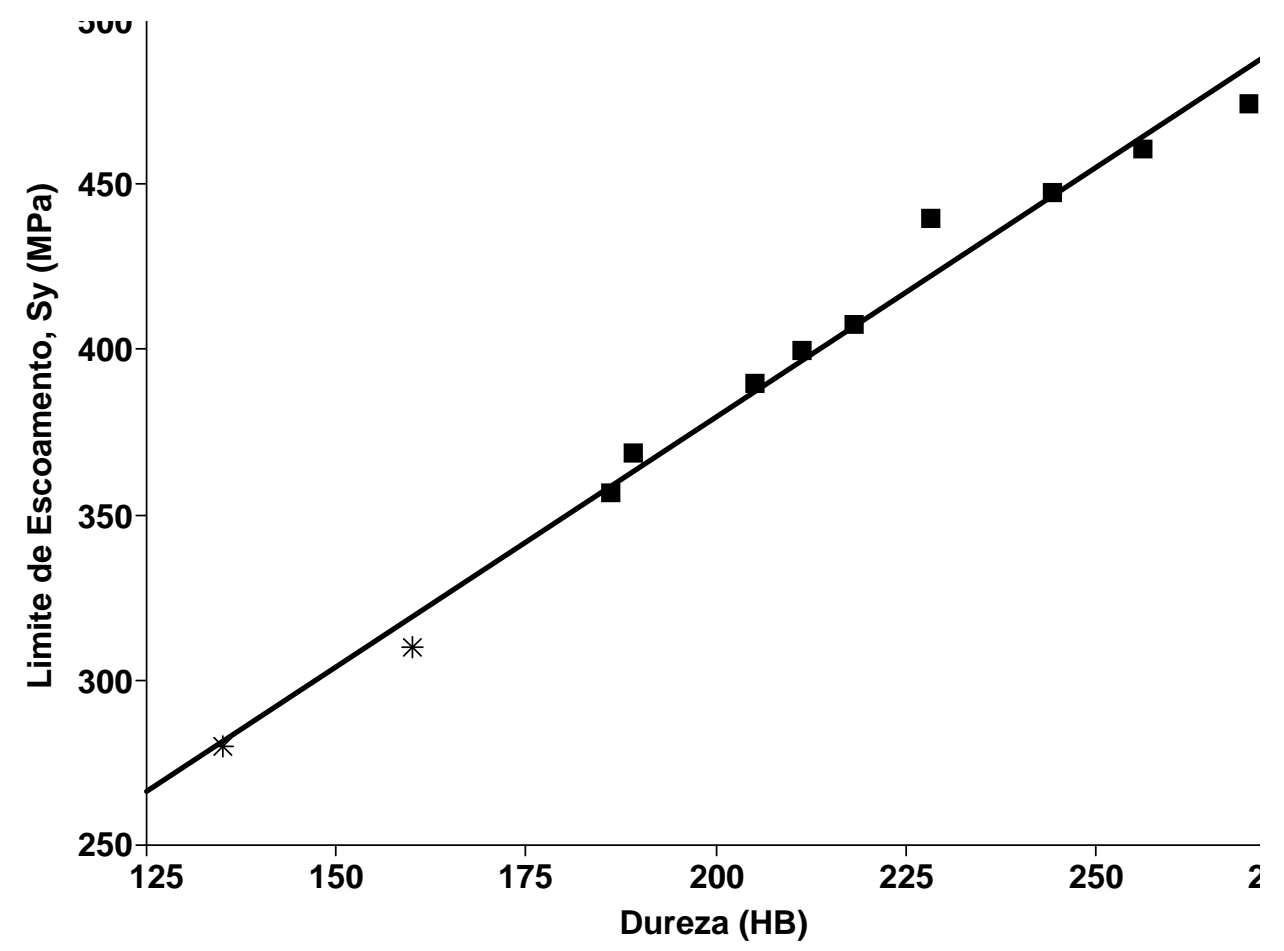

Figura 72: Relação do limite de escoamento com a dureza, $R^{2}=0,98(Q I \geq 80)$ 


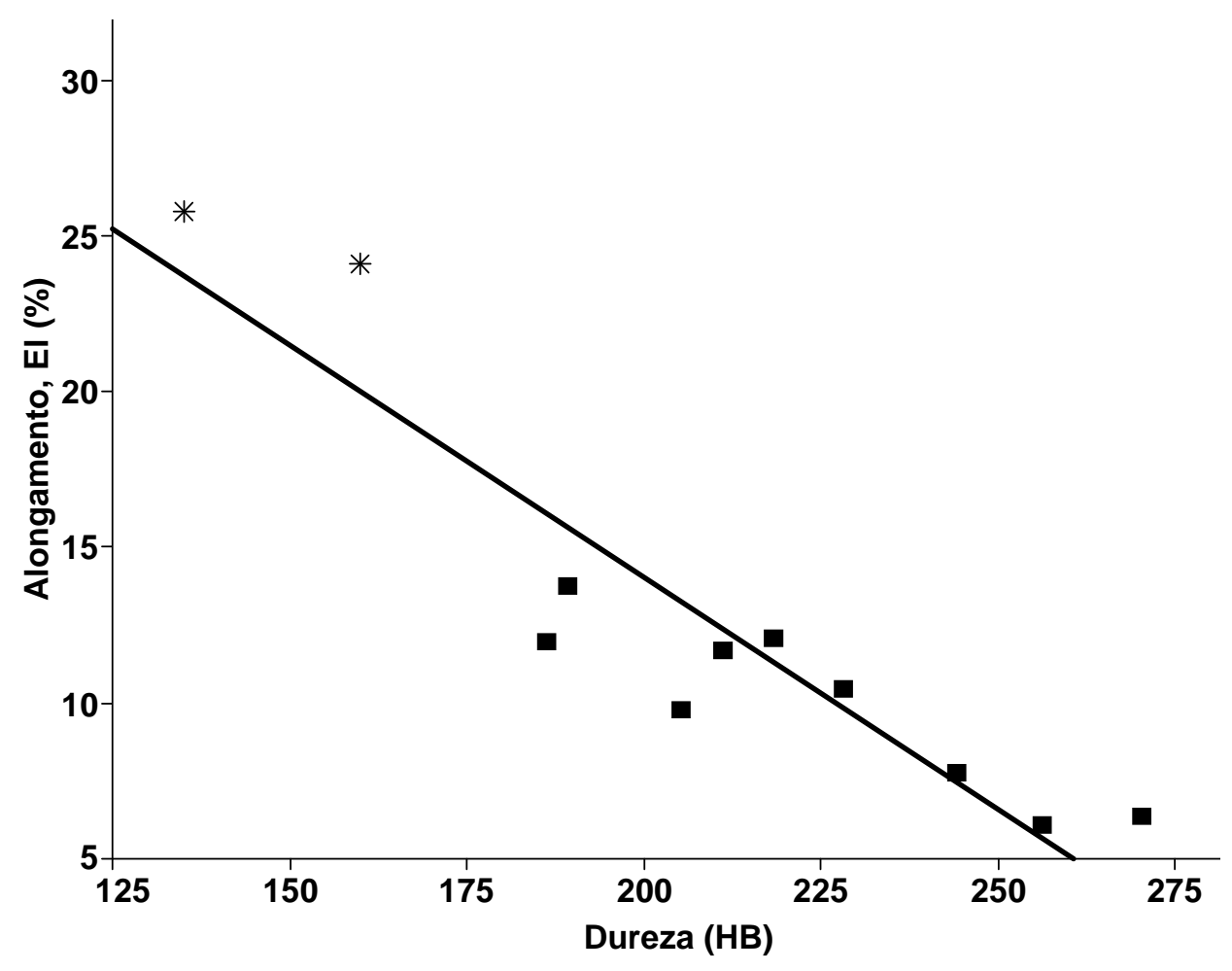

Figura 73: Relação do alongamento com a dureza $, R^{2}=0,85(Q I \geq 80)$

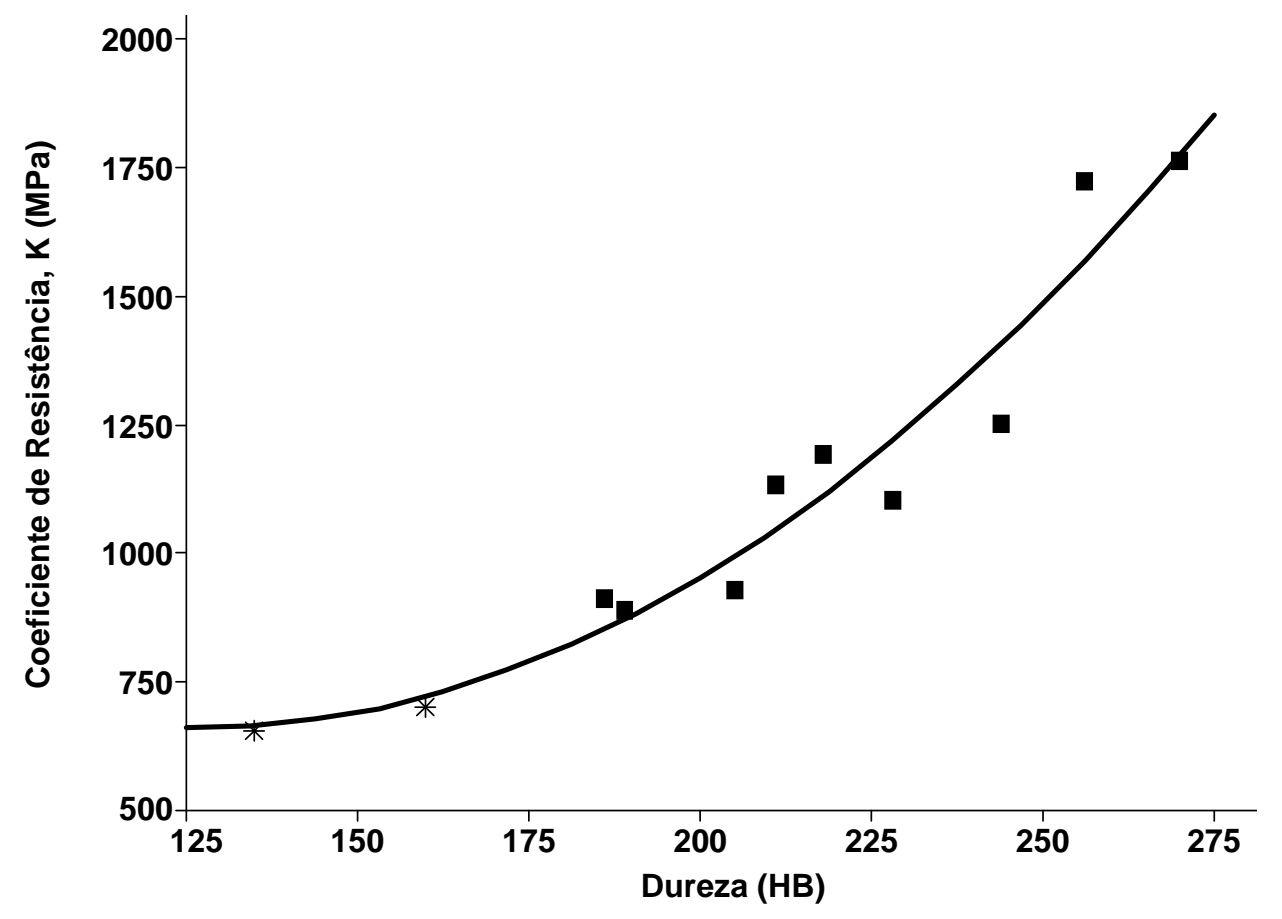

Figura 74: Relação do coeficiente de resistência com a dureza, $R^{2}=0,94(Q I \geq 80)$ 


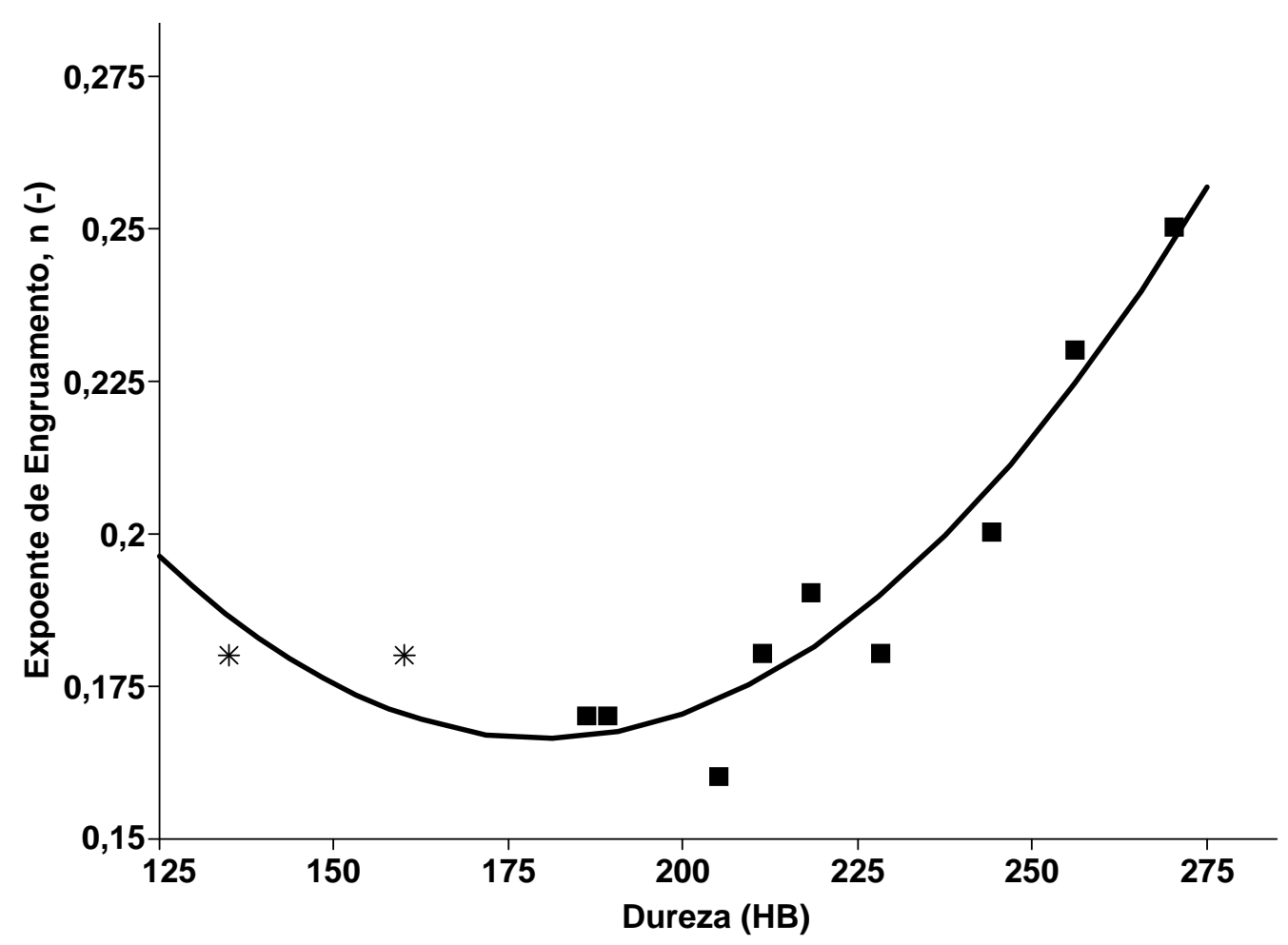

Figura 75: Relação entre o expoente de encruamento e a dureza, $R^{2}=0,92(Q I \geq 80)$

\subsubsection{Propriedades Cíclicas}

Analogamente às propriedades monotônicas foi feito a eliminação dos dados que não atendiam ao requisito de qualidade e a inclusão dos dados ensaiados neste estudo. Foi necessário fazer a exclusão de mais uma faixa de dureza além daquelas que não atendiam ao requisito de qualidade por que foi observado que houve um caso especial devido a uma variação fora dos limites de controle, neste caso, houve um valor discrepante do coeficiente de ductilidade que não é esperado para este tipo de material. 
Tabela 23: Propriedades Cíclicas dos Ferros Fundidos Nodulares - Complemento da literatura

\begin{tabular}{|c|c|c|c|c|c|c|c|c|c|c|c|c|c|c|}
\hline & & & \multicolumn{12}{|c|}{ Dureza (HB) } \\
\hline & & & 130 & 160 & 189 & 211 & 218 & 228 & 236 & 250 & 250 & 256 & 259 & 270 \\
\hline Coef. de Resistência a Fadiga & $\sigma_{f}^{\prime}$ & $\mathrm{MPa}$ & 761 & 787 & 723 & 842 & 1025 & 895 & 940 & 1045 & 983 & 1161 & 1003 & 1030 \\
\hline Exp. de Resistência a Fadiga & $\mathrm{b}$ & $(-)$ & $-0,09$ & $-0,09$ & $-0,06$ & $-0,07$ & $-0,10$ & $-0,07$ & $-0,11$ & $-0,10$ & $-0,09$ & $-0,11$ & $-0,10$ & $-0,08$ \\
\hline Coef. de Ductilidade & $\mathcal{E}_{f}^{\prime}$ & $(-)$ & 0,61 & 0,68 & 0,51 & 0,35 & 1,45 & 0,49 & 0,31 & 0,13 & 0,57 & 0,46 & 0,66 & 0,81 \\
\hline Exp. De Ductilidade & c & $(-)$ & $-0,76$ & $-0,77$ & $-0,68$ & $-0,65$ & $-0,87$ & $-0,69$ & $-0,78$ & $-0,55$ & $-0,73$ & $-0,71$ & $-0,90$ & $-0,72$ \\
\hline Coef. de Resistência Cíclico & $\mathrm{K}^{\prime}$ & $\mathrm{MPa}$ & 607 & 686 & 754 & 949 & 879 & 922 & 775 & 1124 & 1120 & 1295 & 1025 & 1230 \\
\hline Exp. de Endurecimento Cíclico & $\mathrm{n}^{\prime}$ & $(-)$ & 0,08 & 0,09 & 0,09 & 0,11 & 0,10 & 0,10 & 0,08 & 0,14 & 0,13 & 0,16 & 0,11 & 0,15 \\
\hline
\end{tabular}

\begin{tabular}{|c|c|c|c|c|c|c|c|c|c|c|c|c|c|c|}
\hline Indice de Qualidade & $\mathrm{QI}$ & $(-)$ & 90 & 99 & 108 & 102 & 121 & 115 & 49 & 65 & 56 & 84 & 50 & 99 \\
\hline \multirow{2}{*}{ Referências } & & & 3 & 3 & 1 & 2 & 2 & 1 & 2 & 3 & 1 & 2 & 2 & 2 \\
\hline & & & \multicolumn{4}{|c|}{ 1. Tartaglia, 2000} & 2. 1 & er L. & 197 & \multicolumn{5}{|c|}{2011} \\
\hline
\end{tabular}

Dados eliminados por não atenderem ao requisito de qualidade proposto no estudo $(Q \mid \geq 80)$

Dado eliminado devido às evidências de causa especial (Coeficiente de Ductilidade discrepante) 
As novas relações das propriedades cíclicas com a dureza estabelecidas após o tratamento dos dados estão listas nos gráficos a seguir:

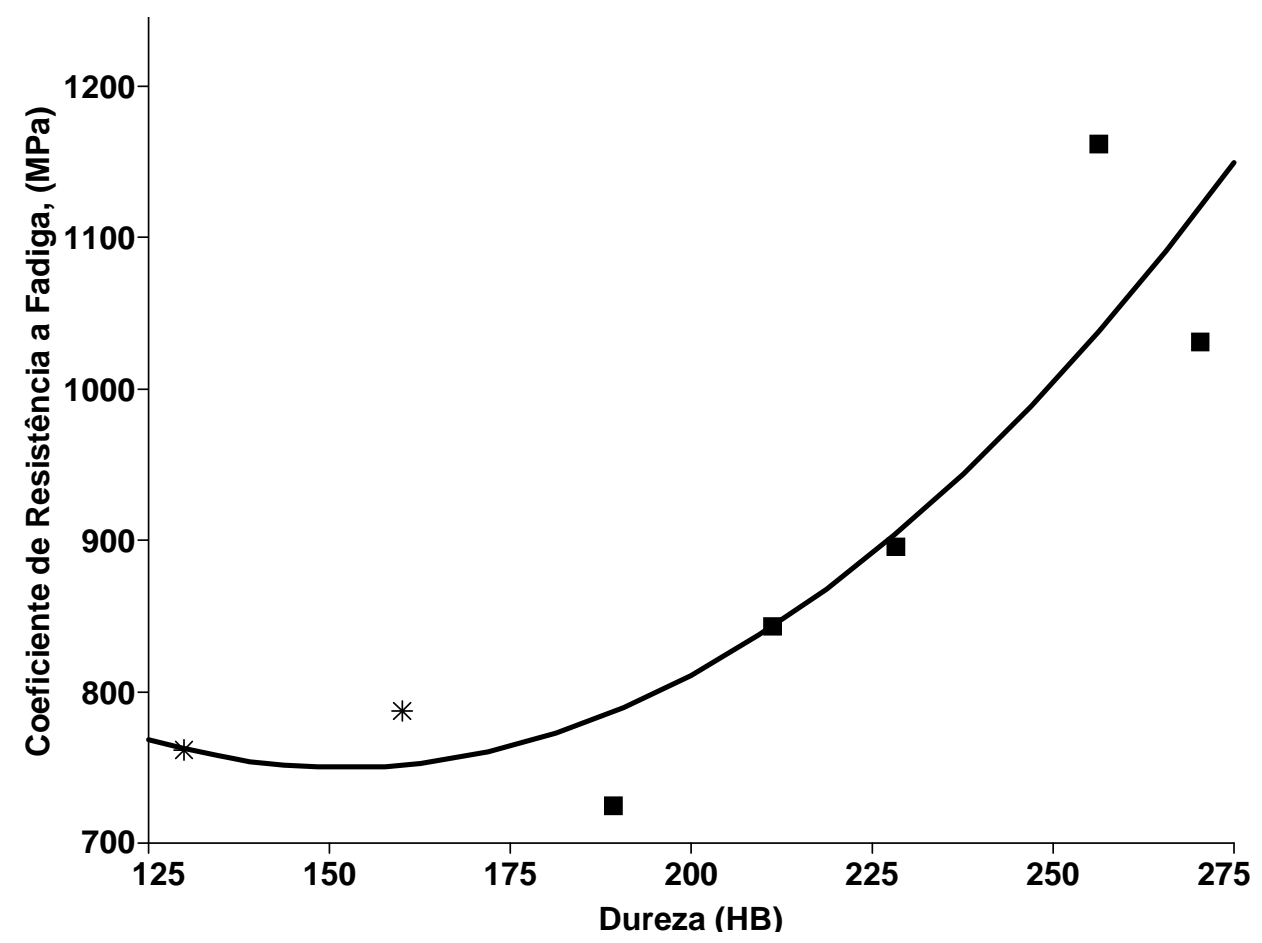

Figura 76: Relação entre o coeficiente de resistência a fadiga e a dureza, $R^{2}=0,81(Q I \geq 80)$

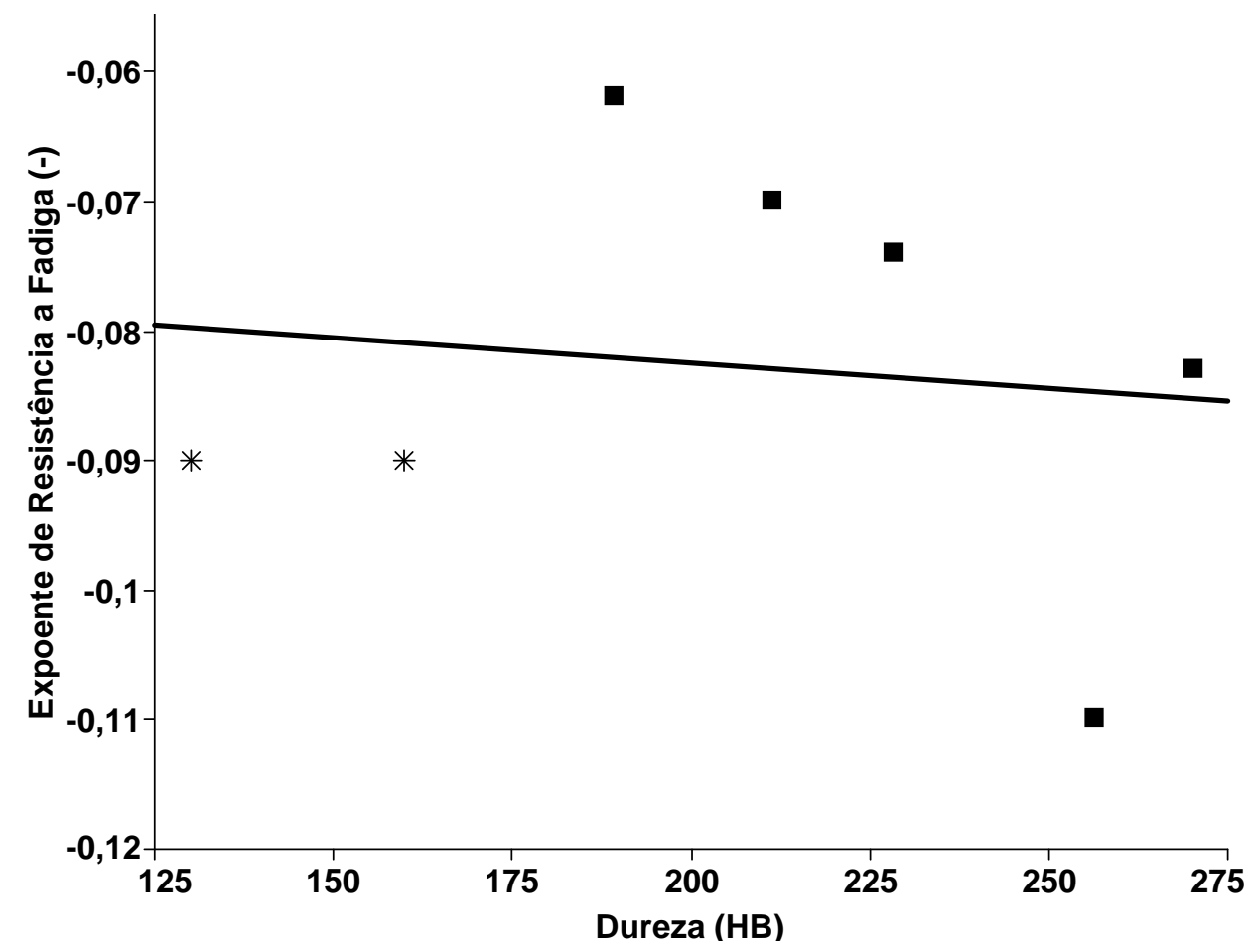

Figura 77: Relação entre o expoente de resistência a fadiga e a dureza, $\mathbf{R}^{2}=0,0(\mathrm{QI} \geq 80)$ 


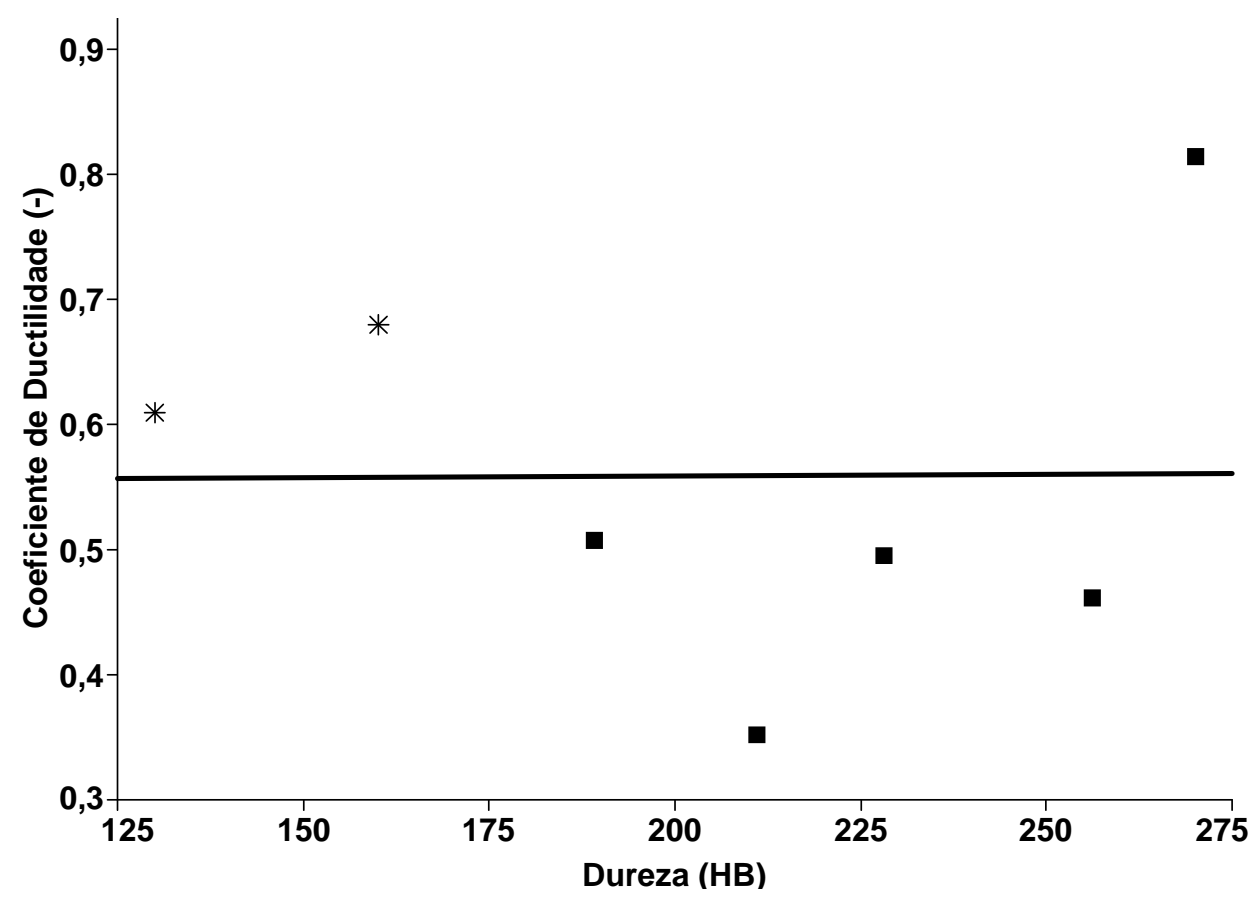

Figura 78: Relação entre o coeficiente de ductilidade e a dureza, $R^{2}=0,00(Q I \geq 80)$

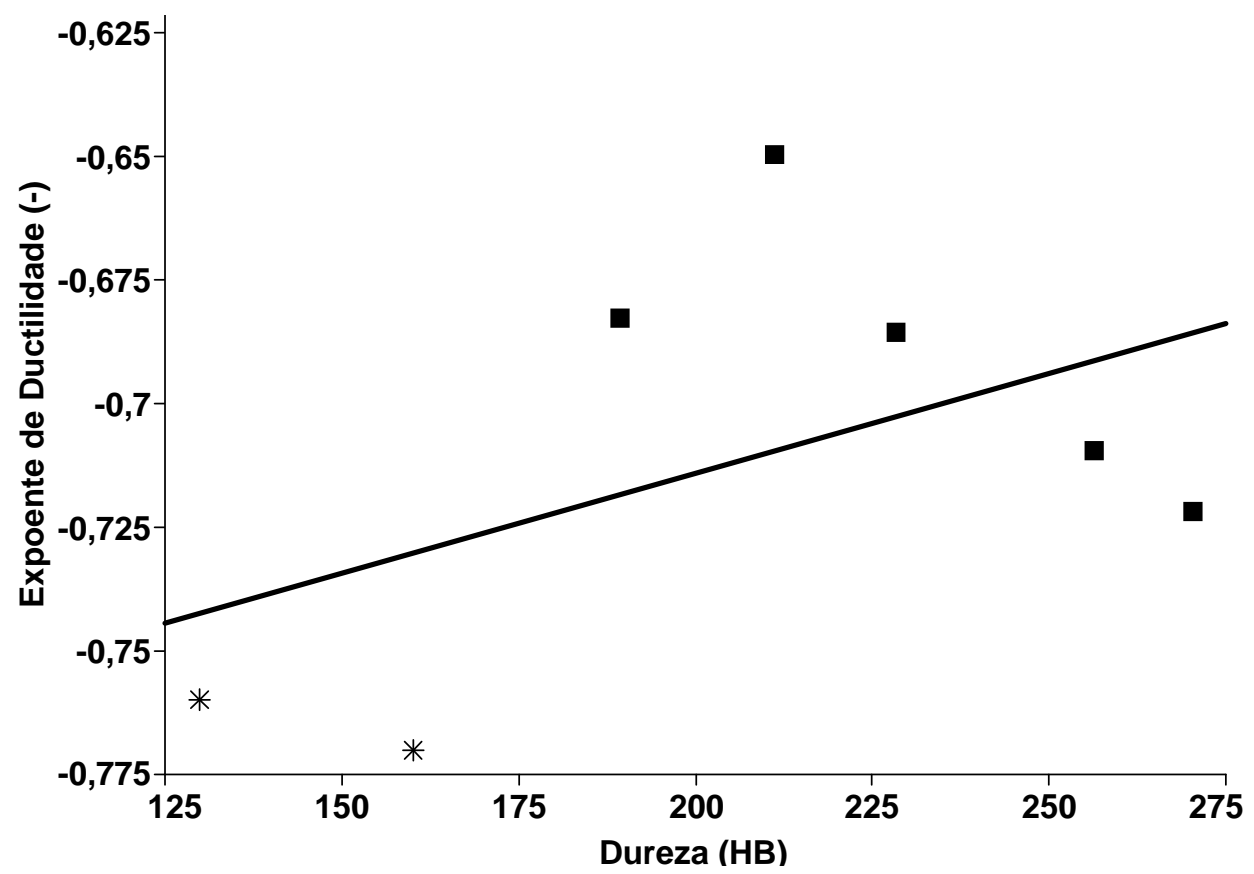

Figura 79: Relação entre o expoente de ductilidade e a dureza, $R^{2}=0,22(Q I \geq 80)$ 


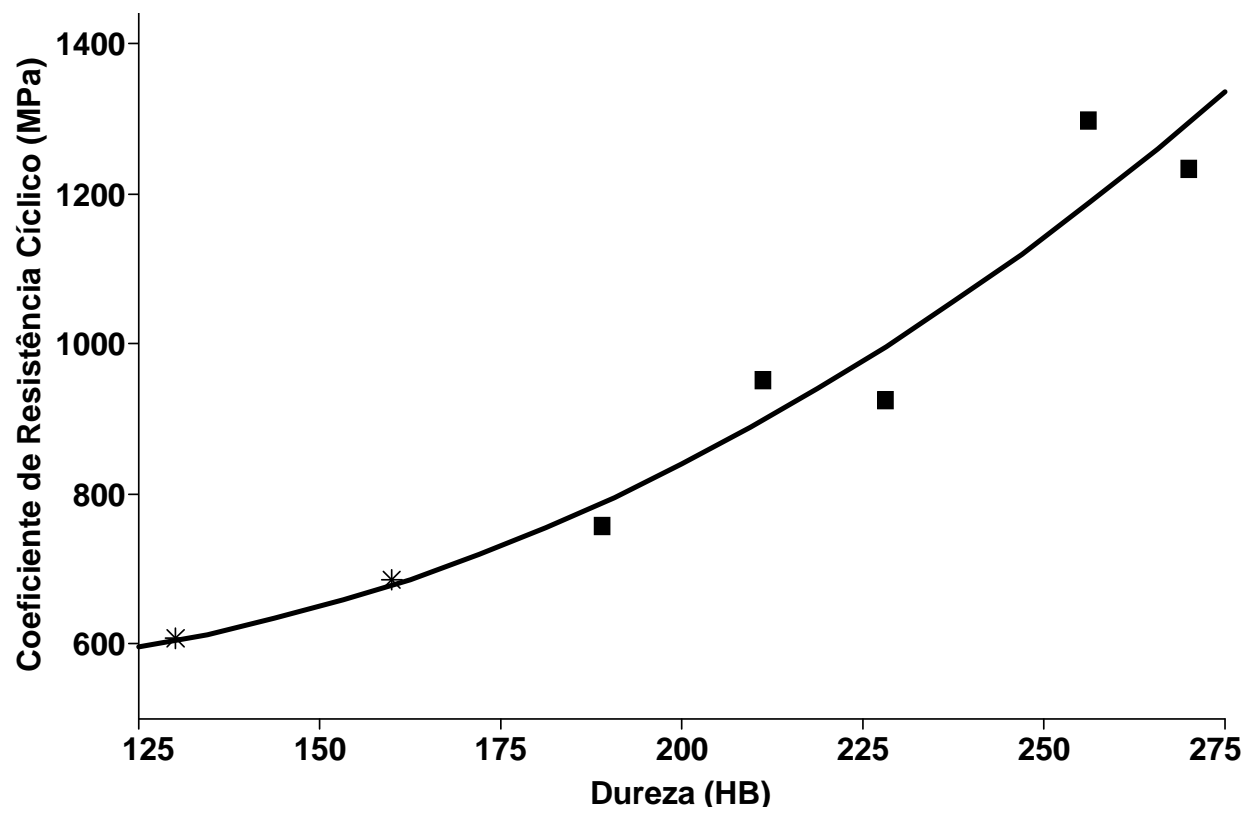

Figura 80: Relação entre o coeficiente de resistência cíclico e a dureza, $R^{2}=0,94(Q I \geq 80)$

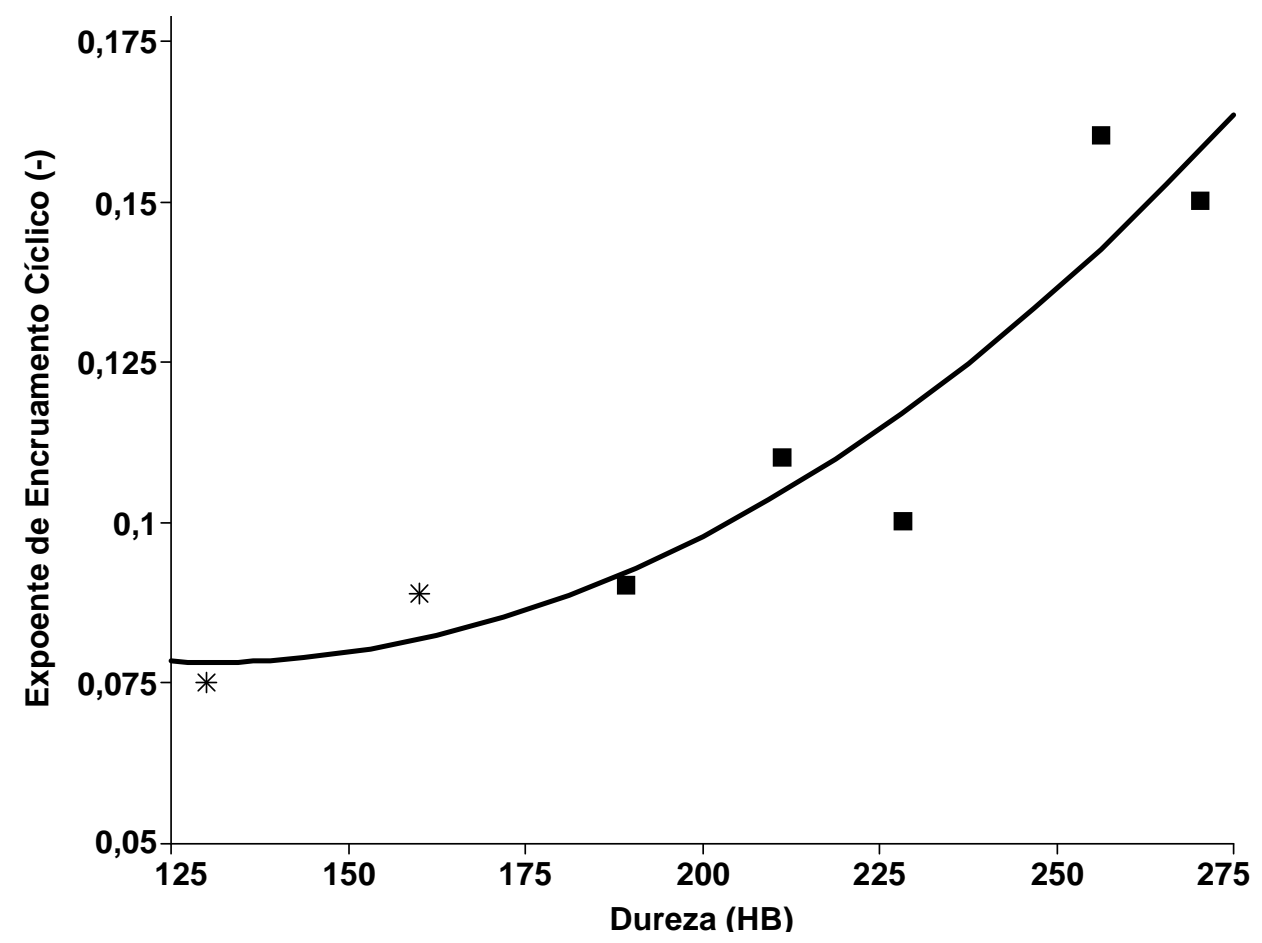

Figura 81: Relação entre o expoente de encruamento cíclico e a dureza, $R^{2}=0,88(Q I \geq 80)$ 


\subsubsection{Correlação e Ajuste das Propriedades Mecânicas com a Dureza}

Agora, tendo aumentado os dados disponíveis na literatura com novas faixas de dureza e a partir da seleção dos dados que possuíam qualidade satisfatória $(\mathrm{QI} \geq 80)$ é possível comparar os ganhos com relação aos dados da literatura que foram resumidos na Tabela 7, estes ganhos estão resumidos na Tabela 24: 
Tabela 24: Propriedades Cíclicas dos Ferros Fundidos Nodulares - Complemento da literatura

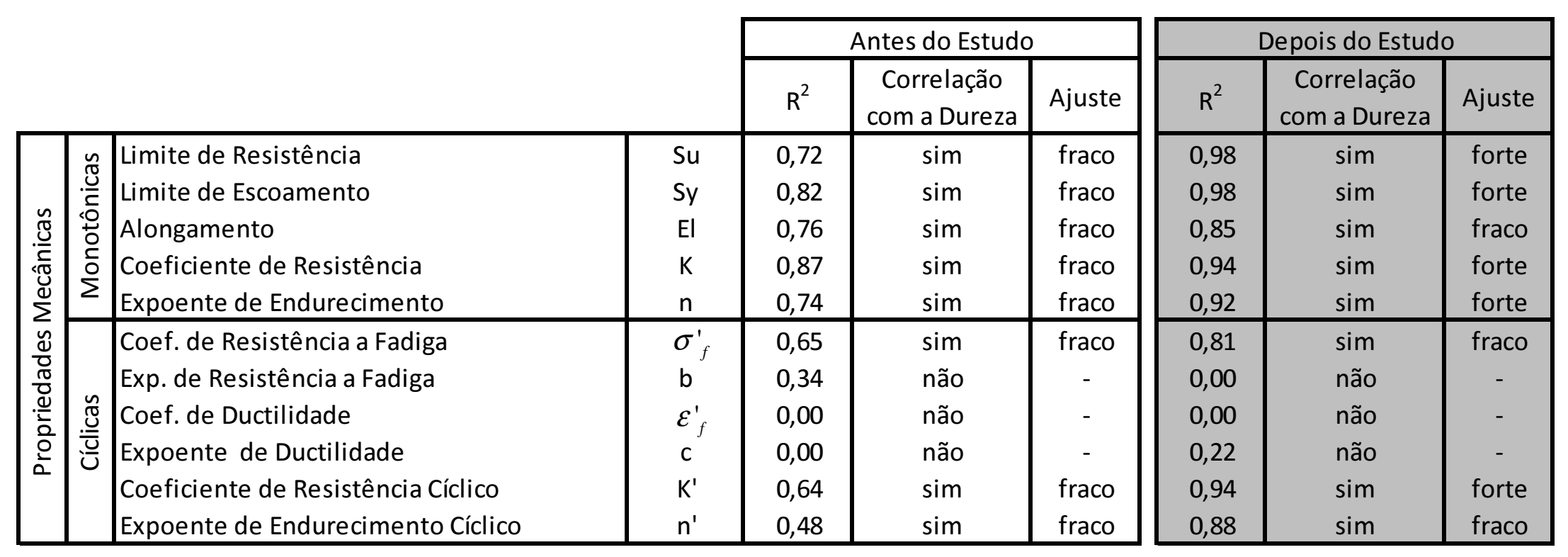


Portanto, observa-se que as correlações das propriedades monotônicas com a dureza foram mantidas, porém, os ajustes que eram considerados fracos se tornaram ajustes fortes $\left(\mathrm{R}^{2} \geq 0,90\right)$. Pode-se considerar o ajuste da curva de interpolação do Alongamento com a dureza um ajuste forte, pois, o valor do $\mathrm{R}^{2}$ correspondente a sua correlação com a dureza está muito próximo de 80 e sabe-se que esta dispersão dos valores do alongamento é devido as variações dos métodos experimentais para a sua determinação e não devido ao comportamento do material.

Com relação aos parâmetros que descrevem a resposta cíclica do material, com exceção do coeficiente de resistência cíclico e do expoente de resistência cíclico, concluíse que eles não se correlacionam com a dureza mesmo quando comparado somente ferros fundidos nodulares de qualidade satisfatória e que supostamente, devido ao fato de possuírem índice de qualidade maior do que 80, não possuíam defeitos que pudessem influênciar suas características mecânicas.

\subsubsection{Método Para Estimar as Propriedades Monotônicas}

Uma vez que as relações das propriedades monotônicas dos ferros fundidos nodulares com a dureza tiveram seus ajustes com a dureza melhorados, passando de ajustes fracos para ajustes fortes, é possível utilizar as equações contínuas com relação à dureza para estimar estes parâmetros que descrevem o comportamento monotônico deste tipo de material.

As relações propostas para estimar as propriedades monotônicas são apresentas nas equações IV.1, IV.2, IV.3, IV.4 e IV.5 no qual o símbolo $H B$ indica a dureza em escala Brinell. Estes modelos são aplicáveis a ferros fundidos nodulares com índice de qualidade igual ou superior a 80 : 
Modelo para estimativa do limite de resistência, $S_{u}$, em MPa:

$$
S_{u}=3,4 * H B-63
$$

Modelo para estimativa do limite de escoamento, $S_{y}, \mathrm{MPa}$ :

$$
S_{y}=1,5 * H B-78
$$

Modelo para estimativa do alongamento, $E l$, em \%:

$$
E l=43,9-1,5 e^{-1} * H B
$$

Modelo para estimativa do coeficiente de resistência, $K$,em MPa:

$$
K=5,4 e^{-2} *(H B-210)^{2}+8,9 * H B-838
$$

Modelo para estimativa do expoente de encruamento, $n,(-)$ :

$$
n=10 e^{-6} *(H B-210)^{2}+5,9 e^{-4} * H B+5,2 e^{-2}
$$




\subsubsection{Método Para Estimar as Propriedades Cíclicas}

Devido ao fato do coeficiente de resistência cíclico e do expoente de encruamento cíclico terem apresentado uma correlação forte com relação a dureza, então, é possível, analogamente às propriedades cíclicas, propor um método contínuo na dureza para estimar seus valores, cujos modelos estão propostos nas equações IV.6 e IV.7:

Método para estimativa do coeficiente de resistência cíclico, $K^{\prime}$,em MPa:

$$
K^{\prime}=2,2 e^{-2} *(H B-206)^{2}+5,9 * H B-203
$$

Método para estimativa do expoente de encruamento cíclico, $n^{\prime},(-)$ :

$$
n^{\prime}=4,1 e^{-6} *(H B-206)^{2}+6,2 e^{-4} * H B-2,6 e^{-2}
$$

Para os demais parâmetros que descrevem o comportamento cíclico dos ferros fundidos nodulares e são empregados na equação de MORROW (1965), por não terem apresentado nenhuma correlação com a dureza, é proposto um modelo discreto com relação à dureza.

Este modelo discreto consiste em recomendações de valores típicos por faixa de dureza. Estes valores foram definidos analisando as faixas de dureza no qual as propriedades cíclicas não apresentavam grandes variações. A figura 83 mostra a metodologia empregada usando como exemplo o coeficiente de resistência a fadiga, ${ }^{\prime}$ : 


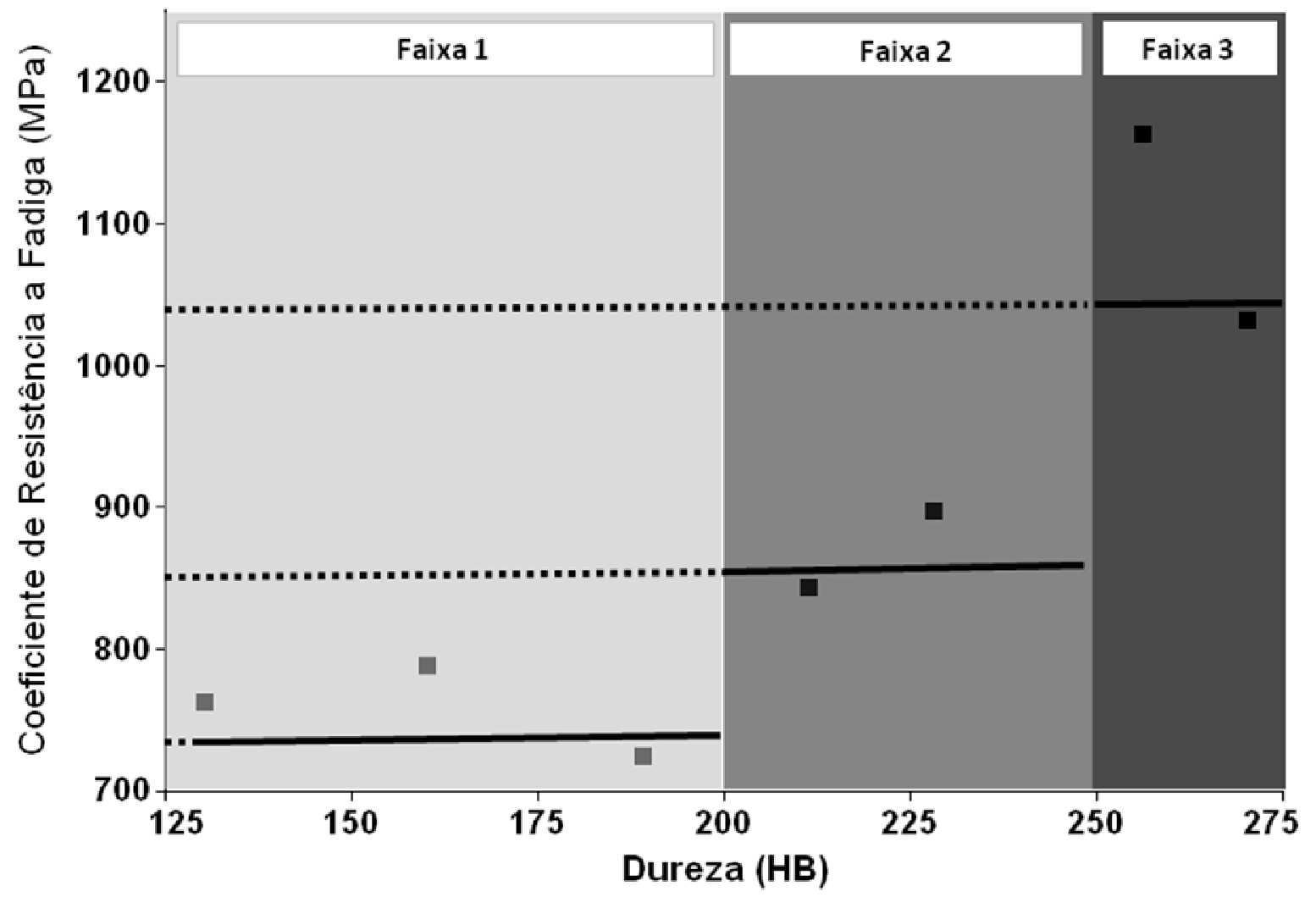

Figura 82: Método discreto para estimativa das propriedades cíclicas - exemplo coeficiente de resistência a fadiga.

Portanto, para o exemplo da figura 83 o valor recomendado para o coeficiente de resistência a fadiga de acordo para as faixas de dureza de 130-199HB, 200-249HB e 250$275 \mathrm{HB}$ seriam $730 \mathrm{MPa}, 850 \mathrm{MPa}$ e $1050 \mathrm{MPa}$, respectivamente. Estes valores recomendados são valores conservativos quando comparados aos valores encontrados nos ensaios para cada faixa, isto pode ser observado no exemplo do coeficiente de resistência a fadiga a partir da distribuição dos pontos dentro de cada faixa de dureza.

Seguindo esta metodologia seguem nas tabelas abaixo os valores dos parâmetros que descrevem o comportamento cíclico dos ferros fundidos nodulares com índice de qualidade igual ou superior a 80 . 
Método de estimativa do coeficiente de resistência a fadiga, $\sigma_{f}^{\prime}$, MPa:

\begin{tabular}{|l|c|c|c|}
\cline { 2 - 3 } \multicolumn{1}{c|}{} & \multicolumn{2}{c|}{ Dureza (HB) } & \multirow{2}{*}{$\sigma_{f}^{\prime}, M P a$} \\
\cline { 2 - 3 } \multicolumn{1}{c|}{} & Valor Min. & Valor Max. & \\
\hline Faixa 1 & 130 & 199 & 730 \\
\hline Faixa 2 & 200 & 249 & 850 \\
\hline Faixa 3 & 250 & 275 & 1050 \\
\hline
\end{tabular}

Tabela 25: Estimativa do coeficiente de resistência a fadiga

Método de estimativa do expoente de resistência a fadiga, $b,(-)$ :

\begin{tabular}{|l|c|c|c|}
\cline { 2 - 3 } \multicolumn{1}{c|}{} & \multicolumn{2}{c|}{ Dureza (HB) } & \multirow{2}{*}{} \\
\cline { 2 - 3 } \multicolumn{1}{c|}{} & Valor Min. & Valor Max. & \\
\hline Faixa 1 & 130 & 179 & $-0,09$ \\
\hline Faixa 2 & 180 & 249 & $-0,07$ \\
\hline Faixa 3 & 250 & 275 & $-0,11$ \\
\hline
\end{tabular}

Tabela 26: Estimativa do expoente de resistência a fadiga

Método de estimativa do coeficiente de ductilidade, $\mathcal{E}_{f}^{\prime},(-)$ :

\begin{tabular}{|l|c|c|c|}
\cline { 2 - 3 } \multicolumn{1}{c|}{} & \multicolumn{2}{c|}{ Dureza (HB) } & \multirow{2}{*}{$\mathcal{E}_{f}^{\prime},(-)$} \\
\cline { 2 - 3 } \multicolumn{1}{c|}{} & Valor Min. & Valor Max. & \\
\hline Faixa 1 & 130 & 179 & 0,60 \\
\hline Faixa 2 & 180 & 275 & 0,45 \\
\hline
\end{tabular}

Tabela 27: Estimativa do coeficiente de ductilidade

Método de estimativa do expoente de ductilidade, $c$, (-):

\begin{tabular}{|l|c|c|c|}
\cline { 2 - 3 } \multicolumn{1}{c|}{} & \multicolumn{2}{c|}{ Dureza (HB) } & \multirow{2}{*}{$\mathcal{C},(-)$} \\
\cline { 2 - 3 } \multicolumn{1}{c|}{} & Valor Min. & Valor Max. & \\
\hline Faixa 1 & 130 & 179 & $-0,75$ \\
\hline Faixa 2 & 180 & 249 & $-0,65$ \\
\hline Faixa 3 & 250 & 275 & $-0,70$ \\
\hline
\end{tabular}

Tabela 28: Estimativa do coeficiente de ductilidade 


\section{PARTE V}

\subsection{Estudo de Caso}

Visando exemplificar a metodologia apresentada no presente trabalho foi escolhido como estudo de caso um redutor de rodas de colheitadeira, a figura 83 mostra a posição de montagem do redutor de rodas na colheitadeira. Observe que o redutor de rodas (azul) é montado em uma viga (comumente denominada de "axle beam") que por sua vez é montada no chassi da colheitadeira.

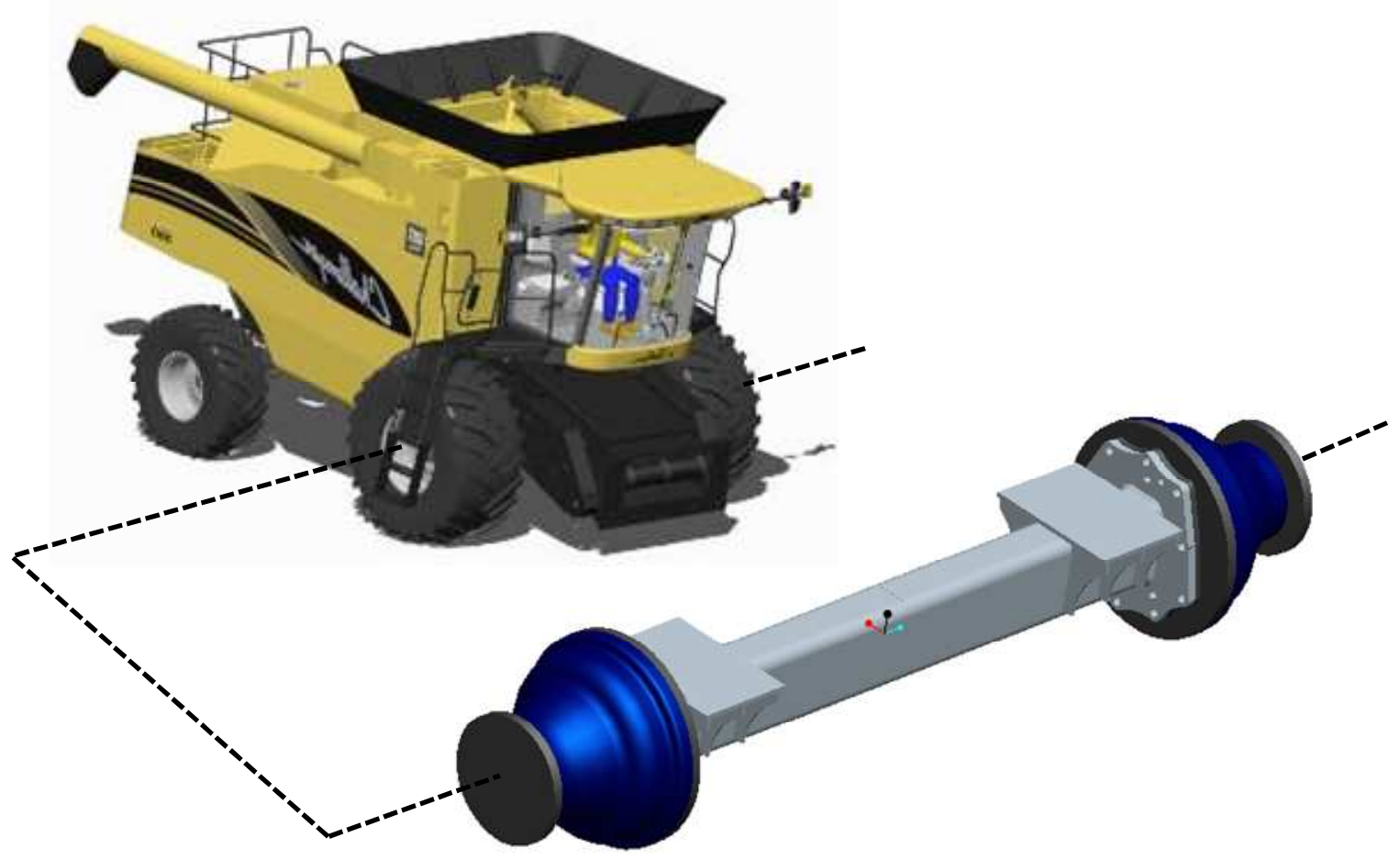

Figura 83: Redutor de roda de uma colheitadeira - montagem

O redutor de rodas da colheitadeira é composto por uma carcaça principal, uma carcaça de fixação do redutor na viga do chassi (“axle beam”) e por um eixo flange no qual a roda é fixada, observe a figura 84: 


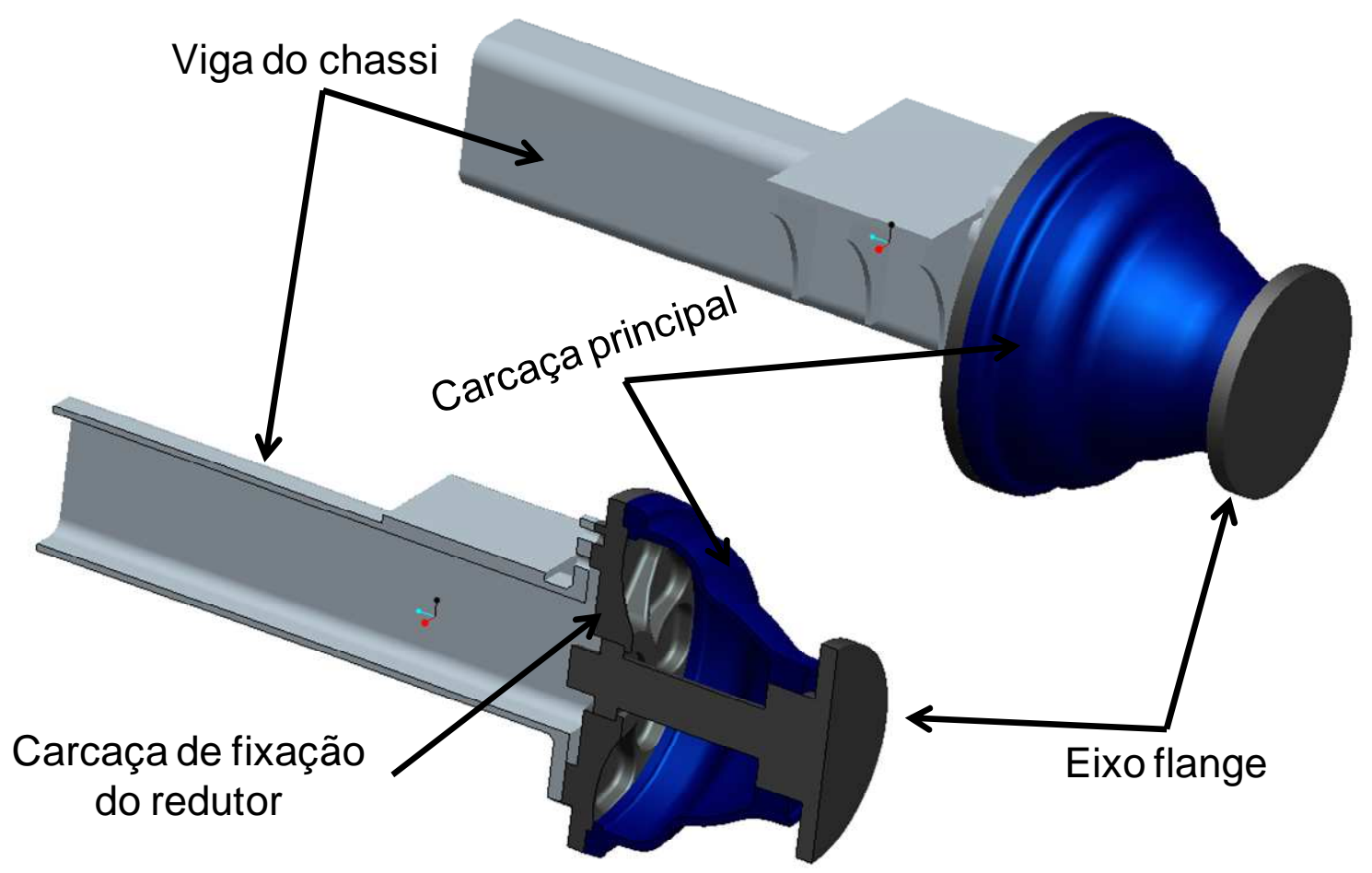

Figura 84: Detalhe em corte do redutor de rodas

O componente de interesse neste estudo de caso é a carcaça de fixação do redutor na viga do chassi da colheitadeira, também denominada de "tampa" do redutor (figura 85). O redutor é composto também por engrenagens internas que foram desconsideradas nesta análise por que elas não influenciam o comportamento estrutural da carcaça de fixação do redutor na viga do chassi, peça de interesse nesta análise.

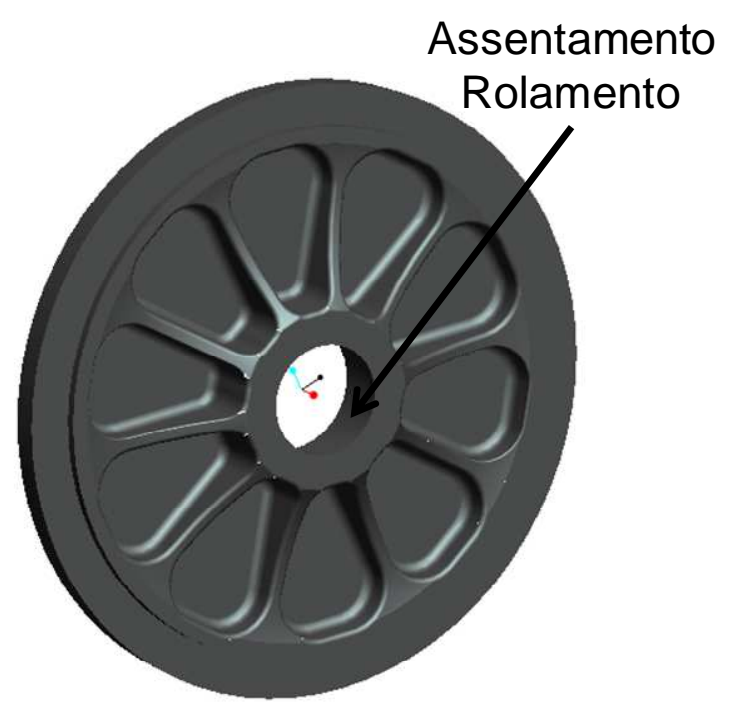

Vista frontal

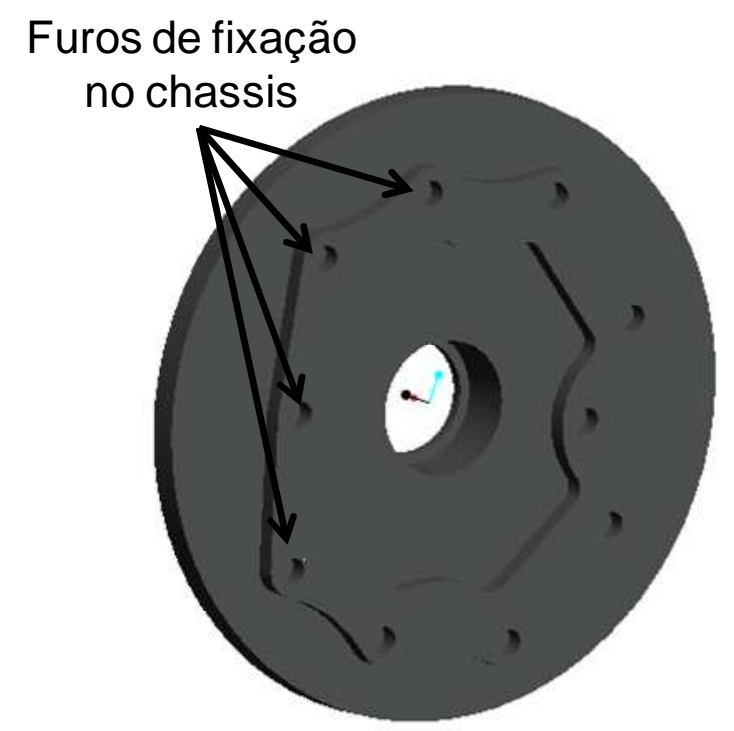

Vista traseira

Figura 85: Carcaça de fixação do redutor no chassi - tampa do redutor 
As análises estruturais foram realizadas no software ANSYS e os componentes modelados são simplificações dos componentes reais do redutor de rodas da colheitadeira.

\subsubsection{Condições de Contorno e Carregamento}

Para a realização da simulação foi usado simetria

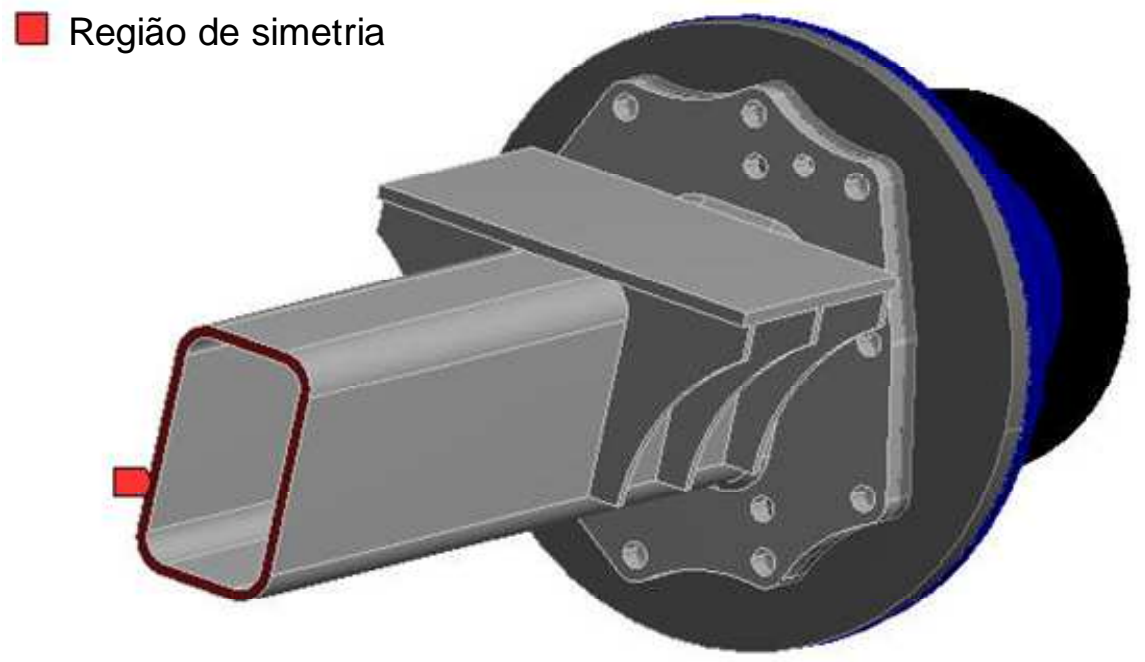

Figura 86: Região de Simetria

A condição de restrição da peça está descrita na figura 87:

A] Força

Suporte fixo

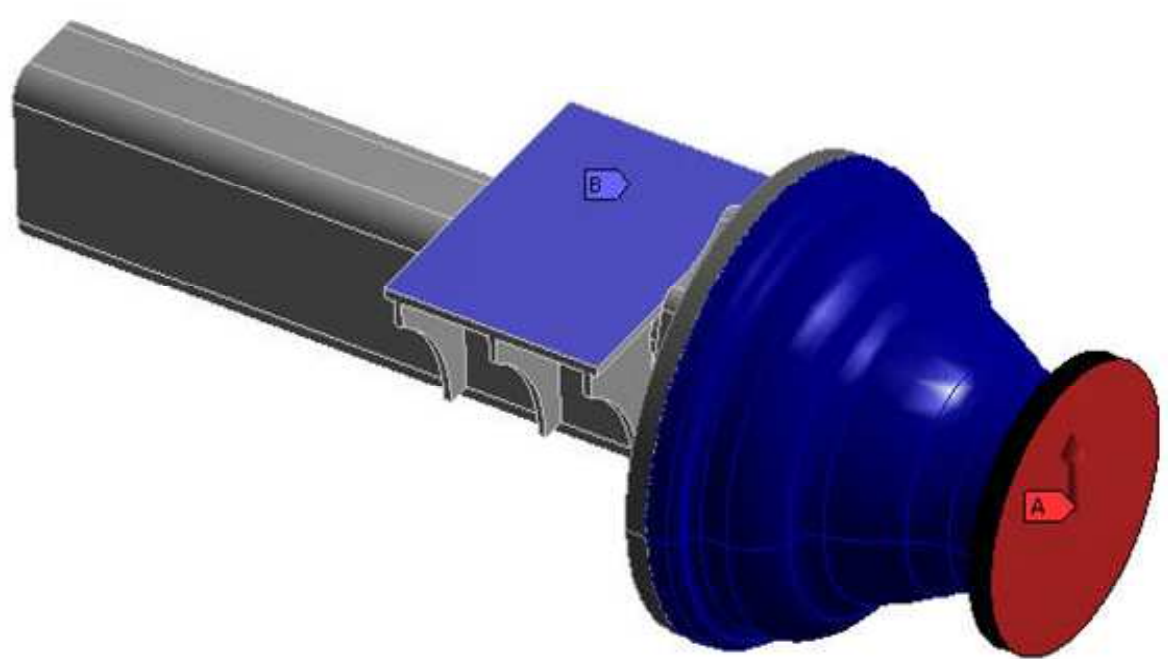

Figura 87: Condições de Contorno - restrição e esforço estrutural 
Como esforço estrutural foi considerado uma força vertical de 42 ton equivalente a distribuição do peso de uma colheitadeira de 35ton na roda dianteira (fator de carga dianteiro de $80 \%$ e traseiro de $20 \%$ ) com fator dinâmico igual a 3.

\subsubsection{Conexões e Malha de Elementos Finitos}

Na figura 88 estão descritos como foram modelados as conexões entre os componentes.

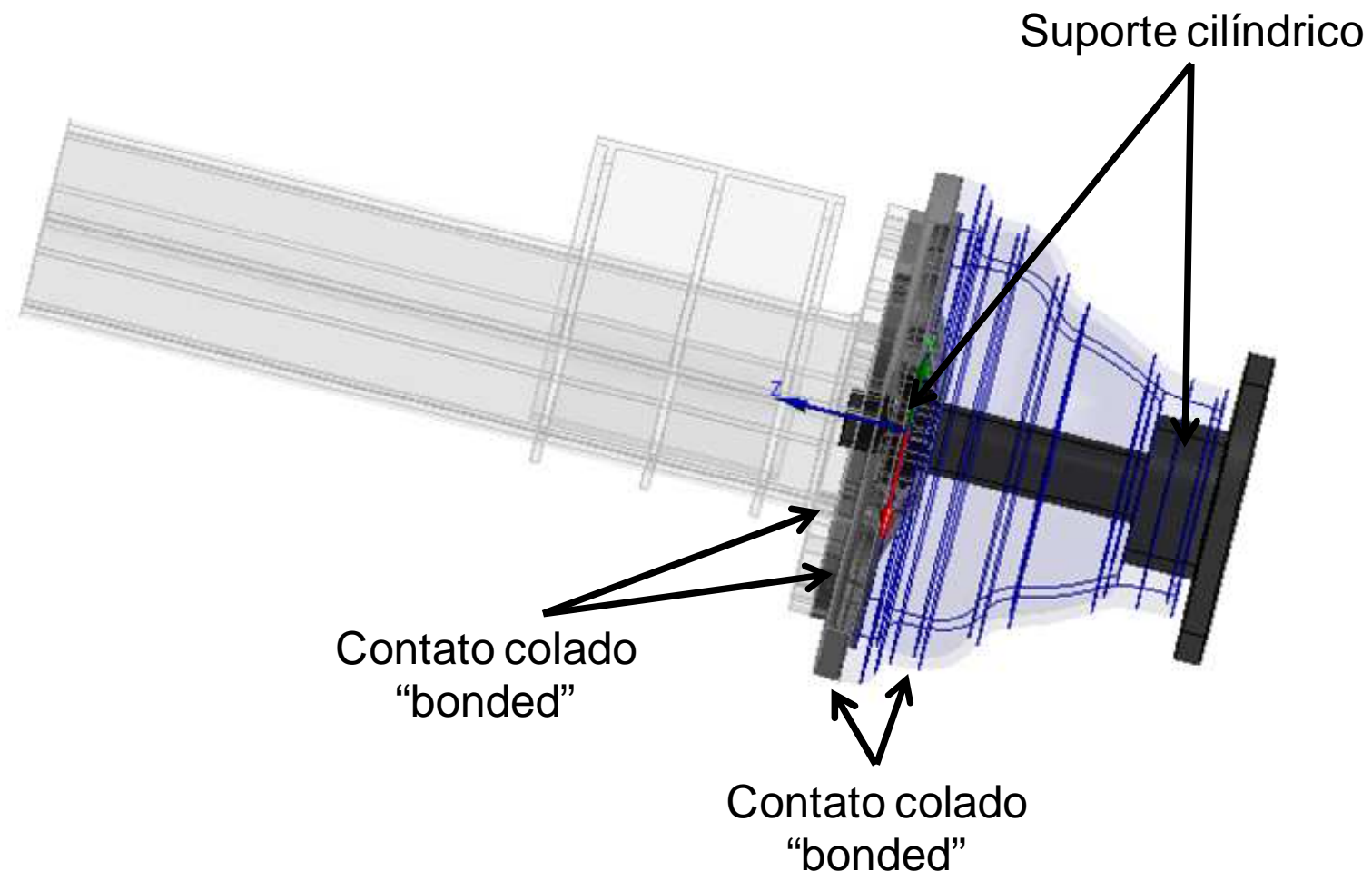

Figura 88: Modelamento das conexões entre os componentes 
Foram utilizados elementos sólidos de 10 nós denominados pelo programa ANSYS como Solid 167. No total foram usados 115758 elementos e o refinamento foi feito apenas no componente de interesse (carcaça de fixação do redutor na viga do chassi tampa do redutor) uma vez que a função dos demais componente era de apenas transmitir os esforços e as reações considerando as suas rigidezes. A discretização da malha pode ser observada na figura 89:

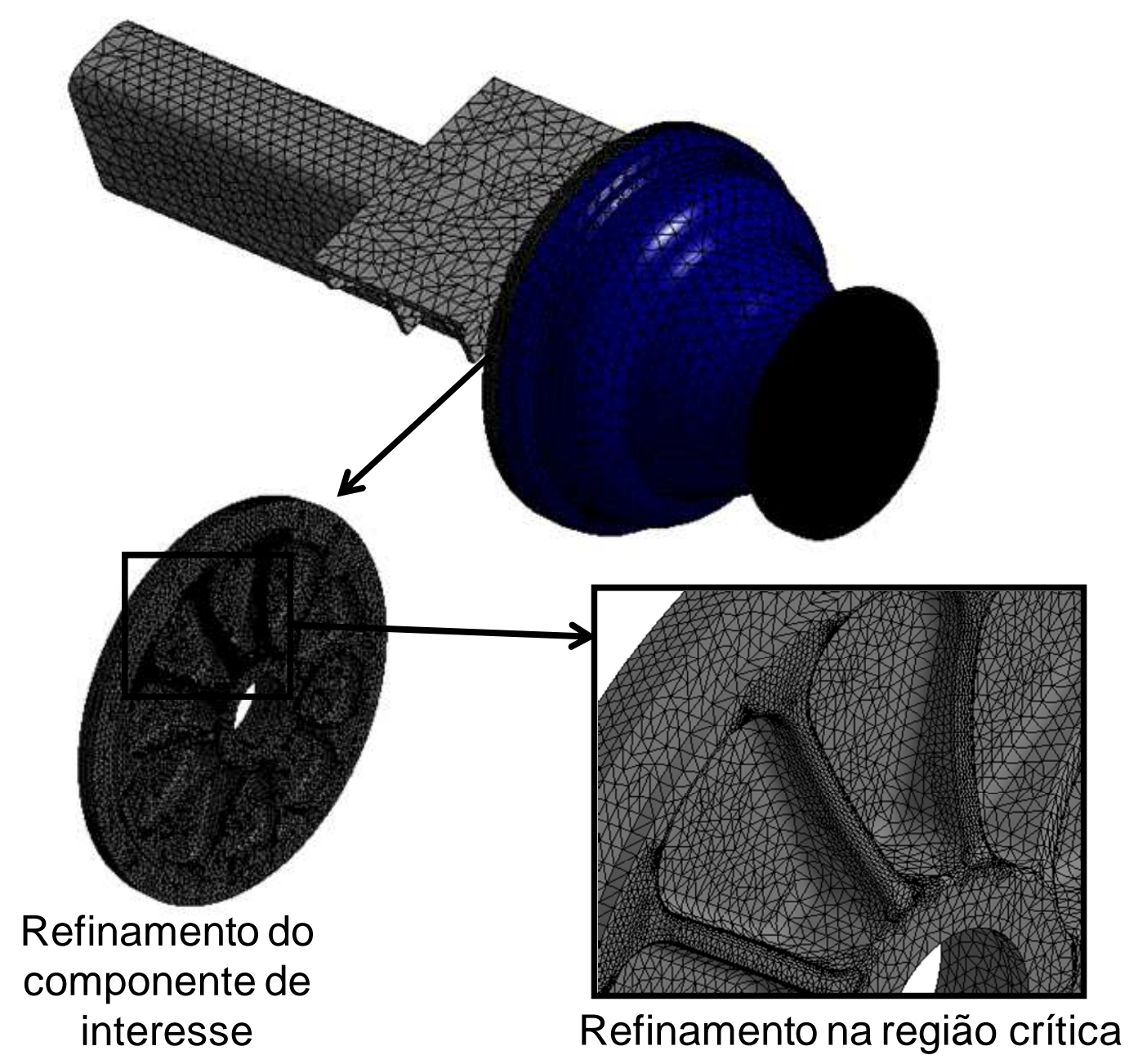

Figura 89: Malha de elementos finitos - ANSYS 


\subsubsection{Tensões}

A tensão máxima principal correspondente ao carregamento vertical aplicado foi de $464 \mathrm{MPa}$, conforme ilustrado na figura 90:

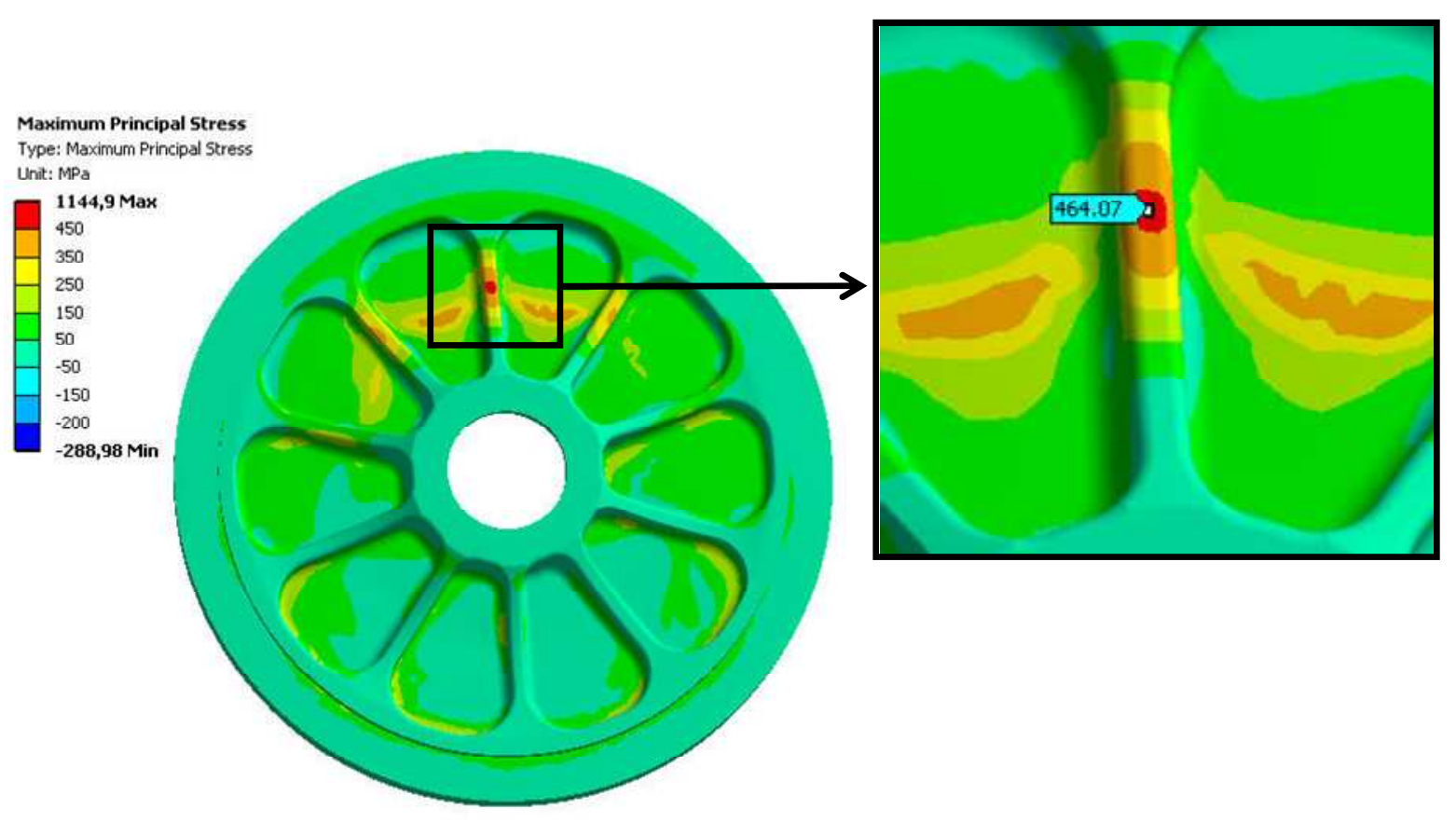

Figura 90: Tensão máxima principal, MPa

\subsubsection{Cálculos de Fadiga}

Para os cálculos de fadiga foram consideradas três condições, listadas na Tabela 29:

Tabela 29: Condições para os cálculos de fadiga e corresponde vida em fadiga

\begin{tabular}{|c|c|c|c|c|}
\hline Condição & Material & Dureza (HB) & Método de Calculo & Vida (Ciclos) \\
\hline 1 & Ferro Fundido Nodular & 160 & S-N & 317 \\
2 & Ferro Fundido Nodular & 160 & $\varepsilon-\mathrm{N}$ & 1866 \\
3 & Ferro Fundido Nodular & 250 & $\varepsilon-\mathrm{N}$ & 5278 \\
\hline
\end{tabular}

As propriedades de fadiga ( $\mathrm{S}-\mathrm{N}$ e $\varepsilon-\mathrm{N})$ para a condição de dureza de $160 \mathrm{HB}$ foram as mesmas da Classe B ensaiada e as propriedades de fadiga de baixo ciclo da condição de dureza de $250 \mathrm{HB}$ foram estimadas a partir do método proposto neste trabalho. As propriedades de fadiga consideradas nas análises estão listadas nas Tabelas 30 e 31: 
Tabela 30: Propriedades de fadiga da Condição 1 (S-N)

\begin{tabular}{|c|c|c|c|}
\hline & & & Condição 1 \\
\hline & & & $\begin{array}{l}\text { Dureza } \\
160 \mathrm{HB}\end{array}$ \\
\hline $\begin{array}{l}\text { Coef. de Resistência a Fadiga } \\
\text { Exp. de Resistência a Fadiga }\end{array}$ & $\begin{array}{r}S_{f}^{\prime} \\
\mathrm{b}\end{array}$ & $\begin{array}{c}\mathrm{MPa} \\
(-)\end{array}$ & $\begin{array}{c}928 \\
-0,09\end{array}$ \\
\hline
\end{tabular}

Tabela 31: Propriedades de fadiga das condições 2 e 3 (e-N)

\begin{tabular}{|l|c|c|c|c|}
\cline { 4 - 4 } \multicolumn{2}{l|}{} & & Condição 2 & Condição 3 \\
\cline { 4 - 5 } \multicolumn{2}{c|}{} & & $\begin{array}{c}\text { Dureza } \\
160 \mathrm{HB}\end{array}$ & $\begin{array}{c}\text { Dureza } \\
250 \mathrm{HB}\end{array}$ \\
\hline Coef. de Resistência à Fadiga & $\sigma_{f}^{\prime}$ & $\mathrm{MPa}$ & 787 & 1050 \\
Exp. de Resistência à Fadiga & $\mathrm{b}$ & $(-)$ & $-0,09$ & $-0,11$ \\
Coef. de Ductilidade à Fadiga & $\mathcal{E}^{\prime}$ & $(-)$ & 0,68 & 0,45 \\
Exp. De Ductilidade à Fadiga & $\mathrm{C}$ & $(-)$ & $-0,77$ & $-0,70$ \\
Coef. de Resistência Cíclico & $\mathrm{K}^{\prime}$ & $\mathrm{MPa}$ & 686 & 1315 \\
Exp. de Endurecimento Cíclico & $\mathrm{n}^{\prime}$ & $(-)$ & 0,09 & 0,14 \\
\hline
\end{tabular}

Nas figuras 91, 92 e 93 são mostradas as vidas em fadiga para cada condição, estas informações também estão resumidas na Tabela 29.

\section{Vida - Condição 1 (160HB/S-N)}

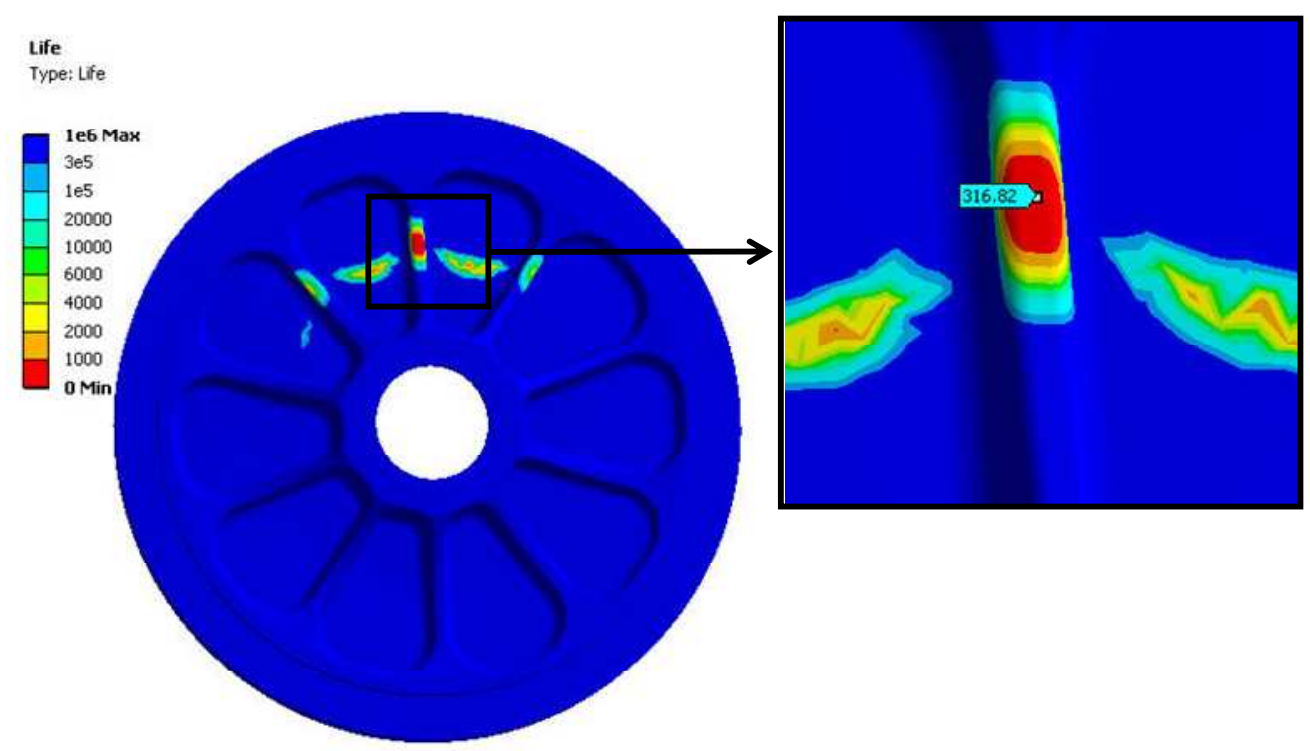

Figura 91: Vida estimada para a condição 1, Ciclos 
Vida - Condição $2(160 \mathrm{HB} / \varepsilon-\mathrm{N})$

Life

Type: Life

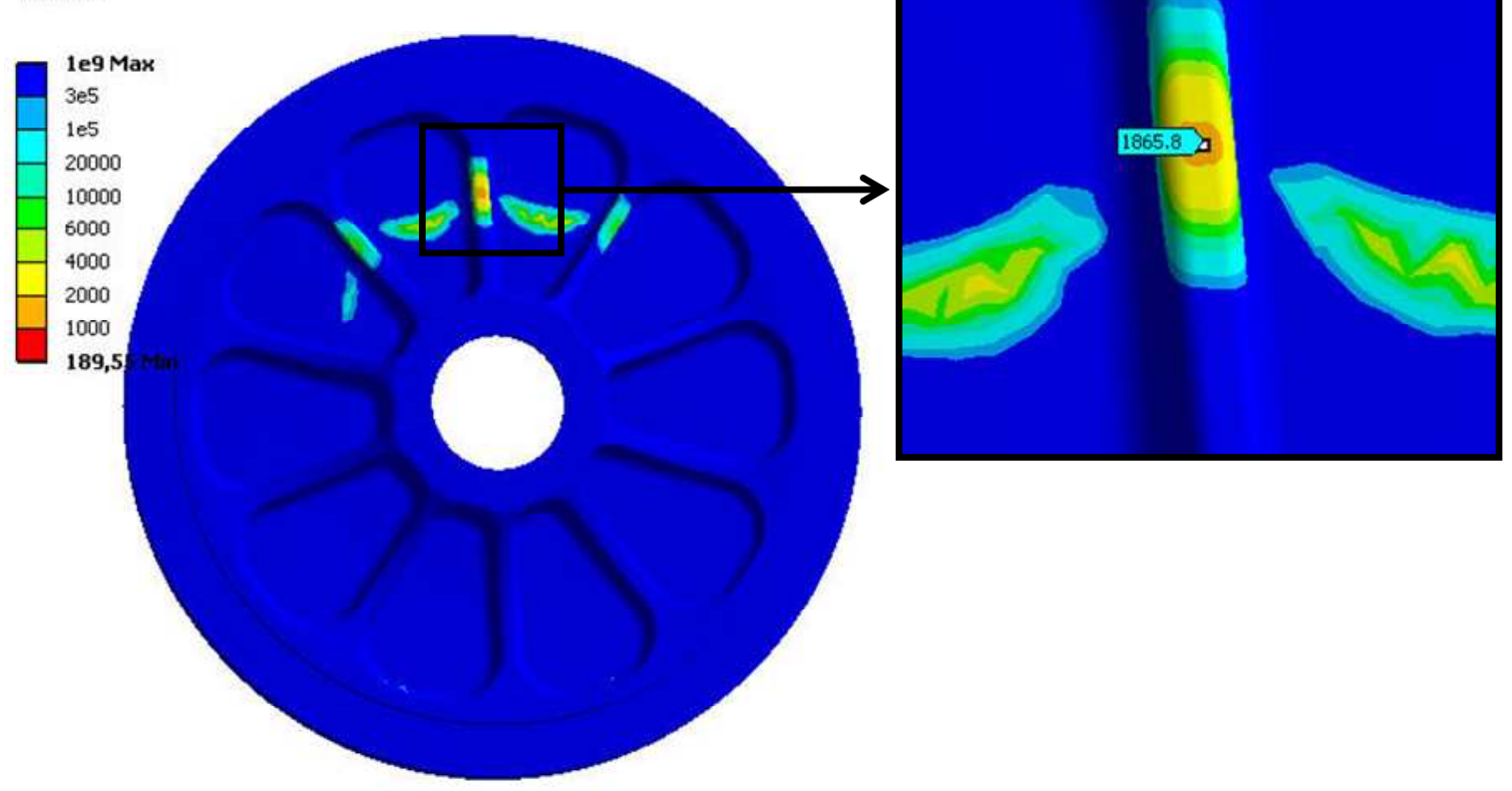

Figura 92: Vida estimada para a condição 2, Ciclos

Vida - Condição $3(250 \mathrm{HB} / \varepsilon-\mathrm{N})$

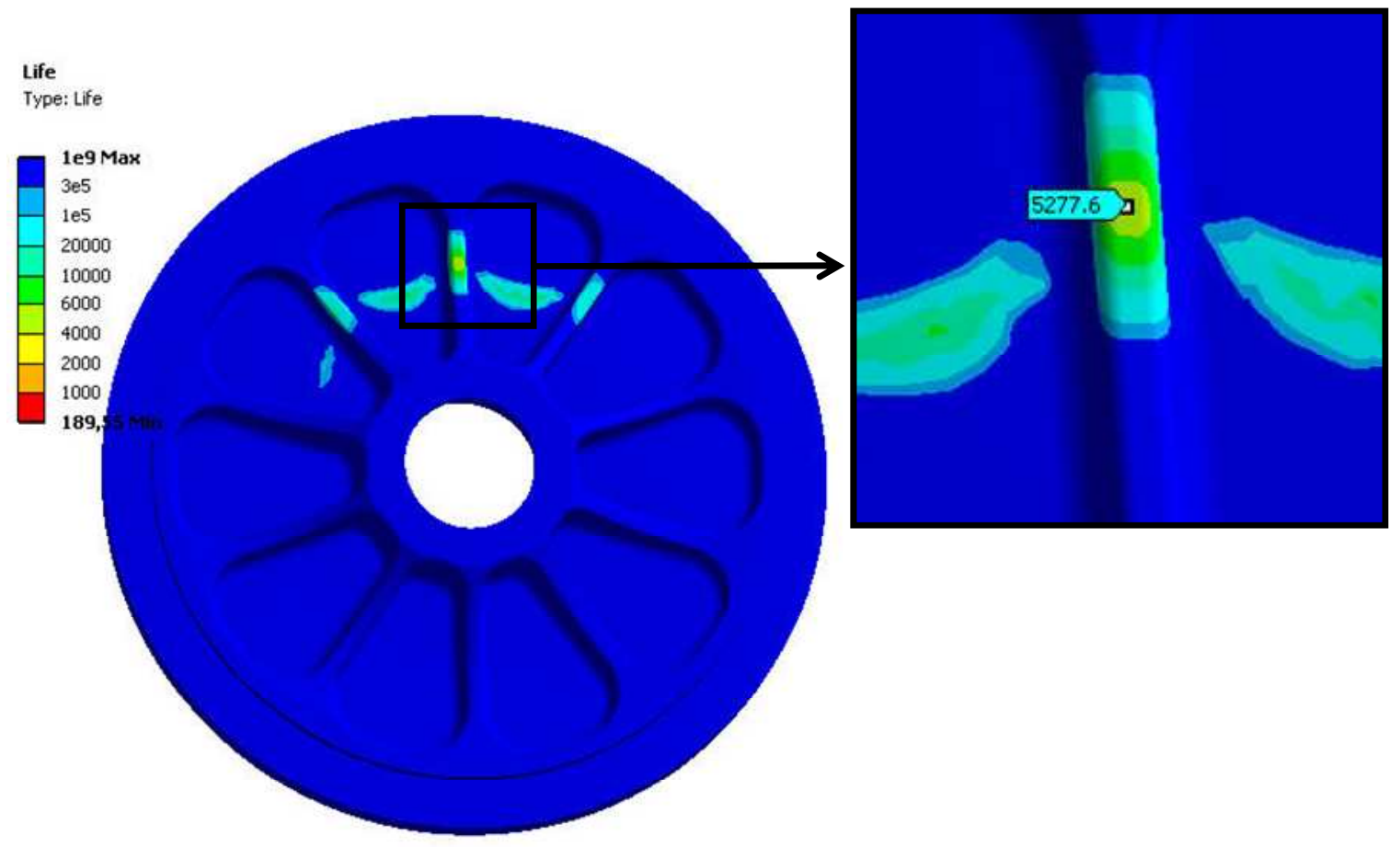

Figura 93: Vida estimada para a condição 3, Ciclos 
Comparando os resultados das análises de fadiga da condição 1 e da condição 2, cujas vidas determinadas foram de aproximadamente 320 e 1900 ciclos, respectivamente, nota-se uma grande diferença que é decorrente da metodologia adotada no cálculo da vida. $\mathrm{O}$ calculo feito para a condição 1 considerou a metodologia de fadiga de alto ciclo (S-N) enquanto na condição 2 foi empregado fadiga de baixo ciclo $(\varepsilon-\mathrm{N})$. Neste caso, pode-se afirmar que a vida determinada na condição 1 está errada, pois, a metodologia S$\mathrm{N}$ desconsidera os efeitos de plasticidade do material (observe que a tensão de $464 \mathrm{MPa}$ correspondente ao carregamento aplicado está acima da tensão de escoamento deste material que é de aproximadamente $310 \mathrm{MPa}$ ). Recomenda-se, portanto, em casos como este, utilizar a metodologia $\varepsilon-\mathrm{N}$ para levar em consideração os efeitos da plasticidade local e evitar erros de superdimensionamento estrutural.

A partir da comparação entre as condições 2 e 3, que levaram em consideração ferros fundidos nodulares com durezas de 160 e 250HB, respectivamente, é possível concluir que a variação de dureza pode também representar grande contribuição na variação da vida em fadiga. Observe que em ambos os casos foi utilizado o método $\varepsilon-\mathrm{N}$ para a determinação da vida em fadiga, porém, a condição 1 com dureza de 160HB apresentou uma vida de aproximadamente 1900 ciclos enquanto que na condição 2 de dureza de $250 \mathrm{HB}$ a vida determinada foi de aproximadamente 5300 ciclos. Variações de dureza da grandeza apresentada neste estudo de caso são possíveis de acontecer em componente com grandes variações geométricas e portanto, pode-se concluir que esta variação de dureza pode ter grande influência na vida em fadiga do componente conforme demonstrado neste estudo de caso. 


\subsection{Conclusões}

Com base no estudo desenvolvido foi possível melhorar as correlações das propriedades monotônicas com a dureza e estabelecer um método discreto, dividido por faixas de dureza, para a estimativa dos parâmetros que descrevem o comportamento cíclico dos ferros fundidos nodulares. A proposição de métodos estimativas das propriedades mecânicas dos ferros fundidos baseados na dureza é importante por que as suas características mecânicas são sensíveis a velocidade de solidificação devido as variações geométricas da peça, podendo-se haver diversas microestruturas e consequentes propriedades mecânicas diferentes em uma mesma peça e/ou grande divergência das propriedades mecânicas inicialmente consideradas no dimensionamento estrutural do componente.

Além da proposição dos métodos estimativos das propriedades monotônicas e cíclicas dos ferros fundidos nodulares, objetivo central do estudo, foi também mostrado o conceito do índice de qualidade e estabelecido um valor mínimo para representar os ferros fundidos nodulares com qualidade satisfatória $(\mathrm{QI} \geq 80)$. Foi comprovado que o índice de qualidade é capaz de identificar diversas deficiências microestruturais do material que podem afetar o seu comportamento mecânico, isto foi comprovado observando a melhoria da correlação das propriedades mecânicas com a dureza, que apresentaram menor dispersão. Este indicador tem grande aplicação prática, pois, sua obtenção se faz através do emprego do limite de resistência do material e do seu alongamento, que são propriedades obtidas no ensaio de tração.

Através dos ensaios de tração e de fadiga sob controle de deformação realizados nas amostras com faixas de dureza de 130-140HB, 155-160HB e 245-255HB foi possível aumentar os dados disponíveis na literatura (caracterização do material) e também observar diversas características deste material, como o seu endurecimento cíclico e a sua tendência de se tornar mais resistente às cargas cíclicas à medida que a sua matriz se torna mais perlítica. De acordo com os cálculos de replicação dos ensaios podem-se recomendar os dados obtidos neste estudo para projeto de componentes.

Também foi explorada a microestrutura dos ferros fundidos a partir das análises micrográficas, no qual foi possível notar a influência do tratamento térmico de 
ferritização na diminuição do tamanho dos nódulos de grafita e aumento da sua quantidade por área. Nota-se, com relação às propriedades mecânicas que este processo influenciou as propriedades monotônicas (houve o aumento da sua ductilidade e a diminuição do seu limite de resistência à tração), porém, não influenciou as suas propriedades cíclicas, isto foi comprovado na comparação feita entre as curvas de fadiga das faixas de dureza de 130-140HB e 155-165HB.

A partir das análises fractográficas foram mostrados a formação de vazios durante a fratura que são correspondentes às localizações dos nódulos de gráfica que foram separados da matriz durante o processo inicialização da trinca, propagação e fratura final.

Através do estudo de caso foi mostrada a grande divergência que pode existir quando a metodologia de cálculo de fadiga não é adequadamente aplicada, neste caso, quando se usa a metodologia de fadiga de alto ciclo (S-N) em casos onde há plasticidade local. Também foi exemplificado as possíveis diferenças no cálculo de fadiga provenientes de variações das propriedades metalúrgicas que podem ser medidos pelas variações da dureza.

Com relação às revisões sobre as metodologias de determinação da vida em fadiga, $\mathrm{S}-\mathrm{N}$ e $\varepsilon-\mathrm{N}$ foram destacadas as principais vantagens de cada método e também as suas limitações. De forma geral a metodologia $\varepsilon-\mathrm{N}$ possui a vantagem da contabilização da plasticidade local e pode ser usada tanto para regimes de alto ciclo como para regimes de baixo ciclo, porém, existe uma maior quantidade de informações sobre as propriedades de fadiga $\mathrm{S}-\mathrm{N}$ do que $\varepsilon-\mathrm{N}$ e também em casos no qual o processo de fabricação induz grandes alterações nas propriedades mecânicas, como por exemplo, processos de soldagem, conformação a frio e quando as condições superficiais do componente, rugosidade e acabamento superficial diferem das condições dos corpos de prova, recomenda-se ensaiar o componente ou mesmo a própria estrutura usando a metodologia de controle de tensão. 


\subsection{Sugestões para Trabalhos Futuros}

Recomenda-se para trabalhos futuros:

- Fazer a caracterização de outras faixas de dureza de ferros fundidos, mantendo o índice de qualidade igual ou superior 80 para aumentar a confiabilidade dos métodos propostos neste estudo;

- Avaliar a influência da qualidade do fundido nas suas propriedades. Isto pode ser feito a partir do ensaio de materiais de mesma dureza, porém, com índices de qualidade diferentes;

- Devido às poucas publicações sobre a qualidade de ferros fundidos, recomenda-se fazer um estudo dos principais parâmetros que influenciam o índice de qualidade e identificar melhorias no processo de fundição para melhorar a qualidade dos ferros fundidos nodulares e

- Aplicar o método apresentado (avaliação local das propriedades dos ferros fundidos a partir de estimativas da dureza e calculo de fadiga usando o método $\varepsilon-\mathrm{N}$ ) no dimensionamento de componentes estruturais - fazer caracterização da dureza, estimativa das propriedades mecânicas, dimensionamento estrutural e validação experimental 


\section{Referencias Bibliográficas}

American Society for Testing and Materials, ASTM E739-91 (2004): "Standard Practice for Statistical Analysis of Linear or Linearized Stress-Life (S-N) and Strain-Life (e-N) Fatigue Data, ASTM International, 2004

American Society for Testing and Materials, E 8M-01 (2001): "Standard test methods for tension testing of metallic materials", ASTM International, 2001

American Society for Testing and Materials, ASTM A247 (2010): "Standard Test Method for Evaluating the Microstructure of Graphite in Iron Castings1", ASTM International, 2010

American Society for Testing and Materials, ASTM A536 - 84 (2009): "Standard Specification for Ductile Iron Castings", ASTM International, 2009

American Society for Testing and Materials, ASTM E466-07 (2007): "Standard Practice for Conducting Force Controlled Constant Amplitude Axial Fatigue Tests of Metallic Materials", ASTM International, 2007

American Society for Testing and Materials, ASTM E 1012-99 (1999): "Standard practice for verification of specimen alignment under tensile loading", ASTM International, 1999

American Society for Testing and Materials, ASTM E 10 (2010): "Standard Test Method for Brinell Hardness of Metallic Materials”, ASTM International, 2010

American Society for Testing and Materials, ASTM E 606 (2004): "Standard Practice for Strain-Controlled Fatigue Testing”, ASTM International, 2004

B. L. SIMPSON 1969: "History of the Metalcasting Industry", American Foundrymen's Society, Des Plaines, IL, 1969.

O. H.,BASQUIN 1910, O. H.: "The exponential law of endurance tests", American Society for Testing and Materials Proceedings, Vol. 10, 1910, pp. 625-630, apud Y.,LEE 2005, P., Jwo, R., Hathaway and M., Barkey: "Fatigue Testing and Analyses" Theory and Practice, Elsevier, 2005.

C. A. PETER 2001: "Statistics for Analysis of Experimental Data", Environmental Engineering Laboratory Manual, S. E. Powers, Ed, AEESP, Champaign, IL, 2001, pp. 24

D. L. CREWS 1974: "Quality and Specification of Ductile Iron." Transactions, American Foundrymen’s Society, Vol. 82, 1974, pp 223-228.

D. P. KANICKI 1988: “Marketing of Ductile Iron”, Modern Casting, April, 1988.

W. Z., GERBER 1874, Calculation of the allowable stresses in iron structures, Z. Bayer Archit Ing Ver, Vol. 6, No. 6, 1874, pp. 101-110, apud Y.,LEE 2005, P., Jwo, R., Hathaway and M., Barkey: "Fatigue Testing and Analyses" Theory and Practice, Elsevier, 2005. 
J., GOODMAN 1899: "Journal of Mechanics Applied to Engineering, 1st ed., Longmans, Green, New York, 1899, apud Y.,LEE 2005, P., Jwo, R., Hathaway and M., Barkey: "Fatigue Testing and Analyses" Theory and Practice, Elsevier, 2005.

B. P., HAIGH 1917: "Experiments on the fatigue of brasses", Journal of the Institute of Metals, Vol. 18,1917, pp. 55-86, apud Y.,LEE 2005, P., Jwo, R., Hathaway and M., Barkey: "Fatigue Testing and Analyses" Theory and Practice, Elsevier, 2005.

J.D. MULLINS 1990, "Ductile Iron Data for EngineeR”, Rio Tinto Iron \& Titanium Inc. 1990.

K. MORTON 1980, "Monotonic and Fatigue Property Data of Several Steels and Cast Irons, Bristish Rail, England, 1980.

R. A., KUGUEL 1961: "Relation between theoretical stress concentration factor and fatigue notch factor deduced from the concept of highly stressed volume", American Society for Testing and Materials Proceedings, Vol. 61, 1961, pp. 732-748.

L. E. TUCKER 1975, "Monotonic Stress-Strain Properties of U.S. vs. European Nodular Iron", TM 280, Deere \& Company, Technical Center, 19 November 1975 and L. E. Tucker, Cyclic Stress-Strain and Fatigue Properties of Nodular Iron, TM 281, Materials Engineering Department, Deere \& Company, Moline, Illinois, 1975.

B. F., LANGER 1937: "Fatigue failure from stress cycles of varying amplitude", Journal of AppliedMechanics, Vol. 59, 1937, pp. A160-A162, apud Y.,LEE 2005, P., Jwo, R., Hathaway and M., Barkey: "Fatigue Testing and Analyses" Theory and Practice, Elsevier, 2005.

S. S., MANSON 1981, and HALFORD, G. R.: "Practical implementation of the double linear damage rule and damage curve approach for testing cumulative fatigue damage", International Journal of Fracture, Vol. 17, No. 2, 1981, pp. 169-192.

G., MASIN 1961: "Eigerspannungen and Verfestigung bein Messing", Proceeding of the 2nd International Congress of Applied Mechanics, Zurich, 1976, pp. 332-335.

Materials Proceedings, Vol. 61, 1961, pp. 732-748.

M. A., MINER 1945: "Cumulative damage in fatigue", Journal of Applied Mechanics, Vol. 67, 1945,pp. A159-A164.

J. D., MORROW 1965: "Cyclic plastic strain energy and fatigue of metals In Internal Friction, Damping, and Cyclic Plasticity”, ASTM, West Conshohocken, PA, 1965, pp. 45-86.

J. M., TARTAGLIA 2000: "Monotonic and Cyclic Design Data For Ductile Iron Castings", Ductile Iron Society, Research Project n 30, 2000

A., PALMGREN: "Die Lebensdauer von Kugellagern, Zeitschrift des Vereinesdeutscher Ingenierure”, Vol. 68, No. 14, 1924, pp. 339-341. 
W., RAMBERG 1943, and OSGOOD, W.R.: "Description of stress-strain curves by three parameters", NACA Technical Note No. 902, 1943, apud Y.,LEE 2005, P., Jwo, R., Hathaway and M., Barkey: "Fatigue Testing and Analyses" Theory and Practice, Elsevier, 2005.

S.D. DOWNING 1982 AND D.F. SOCIE, Simplified Rainflow Counting Algorithms, Int. J. Fatigue, Vol 4 (no.1), Jan 1982, pp31-40

C. R SODERBERG 1930: "Fatigue of safety and working stress", Transactions of the American Society of Mechanical EngineeR Vol. 52 (Part APM-52-2), 1930, pp.13-28, apud Y.,LEE 2005, P., Jwo, R., Hathaway and M., Barkey: "Fatigue Testing and Analyses" Theory and Practice, Elsevier, 2005.

SORELMETAL 2004: “The Sorelmetal Book of Ductile Iron", Rio Tinto Iron and Titanium Inc., Canada

W. SIEFER 1970, and K.ORTHS, "Evaluation of Ductile Iron in Terms of Feasible Properties of the Material, “ Transactions, American Foundrymen's Society, Vol 78, 1970 pp 382-397.

C. R., WILLIAMS 2003, LEE, Y., and Rilly, J. T.: "A practical method for statistical analysis of strain-life fatigue data, International Journal of Fatigue", Vol. 25, No. 5, 2003, pp. 427-436.

Y.,LEE 2005, P., Jwo, R., Hathaway and M., Barkey: "Fatigue Testing and Analyses" Theory and Practice, Elsevier, 2005.

L., YANG 1994, "Mechanical Behavior and cumulative fatigue damage of vanadiumbased microalloyed forging steel", Ph.D. Thesis, University of Toledo, Toledo, OH, 1994.

C.F. WALTON 1981 and T.J. Opar, Ed.: "Iron Castings Handbook", Iron Castings Society, 1981

P. W. BRIDGMAN 1944: Stress distribution at the neck of tension specimen Transactions of the American Society for Metals, Vol. 32, 1944, pp. 553-572.

L.F. COFFIN 1979: Fatigue in Machines and Structures, Fatigue and Microstructure, American Society for Metals, 1979

R. VISWANATHAN 1989: Damage Mechanisms and Life Assessment of High Temperature Components, ASM International, 1989, p 119

R. SCHUBERT 1989: Verformunsverhalten und ri wachstum Bei Low Cycle Fatigue, Ph.D Thesis, Technische Universität Braunschweig, 1989

H.J. CHRIST 1993, In Proc. Fifth Internat. Conf. on Fatigue and Fatigue Threshold, J.P Bailon and J.I. Dickson, Ed., EMAS, London, 1993, pp 115-120

M.R. MITCHELL 1996: Fundamentals of Modern Fatigue Analysis for Design, Fatigue And Fracture, 1996, Volume 19 of ASM Handbook, PP 561-613 
J., FOWLER 1984, D.M. Stefanescu, and T. Prucha, Trans. AFS, Vol 92, 1984, p 361 